\title{
Correcting airborne gravity data for overburden thickness using airborne transient electromagnetic data
}

\author{
by
}

Raymond M. Caron

\begin{abstract}
A thesis submitted to the Faculty of Graduate and Postdoctoral Affairs in partial fulfillment of the requirements for the degree of
\end{abstract}

Doctor of Philosophy

in

Earth Sciences

Carleton University

Ottawa, Ontario

(C) 2016

Raymond M. Caron 


\begin{abstract}
A new methodology is presented that corrects gravity data for lateral changes in overburden thickness through the creation of a bedrock topography (BedTopo) map. The methodology results in a Bouguer anomaly map where bathymetry, overburden thickness, and bedrock are reduced to a reference datum. This methodology applies to airborne, ground, and gravity gradiometry surveying. Also presented is a working methodology for inverting helicopter transient electromagnetic (HTEM) survey data to resolve the overburden-bedrock contact using discrete layered-earth modelling in a highland terrain for the purpose of creating a BedTopo map.
\end{abstract}

A study site with a glacial overburden within the Nechako Plateau of British Colombia, Canada is used as a case study. AeroTEM III HTEM survey data is inverted using $\mathrm{BC}$ Wells water well data, which provides ground-truth to guide inversion. Water well inversions show that the HTEM methodology can estimate the depth of bedrock with an sRMS $\%$ error of $61 \%$ of the total thickness indicated by the water wells. The HTEM methodology was found to be inaccurate in areas where 3D topography effects are prominent and over areas where a conductive anomaly is hosted within the bedrock.

AeroTEM III HTEM survey data is inverted in order to create a BedTopo map. AIRGrav gravity data is reduced using digital elevation model, BedTopo, and bathymetry data in order to create a BedTopo corrected Bouguer anomaly map of the study site. Inversion results of the study site used 4- and 5- layer models with results showing that overburden varies in thickness from 0 to $265 \mathrm{~m}$, with an average of $35 \mathrm{~m}$, and an inverted 
resistivity that ranges from 3 to $\sim 680 \Omega \bullet \mathrm{m}$. Bedrock resistivity ranged from 0.5 to over $10,000 \Omega \cdot \mathrm{m}$. An analysis and comparison of Bouguer anomaly maps with and without a BedTopo correction was conducted. Results show that variations in overburden thickness that are $<30 \mathrm{~m}$ may not be detectable by an airborne gravimeter system due to GPS noise, and that overburden thickness variations $>100 \mathrm{~m}$, which create anomalies larger than $3 \mathrm{mGal}$, if not considered may contribute to interpretation errors on a Bouguer anomaly map. 


\section{Acknowledgements}

This dissertation would not have been possible without the guidance and the help of several individuals, and group of individuals, who in one way or another contributed and extended their valuable assistance in the preparation and completion of this study. First and foremost, my utmost gratitude to Dr. Claire Samson and Dr. Michel Chouteau my PhD supervisors, and to Dr. Martin Bates whose support, guidance, and encouragement I will never forget. I would also like to express my gratitude to Luise Sander and Stephan Sander, of Sander Geophysics for supporting and being a partner for this collaborative research with Carleton University and the Natural Sciences and Engineering Research Council (NSERC) of Canada.

I would like to express a big thank you to the staff at Sander Geophysics, especially the geophysicists who let me feel welcome and provided their assistance and support. I would also like to thank the entire Earth Sciences department at Carleton University for their support. I'd like to personally thank Kyle Harris, Michael Kolaj, and Jennifer Blanchard for spending their time debating the finer points of physics and electromagnetic theory. Last but not the least; I would like to thank my family for providing their encouragement and support throughout my studies... may they finally be at an end. 


\section{Table of Contents}

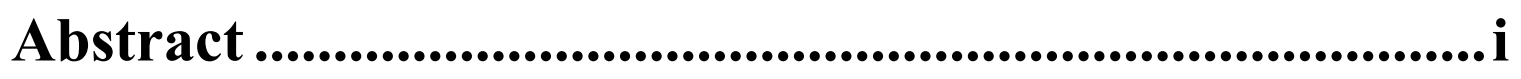

Acknowledgements .........................................................iii

Table of Contents ......................................................... iv

List of Figures ...........................................................vviii

List of Tables ............................................................. xi

Abbreviations ...........................................................xii

1.0 Introduction................................................... 13

1.1 Statement of the Problem ....................................................................... 13

1.2 Structure of the thesis........................................................................ 17

2.0 Study site.......................................................... 23

2.1 Study site selection ................................................................................ 23

2.2 Quest West survey.................................................................................. 25

2.2.1 Study site ................................................................................................... 25

2.3 Geology .......................................................................................... 27

2.3.1 Overburden geology............................................................................... 27

2.3.2 Bedrock geology ......................................................................................... 27

2.4 Ground truth .......................................................................................... 28

2.4.1 Water wells ............................................................................................ 29

2.4.2 Geotechnical boreholes ............................................................................ 30

2.5 Physical properties of the overburden and bedrock ....................... 31

2.6 Glacial history ............................................................................................. 32

3.0 HTEM overburden inversion modelling .............. 41 
3.1 HTEM system capability ......................................................................... 41

3.2 HTEM system design ................................................................................ 42

3.3 Optimizing system parameters ............................................................... 43

3.4 Overburden detectability study ............................................................ 45

3.5 Noise-free modelling .................................................................................. 46

3.6 Modelling with synthetic noise................................................................. 47

3.7 Summary ............................................................................................................ 48

\subsection{Methods ......................................................55}

4.1 Initial assumptions .................................................................................. 55

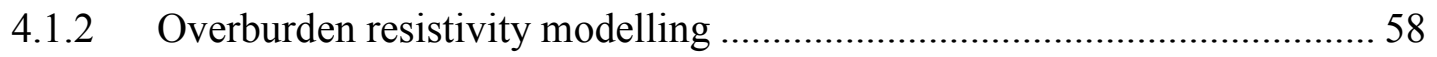

4.2 Calibrated HTEM inversions.................................................................59

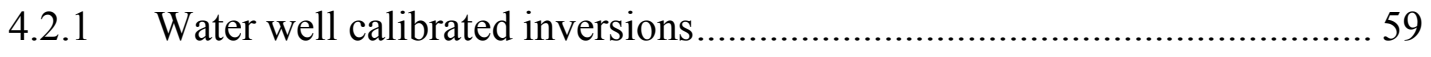

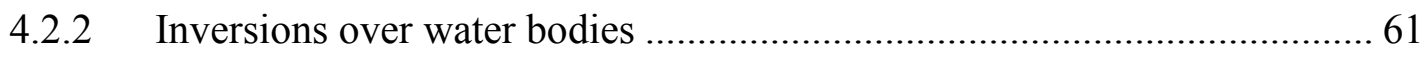

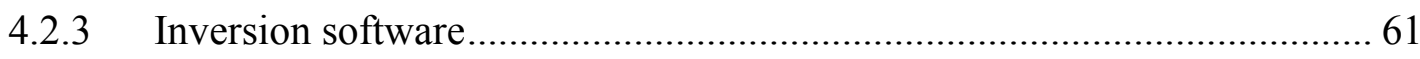

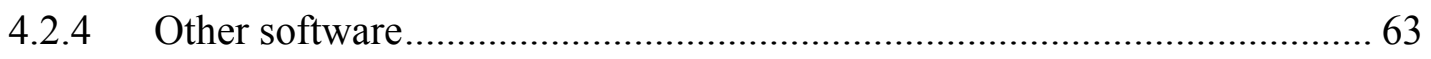

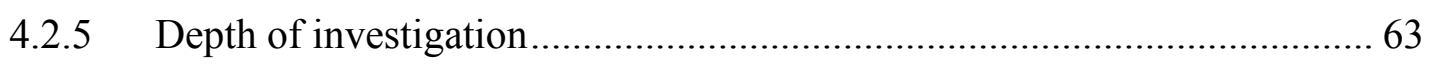

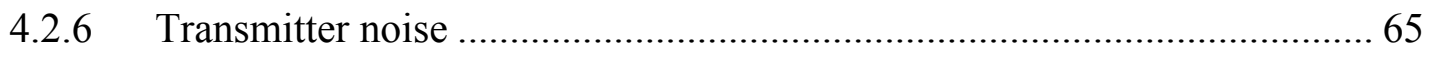

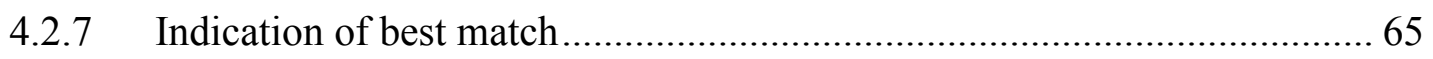

4.3 HTEM 2-layer inversions ..............................................................67

4.4 Multi-layer inversions.....................................................................68

4.5 Multi-layer resistivity reversal inversions ................................... 69

4.6 Resistivity structure inversions...................................................

4.7 Terrain map processing ............................................................................... 73

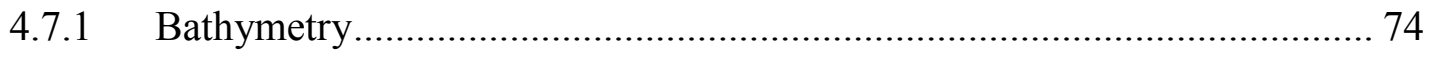

4.7.2 Bedrock topography (BedTopo) ……………….................................. 74

4.8 Overburden thickness analysis ................................................... 75

4.9 Bouguer corrections .................................................................. 76 


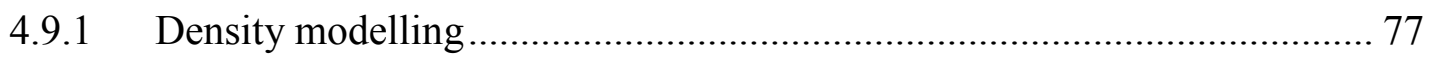

4.9.2 Gravity processing methodology ........................................................... 78

5.0 Results \& Discussion .......................................96

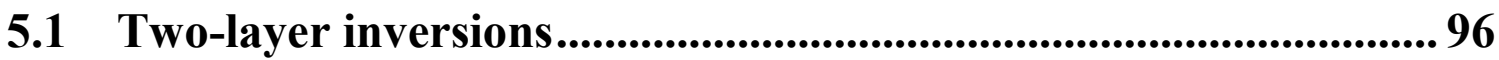

5.2 Multi-layer inversions.....................................................................99

5.3 Resistivity reversals.........................................................................................98

5.3.1 Overburden thickness and surficial geology ............................................. 99

\subsection{HTEM inversion calibration using water wells ........................... 101}

5.4.1 Resistivity structure within the layered earth model.................................... 103

5.4.2 Discrimination between overburden and bedrock resistivity.................... 104

5.5 Resistivity structure inversions................................................. 106

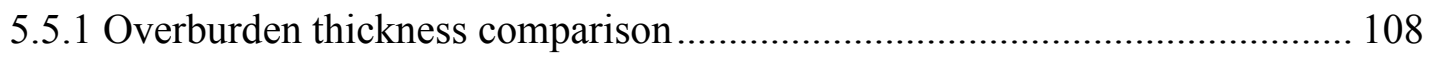

5.5.2 Overburden thickness compared to satellite images .................................. 109

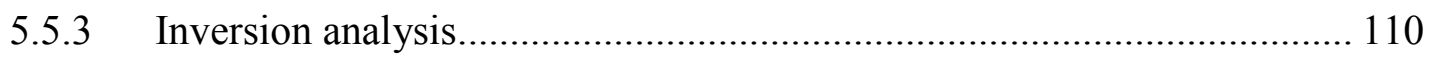

5.5.4 Augmenting overburden thickness map with ancillary data..................... 112

5.6 Bouguer gravity corrections......................................................... 112

5.6.1 Bouguer anomaly profile comparison..................................................... 113

5.6.2 Bouguer anomaly map comparison without bathymetry .......................... 114

5.6.3 Bouguer anomaly map comparison with bathymetry ………………….... 115

5.6.4 Comparisons between Bouguer anomaly and their FVD maps ................ 116

\subsection{Bouguer results calculated from resistivity reversal inversion .. 117}

5.8 Resolution of overburden thickness .................................................... 119

5.8.1 Gravity anomalies created from variations in overburden thickness........ 119

5.8.2 Overburden gravity anomalies at higher resolution.................................. 121

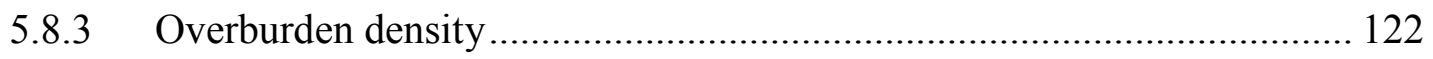

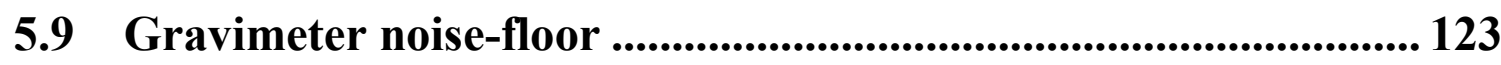

6.0 Conclusion ........................................................... 149

6.1 HTEM inversion summary ......................................................... 149

6.1.1 Water well calibration summary …………………................................ 150 
6.2 BedTopo Bouguer correction summary ........................................ 151

6.3 BedTopo correction application .............................................. 152

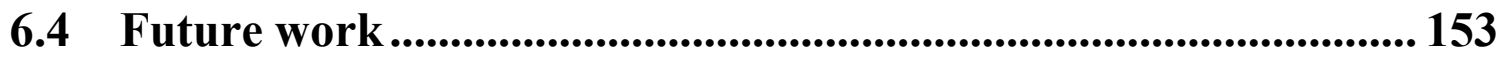

References ....................................................................... 155

Appendix I........................................................... 163

Appendix II ........................................................... 177 


\section{List of Figures}

Figure 1.1: Comparison of modelled overburden thickness and sulphide mineral body gravity anomalies. 18

Figure 1.2: Diagram of Bullard A gravity correction .................................................... 19

Figure 1.3: Diagram of Bullard B gravity correction ................................................. 20

Figure 1.4: Diagram of Bullard C gravity correction .................................................... 21

Figure 1.5: Diagram of proposed BedTopo gravity correction......................................... 22

Figure 2.1: Digital Elevation Map (DEM) of Quest West survey area ............................ 34

Figure 2.2: Digital Elevation Map (DEM) with bathymetry of the study site .................. 35

Figure 2.3: Map of calculated slope of the terrain of the study site................................. 36

Figure 2.4: Compiled surficial geology map of the study site …….................................... 37

Figure 2.5: Bedrock geology map of survey site …………………………………..... 38

Figure 2.6: DEM map showing the distribution of vetted water wells ............................. 39

Figure 3.1: Concept drawing of HTEM system used for modelling................................ 50

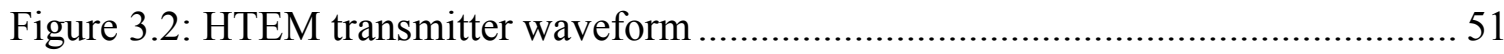

Figure 3.3: Comparison of HTEM response with max duty time and current ................ 52

Figure 3.4: Inversion of noise-free data for 2-4 layer models. ........................................ 53

Figure 3.5: Inversion of noisy data for 2-4 layer models............................................... 54

Figure 4.0.1: Simplified diagram of the BedTopo correction methodology..................... 82

Figure 4.1.1: Resistivity model and starting models...................................................... 83

Figure 4.2.1: Water well inversion starting models .................................................... 84

Figure 4.2.2: Plot of HTEM observed secondary magnetic field inversion results.......... 85

Figure 4.2.3: AeroTEM III waveform and off-time channels used for inversion............. 86

Figure 4.4.1: Volcanic resistivity starting models with resistivity reversals .................... 87

Figure 4.6.1: Resistivity structure inversion starting models .......................................... 88

Figure 4.6.2: Locations of $>160 \Omega \bullet \mathrm{m}$ bedrock interpretation.......................................... 89

Figure 4.7.1: Bathymetry data digitization and georeferencing ..................................... 90 
Figure 4.7.2: Map manipulation steps followed to create Bedrock topography map ....... 91

Figure 4.9.1: Program level gravity modelling ........................................................ 92

Figure 4.9.2: Gravity processing methodology..................................................... 93

Figure 4.9.3: Low-pass cosine filter applied to line data........................................... 94

Figure 4.9.4: Low-pass cosine wavelength filter applied to gravity grids..................... 95

Figure 5.1.1: HTEM line 7240 overburden thickness cross-section............................ 125

Figure 5.2.1: HTEM overburden thickness map from multi-layer inversion ................ 126

Figure 5.3.1: HTEM overburden thickness map from inversions including resistivity

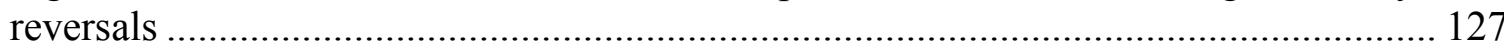

Figure 5.3.2: Surficial geology overlaid on DEM map ............................................ 128

Figure 5.3.3: Surficial geology overlaid on overburden thickness map ....................... 129

Figure 5.4.2: BC Wells and HTEM inversion record, Block C2, line 6261, BC Wells Tag

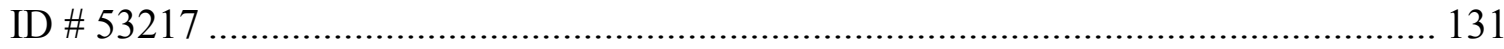

Figure 5.4.3: BC Wells and HTEM inversion record ............................................ 132

Figure 5.4.4 Bedrock resistivity histogram ................................................ 133

Figure 5.5.1: HTEM Overburden thickness map from Resistivity structure inversions 135 Figure 5.5.2: Surficial geology overlaid on overburden thickness map ...................... 136 Figure 5.5.3: HTEM overburden thickness map overlaid on a Google Earth satellite

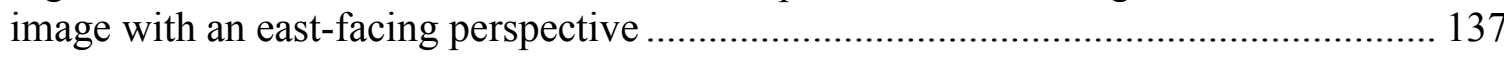

Figure 5.5.4: Line L7420 on satellite image with overburden thickness map ............... 138

Figure 5.5.5: Location of HTEM inversion starting models by type .......................... 139

Figure 5.5.6: Inversion results by starting model for a portion of HTEM line 7420..... 140

Figure 5.5.7: Inversion results by starting model for HTEM line 7420 ........................ 141

Figure 5.6.1: Comparison of Bouguer anomaly (BA) profiles for HTEM line 7420 ..... 142

Figure 5.6.2: Bouguer gravity anomaly map comparison........................................ 143

Figure 5.6.3: Bullard FVD Bouguer anomaly map of the study site.......................... 144

Figure 5.6.4: Bouguer gravity anomaly map comparison with bathymetry corrected .. 145

Figure 5.6.5: Bullard FVD Bouguer anomaly map of the study site with bathymetry

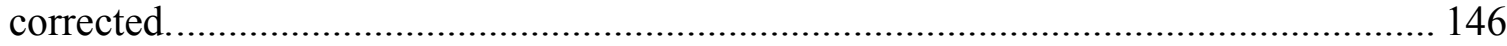


Figure 5.7.1: Resistivity reversal overburden corrected Bouguer anomaly and FVD maps of the study site with bathymetry correction applied.

Figure 5.8.1: Comparison of Bouguer anomaly (BA) profiles for HTEM L7420 created using 100m DEM maps. ........................................................................................ 148

Figure A1-1: BC Wells \#52118 and HTEM inversion record ........................................ 164

Figure A1-2: BC Wells \#52118 Record 2 and HTEM inversion record ........................ 165

Figure A1-3: BC Wells \#89421 and HTEM inversion record......................................... 166

Figure A1-4 BC Wells \#56613 and HTEM inversion record ......................................... 167

Figure A1-5 BC Wells \#47086 and HTEM inversion record ........................................ 168

Figure A1-6 BC Wells \#53217 and HTEM inversion record ......................................... 169

Figure A1-7 BC Wells \#73420 and HTEM inversion record ........................................ 170

Figure A1-8 BC Wells \#12622 and HTEM inversion record ......................................... 171

Figure A1-9 BC Wells \#56720 and HTEM inversion record ........................................ 172

Figure A1-10 BC Wells \#56711 and HTEM inversion record ...................................... 173

Figure A1-11 BC Wells \#20998 and HTEM inversion record ....................................... 174

Figure A1-12 BC Wells \#43637 and HTEM inversion record ........................................ 175

Figure A1-13 BC Wells \#56968 and HTEM inversion record ...................................... 176

Figure A2-1 GSC Equity Silver Borehole 86264 ..................................................... 178

Figure A2-2 GSC Equity Silver Borehole 86246 ..................................................... 179

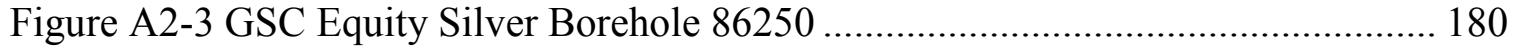




\section{List of Tables}

Table 2.1: Airborne gravity and electromagnetic survey and system specifications........ 33

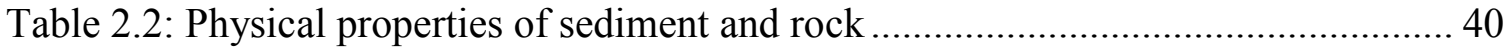

Table 5.4.5: Water well calibration inversion results by starting model ...................... 134 


\section{Abbreviations}

Abbreviation

AEM

asl

$\mathrm{BC}$

BedTopo.

CGIAR-CSI csv

DEM

DTM

DO

EM

FEM

GPS

GSC

HTEM.

NAD83....

NSERC prn

RADAR.

$\mathrm{Rx}$.

SGL

sRMS

SRTM

TEM

Tx

UTM

WGS84

\section{Phrase}

airborne electromagnetics

average sea level

British Columbia

bedrock topography

CGIAR Consortium for Spatial Information comma separated values

digital elevation model

digital terrain model

depth of investigation

electromagnetic

frequency electromagnetics

Global Positioning System

Geological Survey of Canada

helicopter transient electromagnetics

North American datum 1983

Natural Sciences and Engineering Research Council

formatted text, space delimited file

radio detection and ranging

receiver

Sander Geophysics Limited

symmetric root-mean square

Shuttle RADAR telemetry mission

transient electromagnetics

transmitter

Universal Transverse Mercator

World geodetic system 1984 


\subsection{Introduction}

\subsection{Statement of the Problem}

Many prospective areas for mineral exploration in Canada, such as the interior plateau of British Columbia and the Ontario Clay Belt, are covered by a thick overburden that was deposited during and since the end of the Wisconsin glaciation (c. 25-10 ka) (Stumpf et al. 2000). The overburden conceals large areas of bedrock which has complicated mineral exploration efforts. This specific problem exists in the Interior Plateau of British Columbia (Levson and Giles 1997, Mihalynuk 2007, Enkin et al. 2008, Enkin 2014).

The overburden not only masks geological information, it also reduces the reliability of potential-field geophysical methods by concealing changes in bedrock topography, defined here as variations in elevation of the bedrock surface immediately beneath the unconsolidated sediment which makes up the overburden. While bedrock topography often imitates the features expressed by surface topography (a.k.a. the classical definition of topography), it can vary independently, for example, when features such as basins and river beds are covered by sediment. With respect to the gravity method, hidden changes in bedrock topography can create anomalies of the same size and magnitude as those associated with mineral deposits and may be mistaken for them (Chen and Macnae 1997, Caron et al. 2013). For instance, a reduction in overburden thickness can create an anomaly of a similar magnitude to that of a sulphide mineral body, see Figure 1.1 A and B, 
Traditionally, a Bouguer anomaly map is produced by reducing the observed gravity data by applying instrumental drift $\left(g_{I}\right)$, Earth tides $\left(g_{T}\right)$, latitude $\left(g_{L}\right)$, free-air $\left(g_{F A}\right)$, Bouguer $\left(g_{B o u g}\right)$, Eötvös $\left(g_{E}\right)$, and terrain $\left(g_{T e r}\right)$ corrections, see equation 1.1 (Nabighian et al. 2005, Reynolds 2011). Topographic effects are taken into account by approximating topography and applying a Bouguer correction to account for it. The Bullard corrections (Bullard 1936, Nabighian et al. 2005) breaks the Bouguer correction down into 3 components that each correct for a different effect of topography. The Bullard A correction uses an infinite horizontal slab to approximate topography, see Figure 1.2. The Bullard B correction includes the effect of the curvature of the Earth, see Figure 1.3. The Bullard C correction uses a digital elevation model (DEM), which is often combined with bathymetry data, to determine the attraction of gravity due to terrain and water within $170 \mathrm{~km}$ of the measurement station. The Bullard corrections are based on the assumption that the terrain has a homogenous density and can be modelled as bedrock to the depth of the geoid except in areas where bathymetry data is available, see Figure 1.4. For some surveys, a datum is adopted as reference for gravity corrections in lieu of the geoid.

Equation 1.1

$$
G_{\text {Bouguer Anomaly }}=G_{\text {observed }}-\Delta g_{I} \pm \Delta g_{T} \pm \Delta g_{L}+\Delta g_{F A}-\Delta g_{B o u g} \pm \Delta g_{E} \pm \Delta g_{T e r}
$$

In this thesis, in addition to the Bullard A, B, and C corrections, I am proposing a new correction where overburden thickness data can be used, similar to bathymetry data, to correct for the lower density contribution of the overburden, see Figure 1.5. The 
application of this new correction will provide more reliable gravity data where overburden effects have been removed so that gravity anomalies can be more reliably related to deeper bedrock sources. Since one of the by-products of this method is the creation of a bedrock topography map, I will refer to the new correction as the "bedrock topography" (BedTopo) correction (Caron et al. 2015).

The main objectives discussed in this thesis in relation to bedrock topography are:

- Under what situations is the new bedrock topography correction applicable?

- What are the strengths and weaknesses of the new bedrock topography correction?

While this thesis will be discussing the application of the BedTopo correction to airborne gravity data, the BedTopo correction is also applicable to gravity gradiometry and ground gravity surveying.

The BedTopo correction is based on near-surface layered-earth inversion of airborne transient electromagnetic (TEM) data to resolve the thickness of the overburden. Airborne TEM systems are most often employed for their ability to efficiently survey large areas quickly and non-invasively. Airborne TEM systems were initially developed for the purpose of mineral exploration (Palacky and West 1991). Airborne systems such as the MegaTEM and GeoTEM are designed with a large transmitter which is empowered with a strong current of several hundred amperes, 
achieving high magnetic moments with a typical range of 500,000-2,000,000 $\mathrm{Am}^{2}$, in order to induce an EM response deep within the bedrock (Reynolds 2011). These systems are typically able to achieve a penetration depth of several hundred meters, depending on the geology, using low base frequencies of around $12.5-90 \mathrm{~Hz}$ (Reynolds 2011). The off-time gates used to record the EM response induced by these systems are configured to record late-times sensitive to causative bodies located in the bedrock and are not designed to record the early-time response which is sensitive to overburden effects.

More recently, airborne TEM systems have been designed for ground water exploration, such as the Tempest and SkyTEM systems, where they provide hydrogeological information to a depth of a few hundred meters, and have the capability to identify buried Quaternary valleys (Fitterman and Stewart 1986, Auken et al. 2008, Abraham et al. 2012). These systems have a relatively smaller transmitter, through which a weaker current flows in order to produce a magnetic moment that typically ranges from $50,000-500,000 \mathrm{Am}^{2}$. This in turn leads to a lower turn-off time which permits the capture of early-time data to better resolve near-surface features.

This project will also explore the feasibility of using helicopter transient electromagnetic (HTEM) survey systems to measure overburden thickness. The main objectives discussed are: 
- Can an HTEM system designed for mineral exploration measure overburden thickness?

- What features should an airborne TEM system have for this particular application?

A study site in British Columbia, Canada, that has glacially-derived overburden and publicly available AIRGrav airborne gravity and AeroTEM III HTEM survey data will be used to demonstrate the BedTopo methodology, the BedTopo correction, and compare the differences between Bouguer gravity anomaly and first vertical derivative (FVD) Bouguer gravity anomaly maps both with and without the BedTopo correction.

\subsection{Structure of the thesis}

This thesis will begin by introducing the study site, see Chapter 2. It will progress by introducing some preliminary forward modelling which addresses the capability of the purpose-built HTEM system for detecting the overburden-bedrock interface, see Chapter 3. The methods section, see Chapter 4, covers the various HTEM inversion methodologies as well as ground water calibrated inversion results. It also covers the Bouguer and BedTopo correction methodologies as well as a discussion of how the terrain was modelled with respect to lake water, overburden, and bedrock. The results of the HTEM inversions are presented and then discussed, see Chapter 5, followed by the BedTopo correction results, an analysis, and then discussion. Conclusions can be found in Chapter 6. 

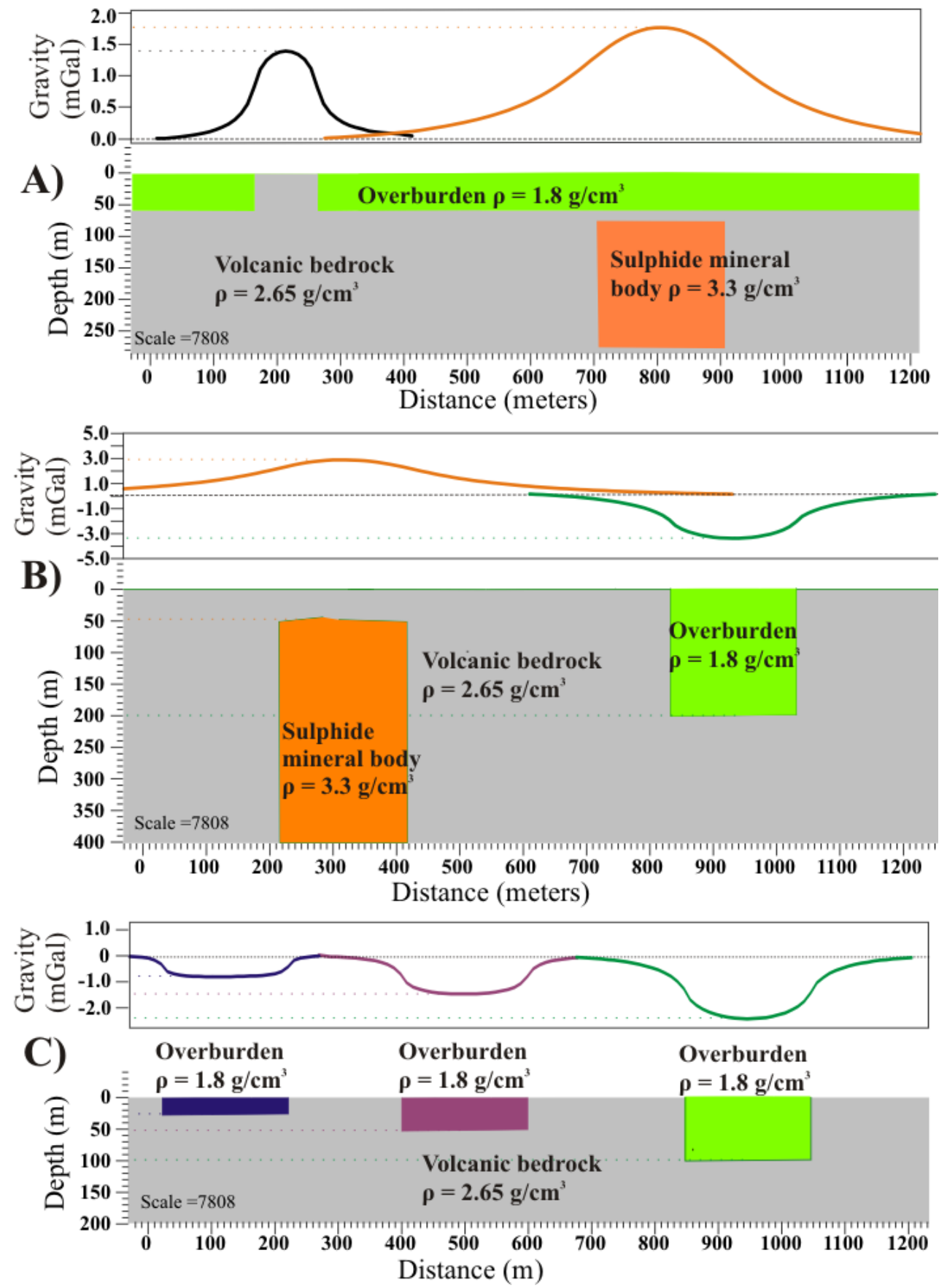

Figure 1.1: Comparison of modelled overburden thickness and sulphide mineral body gravity anomalies.

A) The contribution to the acceleration of gravity created from a $60 \mathrm{~m}$ reduction in overburden thickness is similar in amplitude to that created by a sulphide mineral body, with dimensions $200 \mathrm{~m}$ x $200 \mathrm{~m}$. B) The anomaly created from a $200 \mathrm{~m}$ thick overburden is roughly equivalent to the inverse contribution of a sulphide ore body, $200 \mathrm{~m} \mathrm{x} 350 \mathrm{~m}$. C) Comparison of anomalies created by a silty-sand overburden of density $1.8 \mathrm{~g} / \mathrm{cm} 3$ with thickness of 25, 50, and $100 \mathrm{~m}$. Densities estimated using Table 2.2. Models created using GMSys. 


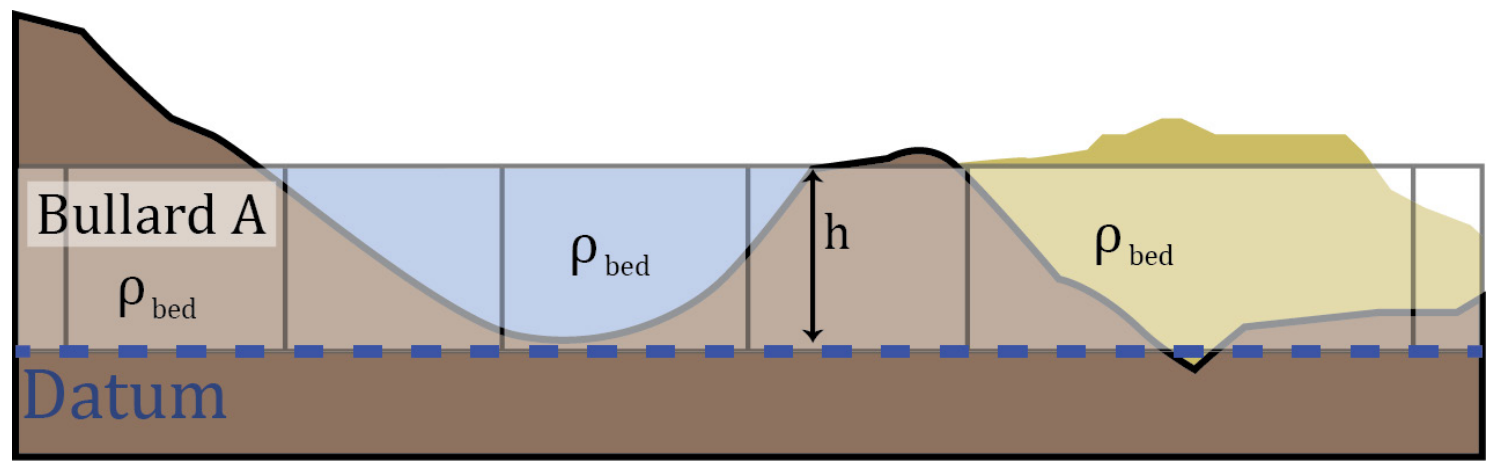

Figure 1.2: Diagram of Bullard A gravity correction

The Bullard A correction is a poor approximation for rough topography. It assumes that the ground is composed of bedrock with an average density $\rho_{\text {bed, }}$ and height $h$. It does not distinguish between changes in density or topography. It is calculated at a series of points located up to a distance of $170 \mathrm{~km}$ from the station. 


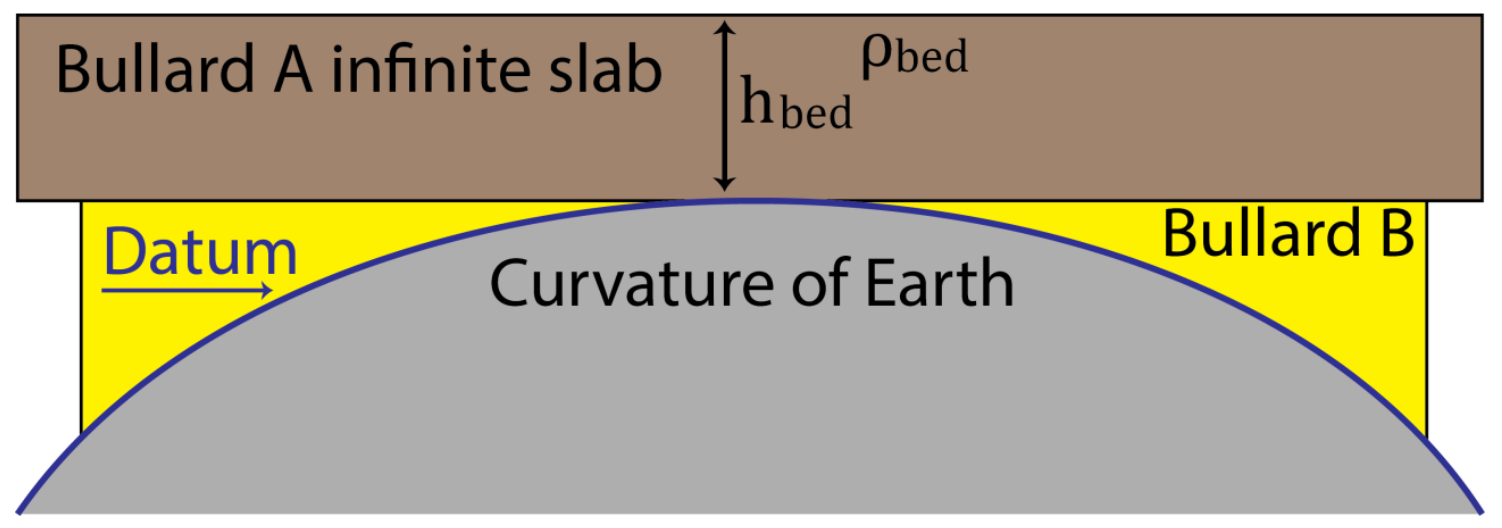

Figure 1.3: Diagram of Bullard $B$ gravity correction

The Bullard B correction takes into account the curvature of the Earth by correcting for the extra gravity pull created by the rock between the Bullard A slab and the datum, shown in yellow. As for the Bullard A correction, it assumes only a single density $\rho_{\text {bed. }}$. It is also calculated up to a distance of $170 \mathrm{~km}$ from the station. 


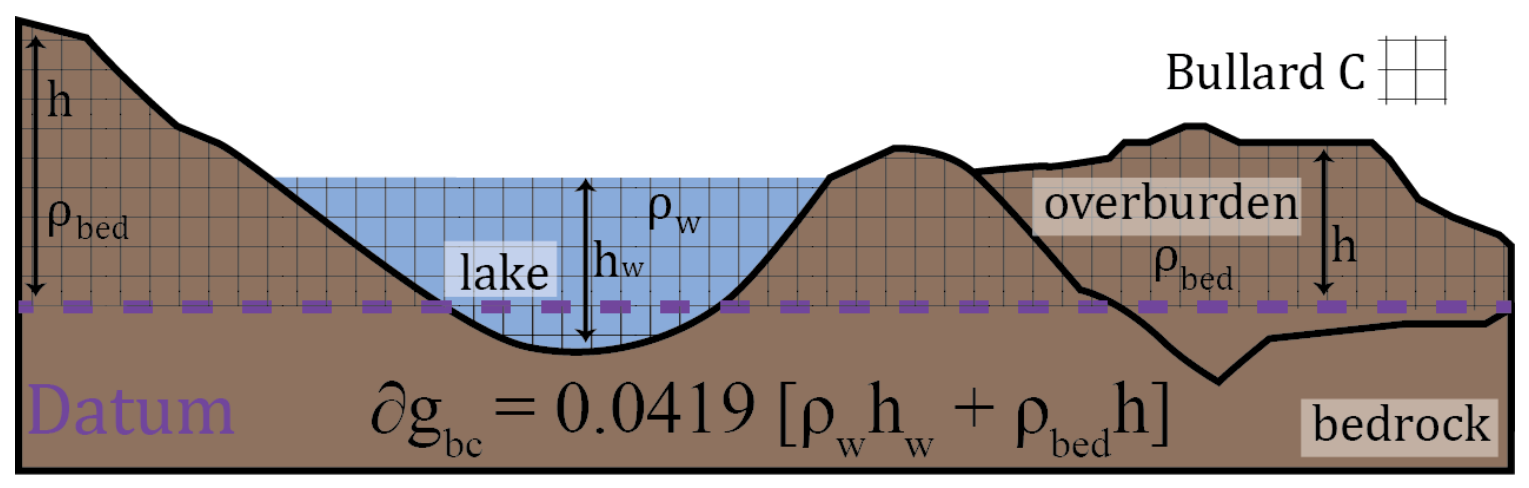

Figure 1.4: Diagram of Bullard C gravity correction

The Bullard C correction uses DEM information to estimate topography and calculate the shape of the ground. It assumes that the terrain can be modelled using an average density $\rho_{\text {bed. }}$. It can correct for the height of a water column $h_{w}$ of density $\rho_{w}$ provided that bathymetry data is available. 


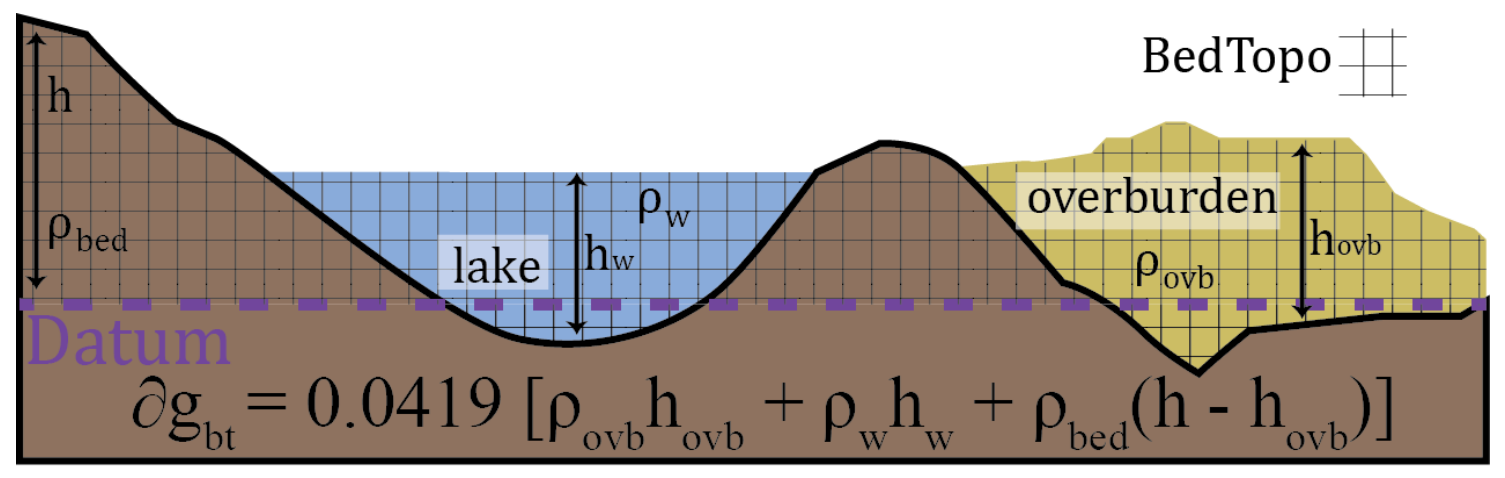

Figure 1.5: Diagram of proposed BedTopo gravity correction

The BedTopo correction relies on the additional information provided by overburden thickness data. This sketch shows the thickness of the overburden $\mathrm{h}_{\text {ovb }}$ above the bedrock enabling the modelling of the overburden using an average density $\rho_{\text {ovb. }}$. The lower mass of the overburden, relative to bedrock, can now be corrected for both above and below the datum. The bedrock contact with both water and with unconsolidated sediment is now mapped, showing the bedrock topography. 


\subsection{Study site \\ 2.1 Study site selection}

The study site was selected based on the following general criteria: (1) availability of coincident airborne gravity and EM data; (2) presence of an overburden with lateral variations in thickness; (3) availability of ancillary geological information such as borehole data, technical reports, water well data, etc.

Most EM systems created pre-2000 were configured to measure signal from large bedrock conductors and were not designed with the sensitivity required to measure the response of the overburden. A great majority of publicly available EM data was acquired using these older systems. In most cases, data acquired with newer systems, built post2000, did not coincide with available gravity data. The Quest-West and the Quest surveys commissioned by Geoscience $\mathrm{BC}$ are amongst the few publicly available data sets where data from relatively recent HTEM systems were gathered, which coincide with data gathered from anairborne gravimeter survey. The Quest-West site, see Figure 2.1, was surveyed separately by helicopter using the Sander Geophysics (SGL) AIRGrav airborne gravity system and the Aeroquest AeroTEM III HTEM system as part of the Quest West survey commissioned by Geosciences BC (Meyer and Bates 2008, GeoScience BC 2008, Aeroquest Limited 2009). The location of the flight lines for each survey do not generally coincide although both surveys do cover the same area. See Table 2.1 for the specifications for these two surveys. The adjacent Quest survey also has data from a relatively new HTEM system, the VTEM system, which coincides with an airborne gravity data set. Of the Quest-West and Quest surveys that have available HTEM and 
gravity data sets, the Quest-West survey with the AeroTEM III system is thought to have a slightly higher resolution in the near-surface compared to the VTEM system, as the first off-time window occurs $24 \mu$ s earlier (Geotech Limited 2007, Aeroquest Limited 2009).

The following is a list of additional selection criteria that were considered in order to select a study site within the Quest West survey:

1. The $Z$ channel, that is, the vertical component of the HTEM data has a strong response.

$>$ A strong response is characterized as 5 or more channels measuring a smooth decay-curve response, which shows a low amount of variation from noise, where the $5^{\text {th }}$ channel has a reading above $10 \mathrm{nT} / \mathrm{s}$. The number of channels provides the minimum number of readings required to adequately reproduce the decaying response of the signal. This was taken as an indication that overburden, or surficial geology, has enough conductivity to enable a successful inversion.

2. The $Z$ channel has a low noise level.

Indicated by a smooth decay response of the secondary field plotted by several off-time channels, and where the noise level is below $10 \mathrm{nT} / \mathrm{s}$.

3. The $\mathrm{X}$ channel, that is, the longitudinal horizontal component of the HTEM data is low amplitude and consistent. 
The $\mathrm{X}$ channel is sensitive to changes in conductivity in direction of the flight line of the helicopter, variations in this channel may indicate changing geological contacts or $3 \mathrm{D}$ geologic structures that may not be accurately modelled using a layered-earth model. Good data is characterized by the preferred absence of high frequency anomalies or variations in the data which may lead to a successful inversion using a layered-earth model (Newman et al. 1987, Spies and Frischknecht 1991).

\subsection{Quest West survey}

The system parameters and survey specifications for the Quest West survey are listed in table 2.1. The airborne gravity survey was flown East-West with a $2 \mathrm{~km}$ traverse line spacing and South-East to North-West with a $17 \mathrm{~km}$ control line spacing, at a drape altitude of $200 \mathrm{~m}$ above ground (Meyer and Bates 2008). The HTEM survey flight lines were oriented East-West and flown with $4 \mathrm{~km}$ traverse line spacing. No control lines were flown (Aeroquest Limited 2009).

Within the area covered by the Quest West survey, the best block of suitable EM line data along consecutive lines was chosen. An 81 x $47 \mathrm{~km}$ study site was selected, (see Figure 2.2), that encompasses the eastern half of Francois Lake.

\subsubsection{Study site}

The study site (see Figures 2.1, and 2.2) is located in the Nechako Plateau of the Interior Plateau in British Columbia, Canada (situated at $53^{\circ} 58^{\prime} \mathrm{N}, 125^{\circ} 34^{\prime} \mathrm{W}$ ). The 
plateau has a high mineral potential but exploration efforts have been hampered by a thick overburden that covers 90-95\% of the bedrock (Levson and Giles 1997, Mate and Levson 2001, Andrews et al. 2011). The area has seen a large amount of porphyry mining activity including the Blackdome gold mine (closed), the Gibraltar copper-molybdenum mine (open), and the Endako molybdenum mine (closed).

Prominent terrain features within the study site include Francois Lake, Tchsinkut Lake, Uncha Mountain, and an area indicated as Highlands, which is primarily a large forest. The digital elevation map (DEM) shown in Figure 2.2 shows the topography of the study site and the bathymetry of the major lakes in the area. Topography across the study site is rugged with nearly $1000 \mathrm{~m}$ difference in elevation from basin to mountain top. Features of the terrain include drumlins, mountains, ridges, hills, lakes, rivers, volcanic necks, and highlands. The slopes within topography of the lower elevation areas, shown in green, falls under the gentle slope category in the terrain classification system for British Columbia (Howes and Kenk 1997) (Figure 2.3), which is defined as a slope that does not typically exceed $15^{\circ}$. The ridges can be described as hummock with slopes that are generally between $15^{\circ}-35^{\circ}$ (Howes and Kenk 1997). The Highlands area is also an elevated and rugged terrain with many slopes classified as gentle to moderately steep. Figure 2.3 shows the rugged nature of the terrain across the study site. Steep slopes can be used to easily identify rock features in the map such as Uncha Mountain and volcanic necks. 


\subsection{Geology}

Surficial mapping data within the study site is sparse and of low resolution as few geological and no geophysical surveys, other than the Quest West survey, have been conducted. Figure 2.4 is a map compiling the available surficial geological information. As the information is of varying quality and resolution there are often contradictions between features in a data set that has a higher spatial resolution compared to features in a lower resolution (1:250,000 scale) map. This occurs most often in areas that are marked as till veneer (defined as $\leq 1 \mathrm{~m}$ of till overlying bedrock by Howes and Kenk (1997)), which coincides with locations of public and private active gravel pits used as a source of aggregate for road construction, and also with areas identified to have glaciolacustrine or glaciofluvial deposits, both of which indicate an overburden thicker than $1 \mathrm{~m}$.

\subsubsection{Overburden geology}

Overburden geology is complex and includes: colluvium, aeolian, fluvial, and lacustrine deposits. Post-glaciation sedimentation from glaciers and proglacial rivers and lakes from the Wisconsin-Fraser glaciation deposited till, glaciofluvial, and glaciolacustrine material (Plouffe 1997; Stumpf et al. 2000). Sediment type includes: clay, silt, sand, gravel, and till, and any mixture of the five. The most common type of sediment in the study site is wet silty-sand (Plouffe and Levson 2001).

\subsubsection{Bedrock geology}

Bedrock geology is shown in Figure 2.5. Volcanic and plutonic igneous rocks are the most common with some sedimentary and occasional metamorphic rocks. The 
volcanic rocks are predominantly rhyolite (light pink) and andesite (dark pink) of the Ootsa Lake and Endako Formations, deposited between 23.3 - 56.5 Ma, with minor dacite (grey-pink), deposited 65-97 Ma (Grainger and Anderson 1999). Also common is the andesite-tuff (yellow) of the Kalsalka group, deposited 65-97 Ma.

The plutonic rocks are mostly granite and granodiorite of the Francois Lake suite with minor diorite that range in age from 35-173 Ma. The 65-178 Ma sedimentary rocks are primarily conglomerates with different sub-types that include carbonate and wacke (shown in green) of the Kalsaka and Bowser Lake groups. The most abundant metamorphic rock is a weathered meta-diorite to foliated gneiss from the Stern Creek Plutonic suite that has an age of 208-223 Ma and can be found in the upper northern section of the study site (Massey et al. 2005). All ages are for rock formations and were taken from Cui et al. (2015).

\subsection{Ground truth}

Ground truth is used to identify data sets that provide an exact measurement of the location of the bedrock hidden beneath overburden. Ground truth within the study site is sparse and largely unavailable. There are no geotechnical boreholes within the study site, although 3 boreholes are situated within $6 \mathrm{~km}$ of the study site, see Figure 2.1. Water wells data is also available both within the study site, the larger Quest West survey area, and the region. 


\subsubsection{Water wells}

Water well information from the WELLS database (British Columbia 2015) provides some information concerning the thickness of the overburden. There are problems with this dataset: (1) the water wells are unevenly distributed throughout the study site, see Figure 2.6; (2) the wells are primarily located in valleys near settlements and are therefore not representative of the entire survey site; (3) the WELLS database contains some errors, most notably where a bedrock depth of $0 \mathrm{~m}$ is assigned to wells that have not been drilled to the bedrock and to wells with missing water table information; (4) the lithological records that indicate sediment or rock type are unreliable (Andrews et al. 2011); (5) the collar elevation of the well was georeferenced to the shuttle RADAR telemetry mission (SRTM) elevation data, as the WELLS database does not identify the collar elevation of each well and only identifies the location of the well by latitude and longitude. SRTM DEM maps typically have a vertical elevation error of $\pm 16 \mathrm{~m}$ (Jarvis et al. 2004).

There are, however, three components of the WELLS database that are considered reliable and were used as information: the technical reports for each well include (1) the measured depth of each well, and (2) the depth to bedrock if the well intercepted bedrock, and (3) the depth to the water table. The depth of the overburden-bedrock contact provides ground truth at a specific location that can aid in EM inversions. For wells that did not intercept the overburden-bedrock contact, the data provides minimum estimates of overburden thickness. 
Data from 134 water wells within the study site were used as an indication of overburden thickness, see Figure 5.3.3. The overburden thickness ranges from 0-122 m. In addition, 12 water wells ( 5 within the study site and 7 from the larger Quest West survey), were used to provide ground truth for HTEM inversion calibration. The location of these water wells are shown in Figure 2.1, with the details and inversion results for each specified in Appendix I.

The BC Wells dataset was also used to indicate the depth of the water table within the study site. The water table is highly variable within the study site with a range in depth of 0-67 m, a median of $12 \mathrm{~m}$, an average of $15 \mathrm{~m}$, and a standard deviation of $13 \mathrm{~m}$. Unfortunately since the dataset is sparsely distributed. When plotted the data only indicates that the depth to the water table is highly variable and likely controlled by topography. HTEM inversions will therefore be conducted over a variety of water saturated and unsaturated overburden sediment and bedrock. Water saturated sediment and rock is known to have a higher conductivity than its unsaturated counterpart (Telford et al. 1990). See Figure 2.2 for water well measured water table levels.

\subsubsection{Geotechnical boreholes}

Three Geological Survey of Canada geotechnical boreholes described in Open File 2610 (Killeen et al. 1995) were drilled in the 1980's within the Quest West survey area, see Figure 2.1. Each borehole was drilled on the Equity Silver mining property but share the same coordinates. Unfortunately the precise location of these boreholes is

unknown. The boreholes are GSC-BC-HO-ES series with identification numbers; 86250, 
86246 , and 86264, and these provide in-situ geophysical logs of density, resistivity, and magnetic susceptibility for the various lithologies encountered in each hole (Appendix III). The geophysical measurements of the in-situ rock properties from these boreholes were used along with published data to create table 2.2 which shows the density and resistivities of different rock and sediment types within the Nechako Plateau, and in general.

\subsection{Physical properties of the overburden and bedrock}

Glacial scouring of the bedrock is widespread throughout glacial terrains. The process often leaves striation marks on the bedrock, which have been observed in the study site trending east-west (Stumpf et al. 2000). This process is known to erode and remove soft rock and debris, thus leaving behind a smooth hard bedrock surface. It also results in large disparities in density and resistivity values between bedrock and overlying unconsolidated overburden that can be exploited using geophysical methods to map the contact between the two. Published resistivities from the Nechako Plateau, see table 2.2, show a contrast between rock and sediment that can vary by several orders of magnitude, where the range of resistivity for sediment is 1 to $360 \Omega \cdot \mathrm{m}$, while the range for volcanic rock is $37-23,000 \Omega \cdot \mathrm{m}$. The density contrast is smaller; sediment can have a density that

ranges from $1.60-2.24 \mathrm{~g} / \mathrm{cm}^{3}$, depending on water content, and volcanic bedrock has a density range of $2.16-3.20 \mathrm{~g} / \mathrm{cm}^{3}$. 


\subsection{Glacial history}

The glacial history of the Nechako Plateau is complex (Stumpf et al. 2000), particularly with respect to glacier ice-flow, which is thought to have occurred during three distinct phases that saw a reversal in ice-flow direction within the study site. Piedmont glaciers advanced from the coastal Hazelton Mountains to the west in an easterly direction towards the Nechako Plateau, controlled by topography. It then met Piedmont glaciers that were advancing from the north and from the Rocky Mountains to the east. They combined to form the Cordilleran ice sheet with a surface that was over $2500 \mathrm{~m}$ above average sea level (asl) in elevation. Within the study site, the glacier advanced westward over the Coastal Mountains, as when it had become thick enough to be uninhibited by topography. When the glacial maximum ended and glacier retreat began, large parts of the Nechako Plateau to the north and east of the study site are thought to have been covered briefly by a proglacial lake and/or river that deposited wellsorted sand, silt, and minor clay sediment forming a glaciolacustrine overburden with repeating progression and regression sequences. The maximum elevation of these deposits are thought to be approximately $770 \mathrm{~m}$ asl north of the study site (Plouffe 1997), $890 \mathrm{~m}$ south of the study site, and $975 \mathrm{~m}$ south-east of the study site (Huscroft and Plouffe 1999, Plouffe and Levson 2001, Mate and Levson 2001), see the contour lines in Figure 2.4. The Cordilleran ice sheet over Francois Lake is thought to have drained east to the Frasier River and then south, and also westward through the Coastal Mountains into the Kitimat Trough or the Gardner Canal (Stumpf et al. 2000). 
Table 2.1: Airborne gravity and electromagnetic survey and system specifications. Specifications are from the 2008 Quest West survey (Tx: transmitter; Rx: receiver)

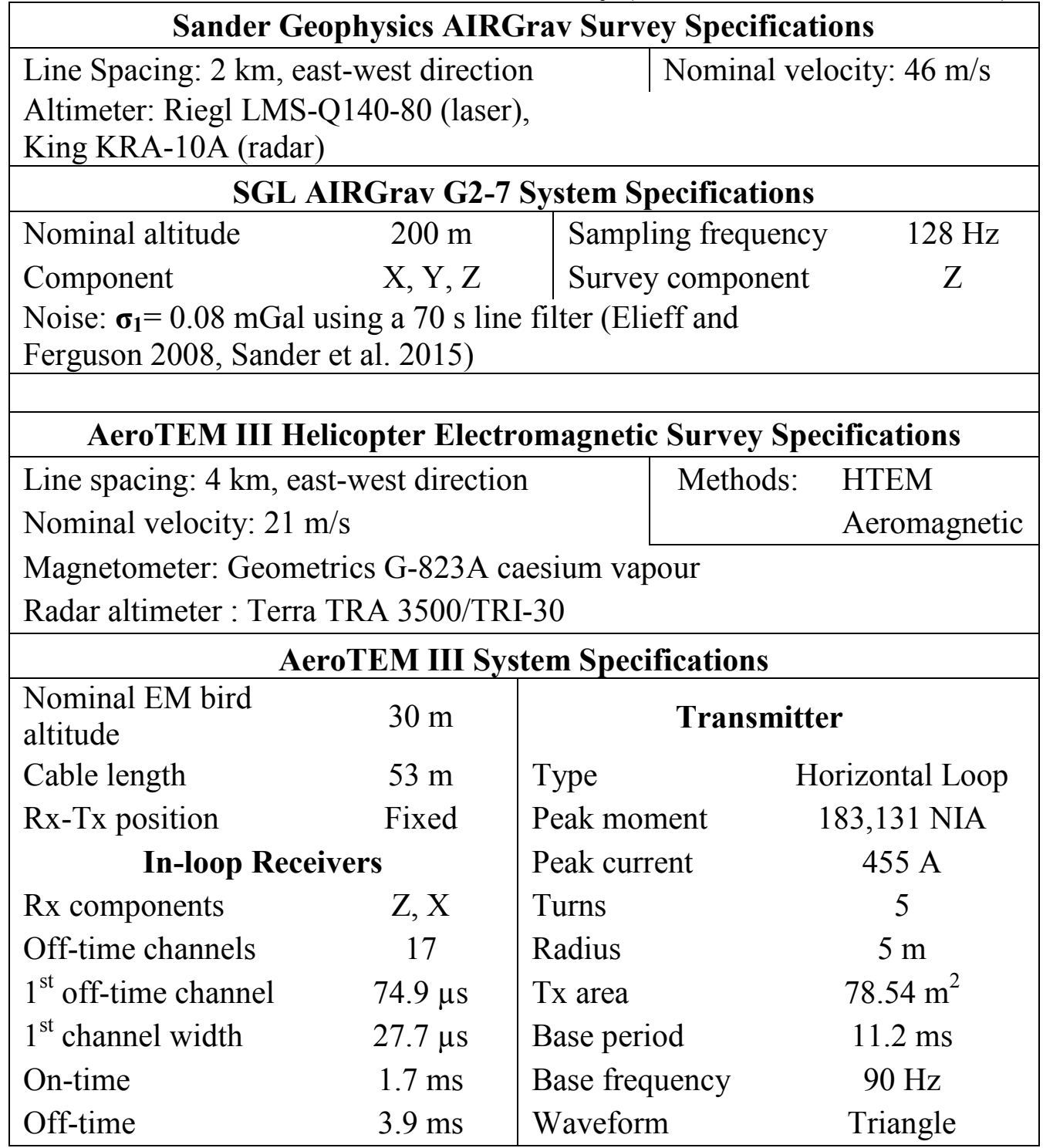




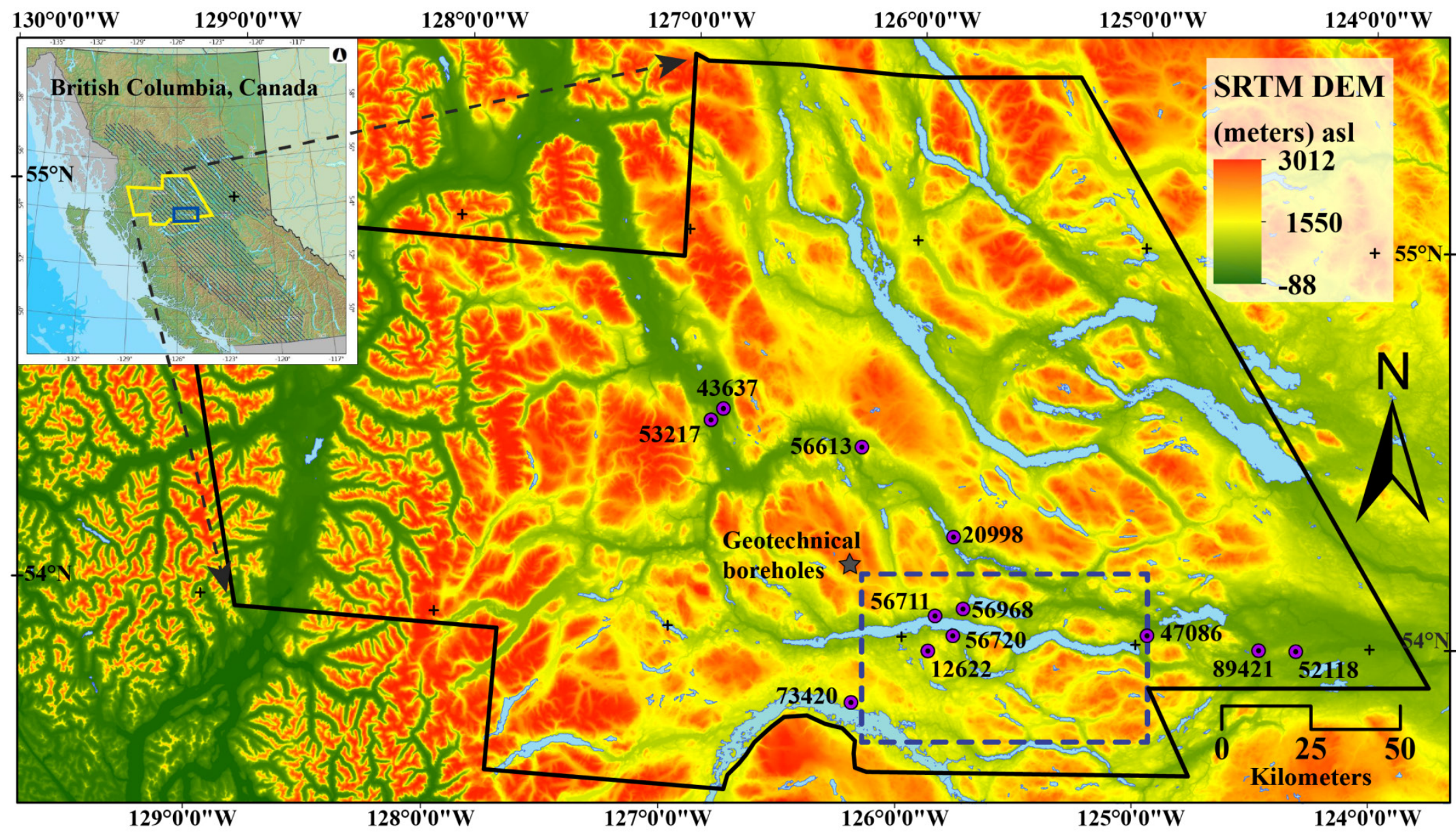

Figure 2.1: Digital Elevation Map (DEM) of Quest West survey area

DEM of Quest West survey area within the Nechako Plateau of British Columbia, Canada. Map shows locations of water wells (purple circles) used for calibration of HTEM inversions and the location of the GSC Equity Silver geotechnical boreholes (grey star). Study site is outlined by the blue dashed box. Geometric coordinates in NAD83. 


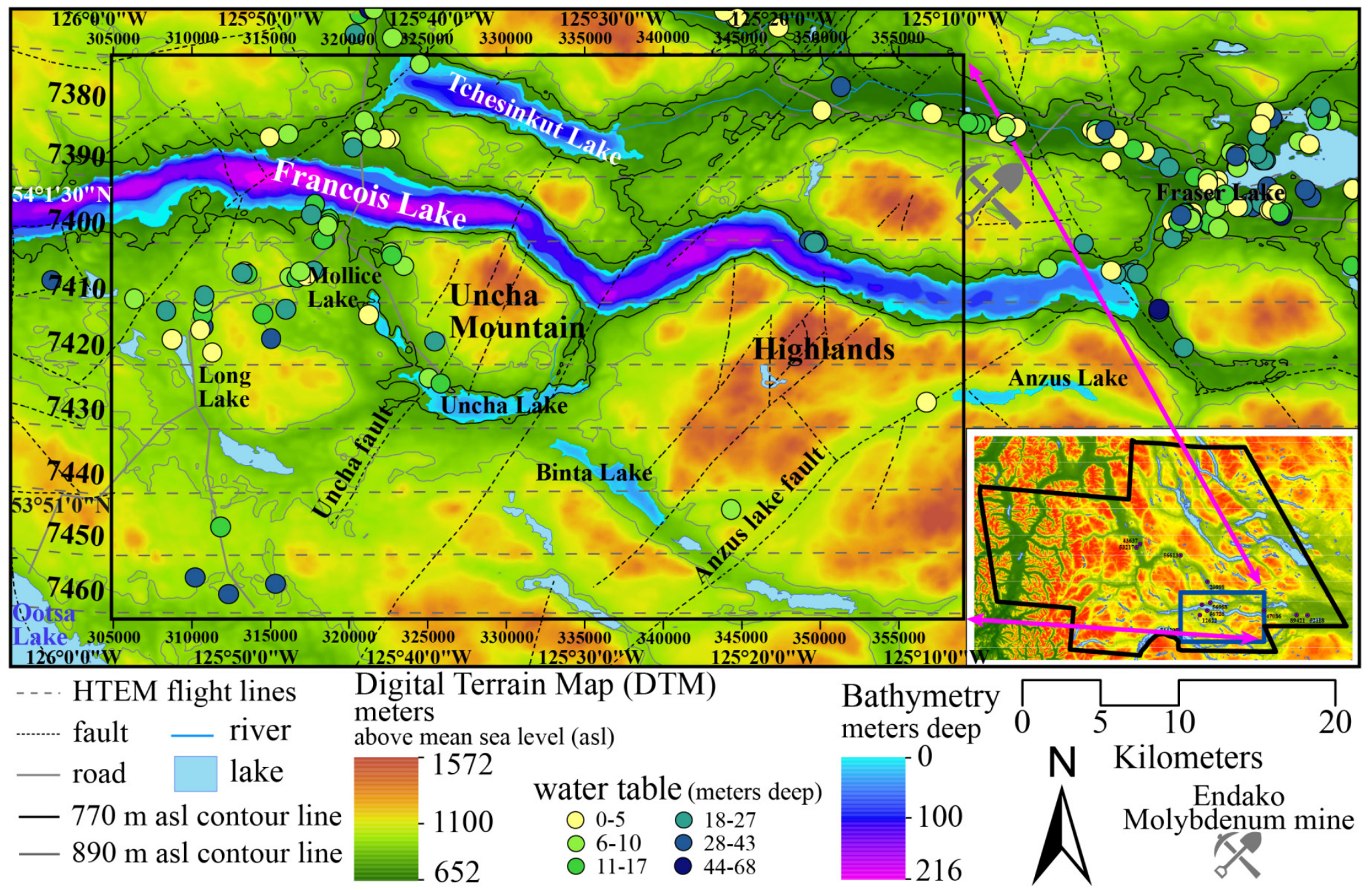

Figure 2.2: Digital Elevation Map (DEM) with bathymetry of the study site

DEM of the study site in the Nechako Plateau of British Columbia, Canada. Black rectangle denotes boundary lines for gravity maps. BC Wells water table data is also shown. Some bathymetry data is not available for many of the smaller lakes in the study site. DEM was created by combining SRTM data from CGIAR-CSI (Jarvis et al. 2008), bathymetry surveys (British Columbia 2014), and HTEM survey telemetry data (Aeroquest Limited 2009). Map cell size is 100 m. UTM 10 N, NAD 83. 


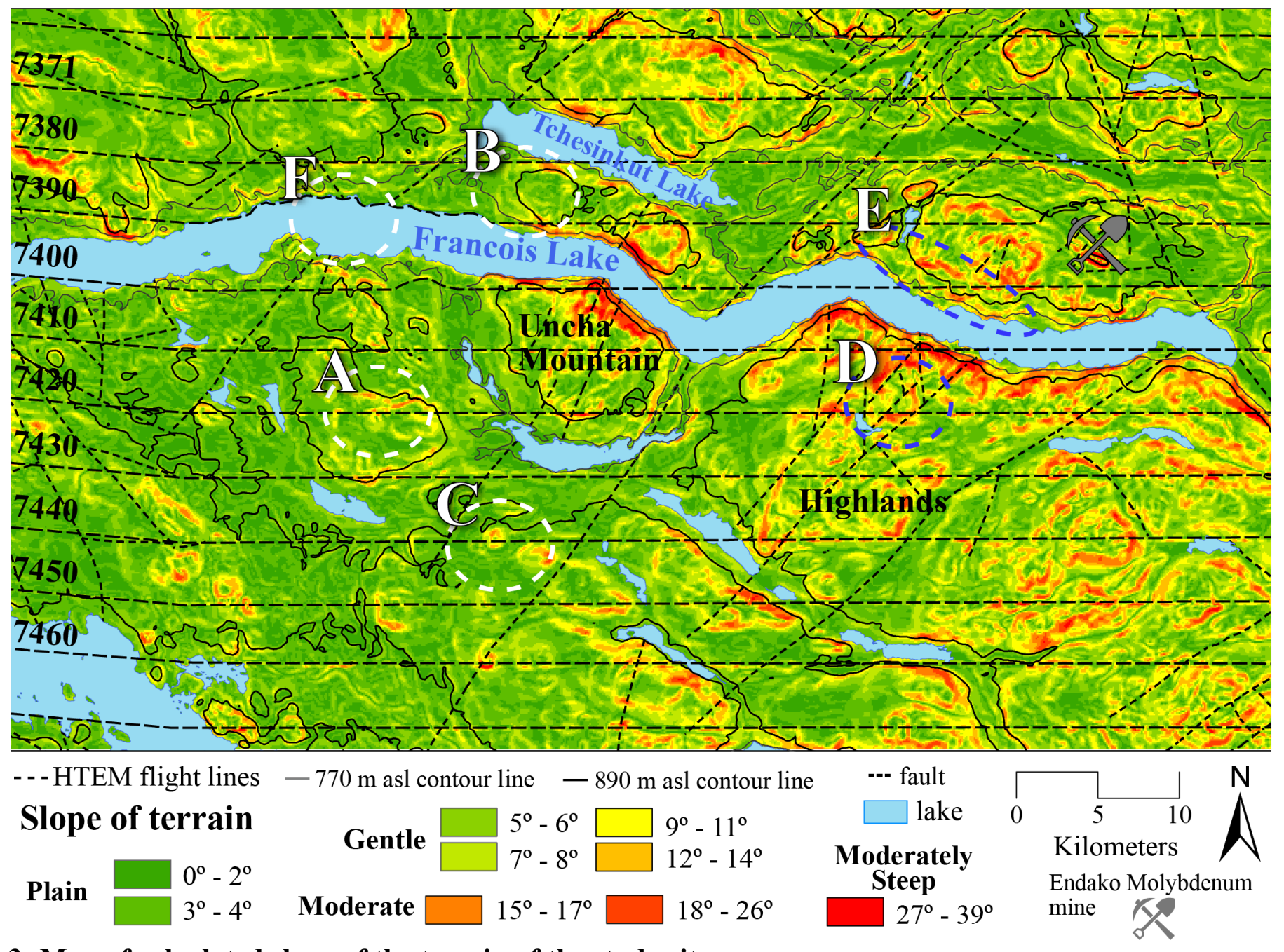

Figure 2.3: Map of calculated slope of the terrain of the study site

Slopes are calculated from 90m resolution SRTM data using the spatial analyst tool in ArcMap. BC terrain class terms plain, gently, moderate, and moderately steep are from Howes and Kenk (1997). Letters with dotted-lines outline features that are discussed in section 5.5 and later. 


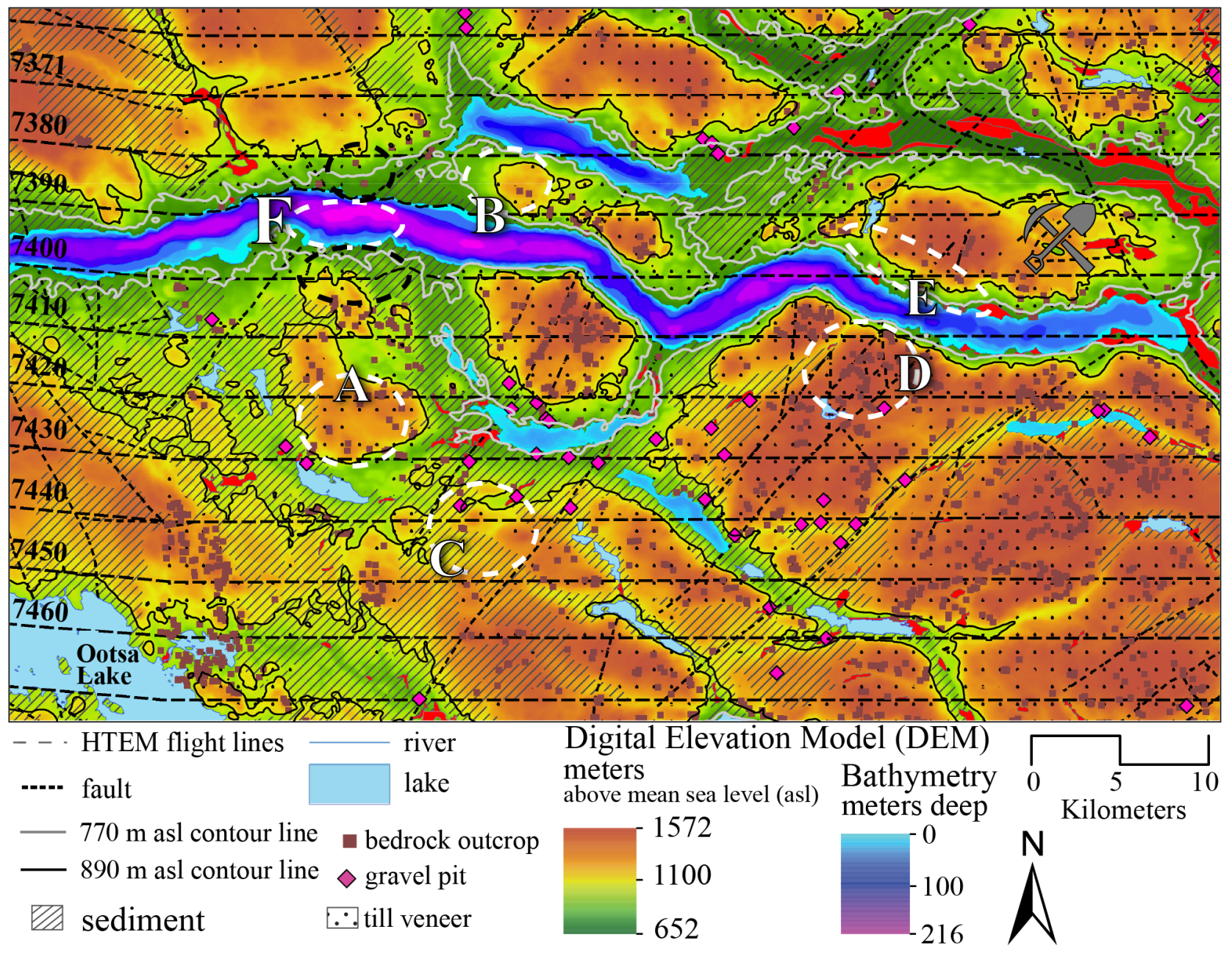

Figure 2.4: Compiled surficial geology map of the study site

Sediment layer denotes areas of Quaternary-aged sediment cover (Massey et al. 2005). The $770 \mathrm{~m}$ asl (above sea level) grey contour line outlines glaciolacustrine strandlines observed in the north and east (Plouffe and Levson 2001). The $890 \mathrm{~m}$ asl black contour line outlines glaciolacustrine deposits near Ootsa Lake (Mate and Levson 2001). Location of bedrock outcrops, till veneer, and gravel pits used for aggregate are indicated (Plouffe 1998a, Plouffe 1998b, MacIntyre and Struik 1999, Plouffe and Mate 2001, Plouffe and Levson 2001, Ferbey 2014, Arnold and Ferbey 2016). Red layer denotes glaciolacustrine or glaciofluvial cover sediment (Plouffe and Mate 2001, Plouffe and Levson 2001, Mate and Levson 2001). 


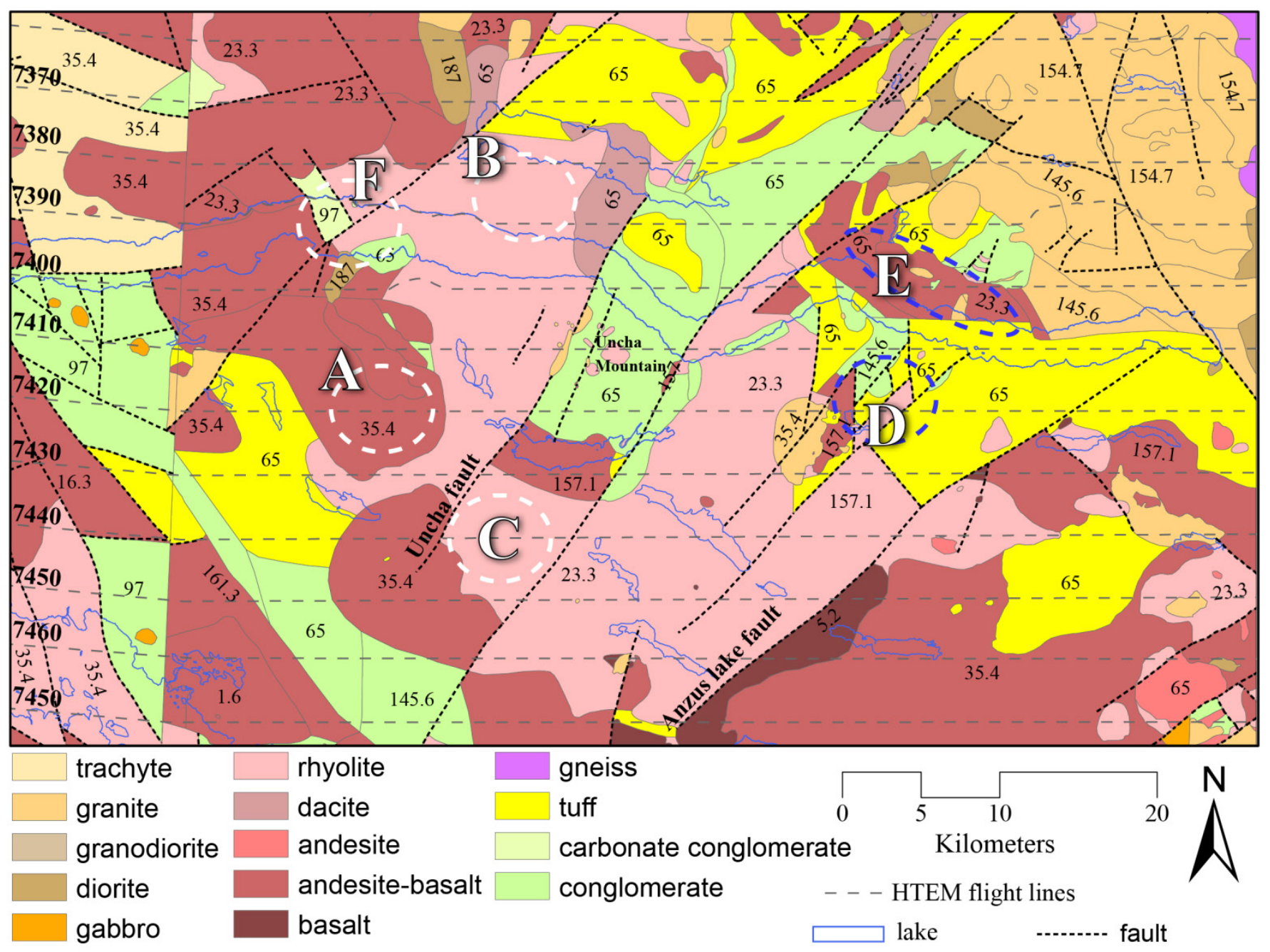

Figure 2.5: Bedrock geology map of survey site

Minimum ages of bedrock units are shown in units of millions of years (Ma). Map has been simplified from Cui et al. (2015). White bold letters indicating dotted-circles outline features that are discussed in section 5.5 and later. 


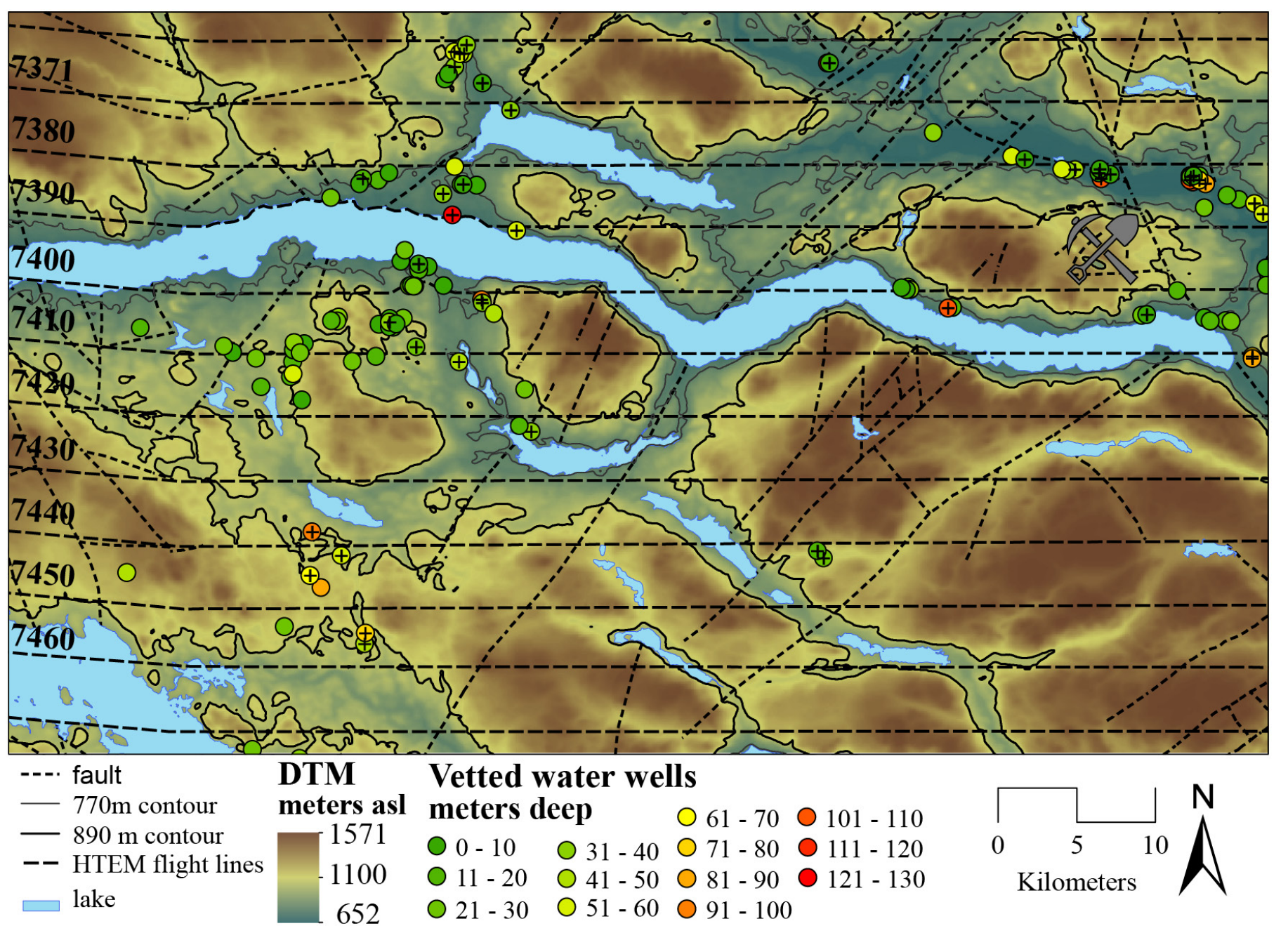

Figure 2.6: DEM map showing the distribution of vetted water wells

BC WELLS distribution is poor throughout the study site. Only the water wells that were vetted following section 2.4 .1 are mapped. Wells with a black cross were not drilled to bedrock and represent an indication of minimum overburden thickness. 
Table 2.2: Physical properties of sediment and rock

Both the frequency electromagnetic (FEM) and TEM surveys were ground-based. Surveys conducted within the Nechako Plateau are indicated. GSC Equity Silver boreholes represent in-situ measurements. The arithmetic average is shown for some bedrock types.

\begin{tabular}{|c|c|c|c|c|c|c|}
\hline Sources & & Soil Type & & \multicolumn{3}{|c|}{ Bedrock Type } \\
\hline Resistivity [ $\Omega \bullet \mathbf{m}]$ & Clay & Sand & Till & $\begin{array}{l}\text { Volcanic } \\
\text { rock }\end{array}$ & $\begin{array}{c}\text { Sandstone } \\
\text { [S] } \\
\text { Limestone } \\
{[\mathrm{L}]}\end{array}$ & Tuff \\
\hline $\begin{array}{l}\text { FEM: Abitibi, ON: } \\
\text { Palacky, } 1991\end{array}$ & $30-60$ & $120-360$ & $90-155$ & $\begin{array}{l}3000-10000 \\
\text { [crystalline] }\end{array}$ & 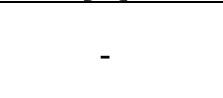 & - \\
\hline TDEM: S.Nechako, BC & & $68-157$ & & $\begin{array}{l}1500-10000 \\
\text { [volcanic] }\end{array}$ & - & - \\
\hline $\begin{array}{l}\text { Nechako: Kushnir et al. } \\
2012\end{array}$ & - & - & - & $\begin{array}{c}37-23000 \\
\text { Avg }=4445\end{array}$ & - & - \\
\hline $\begin{array}{l}\text { Forward Model: Auken } \\
1995\end{array}$ & $10-30$ & $\begin{array}{c}100 \\
\text { (aquifer) }\end{array}$ & - & - & - & - \\
\hline $\begin{array}{c}\text { GSC Equity Silver } \\
\text { boreholes }\end{array}$ & - & - & - & $\begin{array}{l}122-1284 \\
\text { Avg }=495\end{array}$ & - & $\begin{array}{l}0.01-1030 \\
\text { Avg }=308\end{array}$ \\
\hline Telford et.al 1990 & $1-100$ & - & - & $1900-1.3 \times 10^{6}$ & $\begin{array}{l}{[\mathrm{S}] 1-6.4 \times 10^{8}} \\
{[\mathrm{~L}] 50-1 \times 10^{7}}\end{array}$ & $2000-1 \times 10^{5}$ \\
\hline Density $\left[\mathrm{g} / \mathrm{cm}^{3}\right]$ & Clay & Sand & Till & $\begin{array}{c}\begin{array}{c}\text { Volcanic } \\
\text { rock }\end{array} \\
\end{array}$ & & Tuff \\
\hline Telford et.al 1990 & $1.6-2.6$ & $1.7-2.3$ & & $2.35-2.8$ & - & - \\
\hline Balco et.al 2005 & 2.01 & 2.13 & 2.24 & - & - & - \\
\hline $\begin{array}{l}\text { Nechako: Kushnir et al. } \\
\qquad 2012\end{array}$ & - & - & - & $\begin{array}{c}2.16-2.90 \\
\mathrm{Avg}=2.50\end{array}$ & - & - \\
\hline $\begin{array}{c}\text { GSC Equity Silver } \\
\text { boreholes }\end{array}$ & - & - & - & $\begin{array}{c}2.5-3.2 \\
\operatorname{Avg}=2.89 \\
\end{array}$ & - & $\begin{array}{c}0.36-4.1 \\
\text { Avg }=2.88\end{array}$ \\
\hline
\end{tabular}




\subsection{HTEM overburden inversion modelling 3.1 HTEM system capability}

The following physical characteristics of HTEM systems, based on the measurement on the derivative of secondary magnetic field (measured with a coil), are generally accepted:

1. The off-time response of the secondary field can only be sampled after the primary field strength has decayed to zero, at the conclusion of the turn-off time.

2. The earlier the measurement of the secondary magnetic field is made, the closer to the surface of the area that is being sampled. Conversely, the later the measurement of the secondary magnetic field, the deeper the area being sampled is until the depth of investigation (DOI), the estimated maximum depth the system can make a reliable measurement, is reached (Nabighian 1979).

3. The smaller the window of time being sampled, the higher the resolution of each measurement, but this can lead to a lower number of stacked responses which could result in a lower signal to noise ratio.

4. A higher amplitude current in the Tx results in a longer turn-off time. This is a function of the physics governing electron flow through a conductor. 
5. Conductive anomalies have a moderate amplitude initial response with a long decay time, while resistive anomalies have a high amplitude initial response with a short decay time.

Most HTEM systems have been designed for the detection of deep ore bodies. Can they be used to measure the secondary field response of the overburden? To answer this question several of the characteristics of HTEM systems listed above were reexamined. Forward modelling and inversion were conducted using discrete layered earth models with 2, 3 and 4 layers designed to approximate a glaciolacustrine overburden that overlies resistive crystalline bedrock. The purpose is to identify specific system parameters that an HTEM system should have in order to measure the secondary field response originating within the overburden and to develop an initial methodology that can be used to invert survey data to indicate the overburden-bedrock contract. This is largely borrowed from Caron et al. (2013).

\subsection{HTEM system design}

Basic HTEM system physical characteristics used in forward modelling are shown in Figure 3.1. The system is a single-turn in-loop system where the transmitter and the receiver are in a horizontal plane, where the receiver is offset and slightly raised from the transmitter. The transmitter emits a square waveform (Figure 3.2) to maximize the response of the overburden (Lui 1998). The system is designed to be suspended 30m below the helicopter in order to reduce helicopter-generated EM interference and increase subsurface response. 


\subsection{Optimizing system parameters}

Two parameters were investigated through forward modelling in order to optimize the response of the shallow subsurface: transmitter moment and maximum duty time. For simplicity, an in-loop concentric transmitter-receiver geometry has been assumed for modelling. Modelling was done using AirBeo of the P223F EM open source code suite developed by the Commonwealth Scientific and Industrial Research Organization (CSIRO). AirBeo computes and inverts EM responses for 1D layered-earth models (Raiche 2007, Raiche et al. 2008, Chen and Raiche 1998). See Section 4.2.3 for more information on inversion software.

The transmitter moment was chosen by examining the forward modelled responses obtained using AirBeo over a suite of models based on the geology of the Abitibi mining region. The Abitibi was chosen is it was the site of previous research on measuring overburden thickness by inverting frequency electromagnetic (FEM) data (Palacky and Stephens 1990). Several moments were modelled corresponding to currents of $60 \mathrm{~A}, 100 \mathrm{~A}$, and $200 \mathrm{~A}$ which correspond to magnetic moments of 9,200 Am², 15,400 $\mathrm{Am}^{2}$, and $30,800 \mathrm{Am}^{2}$. Since the overburden-bedrock interface is the primary target of the EM system, and since the overburden information is found in the early time response, the transmitter turn-off time must be kept as short as possible. A large current induces a strong response that is desirable, but causes a long turn-off time that overshadows the early time response. On the other hand, a small current induces a weak response. A current of 100 A was chosen as a compromise. For instance the SkyTEM system has a 
turn-off time estimated to be about $4 \mu$ s for a 30 A single-turn in-loop transmitter with a moment of 14,700 $\mathrm{Am}^{2}$ (Sorensen and Auken 2004). The actual turn-off time of the system is a function of the physical characteristics of the transmitter. It is not known at present and will need to be measured experimentally, although it is estimated to be less than $10 \mu \mathrm{s}$.

Optimization of the maximum duty time, see Figure 3.3, was conducted in order to achieve a balance between target response and signal repetition. Studies have shown that by increasing the maximum duty time of the transmitted waveform a higher amplitude response can be obtained from a conductive body (Becker et al. 1984). Conversely, if the target is not as conductive as an ore body, such as lacustrine clay, then the EM system does not require a large maximum duty time. The objective then is to increase the response of the target while maintaining a high repetition of soundings to increase the signal to noise ratio through stacking over the sampling distance.

Responses were calculated using AirBeo for a square 100 A waveform with maximum duty times of $0,0.5,1.0$, and $2.0 \mathrm{~ms}$ and a simple starting model composed of a $20 \mathrm{~m}$ thick horizontal layer over a resistive half-space. The response was calculated over a range of overburden resistivities from $5 \Omega \cdot \mathrm{m}$ to $500 \Omega \bullet \mathrm{m}$. Figure 3.3 shows that the maximum duty times of $0.5,1.0$ and $2.0 \mathrm{~ms}$ correspond to very similar decay curves, typically half a decade stronger that those associated with a $0 \mathrm{~ms}$ maximum duty time. The optimal choice is therefore $0.5 \mathrm{~ms}$ which energizes thoroughly the overburden while allowing for a higher sounding frequency (higher spatial resolution). For example, an on- 
time of $0.8 \mathrm{~ms}$ (a ramp-up time of $0.3 \mathrm{~ms}$ followed by a duty time of $0.5 \mathrm{~ms}$ ) and an offtime of $3 \mathrm{~ms}$ corresponds to a sounding frequency of $250 \mathrm{~Hz}$. A higher sounding frequency will not only lead to a higher signal to noise ratio through stacking, but will also provide increased versatility by alternating this transmitter waveform with other signals optimized for a deeper and/or more conductive target. This is the approach implemented in the SKYTEM system (e.g. Sorensen and Auken 2004).

Acquisition will be conducted at the maximum sample rate allowed by the receiver $(2 \mu \mathrm{s})$ during the transmitter off-time for a period of about $3 \mathrm{~ms}$ to ensure a complete capture of the overburden response. The sampled data can then be averaged into logarithmic gates to increase the signal to noise ratio.

\subsection{Overburden detectability study}

The next step in the study involved modelling the response of the HTEM system under development and inverting the results to check if the system could resolve overburden thickness and intra-overburden layering. The study was first performed with noise-free data, followed by data with different levels of Gaussian noise.

The scenarios (see Figure 4.4.1 A) investigated included 2-layer, 3-layer, and 4layer geological models. All of the models assumed that the glaciolacustrine sediment was deposited horizontally. The resistivities and thicknesses used (see Figure 4.4.1 A) are based on the results of surveys conducted by the Geological Survey of Canada (GSC) near the town of Val Gagné, Ontario, in the Abitibi mining region. Ground-based 
horizontal-loop EM results conducted over boreholes during the surveys determined that the clay, sand, and till have an average resistivity of $47.3 \pm 6.7 \Omega \cdot \mathrm{m}, 251 \pm 70 \Omega \cdot \mathrm{m}$, and $123 \pm 35 \Omega \cdot m$, respectively (Palacky 1992). Lab tests of samples collected from nearby boreholes returned slightly different values for clay at $28.4 \pm 9.8 \Omega \cdot \mathrm{m}$ and till at $83.1 \pm$ $26.8 \Omega \cdot \mathrm{m}$ (Palacky and Stephens 1990). The resistivity of the bedrock was kept constant at $10,000 \Omega \cdot m$ in accordance with results published by Palacky and Stephens (1990) who showed that crystalline bedrock resistivity is typically $>10,000 \Omega \cdot \mathrm{m}$, high enough to make any contribution from the basement to the response negligible.

\subsection{Noise-free modelling}

Noise-free forward modelling and inversion of the HTEM system was conducted where forward models of a layered earth model were created and inverted to reproduce the original layered earth model, were conducted using AirBeo, see Figure 3.4. The objective is to see if the HTEM system is able to resolve the layered earth model created from forward modelling by inverting the result. The process begins with the simplest 2layer case using a starting model composed of 2-layers where the first layer has a thickness of $5 \mathrm{~m}$ and a resistivity of $45 \Omega \bullet \mathrm{m}$, the halfspace has a resistivity of 10,000 $\Omega \bullet \mathrm{m}$. The inversion returns thickness $\mathbf{h}_{1}$ and resistivity $\boldsymbol{\rho}_{1}$ of the shallowest layer. The goodness of fit is expressed as the root mean square of the symmetric mean absolute percentage error (sRMS). If this parameter is less than $0.1 \%$, indicative of a good fit, then the process continues to the inversion of a 3-layer case where the starting model has a thickness $\mathbf{h}_{\mathbf{1}}$ and resistivity $\boldsymbol{\rho}_{\mathbf{1}}$ for its first layer adopted from the previous 2-layer inversion. The second layer $\mathbf{h}_{2}$ has constraints of a thickness of 5-40 m, and a loose 
constraint on the resistivity of 100-300 $\Omega \bullet \mathrm{m}$. In the event that the 3-layer inversion has a RMS\% below $0.1 \%$, a 4-layer inversion is conducted using a starting model that features a first layer thickness $\mathbf{h}_{\mathbf{1}}$ and resistivity $\boldsymbol{\rho}_{\mathbf{1}}$. Loose constraints on $\mathbf{h}_{\mathbf{2}}, \boldsymbol{\rho}_{\mathbf{2}}$ and $\boldsymbol{\rho}_{\mathbf{3}}$ are 5-40 m, 200-300 $\Omega \cdot \mathrm{m}$, and 100-200 $\Omega \cdot \mathrm{m}$ respectively. The $\mathbf{h}_{\mathbf{3}}$ constraints are identical to $\mathbf{h}_{\mathbf{2}}$.

Constraints were selected to coincide with an estimated average resistivity for a clay soil $(45 \Omega \bullet \mathrm{m})$ where more conductive clays were situated near the surface and less conductive sands, gravel, and till were situated near the bedrock contact. , thickness of sediment layers within overburden, and total estimated overburden thicknesses.

\subsection{Modelling with synthetic noise}

Forward modelling and inversion of noisy data were also conducted using AirBeo. Different sources of noise were added to the EM responses following the method outlined in Auken et al. (2008) which models the effect of different sources of noise as they affect the early, middle, and late decay measurements. Gaussian white noise with a mean of 0 and a standard deviation of 1 , with a range of -1 to $1 \mathrm{nV} / \mathrm{m}^{2}$, was added to model sferic sources of noise. $\mathrm{A} \mathrm{db} / \mathrm{dt}\left(\mathrm{nV} / \mathrm{m}^{2}\right)$ uniform noise of $2 \%$ was added to model instrument and other non-specified sources of noise along with an additional term that models radio transmitter noise and other background sources of noise (Auken et al. 2008).

The inversion methodology is the same as outlined for the noise-free inversion. A typical RMS \% is now approximately less than $1 \%$ for a 2 -layer case, $1.5 \%$ for a 3 -layer case, and 1.5-2.3\% for a 4-layer case. Several examples are shown in Figure 3.5 where the largest discrepancy between the model and the inversion occurs in the far-right 4- 
layer case. The RMS \% match is 2.28 , which results in a difference of $4.4 \mathrm{~m}$ in the overall overburden thickness. This is a $7.4 \%$ mismatch between the inversion and the model.

A transmitter current of $60 \mathrm{~A}$ would provide better resolution in the near-surface $(<$ $5 \mathrm{~m}$ ), by collecting data at an earlier time, but would also result in a larger loss of data from sources of noise, while a 200 A current would result in a loss of resolution in the near-surface but provide better results with regard to deeper responses.

A transmitter current of $100 \mathrm{~A}$ and maximum duty time of $0.5 \mathrm{~ms}$ have been found to be a good compromise between generating enough energy to probe the complete thickness of the overburden while allowing very early time responses to be recorded and providing a high sounding frequency.

\subsection{Summary}

The EM responses of a hypothetical HTEM system with these characteristics have been modelled and inverted with and without noise to evaluate its capability to detect the overall overburden thickness and the presence of layers of clay, sand and till within the overburden. For simple 1D models that include up to 4 layers, results have shown that the system is able to measure the thickness of a glaciolacustrine overburden to within $10 \%$ of the thickness with noise added. In addition a transmitter current of $100 \mathrm{~A}$ with a 15,400 $\mathrm{Am}^{2}$ moment and maximum duty time of $0.5 \mathrm{~ms}$ have been found to be a good compromise between generating enough energy to probe the complete thickness of the 
overburden while allowing very early time responses to be recorded while providing a high frequency of soundings. 


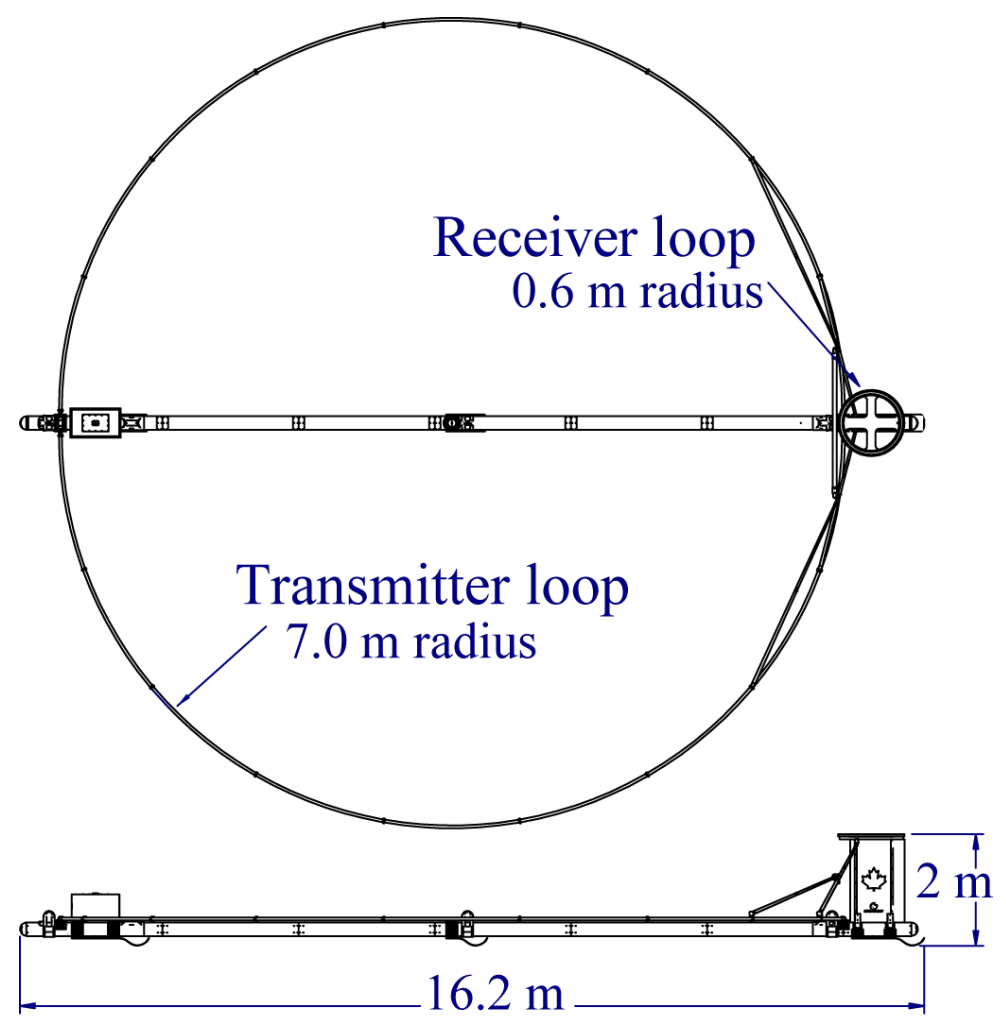

Figure 3.1: Concept drawing of HTEM system used for modelling.

The transmitter is a single-turn $7 \mathrm{~m}$ radius loop with a 100 A current for a magnetic moment of $15,400 \mathrm{~A} / \mathrm{m}^{2}$. The transmitter is designed to hang beneath the helicopter at the end of a $30 \mathrm{~m}$ long cable. The receiver location has not been finalized yet. It is shown here offset and slightly elevated from the transmitter. Figure from Caron et al. 2013. 


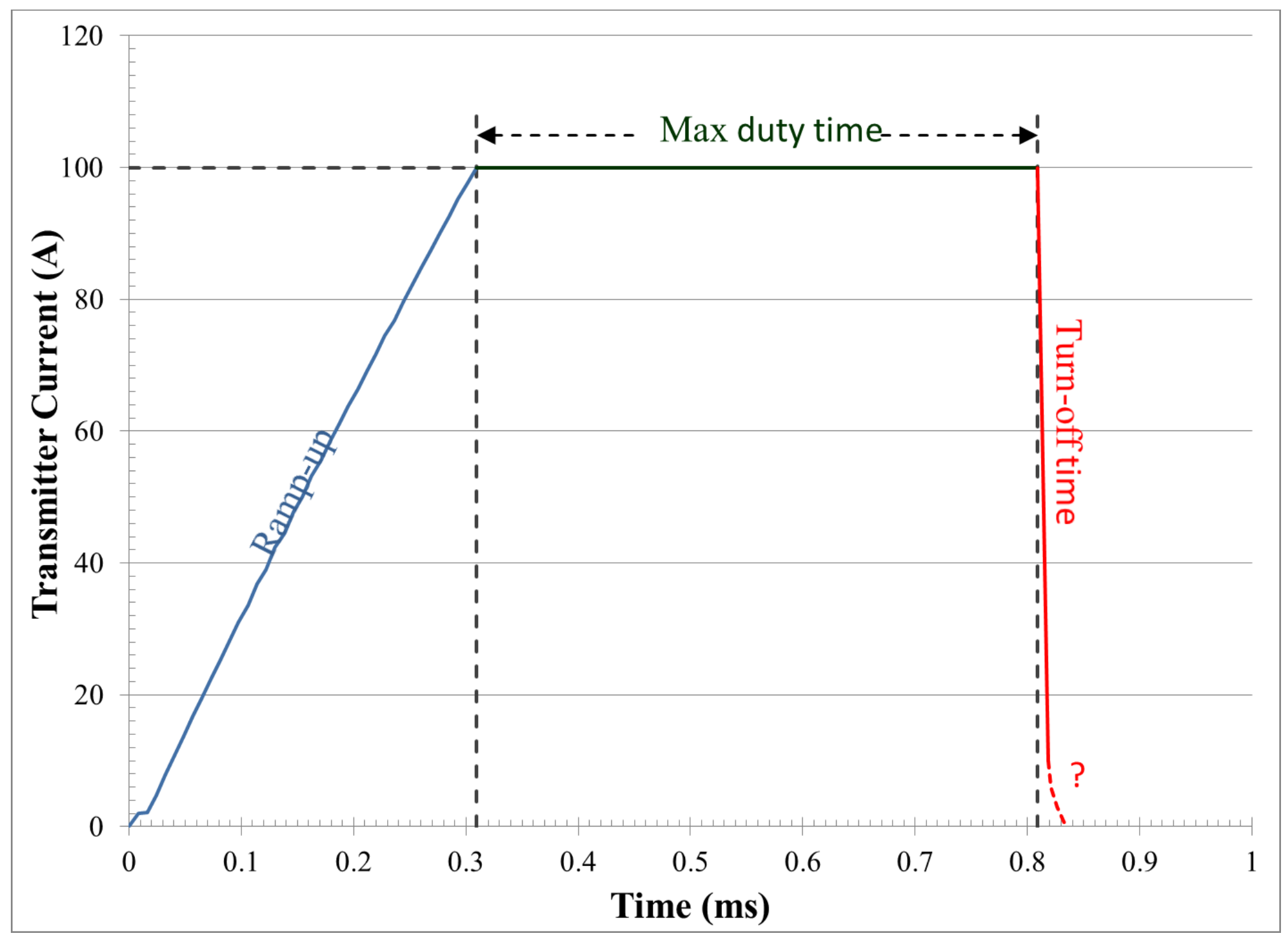

Figure 3.2: HTEM transmitter waveform

Waveform shows the ramp-up, maximum duty time, and turn-off times. Exact turn-off time is undetermined. Figure from Caron et al. 2013. 


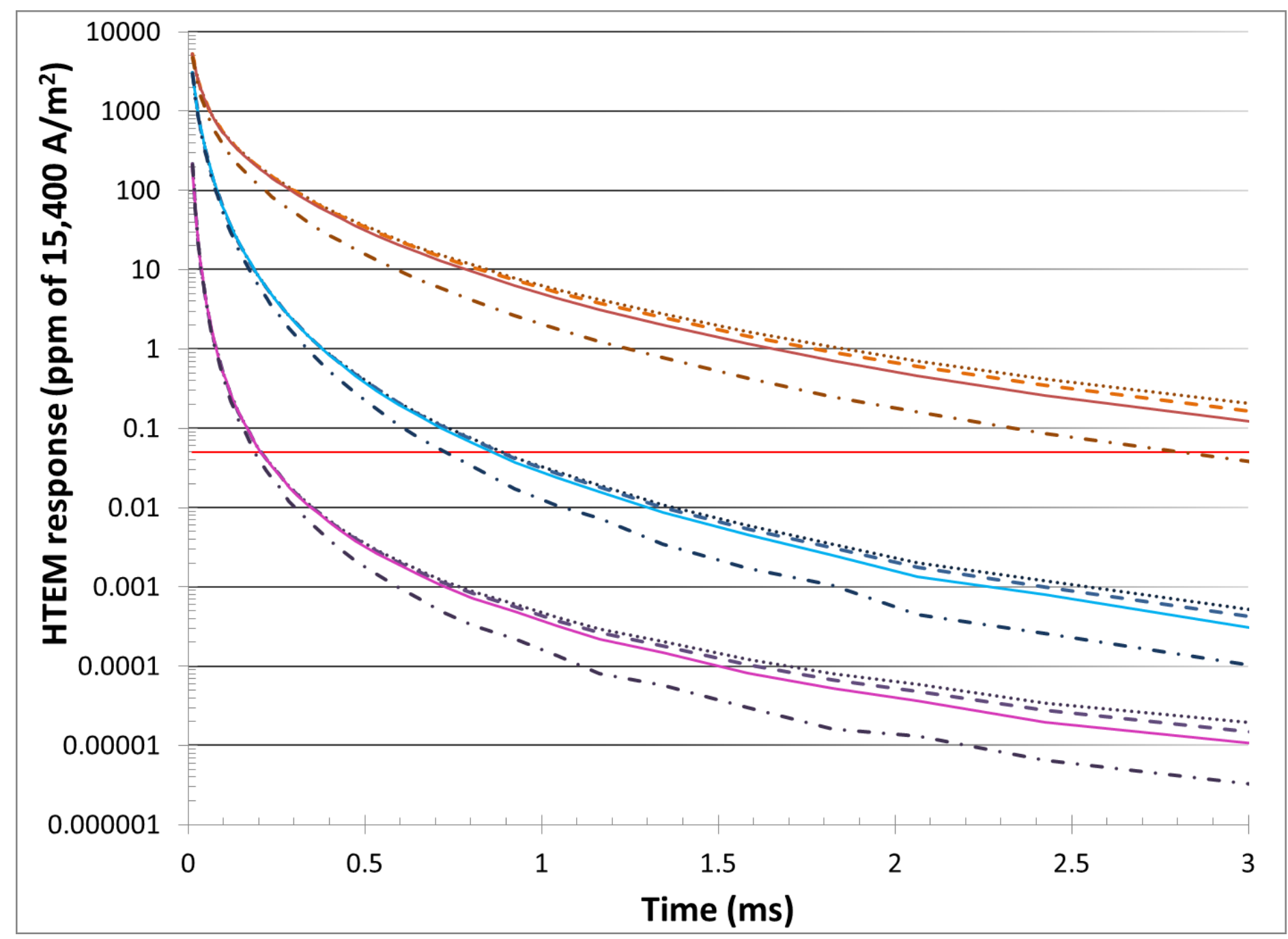

Figure 3.3: Comparison of HTEM response with max duty time and current

Comparison between off-time responses for a transmitteer loop current of $100 \mathrm{~A}$ and different maximum duty times: 0 ms (dotted dashed lines), $0.5 \mathrm{~ms}$ (solid lines), $1.0 \mathrm{~ms}$ (dashed lines), and $2.0 \mathrm{~ms}$ (dotted lines). A simple model featuring a $20 \mathrm{~m}$ thick horizontal overburden layer over a highly resistive $\left(10^{4} \Omega \bullet \mathrm{m}\right)$ half-space was analyzed. Plotted are the results for overburden resistivities of 5 (orange), 50 (blue) and 500 (purple) $\Omega \bullet \mathrm{m}$. Red line indicates modelled noise level for the system. 


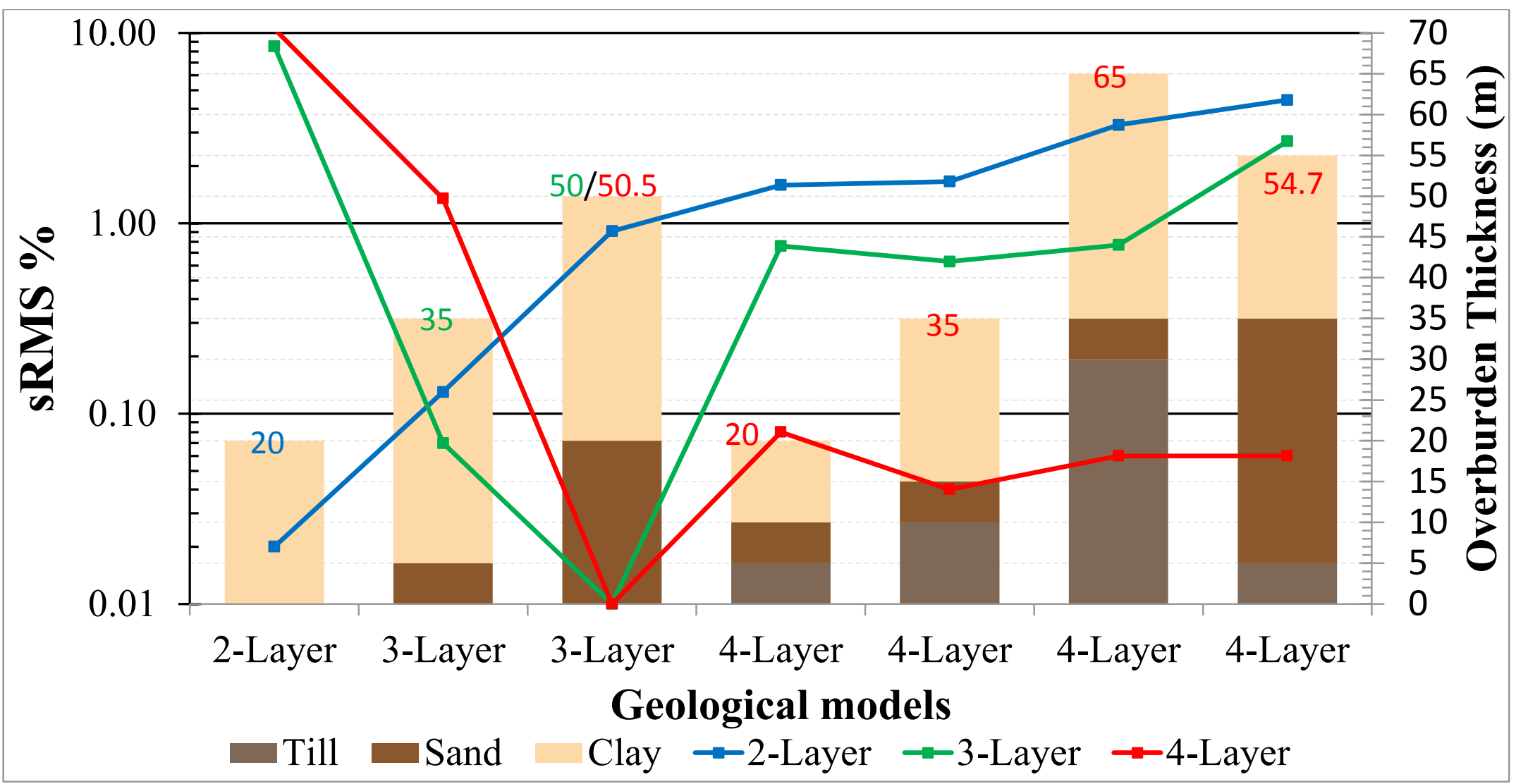

Figure 3.4: Inversion of noise-free data for 2-4 layer models.

Layered earth models are shown as layered columns which add up to a total overburden thickness shown on the right-axis, the bedrock halfspace is not shown. Overburden thickness inversion results by model are indicated by colour where blue, green, and red indicate a 2-, 3-, and 4-layer result, respectively. Inversion goodness of fit error is indicated by the the plotted coloured lines and correspond to the sRMS \% error shown on the left-axis, a lower value is better. Figure shows that while starting models with multiple layers are able to invert the geological models, the inversions with best results (lowest sRMS) are from the starting models with the same number of layers as the geological model.. Half-space representing the bedrock is not shown. An sRMS\% below 0.1 (black solid line) is considered a good fit. The inversion result, total depth to bedrock, is the number above each column. Inversions are a perfect match except for the far right 4-layer case (off by $0.3 \mathrm{~m}$ from $55 \mathrm{~m}$ ), and the 4-layer inversion of the right-most 3-layer case (off by $0.5 \mathrm{~m}$ from $50 \mathrm{~m})$. 


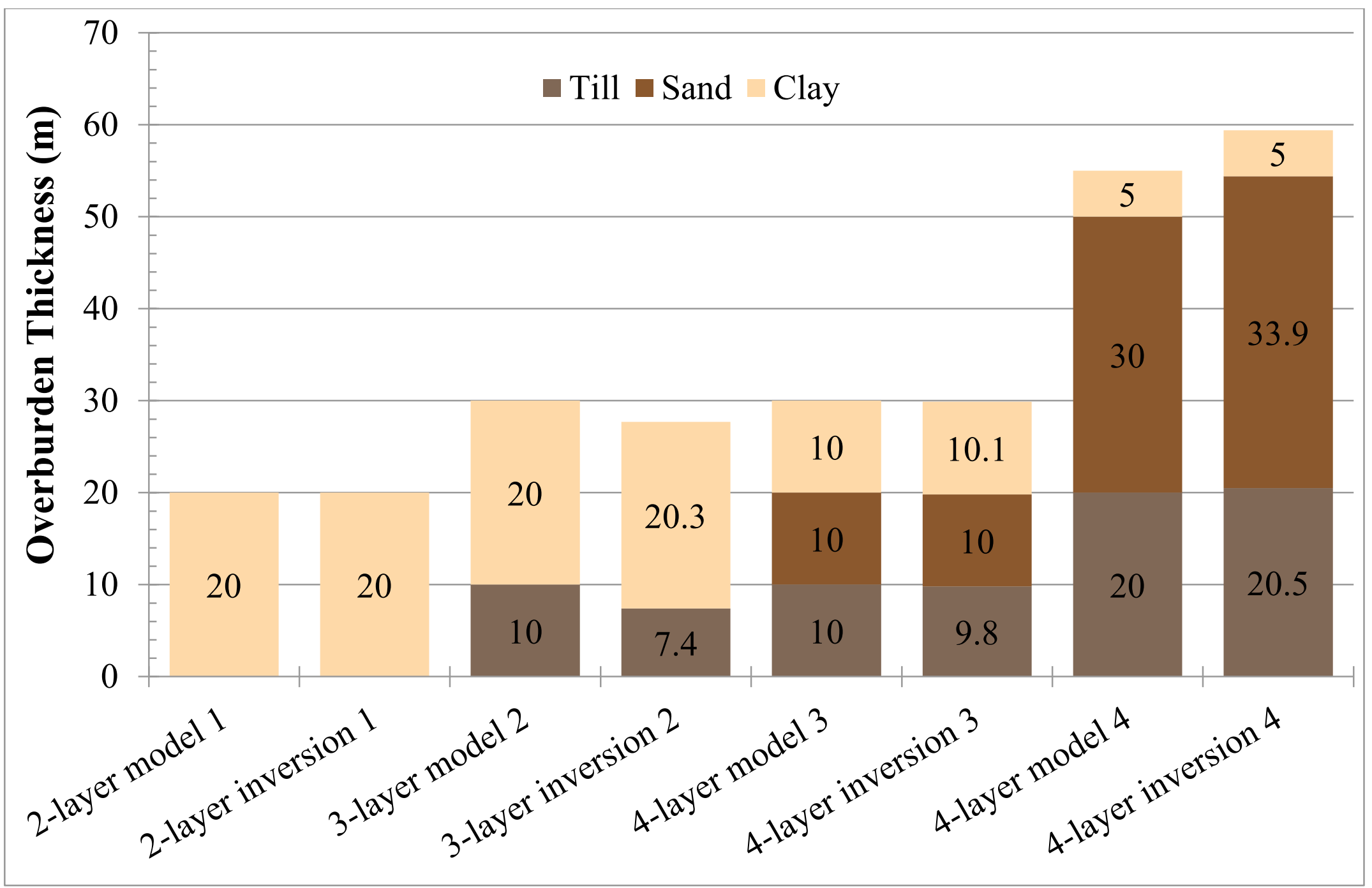

Figure 3.5: Inversion of noisy data for 2-4 layer models

Figure shows various layered earth models and shown adjacent to their respective overburden thickness inversion results. The halfspace representing the bedrock is not shown. Despite noise added to the responses, the inversions are still able to identify the thickness and conductivity of individual layers as well as the overall depth to the bedrock. 


\subsection{Methods}

The methodology applied for HTEM inversion was refined several times during this project as barriers were addressed with new strategies. These strategies are; water well calibrated inversions in section 4.2 , two-layer inversions in section 4.3 , multilayer inversions in section 4.4, multi-layer resistivity reversal inversions in section 4.5, and Resistivity structure inversions in section 4.6. HTEM methodology is then followed by terrain map processing, in section 4.7 , followed by qualitative overburden thickness analysis, in section 4.8, and gravity processing for Bouguer corrections in section 4.9. A simplified flow-diagram of the methodology is shown in Figure 4.0.1.

\subsection{Initial assumptions}

Geological models are required for forward modelling and inversion of the HTEM data and for correction of the gravity data; they are related to the near-surface density and resistivity of the sediment and rocks, as well as to their distribution within the subsurface. The assumptions adopted for this research are listed below.

1. The near-surface geology can be approximated using a layered earth model for both HTEM inversion and gravity data correction.

The layered earth model is not a new concept. Layering of sediment was first introduced by the principle of original horizontality (Steno 1667). While Steno's initial observations were based on outcrops, layering is common in overburden, particularly lacustrine overburden, where sediment falls through a water column to end up on the lake bottom. While 
currents or other processes can disrupt or modify this layered structure, in general a layered earth model can approximate overburden created through sedimentation. Bedrock occurring beneath overburden can be regarded as an additional layer, layers, or a half-space depending on the nature and goal of the project. A layered earth model has the additional advantage of being a model that requires relatively simple calculations as each layer is considered a horizontal plane where resistivity only varies along the $\mathrm{Z}$ component, across each layer of the model.

From an electromagnetic (EM) perspective, the layered earth model accounts for the preference for electrical currents to flow along horizontal layers as opposed to vertically through them. This anisotropic effect can occur within the overburden, bedrock, and even within a water column if layers exist such as a fresh water to brine contact. The layered-earth model is not specifically configured to model this anisotropic effect, but the difference in conductivity between each layer within the model is an approximation.

The layered earth model is less critical with regard to the gravity method as gravity is not influenced by anisotropic ordering within rock or sedimentary units. In addition, the distribution of rock and sediment can generally be described as increasing in density with depth, which simplifies modelling. Rock and sediment units of differing bulk densities contribute directly towards the amplitude of the local gravity anomaly. 
2. A 2-layer earth model is sufficient to approximate near-surface geology for HTEM inversion at different stations along line in the Nechako Plateau.

This assumption is to be tested as part of this research as it is desirable to create quick and simple inversion methodology starting with the simplest 2-layer model, which can then be modified with more layers if required.

3. Resistivity increases with depth.

Table 2.2 shows published resistivity values measured from EM surveys, boreholes, and assays. The data shows that unconsolidated sediment tends to have a lower resistivity than crystalline or volcanic bedrock when measured at low resolutions (i.e. where resistivity is averaged in the response). Higher resolution borehole and laboratory essay results suggest that some bedrock resistivity values span a large range that can overlap the range of values assigned to sediment. The general assumption that resistivity increases with depth is therefore valid, however it warrants some attention to ensure that it remains valid throughout the study site, such as in areas where tuff is located.

i. The level of the water table throughout the study site could be a complication for this initial assumption. Well water data from the $\mathrm{BC}$ Wells dataset indicate that the depth to the water table is highly variable within the study site with a range of 0-67 m, see Section 2.4.1. HTEM inversions are therefore conducted over both saturated and unsaturated overburden and bedrock, depending on 


\section{HTEM System for Mapping Overburden Thickness}

the station. A water-saturated overburden or bedrock, with dissolved ions, may have a lower measured resistivity than its unsaturated counterpart.

4. There exists a large density and resistivity contrast between the overburden and the bedrock.

This assumption is supported by the data presented in Table 2.2. Care must be taken to ensure that it remains valid in areas where volcanic rock is present due to the overlap in resistivity values between volcanic rock and sediment, and where tuff is present due to the overlap of its density and resistivity with corresponding values for sediment.

\subsubsection{Overburden resistivity modelling}

Resistivity modelling of the near-surface was conducted using a 2-layer Earth model of various overburden and bedrock responses as measured from a purpose-built overburden sounding HTEM system. Physical properties of overburden and bedrock from various sources are presented in Table 2.2. The methodology and findings of these models are detailed in Caron et al. (2013), see chapter 3. This paper identified a possible strategy for the successful inversion of the overburden-bedrock contact through forwardmodelling using simple layered-earth models and careful constraints. The strategy starts with a basic 2-layer model, where the first layer represents the overburden and the second layer represents the bedrock as a half-space. The results of that inversion are then used to finely tune the resistivity or thickness of the starting models for slightly more complex 3- 
layer, and then 4-layers inversions, see Figure 4.1.1. The result identifies the number of layers that best characterises the overburden, while seemingly providing the most likely solution using a layered earth model.

When the results of the forward modelling were applied to field data from the study site, it was found that the variations in both measured noise and geology were sufficient to render the methodology described in Caron et al. (2013) ineffective, as multiple realistic solutions, each with an symmetric root-mean square (sRMS) error below $10 \%$, were obtained when following it regardless of the number of layers within the model. The resistivity model required updating to fit the volcanic Resistivity structure present within the study site.

\subsection{Calibrated HTEM inversions}

There are a few limited sources of ground truth with regard to overburden thickness within the study site and within the Quest West survey area. Water wells, outcrops, and lake bathymetry provide information on the resistivity and structure of the near-surface that can be exploited to aid in inverting EM data.

\subsubsection{Water well calibrated inversions}

Twelve water wells from the BC WELLS database were used to calibrate the HTEM response within the Nechako Plateau. These wells were chosen according to 3 criteria: (1) well depth (> $20 \mathrm{~m}$ ), (2) location within $400 \mathrm{~m}$ of a Quest West HTEM line, and (3) intersection with the bedrock. Five wells within the study site and 7 wells within 
the greater Quest West survey area were sufficiently close to an HTEM line to aid in inversion, see Figure 2.1. Published geographic information system (GIS) geological data from the survey site was compared to the bedrock at each well to ensure that similar properties are described, such as bedrock composition, elevation, and terrain type such as valley, basin, or ridge. The inversion results for these water wells, along with the geological information for each well location, are provided in Appendix I.

Inversions were conducted at the HTEM station nearest to the water well using layered-earth models of 2-, 3-, 4-, and 5-layers, shown in Figure 4.2.1. An elastic bedrock constraint with a range of $1500-5000 \Omega \bullet \mathrm{m}$ was applied to starting models with 4-layers and less, the 5-layer model was inverted without the use of constraints. Inversion results using calibration water well A1-3 as an example is shown in Figure 4.2.2. The figure shows a plot of the decay of the secondary magnetic field determined by inversion of the observed secondary field response for each of the starting models presented in Figure 4.2.1. Also shown is the goodness of fit sRMS \% error, explained in Section 4.2.7, between each inverted result with the observed secondary field response where a lower value indicates better matching decay curves. Trial and error inversions were conducted for stations that would not invert in order to determine a match, and for stations where the inversion results could be improved. The stations that would not invert were assumed to have a geology that could not be approximated using a layered-earth model. Results for each well are presented in Appendix I. 


\subsubsection{Inversions over water bodies}

There are a few areas where portions of an HTEM line passes over a water body within the study site, such as along line 7400 (L7400) which passes over Francois Lake. Several of these stations were inverted through trial and error using measured lake water resistivity and bathymetry measurements as a guide. Although these stations inverted with an sRMS error of $<10 \%$, none of the inversions match lake resistivity or bathymetry data. Inversion results showed that the lake appeared as a resistive feature where the resistivity range of the first layer for all trials is $234-698 \Omega \bullet \mathrm{m}$. Laboratory assays of water from Francois Lake, taken in February 1997, determined that the average resistivity of Francois Lake water is $114-119 \Omega \cdot \mathrm{m}$ (Westenhofer et al. 2000). Inverted thicknesses of the first layer, which ranged from 11-22 m, also did not correspond to mapped bathymetry depths of Francois Lake, which is $120 \mathrm{~m}$ deep on average in that area. The discrepancy between the laboratory assays and the inversion results could be due to many factors including inversion model type (layered earth as opposed to a modelled lake basin), lake sediment resistivity, and a change in lake water chemistry. Fortunately lake bathymetry maps are available in the region (British Columbia 2014) removing the need to determine lake depth using HTEM inversion.

\subsubsection{Inversion software}

HTEM inversion relied on the combined use of two programs: AirBeo, part of the P233F CSIRO suite of electromagnetic forward modelling and inversion programs developed by the Commonwealth Scientific and Industrial Research Organization (CSIRO), and Maxwell, developed by ElectroMagnetic Imaging Technology (EMIT). 
Maxwell was used as the graphical user interface to facilitate HTEM data management and inversion using AirBeo. AirBeo is an open-source full-physics discrete EM modelling and inversion program that can forward model and invert a TEM response using 1-dimensional layered-earth models (Raiche 2007, Raiche et al. 2008). Discretelayer inversions are known to be an accurate method at inverting HTEM data to produce a representative model of the subsurface (Hodges 2003). The P233F suite was chosen for investigations on the design of an HTEM system capable of measuring overburden thickness, see Chapter 3, because it does not apply a quasi-static approximation, which is valid for modelling TEM systems recording the secondary response of the electromagnetic field at a frequency lower than $50000 \mathrm{~Hz}$ (Ward and Hohmann, 1988). This is not expected to affect results due to the choice of the Quest West survey with the AeroTEM III system designed to use lower frequencies for mineral exploration.

The software was configured for inversion by specifying the characteristics of the AeroTEM III system: transmitter magnetic moment, waveform, peak current, off-time windows, and turn-off time (see Table 2.1 and Figure 4.2.3). As the exact value of the peak current and its associated turn-off time are influenced by the conductivity on the ground (Fitterman and Anderson 1987), both of these values are updated specifically for each line being inverted using the values recorded during surveying for the corresponding line available from the Quest West database. The HTEM receiver is not normalized and is configured as a db/dt receiver with the units of nanoTeslas per second (nT/s). During inversion, Maxwell was programmed with a data floor of $10 \mathrm{nT} / \mathrm{s}$, which means that the inversion will not take into account any off-time windows after the response falls below 
$10 \mathrm{nT} / \mathrm{s}$. AirBeo was programmed with a maximum of 90 iterations, after which the inversion algorithm stops refining the model to match the observed data.

\subsubsection{Other software}

The results of each inversion were exported as comma separated values (csv) files, to be imported into Excel where they were converted into space delimited formatted text (prn) files. The prn files reorganized the data into columns, where each column is separated by a set number of spaces. This format is essentially an xyz file format that is organized the same way as a prn file, but lacks a header that needs to be manually created to be imported successfully. This step permitted the data to be imported into proprietary Sander Geophysics Limited (SGL) software for gravity processing. Imported information includes UTM coordinates, inverted resistivity of each layer, inverted thickness of each layer, total overburden thickness, and sRMS \% error between the model and the observed data.

ArcMap, developed by ESRI, was used as the GIS software for map and data visualization, map interpolation, and data interpretation.

\subsubsection{Depth of investigation}

The depth of investigation (DOI) is the depth below which inversion results are no longer reliable (Oldenburg and Li 1999, Christiansen et al. 2010). Aeroquest Limited estimated the average depth of investigation for the AeroTEM III system within the Quest West study using the cumulative conductance rules to be within roughly $300 \mathrm{~m}$ 
(Aeroquest Limited 2008). Using the DOI equation of a planar wave (Ward and Hoffman 1988), see equation 4.1, a DOI of $446 \mathrm{~m}$ is obtained after $2.5 \mathrm{~ms}$ of off-time over a halfspace with a resistivity of $50 \Omega \cdot \mathrm{m}$. The DOI is a rough estimate as it does not take into account the transmitter moment, transmitter geometry, or local sources of noise (Christiansen et al. 2010), so all inverted thicknesses were clipped to a maximum depth of $450 \mathrm{~m}$. Any inversion that returned a layer interpreted as overburden, or as any of the two layers describing the overburden-bedrock contact, which has an inverted thickness that goes beyond that depth was discarded. If the layer in question is interpreted as bedrock and is beneath another layer already interpreted as bedrock, then the layer in question is cut to a depth of $450 \mathrm{~m}$. It should be noted that this step was unnecessary for Resistivity structure inversions.

$$
\begin{aligned}
& \text { Equation 4.1 } \\
& \qquad \begin{aligned}
Z_{d} & =\sqrt{\frac{2 t}{\mu \sigma}} \\
& Z_{d} \\
& =\sqrt{\frac{2(0.0025 \mathrm{~s})}{0.02 \mathrm{Sm}^{-1}\left(4 \pi \times 10^{-7} \mathrm{Hm}^{-1}\right)}} \\
Z_{d} & =446 \mathrm{~m}
\end{aligned}
\end{aligned}
$$

where $Z_{d}$ is the DOI (m), $t$ is time (s), $\sigma$ is the conductivity $\left(\mathrm{Sm}^{-1}\right)$, and $\mu$ is magnetic permeability $\left(\mathrm{Hm}^{-1}\right)$. The magnetic permeability of free space is used in the example, equation 4.1, above. 


\subsubsection{Transmitter noise}

Several HTEM lines within the survey site suffered from transmitter noise that was measured by the receiver during the first, and on occasion the second, off-time channels. This noise may be due to a longer than expected turn-off time of the transmitter, where the transmitter has a decaying remnant voltage that is strong enough to generate a magnetic field that is then measured by the receiver while it is measuring the secondary field response of the subsurface. The resulting magnetic field decay measured by the receiver no longer follows an exponential decay-curve as the first, and sometimes second, channel has a higher than expected amplitude due to the addition of the decaying remnant of the primary field. The presence of noise may adversely influence the inverted results and will result in a higher sRMS \% error between the observed data and the inverted result. The HTEM lines that are affected are L7380 and 7450, as well as small portions of 7400 and 7410.

\subsubsection{Indication of best match}

AirBeo provides the use of symmetric root-mean square (sRMS) percent as the primary means of evaluating the degree of error, or goodness of fit, between the inverted response and the observed response of the secondary EM field (Raiche 2007). The sRMS is a value that shows the root mean square (RMS), see Equation 4.2, deviation of the symmetric mean absolute percentage error (SMAPE), see Equation 4.3, between the discrepancy of point decay values given by the observed and inverted modelled response at each channel plotting the decay of the secondary EM field. A smaller sRMS \% error shows a closer match between the inverted model response and the observed response of 
the secondary field. Unfortunately a low sRMS \% error does not necessarily indicate that the inverted model result is an accurate representation of subsurface geology as multiple geological models could have similar secondary field decay responses which can be indistinguishable to the HTEM system due to design, or due to noise. This concept is well illustrated by comparing the inverted results in Appendix I, see Figures A1.4-A1.6, and A1.9 for the best examples.

Equation 4.2: Symmetric root mean square (sRMS)

$$
s R M S=\sqrt{\frac{\sum_{n}\left(\frac{|M-D|}{(|M|+|D|) \div 2}\right)^{2}}{n}}
$$

Equation 4.3: Root mean square (RMS)

$$
R M S=\sqrt{\frac{\sum_{n} x^{2}}{n}}
$$

Equation 4.4: Symmetric mean absolute percentage error (SMAPE)

$$
S M A P E=\frac{|M-D|}{(|M|+|D|) \div 2}
$$

Where $M$ represents the inverted model value, $D$ represents the observed secondary field decay value, $n$ is the number of data channels being summed, and $x$ is a set of $n$ values. 


\subsection{HTEM 2-layer inversions}

This project is concerned with developing a methodology that could one day be applied within the exploration industry. Therefore, a simple model that can accurately and quickly describe the geology in the study site is preferable to a more complex model. The first series of successful inversions that were applied to survey data, from the Quest West survey dataset, were conducted using a 2 layer earth model. This section contains significant material from the SEG extended abstract Caron et al. (2015), which was written and published as a component of this research.

Various configurations of a 2-layer model were attempted through trial and error to invert for overburden thickness. First layer thickness ranging from 5-100 m were attempted along with modelled overburden resistivities ranging from 10-500 $\Omega \bullet \mathrm{m}$, over a halfspace modelled with a resistivity ranging from $1000-10,000 \Omega \bullet \mathrm{m}$. An unconstrained two layer initial model composed of $5 \mathrm{~m}$ thick overburden with a resistivity of $100 \Omega \cdot \mathrm{m}$ and half-space bedrock with a resistivity of $2000 \Omega \cdot \mathrm{m}$ with a 0.5 elastic constraints of 1500-3000 $\Omega \cdot \mathrm{m}$, see Figure 4.1.1, was selected for inversions based on the acheivment of producing consistent results between adjacent inverted stations along HTEM line 7420 . The elastic constraint works by limiting the degree of change of the parameter suggested by the inversion so that the inversion result does not drift too far from the starting model (Electromagnetic Imaging Technology 2010). Resistivities were chosen based on published reports, see Table 2.2. 
Once the EM data is inverted, the results are checked for inconsistencies. To be considered valid, results were required meet the following criteria: (1) symmetric rootmean-square (sRMS) $<10 \%$, and (2) smoothly varying resistivities and depths between adjacent stations. Inconsistent data was discarded. A few lines also showed some minor transmitter interference that primarily affected the 1st channel, and on occasion the 2nd channel as well. These channels were removed for inversion in order to better match the observed HTEM decay and model curves for that station. As this method was applied throughout the study site, some large areas did not fit the 2-layer model and would not successfully invert with an sRMS of $10 \%$ or lower.

\subsection{Multi-layer inversions}

The failure of the 2-layer inversion in some areas of the map was initially addressed by adding layers. The resistivity starting model was updated to include 3 and 4 layers, see Figure 4.4.1 A. Constraints to the resistivity of the half-space, which represents the bedrock, were softened and configured with soft elastic boundaries that provided an elastic bedrock resistivity range of $1500-5000 \Omega \cdot \mathrm{m}$, as resistivities $\geq 5000$ $\Omega \cdot \mathrm{m}$ had a negligible effect on the results through forward modelling. The lower boundary of $1500 \Omega \cdot \mathrm{m}$ was based on published TDEM survey results conducted within the Nechako Plateau, shown in Table 2.2. The overburden was modelled with the same starting resistivity as outlined in Caron et al. (2015). The overburden was left unconstrained, leaving only the resistivity ascribed in the starting model as a guide to the inversion algorithm within AirBeo. This strategy was adopted so that the results of each inversion are guided by constraints associated with the bedrock while allowing a wide 
range of overburden solutions that preserve the independence of each station. This provides an additional indication of inversion accuracy through the correlation of inversion results between independently inverted stations. Inversion throughout the study site progressed with the following strategy:

\section{A 2-layer inversion is conducted first}

I. If the sRMS $\leq 10 \%$, then the inversion is assumed to be good.

II. If the sRMS is between $10-11 \%$, then the results are verified against adjacent stations. If the result is close to that of adjacent stations then it is kept.

III. If the sRMS $>11 \%$, then the inversion is assumed to be a mismatch, and trial and error 3-layer and 4-layer models are attempted.

a. If the sRMS $>11 \%$ for both the 3-layer and 4-layer models then the station is assumed to have a response that is incompatible with a layered earth model. The station will not be used and estimates will be computed in place by interpolation from adjacent stations

Following this strategy, there still remained a few areas that did not invert using any of the layered earth models shown in Figure 4.4.1 A.

\subsection{Multi-layer resistivity reversal inversions}

HTEM stations that failed to invert using the 2-layer and multi-layer inversions were inverted through trial and error using various different configurations of the layered earth model, see Figure 4.4.1 B. For some of these sites, a more complex starting model 
was required for the overburden. The original resistivity model assumed that resistivity increased with depth in the subsurface. While this assumption was valid in most areas, it does not always reflect the depositional nature of sediment. The glacier went through several periods of progression and regression during which sediment was deposited in a progressive sequence of till, sand, and then clay. The sequence would then be deposited in reverse order during glacier regression. This could conceivably lead to resistivity reversals within the overburden that are significant enough to affect inversion results. The starting models were updated to take into account these resistivity reversals within the overburden. Additional updates regarding starting resistivities within the overburden were also made. It was determined through trial and error, guided by inversion results with a lower sRMS \% error, that a starting first layer resistivity of $20 \Omega \bullet \mathrm{m}$ worked better for multi-layer models, and a starting resistivity of $500 \Omega \bullet \mathrm{m}$ worked well for modelling resistivity reversals.

\subsection{Resistivity structure inversions}

Resistivity structure inversions are based on the results from the HTEM inversion calibration using water wells, see Appendix I. The methodology was applied by inverting an HTEM station every $50 \mathrm{~m}$ with each of the starting models shown in Figure 4.6.1, where each starting model describes a slightly different resistivity with depth distribution. The 5-layer model was chosen for its success at inverting water well stations and was chosen as the principle inversion model for this reason. The 4-layer model was chosen as a strategy to invert in those areas where the overburden is better described as a single layer overlying more resistive bedrock. The 4-LR2 model was added to invert the areas 
where there is no large measured disparity in resistivity contrast between the bedrock and the overburden, which is thought to be one of the situations where neither the 5-layer or the 4-layer model are able to invert the data successfully

If the HTEM line being inverted was identified to have the $1^{\text {st }}$ or $2^{\text {nd }}$ channel contaminated by the transmitter turn-off, then the entire line is inverted once again with those channels removed. It is then assumed that the inversion result with the lowest sRMS \% error, compared with all inversions for that station including all of the starting models, both with channels and with transmitter contaminated channels removed, provides the most accurate inversion result. For this, a program was written in Matlab that compares the inversion results for each HTEM station run by each forward model and chooses the inversion result with the lowest sRMS \% error. The inversion results are therefore composed of inversions that can have 4 or 5 layers, or can be missing one or two channels due to transmitter contamination, depending on the sRMS \% error.

In order to determine the thickness of the overburden, an additional interpretive step is required. Two of the starting models included two layers within the overburden, these are the green layers in the 4 LR2 and the 5-layer models, see Figure 4.6.1. The inversion result may assign one of those overburden layers a resistivity that may be better associated with bedrock, or a layer that was assigned as bedrock may have a similar resistivity to overburden. In addition the $4 \mathrm{LR} 2$ model does not have a $500 \Omega \bullet \mathrm{m}$ layer which was observed to be successful when inverting for the overburden-bedrock contact, see Section 5.4.2. The removal of this layer permitted the successful inversion for some 
stations where inclusion of the $500 \Omega \bullet m$ layer was unsuccessful.

Water well calibrated inversions, in Appendix 1, show that on occasion the bedrock can have a resistivity that is well within the range attributed to sediment, such as the limestone bedrock identified in Figure A1-5 and the corresponding 5 LR-2 inversion which was inverted using a model without a $500 \Omega \bullet \mathrm{m}$ bedrock layer. For these inversions the overburden and bedrock become indistinguishable as either can have a resistivity of 175 or $250 \Omega \bullet \mathrm{m}$. An interpretation must therefore be made, based on the resistivity of the layer, to determine which layer represents the overburden and which represents the bedrock. It was made by observing the resistivity of the 2 nd layer, for both 4-, and 5layer starting models, and assigning all resistivities greater than $160 \Omega \bullet \mathrm{m}$ to bedrock. This interpretation was made by comparing the inverted HTEM results with water well calibrated inversions in Appendix I, and by comparing the HTEM response with the DEM and surficial geology information within the study site. Figure 4.6.2 shows the location of each HTEM station where this interpretation was made. The locations mainly correspond to areas of rocky terrain, such as Uncha Mountain, with mapped outcrops, and with deep bodies of water such as Francois Lake and Tchesinkut Lake to the north. Where the inversions correspond to rocky terrain, a thicker interpreted overburden of more than 1 layer is unlikely, especially in areas that correspond to till veneer or with bedrock outcrops, as many of these areas do as shown in Figure 4.6.2. 
It is also important to note that none of the resistivity reversal inversions were discarded or clipped due to exceeding the $450 \mathrm{~m}$ DOI for any layer interpreted as overburden or as part of the overburden-bedrock contact, see Section 4.2.5.

\subsection{Terrain map processing}

Two separate sources of digital terrain data were used to model the terrain. The first source is the Quest West AeroTEM III survey dataset, containing data gathered using a high resolution TRI-3500 radar altimeter, see Table 2.1, at a nominal altitude of $30 \mathrm{~m}$ above terrain. The survey covers the study site with an East-West flight line spacing of $4 \mathrm{~km}$. The TRI-3500 altimeter has an accuracy of $\pm 1.5 \mathrm{~m}$ at a $30 \mathrm{~m}$ altitude and was flown with an along line sampling rate of $3 \mathrm{~m}$ (FreeFlight Systems 2009). The second source of digital terrain data was obtained from the CGIAR Consortium for Spatial Information (CGIAR-CSI) which is gathered by the Shuttle Radar Telemetry Mission (SRTM). The data has a lateral resolution of $90 \mathrm{~m}$ and an expected vertical elevation error of $\pm 16 \mathrm{~m}$ (Jarvis et al. 2004, Tighe and Chamberlain 2009) and a measured absolute vertical error on the most reliable estimates to be $\pm 5 \mathrm{~m}$ (Rosen et al. 2003, Sun et al. 2003, Tighe and Chamberlain 2009). While the HTEM system measures altitude more accurately, the spatial resolution is too low to create a suitable DEM of the study site. The SRTM data, on the other hand, has a large vertical error. The solution was to use the HTEM data for inversion and then to apply the scalar quantity of overburden thickness to the SRTM data set. Without this strategy, a direct combination of two georeferenced grids, the DEM created from the SRTM data and the bedrock topography grid created by the HTEM-DEM referenced inversion results, produced errors where the bedrock had a 
higher elevation than the surface modelled by the DEM, even when overburden was present.

\subsubsection{Bathymetry}

Bathymetry within the study site was obtained from the British Columbia (BC) Ministry of the Environment. The BC Government commissioned a series of lake bathymetry surveys in the 1950 's and published the technical reports online. In order to use this data, the information was digitized and georeferenced using Esri ArcGIS (Figure 4.7.1). Bathymetry data is available for: Francois Lake, Tchesinkut Lake, Ansus Lake, Borel Lake, Binta Lake, Mollice Lake, and Uncha Lake. After the bathymetry was digitized, each lake was added to a single map that presented the lake bathymetry for the survey site based on a $100 \mathrm{~m}$ grid. The map includes all of the lakes within the study site that have a bathymetry greater than $10 \mathrm{~m}$; all other cells on the map were set to zero. A copy of the map was then created with the cell size reduced to a lower resolution of 1000 $\mathrm{m}$ in order to match the cell size from the overburden thickness map created from HTEM inversion. The $1000 \mathrm{~m}$ cell size, which is a quarter of the $4 \mathrm{~km}$ line spacing, provides an acceptable level of resolution with a low amount of spatial aliasing errors (Reeves 2005). Final maps were registered to the NAD83 datum.

\subsubsection{Bedrock topography (BedTopo)}

The bedrock topography was not measured directly with respect to elevation; instead it was determined through HTEM inversion which returned the resistivity of the overburden, the thickness of the overburden, and the resistivity of the bedrock, see Figure 
4.0 and 4.7.2 for a summary of the methodology followed to create a BedTopo DEM. Bedrock topography was calculated by subtracting the thickness of the overburden from the DEM. In a separate stream, bathymetry data was integrated with overburden thickness in order to model the bedrock topography as it exists beneath lakes as well as beneath the overburden. This approach assumes that the inverted thickness of the overburden can exceed the depth of a lake, and so there exists areas in the study site where a lake bottom intersects bedrock and other areas where it intersects overburden.

\subsection{Overburden thickness analysis}

The overburden thickness map created from HTEM inversion was interpolated using cosine distance weighted average over a $1000 \mathrm{~m}$ cell size, which corresponds to the $4 \mathrm{~km}$ line spacing and means that only 14 flight lines pass through the survey site, see Figure 2.2. As an objective of this project is to create a methodology that can measure the thickness of overburden and use it to correct the overburden effect in gravity data, a determination of the accuracy of the HTEM inversion is required. Boreholes are typically used for ground truth, but as there are only 3 boreholes and a handful of water wells that are poorly distributed within the study area, see Figure 2.6, alternative sources of ground truth were sought, such as bedrock outcrops, mapped areas with glaciofluvial and glaciolacustrine sediment or till veneer, and aggregate gravel pits, see section 2.4 and Figures 2.4 and 2.6, while these sources provide a qualitative estimation of overburden thickness, none of these sources can provide a quantitative measurement of ground truth, and there are none within the study site other than those provided by the water wells. Another technique used to provide an indication of ground truth is satellite image 
processing from Google Earth images. Satellite images were used to identify terrain features that could be used as an indication of sediment thickness. The following assumptions were made:

1. Angular features occurring in hilly areas, mountains, and near cliffs are an indication of bedrock outcrops and may indicate areas where overburden is thin.

2. Rounded features in low-lying areas, such as basins and valleys, may indicate areas where overburden is thick.

\subsection{Bouguer corrections}

In order to correct for gravity effects due to the presence of a basin or a body of water, the density and thickness of the causative body must first be determined. The gravitational contribution of a body can be estimated using equation 4.1.

$$
\text { Equation } 4.1 \quad \delta G_{b}=2 \pi G \rho h=0.04192 \rho h
$$

where $\delta \mathrm{G}_{\mathrm{b}}$ is the gravitational constant $6.67 * 10^{-11} \mathrm{~m}^{3} /\left(\mathrm{kg} \mathrm{s}^{2}\right), p$ is density in $\mathrm{g} / \mathrm{cm}^{3}$, and $h$ is the height of the terrain with respect to the WGS84 datum in meters.

To reduce the gravity data, the Bullard methodology is a useful approach as it neatly separates the different types of terrain and Bouguer corrections. An overview of the Bullard method and gravity corrections can be found in Bullard (1936), Nowell 
(1999), and Hinze et al. (2005). In order to apply a Bullard C correction to gravity data, see Figure 1.4, the geology within the survey site must be modelled using a single density. This step is even more critical when applying the suggested BedTopo correction, see Figure 1.5. Caron et al. (2013), see section 3.4, adopted the geological characteristics that are typical of the Abitibi mining province spanning Ontario and Quebec, Canada, which include a glacially-derived overburden composed primarily of clays, sand, and till that may repeat in sequence depending on the nature of the transgression and regression of the Laurentide ice sheet at the time of deposition. The bedrock is typically either igneous or metamorphic with little to no saprolite alteration (Palacky and Stephens 1990), and has been glacially scoured. Considering that the same glacial processes affected both the Abitibi Belt and the Nechako Plateau, there exists large differences in density and resistivity values between the overburden, bedrock, and water bodies as described in section 2.5 and Table 2.2 .

\subsubsection{Density modelling}

The density of the near-subsurface in the study site was modelled with a simple three layer model where each layer represents a different medium: water, overburden, or bedrock. Applying average values for bedrock and overburden provides us with a conceptual layered earth model of near-surface density shown in Figure 4.9.1. An average bedrock density of $2.65 \mathrm{~g} / \mathrm{cm}^{3}$ is used, along with an estimated water-saturated overburden composed of sandy-silt with a density of $1.8 \mathrm{~g} / \mathrm{cm}^{3}$. A density of $1.0 \mathrm{~g} / \mathrm{cm}^{3}$ was used for fresh lake water. 


\section{HTEM System for Mapping Overburden Thickness}

In order to correct the gravity data, the conceptual model must be portrayed in terms of a software algorithm, see Figure 4.9.1. The layers can be regarded as superimposed half-spaces, each configured with a density that is added when occupying the same space. Since the density of all layers being considered is greater than $1 \mathrm{~g} / \mathrm{cm}^{3}$, which is the modelled density of fresh water, this density can be assigned to each layer, according to Figure 4.9.1. This is represented by the red border that outlines the water, overburden, and bedrock layers in Figure 4.9.1. Overburden, on the other hand, is modelled with a density of $1.8 \mathrm{~g} / \mathrm{cm}^{3}$, which corresponds to the density of wet silty-sand, the most common sediment type in the region (Plouffe and Levson 2001). Overburden thickness information inverted from HTEM data can be used to isolate the overburden layer from the bedrock and an overburden-specific correction can be applied equal to the difference between the modelled density of overburden and water, $0.8 \mathrm{~g} / \mathrm{cm}^{3}$. This area is shown by the horizontal pattern fill in Figure 4.9.1. The remaining density difference, $0.85 \mathrm{~g} / \mathrm{cm}^{3}$, can then be applied to all areas where no water or overburden exists. This is shown by the area filled with a brown colour in Figure 4.9.1. The program model itself is created through the manipulation of SRTM DEM data, shown in Figure 2.1, with lake bathymetry data, and overburden thickness information obtained from HTEM inversion.

\subsubsection{Gravity processing methodology}

AIRGrav survey data gathered from the Quest West gravity survey, see Table 2.1, was downloaded from the $\mathrm{BC}$ Geosciences website as a xyz file that contained various fully-processed and levelled gravity channels from each flight line, and that includes the Bouguer anomaly, free-air anomaly, isostatic corrected, GPS, DEM, altimeter, and other 
parameters. As the gravity data was already processed and levelled, this section will focus on the steps followed to perform a BedTopo correction to this data, as illustrated in Figure 4.9.2.

The first step involves integrating data sets that are required to apply a Bouguer correction to gravity data. The BC Geosciences xyz gravity data was imported into proprietary SGL software for processing along with the DEM map, the DEM with bathymetry map, and the BedTopo map, see Figure 4.9.2. SGL performs a Bouguerequivalent correction that incorporates all the Bullard corrections A, B and C in one step. The method employs a 3D mesh of prisms created from the information provided in the topography, bathymetry, and BedTopo maps. Bouguer corrections are then calculated at each gravity station, by calculating the attraction of gravity, using information provided by each prism within the 3D mesh. Regional corrections are made up to a distance of 160 $\mathrm{km}$, and Earth's curvature is modelled by a spherical approximation produced by the prisms within the 3D mesh, see Figure 4.9.1.

On single profile data, GPS noise on the airborne gravity data is reduced by low pass filtering. The wavelength of the filter is chosen based on a trade-off between desired wavelength resolution and acceptable noise levels, where the amplitude of the GPS noise increases exponentially at shorter wavelengths (Elieff and Ferguson 2008). For multiple survey lines, noise can be reduced further by low pass filtering of gridded data that effectively stacks common signal from adjacent lines and cancels out random noise. The correction is applied to the data in the form of a new line channel. 
A low pass filter was applied to $2 \mathrm{~Hz}$ data rate profiles of the full Bouguer corrected gravity with the terrain corrections applied for two reasons (1) to reduce the along-line sampling rate from $50 \mathrm{~m}$ to an average reading every $1 \mathrm{~km}$ to avoid antialiasing effects creating from a difference in resolution in direction compared to another in 2D map with a large cell size, and (2) to reduce the amount of residual high frequency GPS noise common to airborne gravity data. GPS noise appears in a profile view of unfiltered gravity data as a rapidly oscillating signal, see the green line in Figure 4.9.3. The filter applied has a mid-point with a full wavelength of 56 seconds and a cosine taper from $100 \%$ pass at 84 seconds to $0 \%$ pass at 42 seconds. At the average survey speed of the helicopter employed on the survey, this is equivalent to a low pass filter with a 2576 $\mathrm{m}$ midpoint. The data is gridded to create a Bouguer anomaly grid, which is inspected for quality control. Various low-pass cosine tapered filters are then applied to the gridded Bouguer gravity data, see Figure 4.9.4. For the purposes of this study, a low-pass filter with a mid-point of $4 \mathrm{~km}$ was selected, with a cosine taper from $100 \%$ pass at $6 \mathrm{~km}$ to $0 \%$ pass at $3 \mathrm{~km}$, see Figure 4.9.4 C. Filtering the grid in this way further reduces random residual noise whilst enhancing common geological signal from adjacent lines, and removes aliasing effects that result from sub-sampling perpendicular to survey lines with data only every $2 \mathrm{~km}$ as compared to the higher resolution data along lines that is visible as ripples in the grid along the survey lines.Figure 4.9.4 A and B show a portion of this effect where higher frequencies along line create ripples that reveal the flight line itself. The effect is removed with the applied 3000-6000 m filter in Figure 4.9.4 C. 
It should be noted that in this project the 3D mesh that was created for Bouguer corrections is at minimum $8 \mathrm{~km}$ larger than each map edge. This is influenced by the size of the BedTopo map which was created through HTEM inversion. The final step of the Bouguer correction process is to trim the map along each border by $8 \mathrm{~km}$ to remove processing artefacts, known as ringing, which were created when the gravity data was filtered.

The BedTopo Bouguer anomaly map and its corresponding FVD map were then created using minimum curvature interpolation (Briggs 1974) with a cell size of $500 \mathrm{~m}$, which corresponds to a quarter of the width between survey lines, see Table 2.1. A cell size which is a quarter of the line spacing provides an acceptable level of resolution with a low amount of spatial aliasing errors (Reeves 2005). These maps and the ones created using the conventional Bullard method, where overburden thickness is not corrected, will be contrasted to evaluate the performance of the BedTopo methodology, see results chapter. 


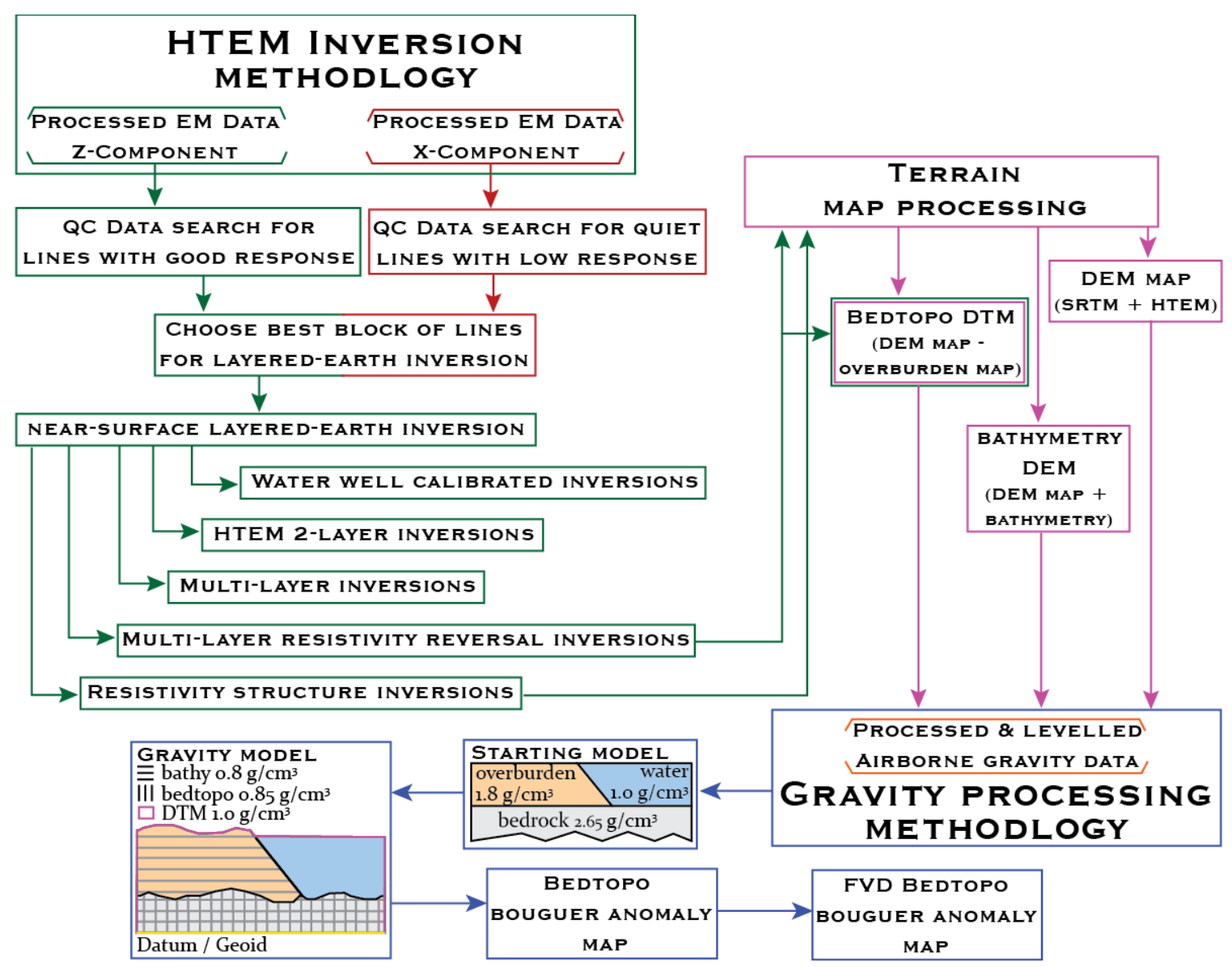

Figure 4.0.1: Simplified diagram of the BedTopo correction methodology.

Diagram shows the basic steps followed to perform a BedTopo correction to gravity data. HTEM related methodologies are covered in sections 4.1 to 4.6. Terrain map processing is covered in sections 4.7 and 4.8 , and gravity processing methodology is covered in section 4.9. 

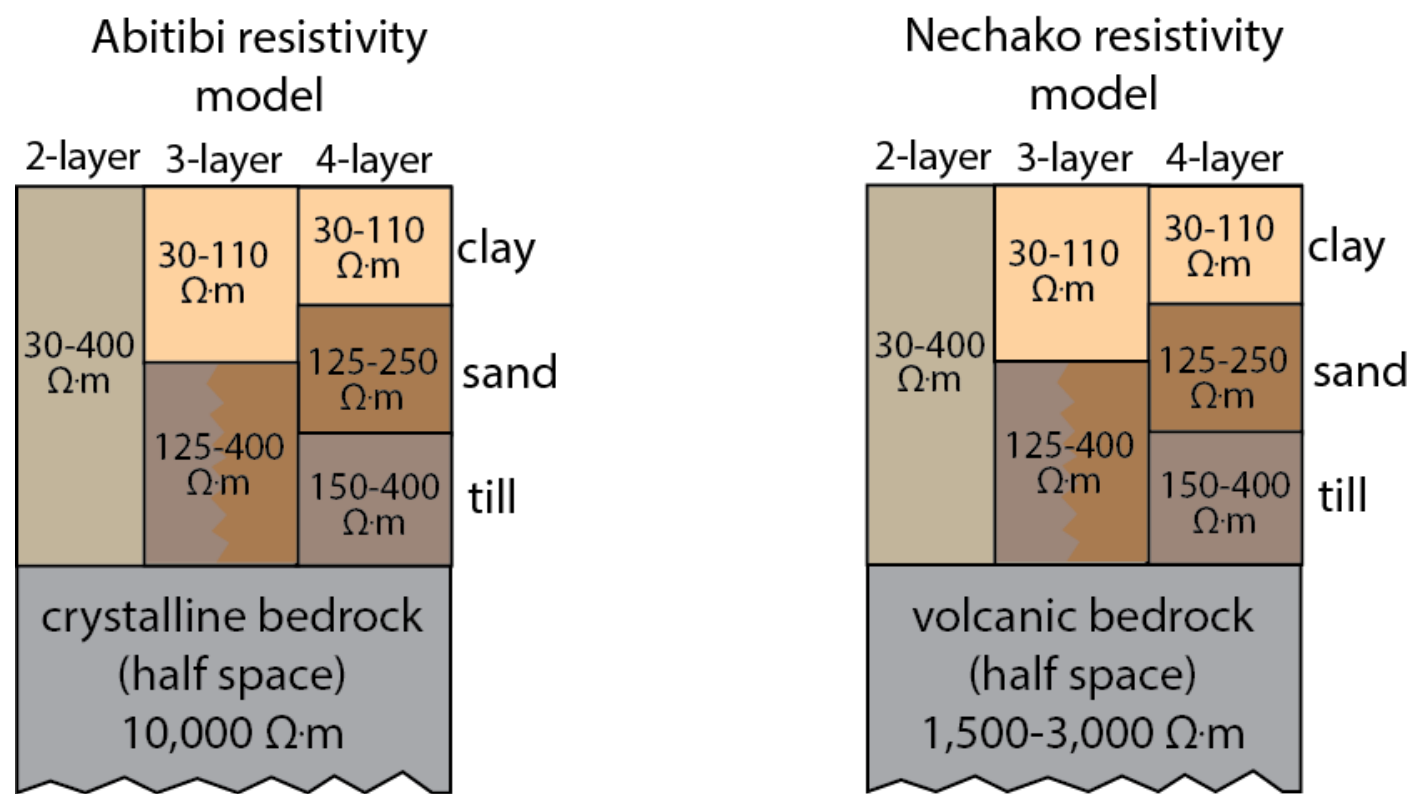

Figure 4.1.1: Resistivity model and starting models

Models were adapted for inverting Quest West survey HTEM data within the study site using layered earth models. The resistivity of the bedrock was updated from the Abitibi model to the Nechako model. Overburden resistivities were kept the same as no apriori information indicated otherwise. 
water well starting models

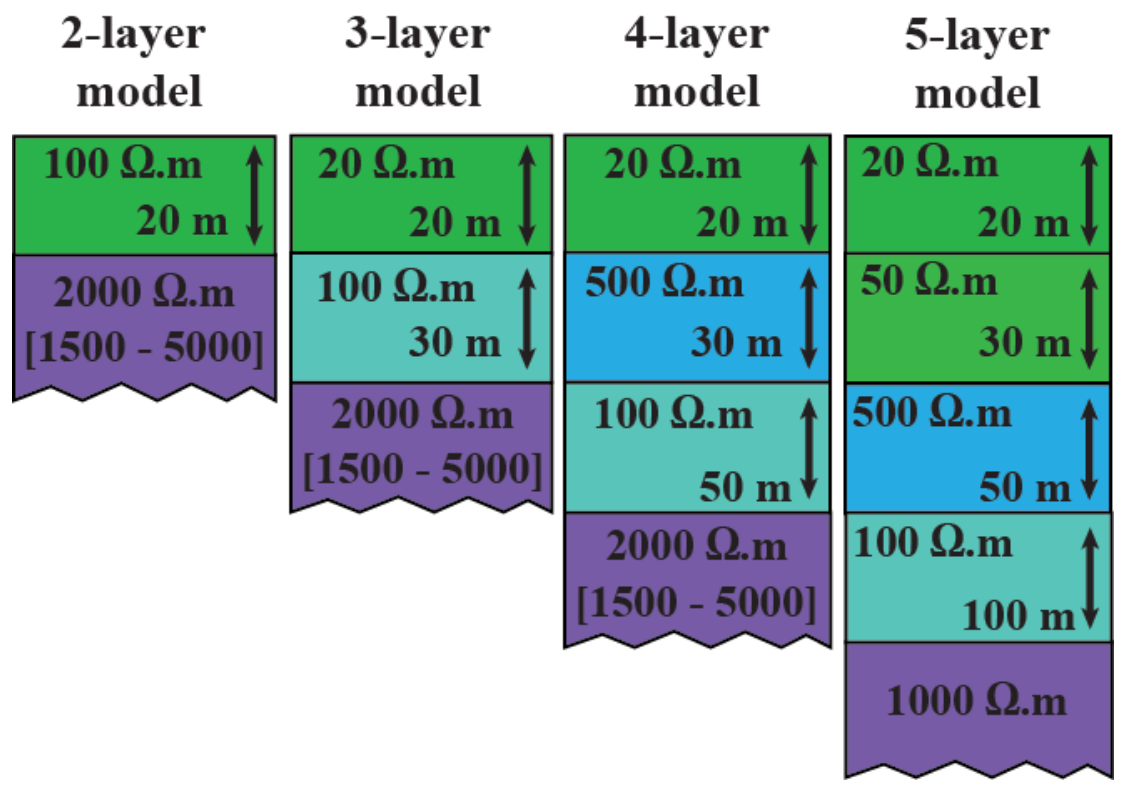

\section{Figure 4.2.1: Water well inversion starting models}

Each model is composed of an overburden overlying bedrock. The 3- and 5- layer models model the overburden as having two distinct layers, while the 4- and 5-layer models model two layers in the bedrock. The three models, 2-, 3-, and 4-layer models, were chosen from the 2-layer, multi-layer, and resistivity reversal inversion attempts in order to determine the accuracy of inversions within the study site by using water wells as ground truth. The 5-layer model was discovered through trial and error inversions in order to find a model with a lower sRMS \% error and an overburden thickness that matches the water well. Inversion results for each water well used for calibration can be found in Appendix 1. 


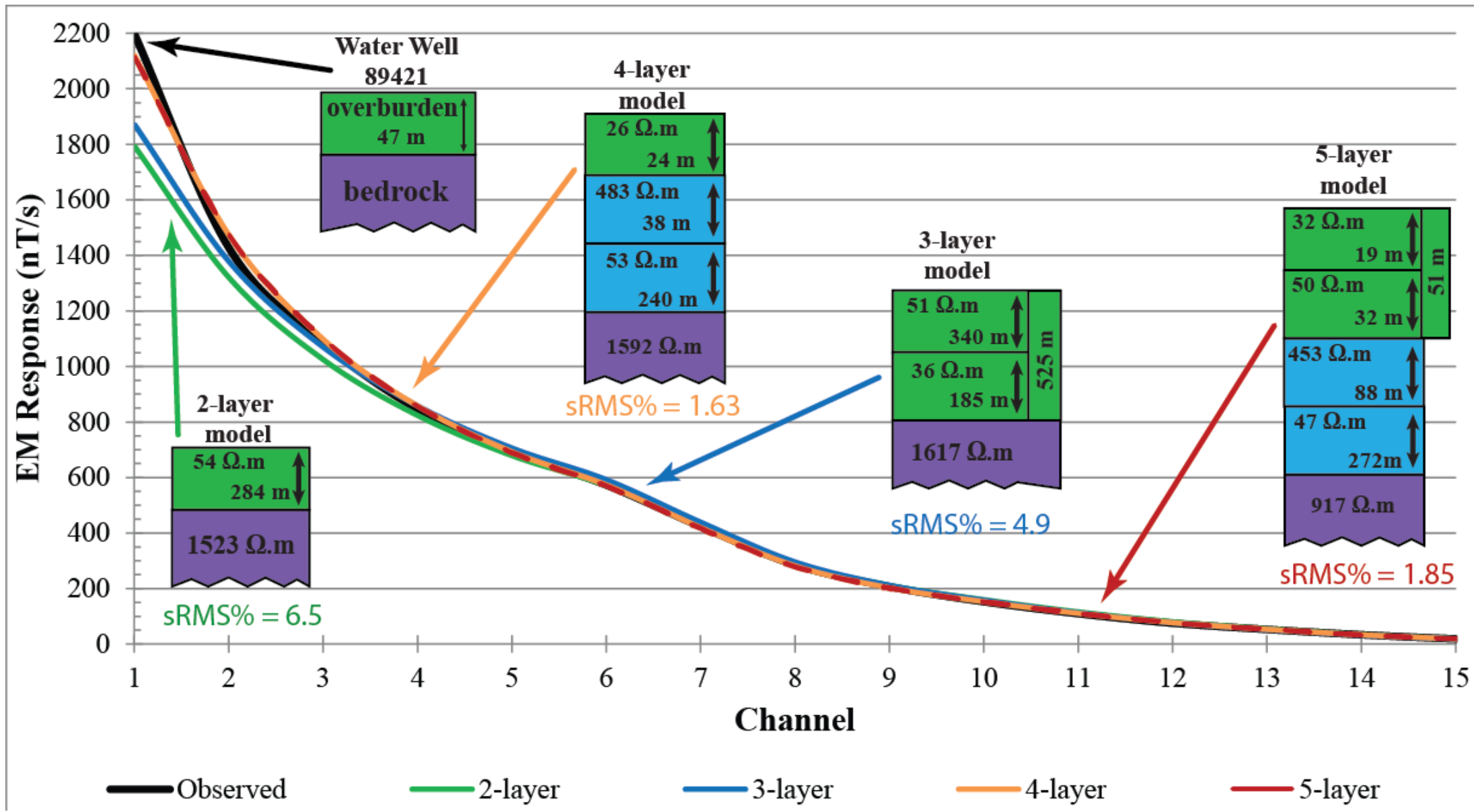

\section{Figure 4.2.2: Plot of HTEM observed secondary magnetic field inversion results}

Figure shows inversion results for the HTEM station presented in Appendix I Figure A1-3. Curves indicate the plotted decay of the observed secondary magnetic field (black line) and the inverted model responses for the layered earth starting models shown in Figure 4.2.1. Illustrated is the difference in decay curves between the models and the observed response. Overburden thickness is indicated to be $47 \mathrm{~m}$, The 5-layer model has the best accuracy while the 4-layer model has the lowest sRMS \% error for this station. 


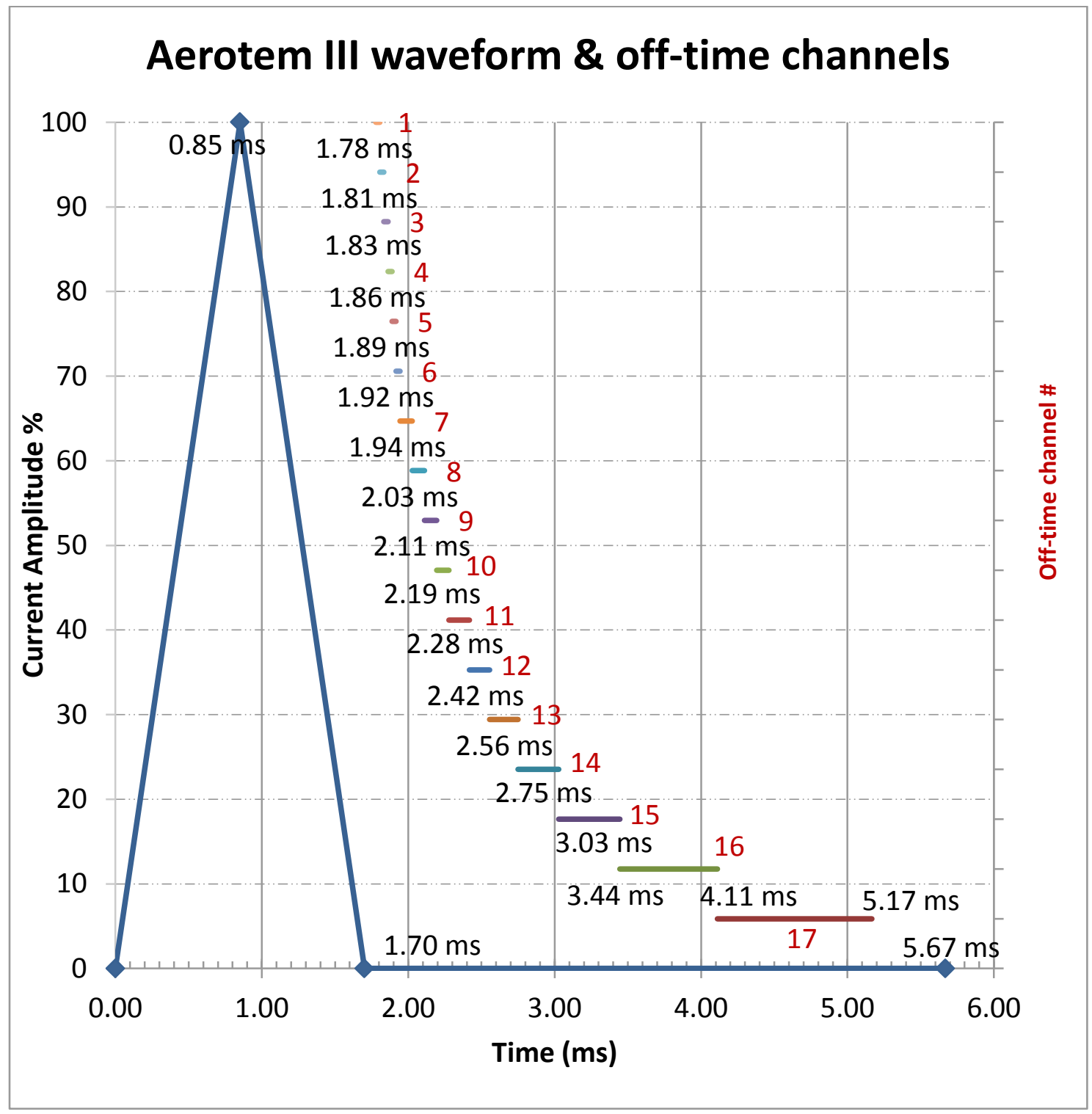

Figure 4.2.3: AeroTEM III waveform and off-time channels used for inversion. The AeroTEM III waveform, shown by the blue line, is triangle-shaped and reaches its peak current after $0.85 \mathrm{~ms}$, with a turn-off time that typically ends $1.7-1.8 \mathrm{~ms}$ after time zero. Peak current typically ranges from 450-460 A within the survey site. The off-time gate locations and starting times are shown by each short coloured horizontal bar. The starting time for one corresponds to the ending time of the previous gate. The first gate starts $80 \mu$ s after the turn-off time. 


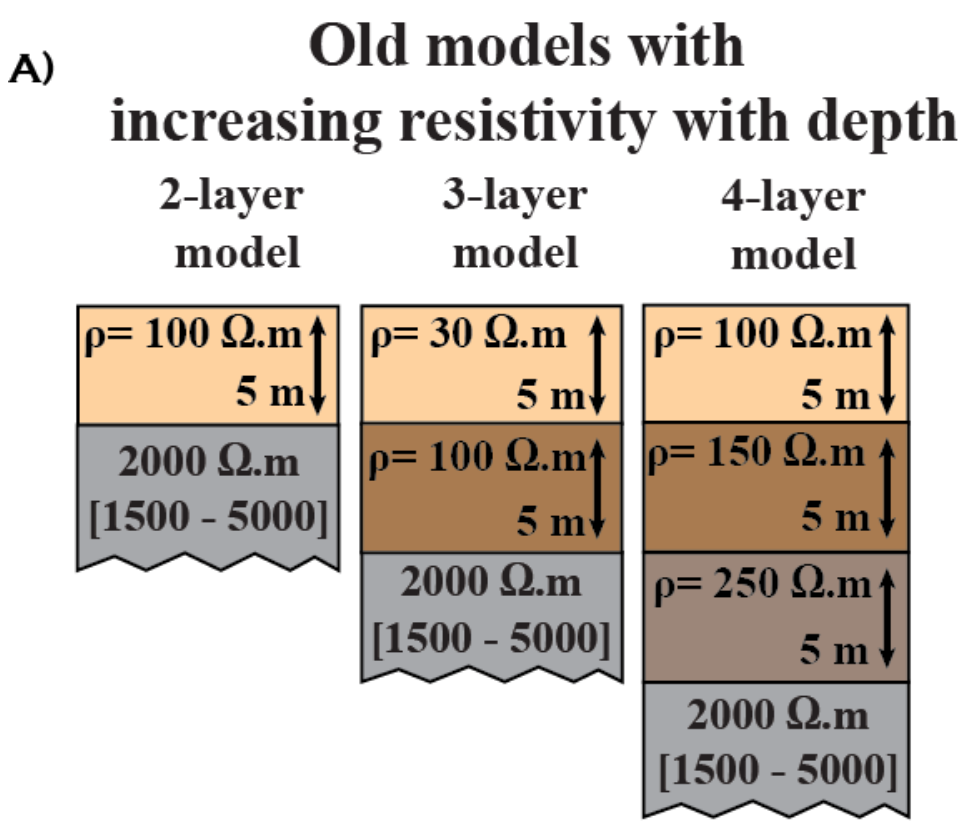

B) New models allowing for overburden resistivity reversals

$\left.\begin{array}{c}\begin{array}{c}\text { 2-layer } \\ \text { model }\end{array} \\ \hline \begin{array}{c}100 \Omega . m \\ 5 \mathrm{~m}\end{array} \\ \hline 2000 \Omega . m \\ {[1500-5000]}\end{array}\right]$

\begin{tabular}{cc}
$\begin{array}{c}\text { 3-layer } \\
\text { model }\end{array}$ & $\begin{array}{r}\text { moder } \\
\text { model }\end{array}$ \\
\hline
\end{tabular}

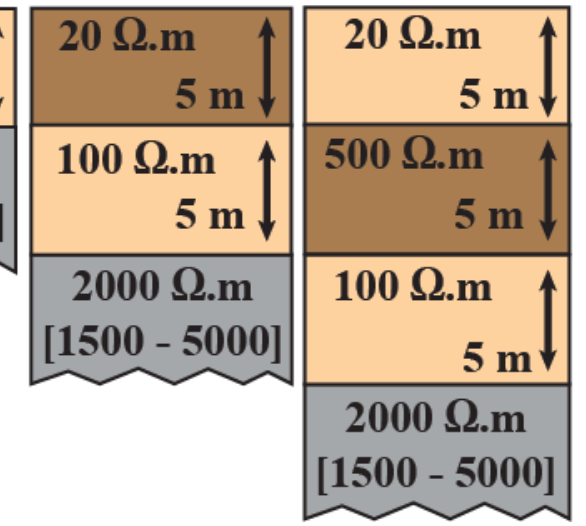

Figure 4.4.1: Volcanic resistivity starting models with resistivity reversals

Models were updated when trial and error inversions detected resistivity reversals within the overburden. Overburden resistivities for the starting model were also updated. Resistivities for the 4-layer starting model were updated to reflect a resistivity reversal within the overburden located between the $1^{\text {st }}$ and $3^{\text {rd }}$ layers, where the $2^{\text {nd }}$ layer was assigned a resistivity of $500 \Omega \cdot \mathrm{m}$. The $30 \Omega \cdot \mathrm{m}$ for the first layer of the 3-layer model was also replaced in favor of $20 \Omega \cdot \mathrm{m}$. 


\section{Resistivity starting models}

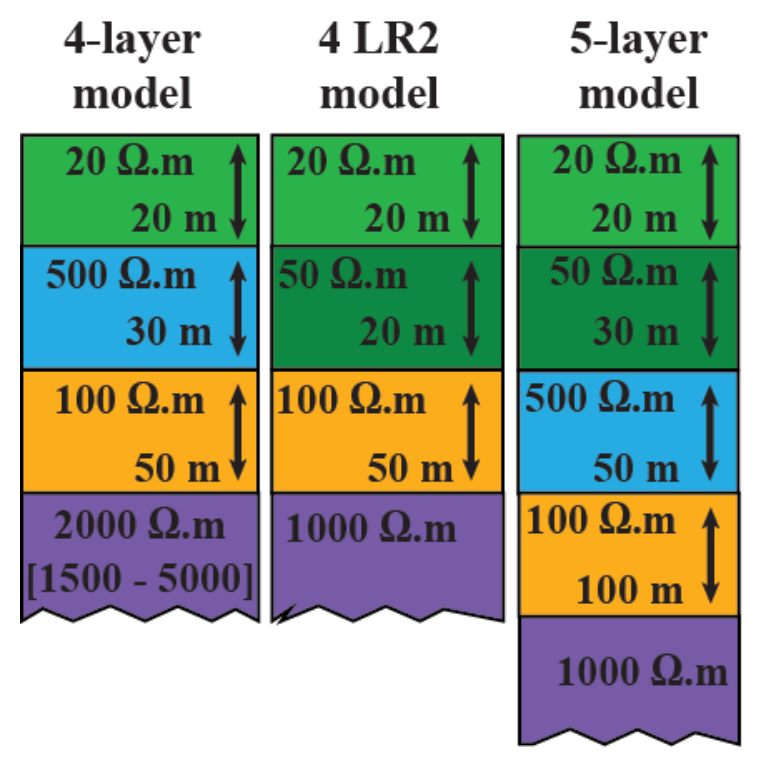

Figure 4.6.1: Resistivity structure inversion starting models

These three starting models each displays a slightly different resistivity change with increasing depth. The green layers are modelled as overburden while the blue and purple layers are modelled as bedrock. The orange layer represents either bedrock or sediment depending on interpretation of the results. 


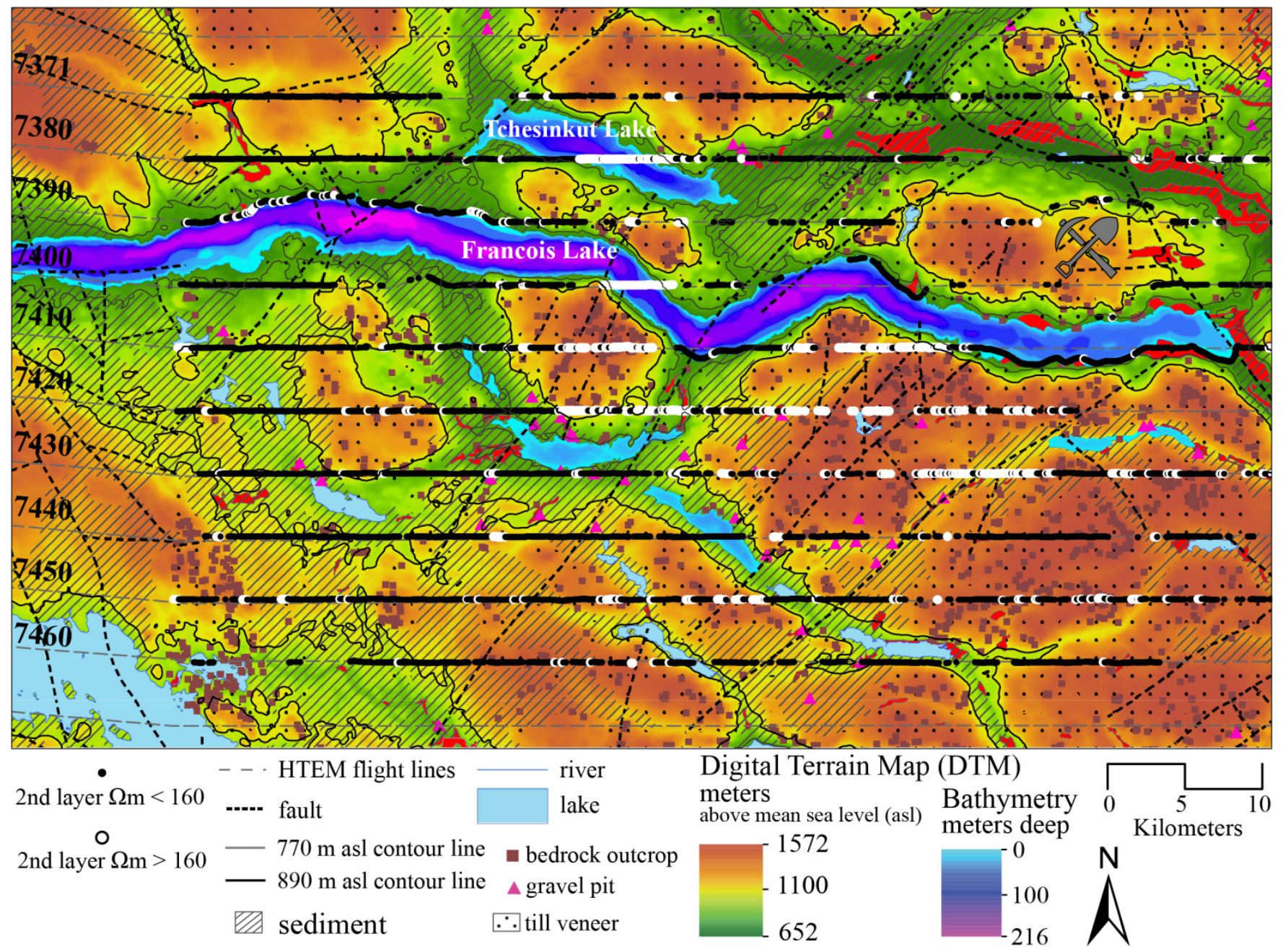

Figure 4.6.2: Locations of $>160 \Omega \cdot m$ bedrock interpretation

Black dots represent HTEM stations where the inverted $2^{\text {nd }}$ layer has a resistivity of $<160 \Omega \bullet \mathrm{m}$. These stations correspond to more conductive areas, such as sediment. White dots represent HTEM stations where the second layer has a resistivity $>160$ $\Omega \bullet \mathrm{m}$. These stations correspond to resistive areas, such as bedrock outcrops and deep lakes. White dots inverted from the stations over Francois Lake and Tchesinkut Lake, in lines 7380 and 7400, were omitted when gridding the overburden thickness map. 


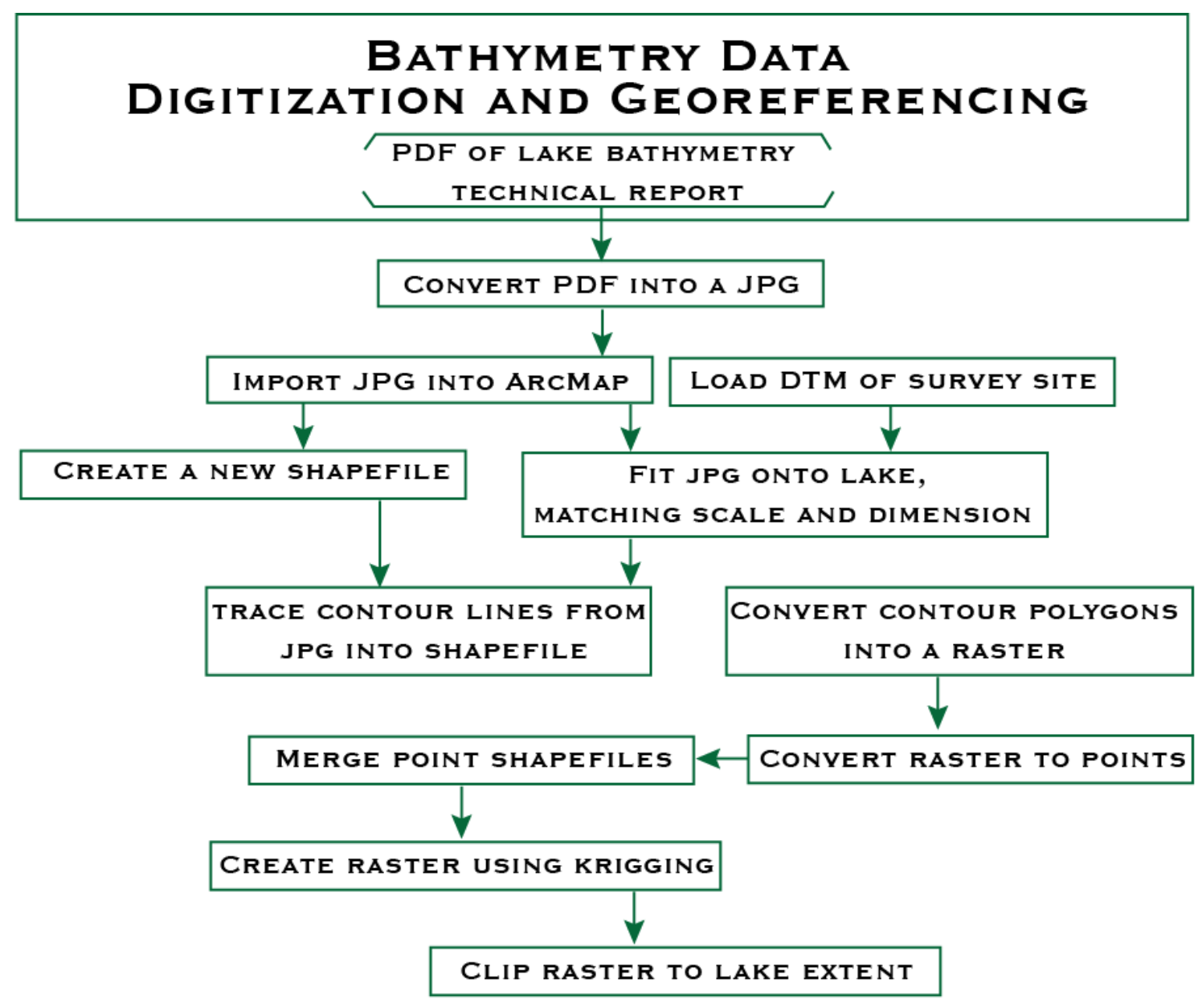

Figure 4.7.1: Bathymetry data digitization and georeferencing

Data-flow diagram outlines the steps followed to digitize and georeference lake bathymetry surveys, using ArcGIS. 


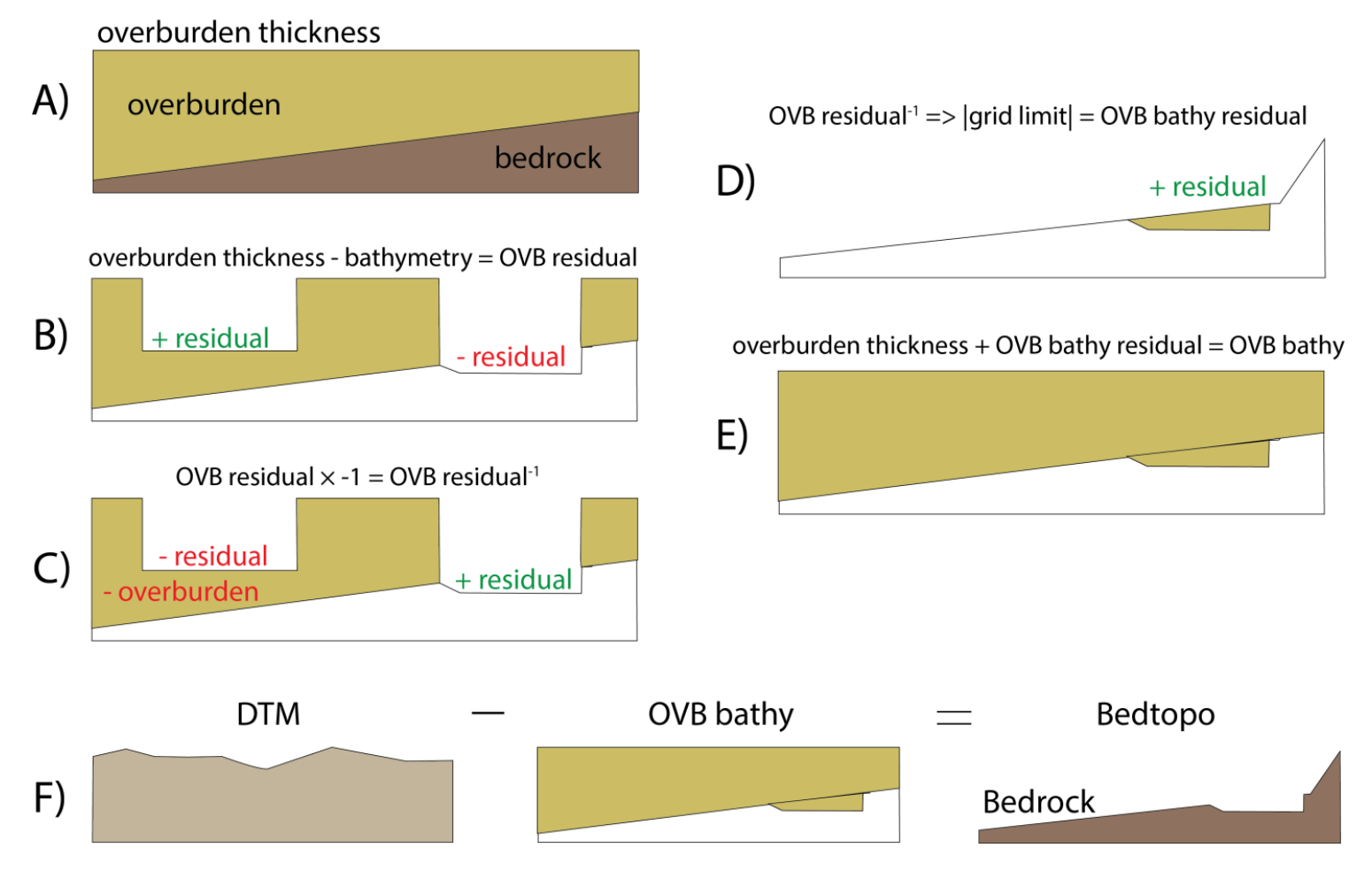

Figure 4.7.2: Map manipulation steps followed to create Bedrock topography map

A: Simple cross section of an overburden-bedrock model. The overburden-bedrock contact is shown for reference, as the HTEM inversion only provides an estimate of overburden thickness and not the elevation of the bedrock surface, it needs to be calculated. B: The result after lake bathymetry is subtracted from overburden thickness, creating OVB residual. Depending on the depth of the lake and the thickness of the overburden, the lake bottom may extend into bedrock or be situated within the overburden. C: Processing to isolate the spatial extent of the elevation of the lake bottom as it protrudes into the bedrock. It is identified as + residual. D: Isolation of the area, + residual, of the lake bottom in the bedrock. E: The + residual is added back to the overburden + lake bathymetry as a layer called OVB Bathy, in order to isolate the bedrock contact. F: OVB Bathy is subtracted from the DEM, thereby creating the BedTopo map registered to the NAD83 datum. 


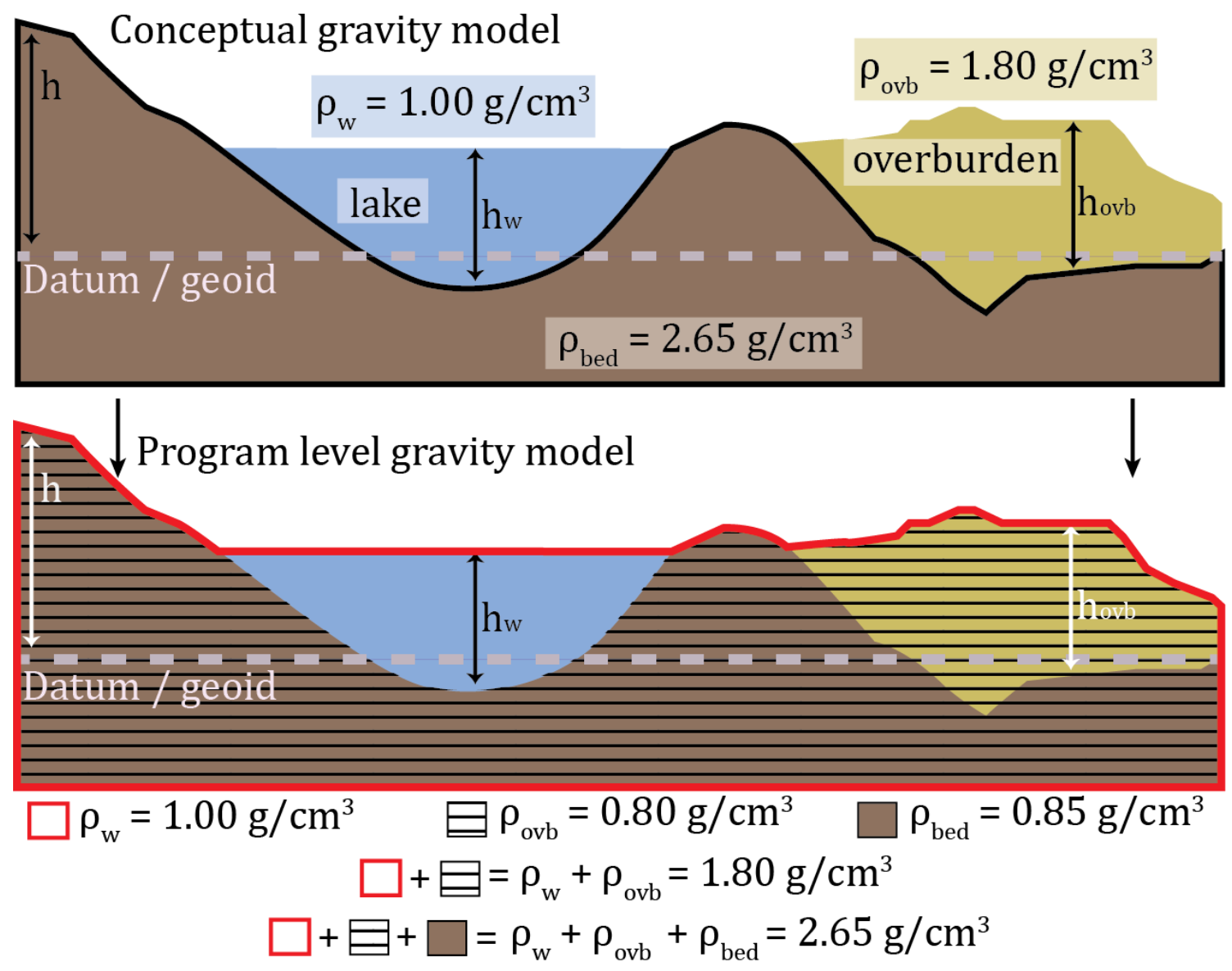

Figure 4.9.1: Program level gravity modelling

The conceptual model shows how the geology within the survey site is modelled by classifying water, overburden, and bedrock as individual layers. Each layer is described by a finite upper elevation that represents the surface of the layer and has an infinite depth. The densities of each layer add up to the density value of the halfspace, see bottom panel, which is $2.65 \mathrm{~g} / \mathrm{cm}^{3}$. The program level gravity model shows how the conceptual model is programmed and manipulated into software for processing. 


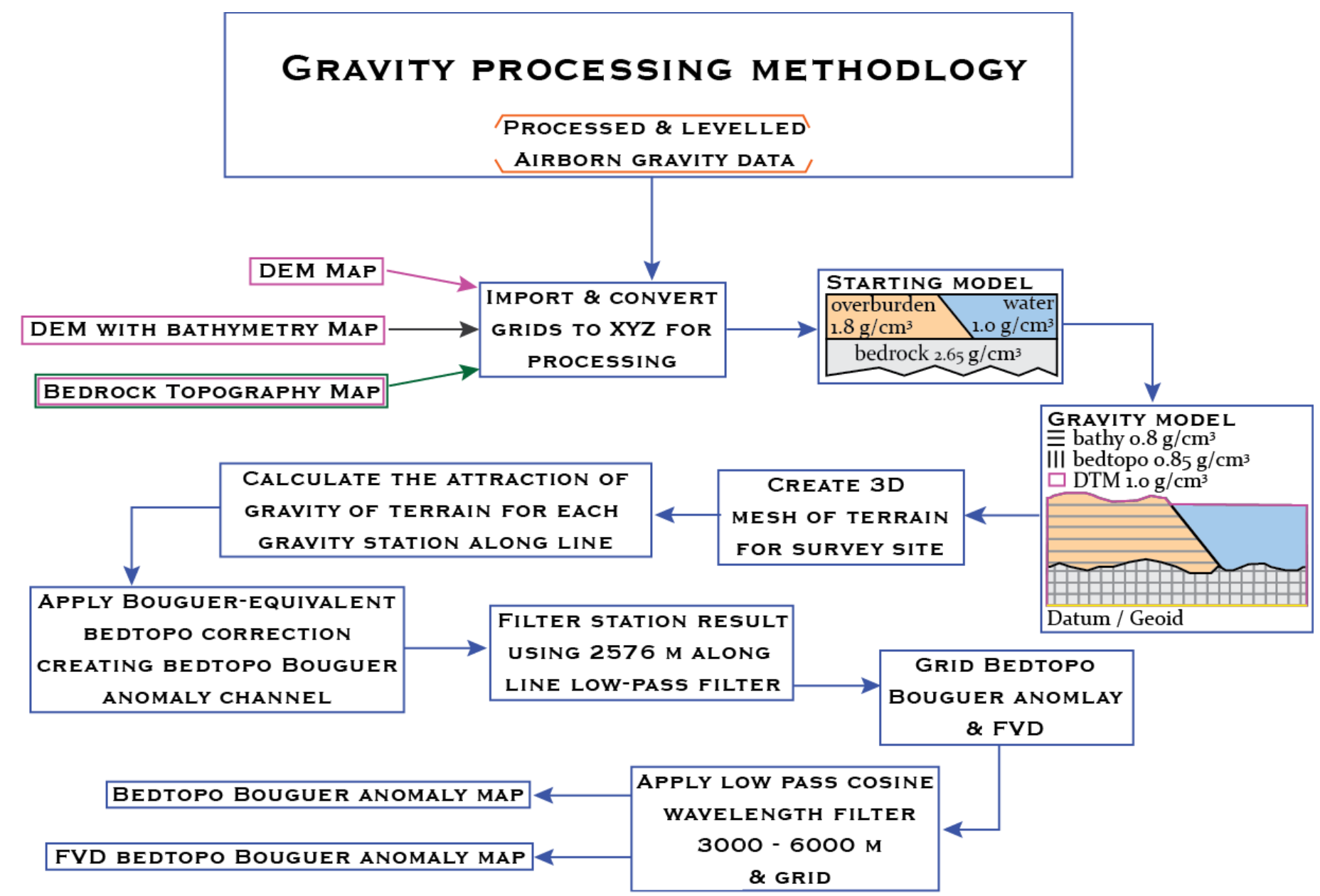

Figure 4.9.2: Gravity processing methodology

Data-flow diagram of the steps followed to apply a BedTopo Bouguer-equivalent correction to gravity data to create the BedTopo Bouguer anomaly and the FVD BedTopo Bouguer anomaly maps. 


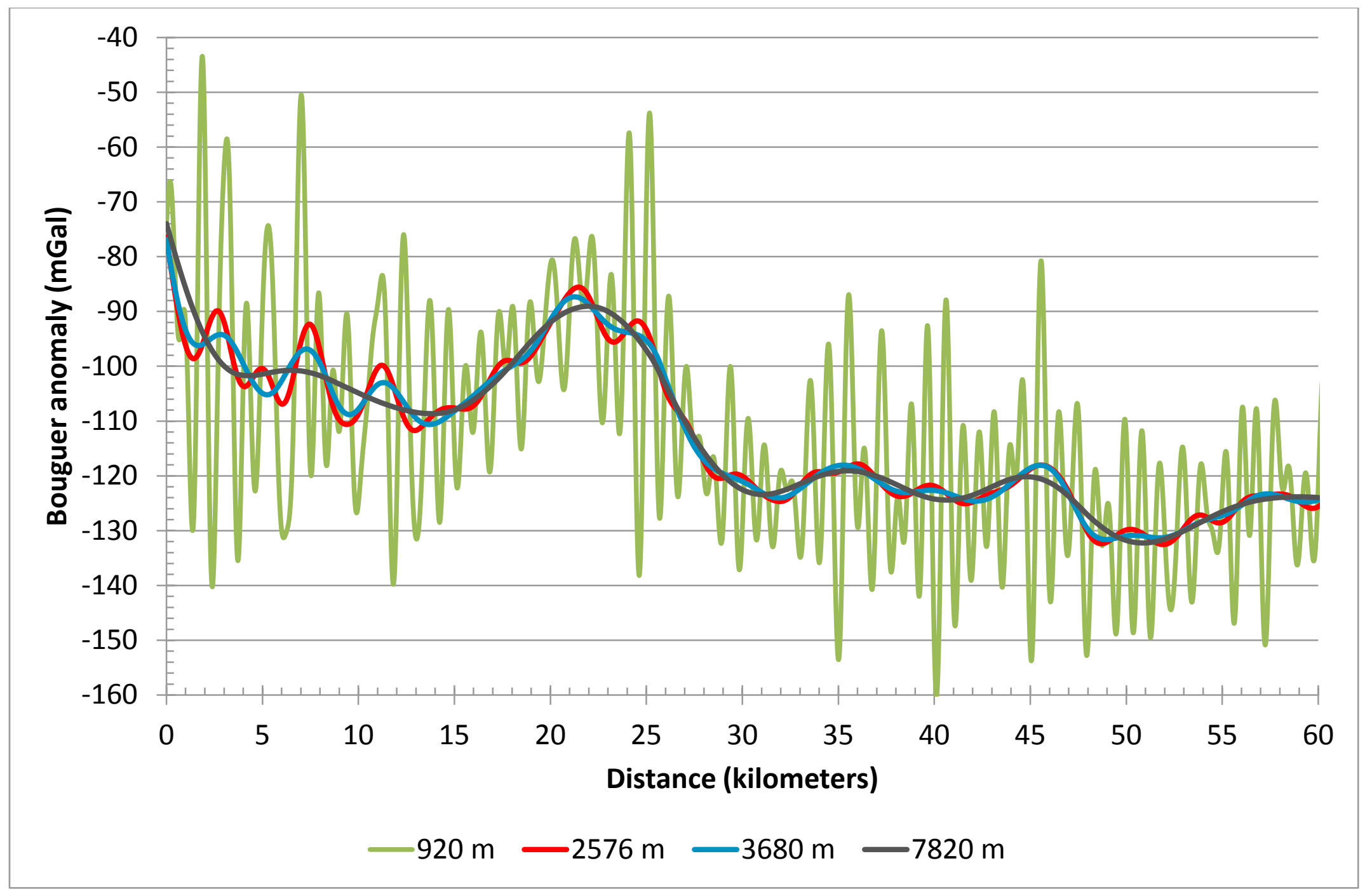

Figure 4.9.3: Low-pass cosine filter applied to line data.

The high frequency GPS noise apparent in the $920 \mathrm{~m}$ filtered data, shown by the green line, is high amplitude and has a wavelength of 1-2 km. This noise is removed by applying an along line cosine low-pass filter. A filter length of $2576 \mathrm{~m}, 56$ seconds, was chosen. The filter attenuated GPS high frequency noise while retaining some mid-frequency gravity features. 

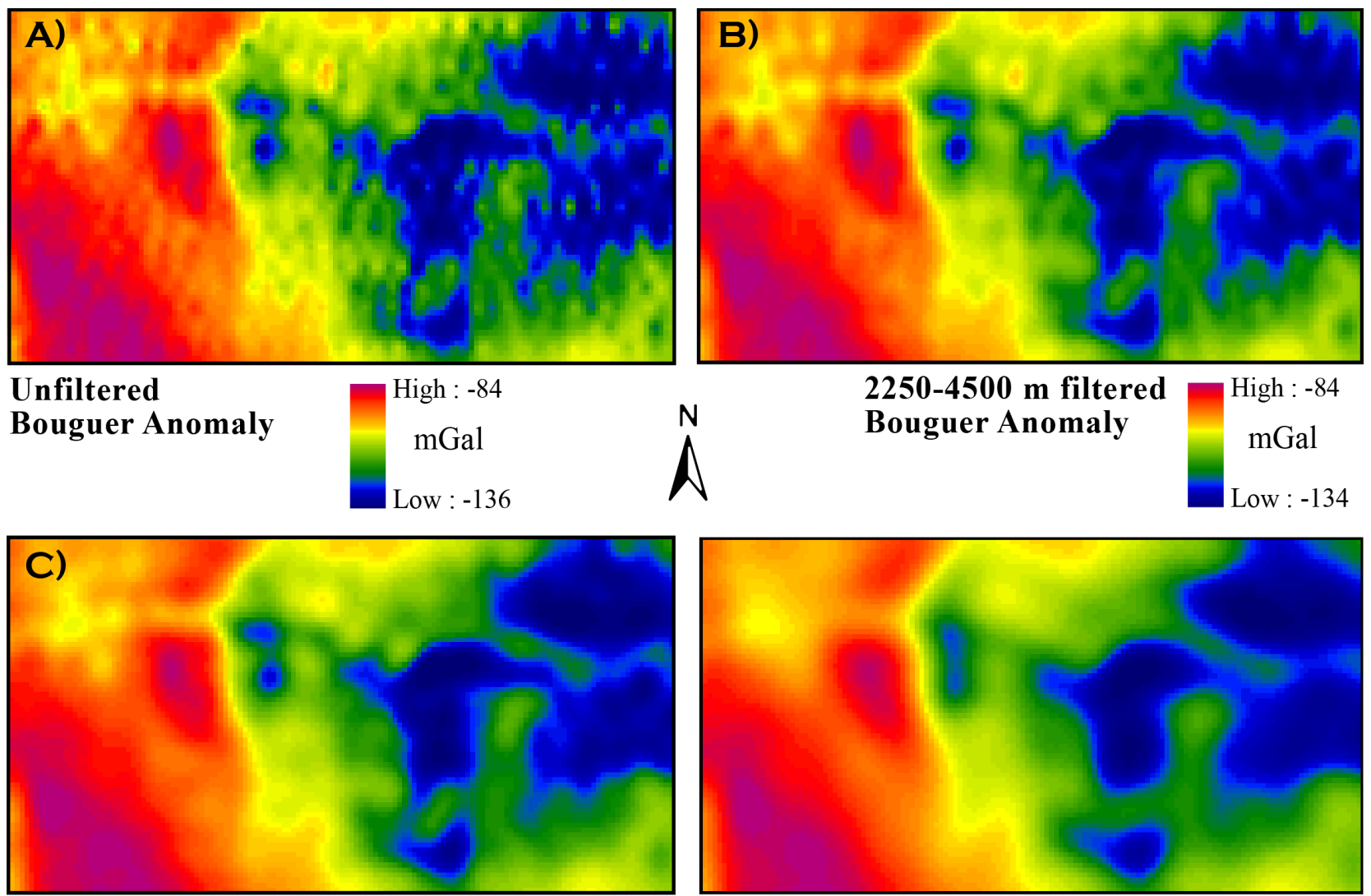

$3000-6000 \mathrm{~m}$ filtered Bouguer Anomaly
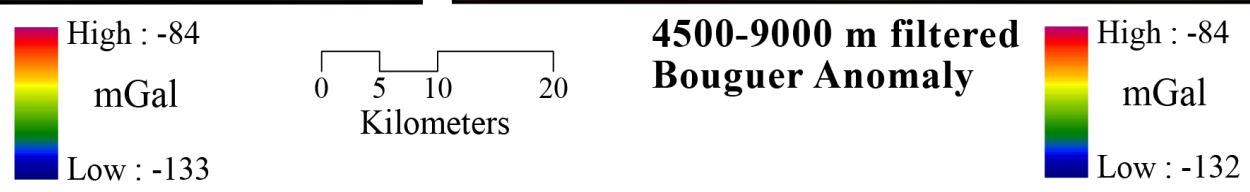

Figure 4.9.4: Low-pass cosine wavelength filter applied to gravity grids.

In this case the high frequencies are considered noise from a host of various sources, such as GPS. All grids have been previously filtered with a low-pass 56 second line filter. A) No grid filtering; the individual survey lines are visible. B) 2250$4500 \mathrm{~m}$ transitional band cut-off. C) Selected grid filter, a 3000-6000 $\mathrm{m}$ transitional band cut-off. Survey lines are no longer visible. D) 4500-9000 m transitional band cut-off. 


\subsection{Results \& Discussion}

This chapter presents the results of the progressively more sophisticated inversions of HTEM data applied herein. It starts with information garnered from preliminary studies described in Caron et al. 2015 and goes on to explore the results of several inversion strategies. The chapter continues by presenting results for the overburden correction of gravity data and compares those results using Bouguer anomaly maps. Discussion of the results is presented following the results in each section.

\subsection{Two-layer inversions}

The first inversion of HTEM data from the study site was performed along line 7420 using a simple two-layer strategy (see Figure 5.1.1 and Section 4.3) with the first layer interpreted as overburden overlying a bedrock halfspace. Results show that the bedrock resistivity is uniform, at $2000 \Omega \bullet \mathrm{m}$, along line 7420 , and that the overburden resistivity varies smoothly within a 33-138 $\Omega \bullet \mathrm{m}$ range. They also show that the overburden thickness along this line ranges from 30 to $\sim 300 \mathrm{~m}$, and does so within a distance of $1 \mathrm{~km}$. Also shown are shortwavelength, $\sim 100 \mathrm{~m}$ wide, irregularities along the bedrock contact that vary by as much as $100 \mathrm{~m}$ in thickness. While some of these features could be real, most are thought to be a result of the inversion sampling rate of $50 \mathrm{~m}$, which roughly corresponds to every $15^{\text {th }}$ HTEM station, and a result of the inversion inconsistency between stations due to the largely unconstrained inversion methodology. 
The rest of the survey site was inverted using the same 2-layer layered earth model. The overburden is found to vary in thickness from $3 \mathrm{~m}$ to over $450 \mathrm{~m}$ with a mean of $119 \mathrm{~m}$. Its resistivity ranges from 2 to $455 \Omega \bullet \mathrm{m}$ with a median of $47 \Omega \bullet \mathrm{m}$ and a mean of $56 \Omega \bullet \mathrm{m}$. The resistivity of the bedrock has a range of $1000-8980 \Omega \bullet \mathrm{m}$ with a mean of $1941 \Omega \bullet \mathrm{m}$. These results are consistent with the findings from a previous two-layer ground TEM survey conducted in the southern Nechako Plateau that found conductive overburden overlying resistive bedrock with a thick overburden (Best et al. 1997). In the 1997 study, the interpreted range in overburden thickness was 30-120 m. The overburden resistivity ranged from $68-157 \Omega \bullet \mathrm{m}$, and the bedrock resistivity ranged from $8000-10,000 \Omega \bullet m$ (Best et al. 1997).

While the inversion returned soil and bedrock resistivities similar to published data, see Table 2.2, the 2-layer inversion strategy employed to create Figure 5.1.1 was unable to invert large portions of the study site with a sRMS \% error of $10 \%$ or less. Inversions conducted using water wells as ground truth also show that 2-layer inversions often overestimate the thickness of the overburden, see AppendixAppendix I.

\subsection{Multi-layer inversions}

Many stations for which 2-layer inversions failed were successfully inverted using 3- and 4- layer models with sRMS \% errors of $<10 \%$, see Section 4.4 for the methodology. These models were built with the assumption that resistivity increases with depth, see Figure 4.4.1. While many stations inverted successfully using the multi-layer method, there are many gaps in the map shown in Figure 5.2.1. These gaps represent HTEM stations that would not invert with 
an sRMS \% error below $10 \%$ using any of the starting models. The Figure suffers from poor data coverage, indicated by the spaces between HTEM stations along line.

There are two overburden thickness features in Figure 5.2.1 that stand out, a linear high that runs north-south on the western side of the map, and a moderately extensive, roughly rectangular high, extending east-west in the central portion of the eastern side. When inversion was successful, the results were consistent along line in some cases but highly variable in others. The area that showed the highest amount of variability was found to be primarily limited to a ridge along line 7420 on the western side of the map. This is indicated by the high variability in red and yellow dots on Figure 5.2.1. Areas that showed consistent results were primarily located in areas where overburden thickness is known to be thin, such as till veneer. These areas are indicated by the green dots. Inversions conducted using water wells as ground truth showed that 3-layer inversions may also return a result where the thickness of the overburden is overestimated, see Appendix I.

\subsection{Resistivity reversals}

Trial and error inversions for HTEM stations in areas where multi-layer inversions failed showed that successful results could be obtained if a resistivity reversal was modelled within the overburden (see Figure 4.4.1 B and Section 4.5). This strategy resulted in enough inversions that provided sufficient spatial coverage, which is one data point every $1 \mathrm{~km}$ along line, to allow interpolation of an overburden thickness map with a $1 \mathrm{~km}$ cell size resolution. This map shows the following trends (see Figure 5.3.1): the overburden is thicker than $100 \mathrm{~m}$ in a broad zone extending from the northwest corner of the area to the southeastward to the central portion of the 
southern margin, and within an elongate oval area immediately south of the east end of Francois Lake., It is thinner than $30 \mathrm{~m}$ in the middle of the area south of the lake and in the northeast and southwest corners of the study site. While inversion results appear to be related to geological features, such as where thin overburden coincides with Uncha Mountain and the Highlands, the data includes 2- and 3-layer inversions which have been shown by water well calibrated inversions to over-estimate overburden thickness. This may have led to an overestimation in overburden thickness in some of these areas as several large estimations in overburden thickness may skew the average interpreted overburden thickness within a $1 \mathrm{~km}^{2}$ map cell.

Multi-layer inversions were also tested to resolve the scenario where there is no overburden overlying bedrock. These inversions had a first layer resistivity of $500 \Omega \cdot \mathrm{m}$ followed by a less resistive layer of $100 \Omega \cdot \mathrm{m}$ over a $1000 \Omega \cdot \mathrm{m}$ halfspace. While these inversions proved to provide a good sRMS fit to the observed data, the sRMS \% error was rarely improved over the 4-layer model shown in Figure 4.4.1 B. While these models seemed to work in areas of flat bedrock outcrops with till veneer, such as in the highlands of the study site, they were unable to resolve any amount of overburden, even in areas where overburden was known to exist, while the 4-layer model, in Figure 4.4.1 B, was able to resolve thickness as small as $5 \mathrm{~m}$ within the highlands while also being able to resolve areas where overburden is known to exist, such as between Uncha Lake and Mollice Lake, see Figure 2.2 for lake location and Figure 5.3.3 for surficial geology information.

\subsubsection{Overburden thickness and surficial geology}


The surficial geology overlaid on the DEM map, shown in Figure 5.3.2, can be compared to a map of surficial geology overlaid on the overburden thickness map shown in Figure 5.3.3. The DEM map, Figure 5.3.2, shows many areas where the surficial geology information correlates with topographical features, such as where topographic highs are covered by till veneer and bedrock outcrops. Indications of sediment also correlate with many areas of thick overburden such as where some glaciofluvial deposits are mapped, and where sediment is mapped in most low elevation areas. On the overburden thickness map, see Figure 5.3.3, surficial geology features do not correlate as well with inversion results. This is most easily seen by comparing Feature A to Uncha Mountain. Both features were mapped to be mostly bare rock with some till veneer, however while Uncha Mountain is inverted to have thin overburden, Feature A is inverted to have an overburden thickness of approximately $230 \mathrm{~m}$. A similar but opposite observation can be made over areas where HTEM inversion interpreted thin overburden but where geological data indicates glaciofluvial or glaciolacustrine sediment, such as in the northeast corner of the map. In this area however plotted $\mathrm{BC}$ water wells show that the depth to bedrock is variable but often shallow.

Although the overburden thickness map shows trends that correlate with topographical features on the DEM map, the surficial geology information was considered to be unsupportive of the inversion results in several areas. This disagreement is caused by several unrelated factors such as map resolution, where point measurements are averaged over large distances (overburden thickness map has a $1 \mathrm{~km}$ cell size), and HTEM system limitations in detecting the minimum thickness of overburden. The overburden thickness map in Figure 5.3.3, however, 
present results of inversions with the smallest number of layers and would be the quickest to compute in operational conditions.

\subsection{HTEM inversion calibration using water wells}

Water well records within the greater Quest West survey area were used to calibrate HTEM inversions, see Sections 2.4.1 and 4.2.1. Of the 12 wells that were used, 10 provided calibration information while the remaining 2 did not generate models that provided an sRMS error $<10 \%$. The inversion records for these wells can be found in Appendix I. The inversion records lists the location of the well, the HTEM station used for inversion, and the horizontal distance and difference in elevation between the well and the HTEM station. The record also displays the water well record in graphical form, the starting resistivity models used for inversion, the results of each inversion, and any special notes that identify issues that may have influenced inversion. The results of each inversion can be compared visually and by using the sRMS \% error value listed above each inversion. As the water well can be situated up to $400 \mathrm{~m}$ away from the HTEM station and at a different elevation, the inverted thickness of the overburden is assumed to be accurate if it is reasonably close to the depth to bedrock measured from the water well. A reasonable value is within $70 \%$ of the overburden thickness indicated by the water well.

Comparisons between the Figures in Appendix 1 show that the simpler 2- and 3-layer models largely overestimated the thickness of the overburden in 9 of 13 wells. The 2-layer only returned an accurate result in 3 of 13 wells while the 3-layer model only returned accurate results in 2 of the 13. Neither of these models returned an inversion result with a sRMS \% error lower 
than that obtained for the 4- or 5-layer models for any of the calibration stations, so even the best results from these models were disregarded in favour of the 4- or 5- layer inversion results.

Comparisons with water well data also show that the 5-layer model was the most successful at inverting the largest number of EM stations with a competitive sRMS match relative to the other models. Both the 4- and 5-layer models correctly determine the overburden thickness to within $80 \%$ in 4 of 11 wells with an additional 3 records within $70 \%$ of the total thickness. This corresponds to an sRMS \% error of $54 \%$ for 5 -layer inversions, and $55 \%$ for 4 layer inversion. When the 4- and 5-layer models are considered together, where the lowest sRMS $\%$ error determined the selected model for that station, out of the 11 wells that were successfully inverted the overburden thickness was within $80 \%$ in 4 wells, with an additional 2 wells being within $70 \%$ of the total overburden thickness, which corresponds to an sRMS $\%$ error of $61 \%$. Unfortunately the calibration results in Figure 5.4.1 and Appendix 1 also show that the 5-layer model inversion result could have a lower sRMS \% error than the 4-layer model inversion result even in the situation where the 4-layer model was more accurate at determining the depth to bedrock where the 5-layer model was not, see Appendix I, figures A1-2, A1-7, and A1-10. This creates the situation where an inversion with the incorrect determination of overburden thickness is chosen in lieu of the correct inversion due to the lower sRMS \% error. Unfortunately there is little else to assist in selecting the best inversion result other than by choosing the one with the lowest sRMS \% error with a plausible geological model. It should be noted that the sRMS \% error calculations include inversions where the overburden is known to be incorrect, such as over Feature A, and so does not represent a best estimate of inversion accuracy. 
Inversions also show that overburden typically has a resistivity that ranges from 5-150 $\Omega \bullet \mathrm{m}$, with an average of $50 \Omega \bullet \mathrm{m}$. Bedrock has a resistivity that ranges from 5 to over 5000 $\Omega \bullet \mathrm{m}$. Of note however is that the first identifiable layer of bedrock beneath overburden, for the 4- and 5-layer models (4LR, 5LR), has a resistivity that ranges from $445-878 \Omega \bullet \mathrm{m}$ with an average of $505 \Omega \bullet \mathrm{m}$. This provides a useful tool for identifying the first layer of bedrock as it occurs beneath overburden, should it hold true for all inversions. It may also be an artifact of the

inversion models, shown at the bottom of each Figure, where the primarily sRMS selected 4- and 5-layer models are configured with a $500 \Omega \bullet \mathrm{m}$ layer beneath a more conductive overburden. While such a layer tended to result in a successful determination of the overburden-bedrock contact, it may be artificially interpreting a more resistive layer in order to better match the observed decay of the secondary magnetic field.

\subsubsection{Resistivity structure within the layered earth model}

The calibration with the water well data shows that in order to get the best inversion result, the layered earth model should be a crude approximation to the actual Resistivity structure of the subsurface controlled by geology. The sRMS \% error can then be used to discriminate between geologic models as the best result can most often be identified by the lowest sRMS \% error value, see Appendix I. The Appendix 1 Figures show that different overburden thickness results are obtained through inversion depending on the number of layers and Resistivity structure within the model, where fewer layers in the model often results in a large overestimation in the thickness of the overburden. 
Using the water well results shown in Figure 5.4.2 as an example, when the number of layers in the model is increased from 2-, to 5-layers, the resistivity-depth profile of the model gains the ability to better model resistivity changes with depth. When the starting model is a better approximation to the resistivity-depth profile of the surficial geology, it leads to a lower sRMS \% error. As the resistivity-depth structure of the surficial geology is unknown, the chance of a successful and accurate inversion may be increased if multiple models are used for inversion, where each model describes a different but general trend in resistivity-depth of the subsurface. This can be seen by the layers representing overburden for the 4-layer and 5-layer models, in Appendix Figures A1-1 to A1-4, A1-7, A1-8, A1-10, and A1-11, which show that inversion results for overburden thickness are improved when the overburden and/or bedrock is modelled as 2 or more distinct layers . This is also supported by the success of the 5 LR-2 inversion, see Figure 5.4.3, where a 5-layer model succeeded in inverting the thickness of the overburden if the bedrock was interpreted to have a resistivity of greater than $170 \Omega \bullet \mathrm{m}$. The 5 LR-2 inversion was also able to successfully discriminate between sediment types that match the water well record of silty-gravel and glacial till, as well as between sandstone and what is most likely granodiorite bedrock from the Endako batholith of the Francois Lake suite. Granodiorite is often reported to have a resistivity of well over $1500 \Omega \bullet \mathrm{m}$, see table 2.2 .

\subsubsection{Discrimination between overburden and bedrock resistivity}

A visual comparison of the calibration inversions also show that a discrimination based on resistivity is required to distinguish overburden from bedrock. Figure 5.4.3 shows that the bedrock can have a resistivity as low as $174 \Omega \bullet \mathrm{m}$ from HTEM inversions, while Figure A1.1 
shows that the overburden can have a resistivity as low as $140 \Omega \bullet \mathrm{m}$. Both of these valyes are in support of the $160 \Omega \bullet m$ choice of a bedrock cut-off for the $2^{\text {nd }}$ layer, see Section 4.6.

It should be noted that Appendix I shows that the resistivity of the bedrock determined from inversion could be as low as $0.5 \Omega \bullet \mathrm{m}$. This low resistivity value is supported by the 3 geotechnical boreholes drilled near the study site that show the in-situ measured resistivity of different bedrock units, see Figure 5.4.4 and Appendix II. The associated GSC report attributes these low resistance values to conductive minerals such as sulphides, oxides, and graphite. In the case that these minerals are absent or less abundant, the low resistances are attributed to porosity, degree of fracturing, and pore water salinity and saturation (Killeen et al. 1995). It is likely that bedrock with a lower resistivity exists within the survey site that is indistinguishable from overburden and vice versa, such as a porous limestone and tuff, see table 2.2. Unfortunately, there is no published information concerning the resistivity of surficial sediment for the study site or within the Nechako Plateau.

\subsubsection{Water well calibration inversion results by starting model}

The 2-layer starting model, which is the 2-layer inversion strategy presented in Section 4.3, was able to invert for overburden thickness however it was not able to do so with consistent results and often greatly overestimated the thickness. Despite being the simplest model it was ineffective at inverting stations, having inverted only 6 out of the 13 water wells used for HTEM calibration. With respect to accuracy, the 2-layer starting model has an sRMS error of 104\%, the lowest accuracy of any of the attempted starting models. 
The 3-layer model was only a slight improvement over the 2-layer model but suffered from the same inconsistency with great overestimations of overburden thickness. Like the 2layer model it was only able to invert 6 out of the 13 water well calibration stations, and has an inversion accuracy sRMS \% error of 94\%. Both the 2- and 3-layer models also suffer from the occasional habit of returning an inversion result that exceeds the depth of investigation of the HTEM system.

The 4-layer and 5-layer models were found to be a significant improvement over the 2and 3-layer models. Both models were able to invert 11 of 13 water well calibration stations and have similar levels of accuracy with $54.7 \%$ for the 4-layer model and 54.3\% for the 5-layer model. All of the inversion models performed more accurate inversions, with better sRMS \% error values, over flat terrain where overburden was known to exist. Accuracy was calculated with respect to the inverted overburden thickness compared to the water well measured thickness, results from inversions that exceeded the DOI of the HTEM system were omitted from the calculation. Results are based on the water well inversions presented in Appendix I. See Table 5.4.5 for comparison.

\subsection{Resistivity structure inversions}

Inversion using the Resistivity structure inversion method, see Section 4.6, progressed with a higher degree of success than the 2-layer, multi-layer, and resistivity reversal inversion strategies. A comparison of Figures 4.6.2 and 5.5.1 with Figures 5.2.1 and 5.3.1 shows that the successful Resistivity structure inversion stations are more numerous along line and cover a greater portion of each HTEM line than the resistivity reversal strategy. Gaps along line are also 
smaller and there are fewer gaps. This provides a better along-line sampling of the study site and a more accurate averaging of the data within the $1 \mathrm{~km}^{2}$ cell size of the map. In addition, the accuracy of results are supported by the HTEM inversion calibration using water wells, as the same 5-layer model was used to perform the Resistivity structure inversions. The sRMS \% error of the Resistivity structure inversions is also lower, with a median of $3.9 \%$ and an average of $4.4 \%$, compared to the resistivity reversal inversions, which have a median and an average over $6 \%$.

An analysis of Resistivity structure inversion results by station shows that the overburden varied in thickness from 0-265 $\mathrm{m}$ with an average of $38 \mathrm{~m}$. The first layer of overburden has a range in resistivity of 3-680 $\Omega \bullet m$, with an average of $46 \Omega \bullet m$. This range includes all successfully inverted HTEM stations where the overburden was determined to be at least $5 \mathrm{~m}$ thick, which includes 11048 stations out of 11177 or $98.8 \%$ of successful inversion results. Resistivities for inversions where the thickness was determined to be less than $5 \mathrm{~m}$ were found to have resistivities less than $3 \Omega \bullet \mathrm{m}$, down to $0.02 \Omega \bullet \mathrm{m}$, and as high as $775.6 \Omega \bullet \mathrm{m}$, and are considered to be unreliable due to the small thicknesses of the layer relative to the low resolution - long EM wavelenths involved. Bedrock resistivities have a range of $0.5 \Omega \bullet \mathrm{m}$ to $>10,000 \Omega \bullet \mathrm{m}$, most likely due to the large variation in volcanic bedrock resistivities, which in some locations include tuff (see Figure 2.5). This range is supported by the bedrock resistivity histogram shown in Figure 5.4.4. When the inversion data set is gridded and averaged over a $1 \mathrm{~km}$ cell-size, overburden has a thickness range of 15-60 m with an average of $36.5 \mathrm{~m}$, see Figure 5.5.2. 


\subsubsection{Overburden thickness comparison}

Figure 5.5.2 shows an overburden thickness map created from the Resistivity structure inversions and overlaid with surficial geology data. This map can be compared to the overburden thickness map created from the resistivity reversal inversions, see Figure 5.3.3. The trends in overburden thickness between the two maps are similar, where areas of thick and thin overburden are collocated in most cases. Areas of mapped gravel pits are also in agreement with inverted overburden thickness. There are a few discrepancies between the maps, where mapped outcrops, till veneer, and glaciolacustrine sediment does not seem to match overburden thickness. The largest difference between each map is the thickness of the overburden where the Resistivity structure inversions in Figure 5.5.2 show an overburden which is about $1 / 4$ the thickness as that shown in Figure 5.3.3. The point measurements of overburden thickness measured at each water well are in disagreement with the inverted overburden thicknesses shown in both maps, however the HTEM data is averaged over a $1 \mathrm{~km} 2$ cell size, and the disparity is smaller in the Resistivity structure inversions of Figure 5.5.2.

The difference between the water well measurements and the $1 \mathrm{~km}$ cell size-averaged overburden thickness values shown in Figure 5.5.2 could be due to topographic and overburden thickness changes that are occurring on a scale too small to be resolved with a $1 \mathrm{~km}$ cell size. The study site has a topography that varies rapidly over small distances, as indicated in Figure 2.3. While the slopes are classified as gentle, they are widespread throughout the study site and indicate a topography that changes rapidly within a distance of $100 \mathrm{~m}$. The overburden thickness results from both the resistivity reversal and the Resistivity structure inversions could also be 
overestimated due to 3D topography effects surrounding HTEM stations that are situated on or near a slope, see Section 5.5.2 (Newman et al. 1987, Auken 1995).

\subsubsection{Overburden thickness compared to satellite images}

When the Resistivity structure overburden thickness map is superimposed on a Google Earth satellite photo of the study site, shown in Figure 5.5.3, two additional observations can be made with regard to inversion results. The relationship between terrain structures and overburden thickness is shown, where thin (blue coloured) overburden coincides with the angular features of a ridge or mountain, such as Uncha Mountain in the upper left of the figure, and where thick overburden (yellow to red) coincides with flatter terrain, such as the rolling plains around Molice and Uncha lakes. All trends are general, due to the large spacing between HTEM lines that can miss major terrain features, such as the volcanic neck on the left edge of Figure 5.5.3.

Feature A is an anomaly that seems to contradict the overburden thickness versus terrain trend. The satellite photo, see Figure 5.5.3 shows a rocky ridge (red colour) covered in white scars (that appear pink in the Figure due to the transparency overlay) from logging activity, see Figure 5.5.4 for a closer look.

Inversion results from HTEM line 7420 over Feature A shows the overburden thickness to be highly variable, ranging from 10-180 $\mathrm{m}$ in thickness. These results are somewhat less plausible due to the rocky appearance of the ridge. When these stations are plotted on a satellite image using Google Earth, they reveal that thick overburden is limited to areas where the HTEM stations are located on the side of a steep slope, see Figure 5.5.4. This suggests that the inversion 
results in this area could be affected by $3 \mathrm{D}$ topography effects that are not well modelled by a layered earth model. Feature A was therefore partially created as a result of 3D topographical effects on many stations that led to an overestimation of overburden thickness. This error was propagated and averaged through interpolation with stations from another HTEM line $4 \mathrm{~km}$ away. A more suitable model that accommodates station specific changes in terrain and geologic structure should be used in areas of steep slopes in order to provide a more accurate inversion of overburden thickness.

\subsubsection{Inversion analysis}

As the inversions were mostly conducted without constraints and because more than one starting model was used, a quick analysis of the inversion results is in order; specifically to see if the results from station to station are comparable, and if the results between starting models are comparable. The overburden thickness inversion results for each starting model are plotted in Figure 5.5.5, and as a profile of HTEM line 7420 in Figure 5.5.6. The map shows that the survey area is inverted primarily using the 4-layer and5-layer starting models, and that the model chosen does not seem to be influenced by topography or by bedrock geology (compare with Figure 2.5). Figure 5.5.6 shows that adjacent stations for inversions conducted with the same model are in good agreement, and that inversions conducted using different starting models are comparable. There also exist several individual outliers, identified within the black dashed circle, as well as several groups of outliers. Individual outliers can show a large deviation from the average, while groups of outliers seem to occur within $20 \mathrm{~m}$ of each other, see the two green dashed oval shapes in Figure 5.5.6. This difference may be due to the choice of using a $160 \Omega \bullet \mathrm{m}$ cut-off to identify

the bedrock in the $2^{\text {nd }}$ layer of the inversion results, and due to $3 \mathrm{D}$ effects from the rocky terrain. 
The groups of outliers could also be due to local changes in terrain, overburden thickness, or water table as each group of outlier is made up of both the 4- and 5-layer starting forward models. In this particular area the resistivity of the $2^{\text {nd }}$ layer is variable with a range of 71-1500 $\Omega \bullet \mathrm{m}$. A cosine distance weighted average was used for interpolation, and has the effect of averaging the data within a $1 \mathrm{~km}$ cell size, chosen due to the $4 \mathrm{~km}$ HTEM line spacing. As the reduction in resolution is large, the outliers were left to be averaged into the $1 \mathrm{~km}^{2}$ cell data as the contribution from a single outlier is greatly reduced over a distance of $1 \mathrm{~km}$. The contribution of outliers are further reduced in processing of airborne gravity data acquired on wide spaced survey lines which is insensitive to high frequency effects.

Figure 5.5.6 also shows an average response for till veneer, or where the bedrock is resistive and near surface. From UTM X coordinates 32.70 to 33.55 and again from 34.25 to 34.80, which coincides with till veneer and mapped bedrock outcrops, the inverted overburden thickness distribution for all starting models ranges from 3-10 $\mathrm{m}$. This suggests that the nearsurface resolution is within this envelope over rocky terrain, depending on the overall conductance of the bedrock. The presence of the group of outliers which has overburden thickness in the range of $20-30 \mathrm{~m}$, from UTM X coordinates 32.70 to 33.55 , could be due to local changes in terrain that are not visible at the resolution provided by SRTM data, geologic surveys, or statellite photos.

Inversion results for a profile of line 7420 over Feature A, which showed a disagreement with satellite imagery regarding its rocky nature, is shown in Figure 5.5.7. The Figure shows an increase in scattering and an increase in outliers when the terrain changes from rolling hills to 
rocky peaks on each side of Feature A, where 3D effects are common and where the layered earth model is less suitable for modelling. 3D effects may have contributed to inversion overburden thickness estimation errors throughout the study site. Over Feature A along line 7420 the X-component showed variations in amplitude from -114 to $160 \mathrm{nT} / \mathrm{s}$. The entire line had a range of -208 to $614 \mathrm{nT} / \mathrm{s}$ with an average of $2.6 \mathrm{nT} / \mathrm{s}$ and a standard deviation of $31 \mathrm{nT} / \mathrm{s}$. It should be noted however that the same large estimate of overburden thickness did not occur over Uncha Mountain, that in this area the inversions found thin to no overburden. While 3D effects may have plagued inversions throughout the study site there is another factor at play over Feature A.

\subsubsection{Augmenting overburden thickness map with ancillary data}

The surficial geology data shown in Figure 5.5.2 could be used to augment the overburden thickness map by constraining the areas with bedrock outcrops and till veneer to $0 \mathrm{~m}$ and $1 \mathrm{~m}$ in thickness, respectively, however the process can be complex due to the different ways the data was gathered (along line versus a random point data set). There are also other data sets less commonly applied that may also be added to augment an overburden thickness map, such as infrared remote sensing. Augmenting the overburden thickness map to improve resolution and accuracy of the inverted discrete layered earth HTEM data with ancillary data is suggested for future work and is further discussed in Section 6.4.

\subsection{Bouguer gravity corrections}


This section will compare Bouguer anomaly maps created using the method, called

Standard Bouguer outlined in Section 4.9.2, with one created using the same process but which incorporates overburden thickness data for a BedTopo correction, which will be referred to as

BedTopo Bouguer. The Bouguer corrections are applied to Quest West gravity data (Standard Data), and use Resistivity structure inversion overburden thickness results. These maps will be compared both with and without a bathymetry correction in order to better isolate the effect of the BedTopo correction. The first vertical derivative (FVD) which is used to delineate geological structures based on density will also be compared.

\subsubsection{Bouguer anomaly profile comparison}

A profile view of HTEM line 7420 shows the effect of the overburden correction on Bouguer anomaly data, see Figure 5.6.1. The Figure shows topography, bedrock topography, Bouguer anomaly, and the Bouguer BedTopo anomaly. The difference between the topography and the bedrock topography curves is the interpreted overburden thickness. The most notable trend on the Figure is the difference in gravity intensity between the Standard Bouguer and the BedTopo Bouguer curves. This difference represents the modelled gravity contribution of overburden thickness. Other than an average $7 \mathrm{mGal}$ static shift, the difference in the shape of the curves is little. Most changes in overburden thickness did not result in any significant changes between the two Bouguer anomaly profiles, and is only visible as a static shift between the Standard Bouguer and the BedTopo Bouguer profiles. This is a result of $1 \mathrm{~km}$ grid cell size for overburden thickness which has the effect of filtering out the high frequency variations in overburden thickness inverted from the HTEM data. 


\subsubsection{Bouguer anomaly map comparison without bathymetry}

A comparison of the Standard Bouguer and the BedTopo Bouguer maps, without a bathymetry correction, can be seen in Figure 5.6.2. The largest difference between the two figures is an $8 \mathrm{mGal}$ static shift increase in intensity on the BedTopo Bouguer anomaly map, which is due to the presence of less dense overburden in place of bedrock. Otherwise the two figures are nearly identical to each other with only minor changes in intensity near Features B, C, and E. This suggests that an overburden correction performed using $1 \mathrm{~km}$ grid averaged data is of insufficient resolution to adequately portray any changes that are a result of overburden thickness variations on a $500 \mathrm{~m}$ grid Bouguer anomaly map. It could alternatively suggest that most changes in overburden thickness are too small andcreate gravity anomalies that are too low in intensity to be visible on a Bouguer Anomaly map.

A comparison of the first-vertical derivative (FVD) of the Bouguer anomaly maps without the bathymetry correction may reveal more detail, see Figure 5.6.3. Anomalies associated with Features B, C, D, and E display small differences on the maps. Other small differences can be seen in the shape and size of small anomalies in the middle of the map. Of particular interest are the two linear trends merging into the anomaly at Feature B, shown in the dotted black circle in Figure 5.6.3A. In Figure 5.6.3B these linear trends were removed by the BedTopo correction, showing that the anomaly at feature B is more circular. Feature D has changed, the anomaly is now more prominant over the faulting that created a geologic window in that area to expose older bedrock, see Figure 2.5. The boudinage-look of Feature E has also been reduced, where 6 individual anomalies have been transformed into a high ridge with two anomalous peaks. Feature $\mathrm{E}$ is a by-product of not applying a bathymetry correction to the data, 
as Francois Lake in this map is interpreted as bedrock, and so more gravity is reduced in that area creating a gravity high above Francois Lake that mirrors the shape of the lake. An overburden correction partially corrects this feature, which suggests that overburden thickness contributes to this feature. Since an overburden correction is similar to a bathymetry correction it results in a lower gravity reduction than if the overburden was modelled as bedrock. This suggests that some of the peaks in Feature E were created due to a change in overburden thickness.

\subsubsection{Bouguer anomaly map comparison with bathymetry}

A comparison between the Standard Bouguer and the BedTopo Bouguer anomaly maps after bathymetry correction is shown in Figure 5.6.4. The largest difference between maps is a small $2 \mathrm{mGal}$ shift in gravity intensity which can be attributed to the difference in overburden thickness. The difference in amplitude of the static shift here, compared to Figure 5.6.2 (2 mGal vs $8 \mathrm{mGal}$ ) is most likely due to the application of the bathymetry correction which has a larger overall correction effect on gravity intensity due to the size of the correction (there is a much larger difference in density between water and bedrock than between overburden and bedrock), and due to the relatively large area of the lake compared to overburden thickness in the immediate surrounding area. No other differences are detectable between the two maps in Figure 5.6.4. This also supports the theory that an overburden correction performed with HTEM data of low spatial resolution is not detailed enough to illustrate most changes in gravity intensity due to overburden thickness variations on a Bouguer anomaly map. 
A comparison of the first-vertical derivative (FVD) of the Bouguer anomaly maps with bathymetry correction is shown in Figure 5.6.5. There are not as many differences between these two FVD maps as most anomalies have similar shapes and intensities. Only very small

differences can be seen near Features B, C, E, and F. None of these differences are large enough to influence map interpretation. The largest difference between both maps can be seen around Feature F, which is largely due to the bathymetry correction. Here the FVD Standard Bouguer map does a better job at correcting the north trending gravity high anomaly directly to the north and south of Feature F, and mostly restores the anomaly as a single feature within the white circle at Feature F. On the BedTopo FVD Bouguer map, the anomaly is mostly restored but it seems that the overburden correction in this area is incorrect. This is most likely due to an overestimation of overburden thickness in this area, which led to a larger correction of gravity than necessary. Since this same feature was not completely corrected on the FVD Standard Bouguer map, the bathymetry data in this area may also be inaccurate, or the geologic feature that created the north trending gravity high anomaly has been partially eroded during lake formation.

\subsubsection{Comparisons between Bouguer anomaly and their FVD maps}

There are some features that are interesting to compare between maps of Bouguer anomaly and their FVD equivalent. Feature A for instance is a rocky ridge, interpreted from satellite photos, where the HTEM inversion was affected by a conductive anomaly hosted in the bedrock as well as from 3D effects resulting from measurements being taken on the slope of a ridge. These combined to contribute to an overestimation of the thickness of the overburden. When this excess overburden thickness was corrected for, it resulted in no visible change in the 
shape of the anomaly in either the Bouguer anomaly maps, or in their respective FVD's, compare anomalies in the area of Feature A across Figures 5.6.2-5.6.5. If the overburden thickness is drastically increased from the Resistivity structure inversion of $\sim 50 \mathrm{~m}$ to $\sim 230 \mathrm{~m}$ result from the resistivity reversal inversion, with the overburden thickness and bathymetry corrections applied, the anomaly still remains unchanged, see Figure 5.7.1. This suggests that the gravity high anomaly is hosted in the bedrock as even large changes in overburden thickness have little effect on this anomaly. The conductivity may be due to a specific conductive bedrock unit, a change in composition of the bedrock, or an intrusion.

\subsection{Bouguer results calculated from resistivity reversal inversion}

Minor differences are observed between the resistivity reversal Bouguer anomaly maps with bathymetry corrections applied, compare Figures 5.7.1 A and 5.6.4. The average gravity intensity throughout the map in Figure 5.7.1 has increased relative to the Standard Bouguer map and the BedTopo Bouguer map. This is due to the larger amount of interpreted overburden thickness, See Figure 5.3.1, which when corrected for results in a smaller terrain correction of the observed gravity data due to the lower density of overburden compared to bedrock. Minor differences can also be seen between the maps in the vicinity of Features B, D, and F. Of these, Features B and D show an expected increase in gravity intensity due to the interpretation of a thicker overburden. Feature $\mathrm{F}$ however shows the opposite trend where the gravity intensity is reduced despite an increase in overburden thickness.

Minor differences can also be seen between the FVD maps near Features B, C, D, E and F. Of these features, only B and F show any significant difference, see Figures 5.7.1 B and 5.6.5. 
Feature $\mathrm{F}$ shows that the gravity intensity is changing negatively, shown by the blue low (Figure 5.7.1 B). This low is due to thick overburden, within the black-dashed circles above and below Feature F in Figure 5.3.3, interpreted through HTEM inversion on the banks of Francois Lake immediately to the north and south of the lake at Feature F. The gravity highs to the north and south of Feature F, shown in red in Figure 5.7.1 B within the black-dashed circles, shows that gravity intensity has a stronger high relative to the other FVD maps. This is because these areas were identified, through HTEM resistivity reversal inversions, as overburden with an average thickness of $200 \mathrm{~m}$, as shown in Figure 5.3.3. When an overburden density is applied down to a depth of $200 \mathrm{~m}$ as part of the correction of the observed gravity data, it will result in a smaller gravity correction than the standard data Bouguer correction, as less gravity will be subtracted from the observed data than would have been had the area been interpreted as bedrock. This is due to the average density of overburden, which this study has estimated to be $1.8 \mathrm{~g} / \mathrm{cm}^{3}$ which is $0.85 \mathrm{~g} / \mathrm{cm}^{3}$ less dense than $2.65 \mathrm{~g} / \mathrm{cm}^{3}$ bedrock. Surficial surveys indicate that the overburden is thin, from the presence of till veneer and a water well with a bedrock contact at a depth of $21 \mathrm{~m}$, see Feature F on Figure 5.3.3. Therefore the gravity data was over-corrected resulting in excess gravity intensity. Within Feature F Francois Lake has a depth of $180 \mathrm{~m}$, from bathymetry data, and the water was assigned a density of $1 \mathrm{~g} / \mathrm{cm}^{3}$. The mass of water in this area has been adequately corrected for. However since the both sides of the lake have a larger gravity intensity, due to the over-correction, than the lake itself, the FVD map will show a trough between these two highs once the $2 \mathrm{~km}$ separated gravity lines are interpolated. This effect is minimized with a thinner interpreted overburden, see Figure 5.6.5 B. Such features are useful in identifying problems in accuracy relating tothe determination of overburden thickness through inversion. In this case, the low was created due to the conductive north-south trending anomaly, which 
connects Features A and F, hosted within the bedrock, which led to an over-estimation in the thickness of the overburden, see Figure 5.5.2 and Section 5.5.2.

\subsection{Resolution of overburden thickness}

A problem regarding the HTEM resolution of overburden thickness was highlighted in section 5.5.3 and was found to have influenced gravity correction results, presented in section 5.6. The $4 \mathrm{~km}$ line spacing between HTEM lines means that the data should be gridded with cell size no smaller than around $1 \mathrm{~km}$ (typically $1 / 4$ to $1 / 5$ the line spacing is employed) so as to reasonably interpolate the data between lines when using a minimum curvature algorithm. Unfortunately this limitation complicates the determination of how large a change in overburden thickness needs to be (in depth and in area) in order to be visible, and in order to influence interpretation, on a Bouguer anomaly map.

\subsubsection{Gravity anomalies created from variations in overburden thickness}

A comparison of Feature B on the Bouguer anomaly and FVD maps corrected using resistivity reversal inversions and Resistivity structure inversions provides some information on how large a lateral change in overburden thickness is required to affect a Bouguer anomaly map generated from data flown by an airborne gravity survey with $2 \mathrm{~km}$ line spacing. Feature B is a

circular ridge composed of rhyolite within the Endako Formation of the Nechako Plateau Group, see Figure 2.5, that was dated at 23.3-56.5 Ma (Massey et al. 2005). A comparison between the extent of this rhyolite unit, see Figure 2.5, and the mapped conductivity response that correlates to areas of thicker overburden, see Figures 5.3.3 and 5.5.2, shows that this rhyolite unit is not related to any resistivity features. It is covered by till veneer and has 3 mapped bedrock outcrops 
(Arnold and Ferbey 2016). The resistivity reversal inversion, see Figure 5.3.3, indicates that Feature B lies within an area having an overburden thickness of 200-210 m. The Resistivity structure inversions, however, interpreted Feature B to have a thickness of 30-39 m.

The Bouguer anomaly maps from the Resistivity structure inversions, without bathymetry corrected, see Figure 5.6.2 shows that when feature B is corrected for an overburden $\sim 35 \mathrm{~m}$ thick, that a slight change is visible where a north-trending linear anomaly disappears from Figure A to be replaced by a west-trending anomaly in Figure B. When a bathymetry correction is applied, see Figure 5.6.4, the north-trending anomaly reappears along with an even smaller west-trending anomaly. This suggests that a change in overburden thickness of $\sim 35 \mathrm{~m}$ is sufficient to be visible on a Bouguer anomaly map, but it is unlikely that such a small anomaly could affect map interpretation. This is supported by comparing Feature B on the FVD maps in Figures 5.6.3 and 5.6.5 which together show that a BedTopo correction has little effect on Feature B. Figure 5.7.1 B shows that an increase in overburden thickness to $200 \mathrm{~m}$ modifies the anomaly by $7 \mathrm{mGal}$ on the Bouguer anomaly map, and by 16 Eötvös on the FVD map. At this point, the anomaly could negatively affect geological interpretation. This suggests that a change in overburden thickness needs to be on the order of $100 \mathrm{~m}$ in order to generate an anomaly, with an amplitude of roughly $3.5 \mathrm{mGal}$ that is visible on a Bouguer anomaly map. This finding is supported by the overburden gravity anomalies modelled in Figures 1.1 B, and C which show that anomalies are on the order of 2-3 mGal for overburden thickness changes that are larger than $100 \mathrm{~m}$. 


\subsubsection{Overburden gravity anomalies at higher resolution}

Previous sections showed that only large changes in overburden (thickness $>100 \mathrm{~m}$ ) would be visible on a Bouguer anomaly map due to the use of a $1 \mathrm{~km}$ cell size for processing the DEM, overburden thickness, and bathymetry maps for gravity correction. If the data was processed assuming a cell size of $100 \mathrm{~m}$, higher resolution changes in overburden thickness can be compared between the Standard and BedTopo Bouguer anomalies in profile view. Figure 5.8.1 shows a profile comparison along line 7420 (L7420) of Bouguer anomalies calculated using terrain maps with a $1 \mathrm{~km}$ cell size, from Figure 5.6.1, and with Bouguer anomalies calculated with a $100 \mathrm{~m}$ cell size. The Figure shows the increase in resolution for the DEM (green line) and the $100 \mathrm{~m}$ BedTopo profile (grey line) contrasted with the $1 \mathrm{~km}$ cell size BedTopo profile (dotted orange line). Also compared are the 30 s, 40 s, and 56 s low-pass cosine filters applied to filter out higher frequency GPS noise, where the difference between the $100 \mathrm{~m}$ Standard BA $30 \mathrm{~s}$ and the $100 \mathrm{~m}$ Bedtopo BA $30 \mathrm{~s}$ is the BedTopo corrected effect of overburden thickness. The high frequency oscillations affecting the $100 \mathrm{~m}$ BedTopo $30 \mathrm{~s}$ Bouguer anomaly and the $100 \mathrm{~m} 30 \mathrm{~s}$ Standard Bouguer anomaly profiles are created mostly from GPS noise due to positioning error. Minor differences between these two profiles are due to changes in overburden thickness. Applications of along-line filters, as described in Section 4.9.2, are designed to remove GPS noise using a low-pass cosine filter. These two gravity profiles were filtered with a $1380 \mathrm{~m}, 30 \mathrm{~s}$, low-pass cosine filter in order to isolate the contribution of overburden to the gravity signal.

Figure 5.8.1 shows that corrections for changes in overburden thickness result in only minor differences between the $100 \mathrm{~m}$ BedTopo $30 \mathrm{~s}$ and $100 \mathrm{~m}$ Standard $30 \mathrm{~s}$ Bouguer anomaly 
profiles. These minor differences resemble static shifts in the data as opposed to individual anomalies, such as those modelled in Figure 1.1. Furthermore, the gravitational contribution of the overburden is much less than the amplitude of GPS noise and is filtered and removed by the same low-pass line filters applied to remove GPS noise. This can be seen by the application of the $40 \mathrm{~s}, 1840 \mathrm{~m}$ low-pass filter shown by the black-dotted line, which shows many of the smaller wavelength features to be completely removed from the data, such as the gravity low anomaly at X-coordinate $35.4 \mathrm{~m}$, shown by the blue and fuchsia lines. By the time the $56 \mathrm{~s}$ linefilter is applied along with the grid interpolation with a larger cell-sized, high frequency changes within the overburden have been averaged over a larger area and reduced in amplitude and resembles a static shift in the gravity data. A static shift in data is a minor error and may not interfere with the interpretation of a single feature such as a bedrock hosted gravity anomaly.

\subsubsection{Overburden density}

Table 2.2 shows a sediment density range of $1.6-2.6 \mathrm{~g} / \mathrm{cm}^{3}$ depending on clast size and water content. Since the overburden is composed of sequences of sediment that change in clast size, the density of the overburden can vary depending on location and clast assortment. While the range in density is large, the range in average density may not be, and the discrepancy in density due to a change in sediment content within the overburden may not be significant enough to be visible on a Bouguer anomaly map, depending on map resolution and line spacing. This is supported by Figure $1.1 \mathrm{C}$, which shows that a change in density of $0.85 \mathrm{~g} / \mathrm{cm}^{3}$ with the dimensions $25 \mathrm{~m}$ by $200 \mathrm{~m}$, see blue curve in Figure $1.1 \mathrm{C}$, results in a change of less than 1 mGal on a Bouguer anomaly map. Smaller variations in density created from changes in sediment density, within that 25-30 m of overburden thickness, would only have a small effect 
on the total gravity contribution of the overburden. A doubling in the thickness of overburden from $25 \mathrm{~m}$ to $50 \mathrm{~m}$, see Figure $1.1 \mathrm{C}$, only results in a $0.5 \mathrm{mGal}$ increase in gravity intensity. Changes in sediment type within the $25 \mathrm{~m}$ column of sediment, following the values in table 1.2, will not have as large of an effect on the amplitude of gravity as doubling the amount of sediment from 25 to $50 \mathrm{~m}$. Since a $1 \mathrm{mGal}$ change in gravity intensity is not visible in the Bouguer anomaly maps in Figure 5.6.2 or 5.6.4, density differences within the overburden from changes in sediment type would have to cover a larger area with a greater thickness, or have a much larger density discrepancy, in order to be visible on a Bouguer anomaly map.

\subsection{Gravimeter noise-floor}

The SGL AIRGrav system is capable of rendering gravity data with noise levels as low as $0.2 \mathrm{mGal}$ for half-wavelengths as low as $700 \mathrm{~m}$. To achieve this, low pass filtering is applied to gridded data so as to stack common signal from adjacent lines and cancel out random noise. The tighter the survey line spacing is, the less filtering is required to achieve equivalent degrees of noise reduction, or alternatively the noise can be reduced for the same degree of filtering (Sander et al. 2003). For example, halving the line spacing results in a reduction of noise by a factor of $\sqrt{2}$ if the filter length is not changed. For a single profile of airborne gravity data that does not benefit from this process, noise levels are only reduced by low pass filters applied to the single profile only, with no noise cancellation applied. Under these circumstances, a 56 second low pass filter equivalent to $2576 \mathrm{~m}$ for an aircraft travelling at $46 \mathrm{~m} / \mathrm{s}$, see Table 2.1 (M. Bates, SGL, personal communication) typically results in data with a standard deviation of $0.537 \mathrm{mGal}$ from a pre-established ground truth average. Two-standard deviations of noise, $\sim 1 \mathrm{mGal}$, is roughly equal to the modelled change in gravity intensity for a change in bedrock topography or 
overburden thickness, see Figures 1.1 A and C. There is therefore a limit on the resolution of airborne gravimeter systems at detecting changes in overburden thickness that is a function of the area, thickness, and density contrast between the overburden and the bedrock. For instance from Figure 1.1 A and C, the AIRGrav system with a $56 \mathrm{~s}$ filter applied should be able to resolve changes in overburden thickness that are approximately $30 \mathrm{~m}$ or larger. This reduces the resolution requirement for a BedTopo correction of gravity data, as gravitational acceleration contributions from near-surface variations in overburden thicknesses, approximately $30 \mathrm{~m}$ or less, may be obscured by GPS noise. This is supported by results presented in Section 5.8 which show that an overburden thickness change of $35 \mathrm{~m}$ is barely visible on a Bouguer anomaly map.

Due to the resolution limitations of airborne gravimeters to changes in overburden thickness, TEM systems that are not typically considered for overburden thickness corrections may have an application in areas where lateral changes in overburden thickness exceed $30 \mathrm{~m}$ and where the size of the basin is small enough to create an anomaly as opposed to a static shift in the gravity data. For instance a method to invert for the conductivity-thickness of the overburden using MegaTEM survey data inverted using a 2-layer model combined with measured conductance from geotechnical boreholes and applying cokriging to estimate the thickness of the overburden from the conductivity-thickness was found to be accurate with a RMS of $10 \mathrm{~m}$ (Chouteau et al. 2013). This provides an application for the MegaTEM system to be used as a dataset for the generation of an overburden thickness map for BedTopo gravity corrections, so long as GPS noise remains a limitation for airborne gravimeters. 


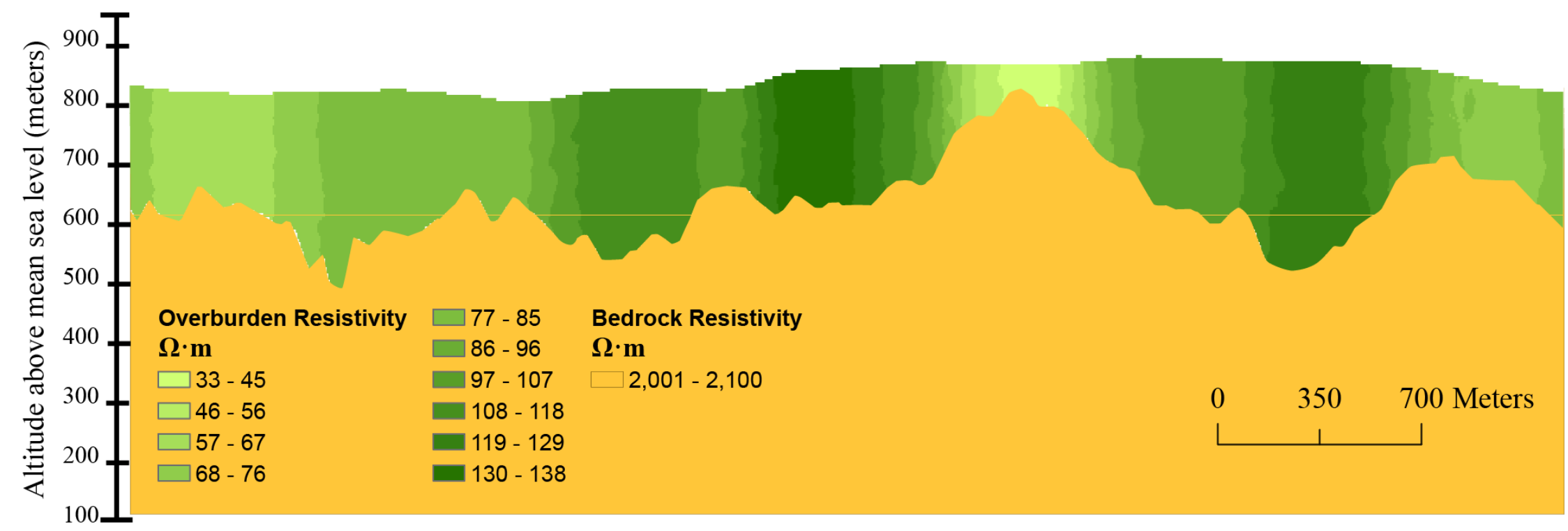

Figure 5.1.1: HTEM line 7240 overburden thickness cross-section

Resistivity-thickness profile created from an unconstrained 2-layer layered-earth inversion of 1D HTEM data. Overburden (in green) is overlying bedrock (in yellow). Overburden resistivity varies smoothly from sounding to sounding. Bedrock resistivities in this area are uniform. 

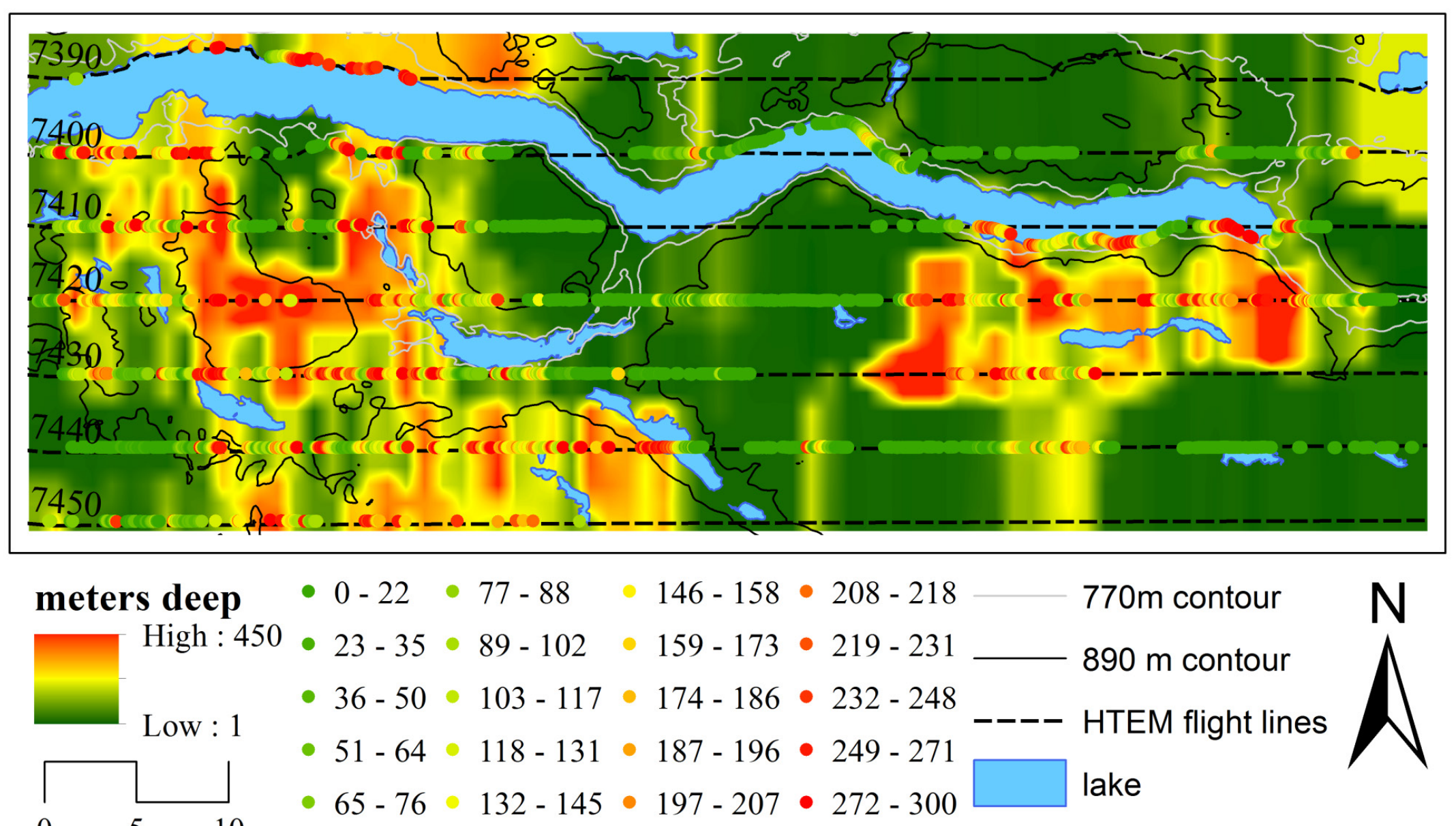

\section{Kilometers}

Figure 5.2.1: HTEM overburden thickness map from multi-layer inversion

Thicker overburden is shown as red, orange, and yellow. HTEM lines shown as dashes where individual HTEM station inversion results are shown as quantified coloured dots. Figure is based on 2-, 3-, and 4-layer inversions, see Section 3.5.2. Circles indicate HTEM stations that inverted successfully, gaps indicate areas where inversion was not successful using the models in Figure 4.4.1 A. Interpolation was done using standard semivariogram spherical kriging. Meters deep indicates the thickness of the overburden layer from the surface. 


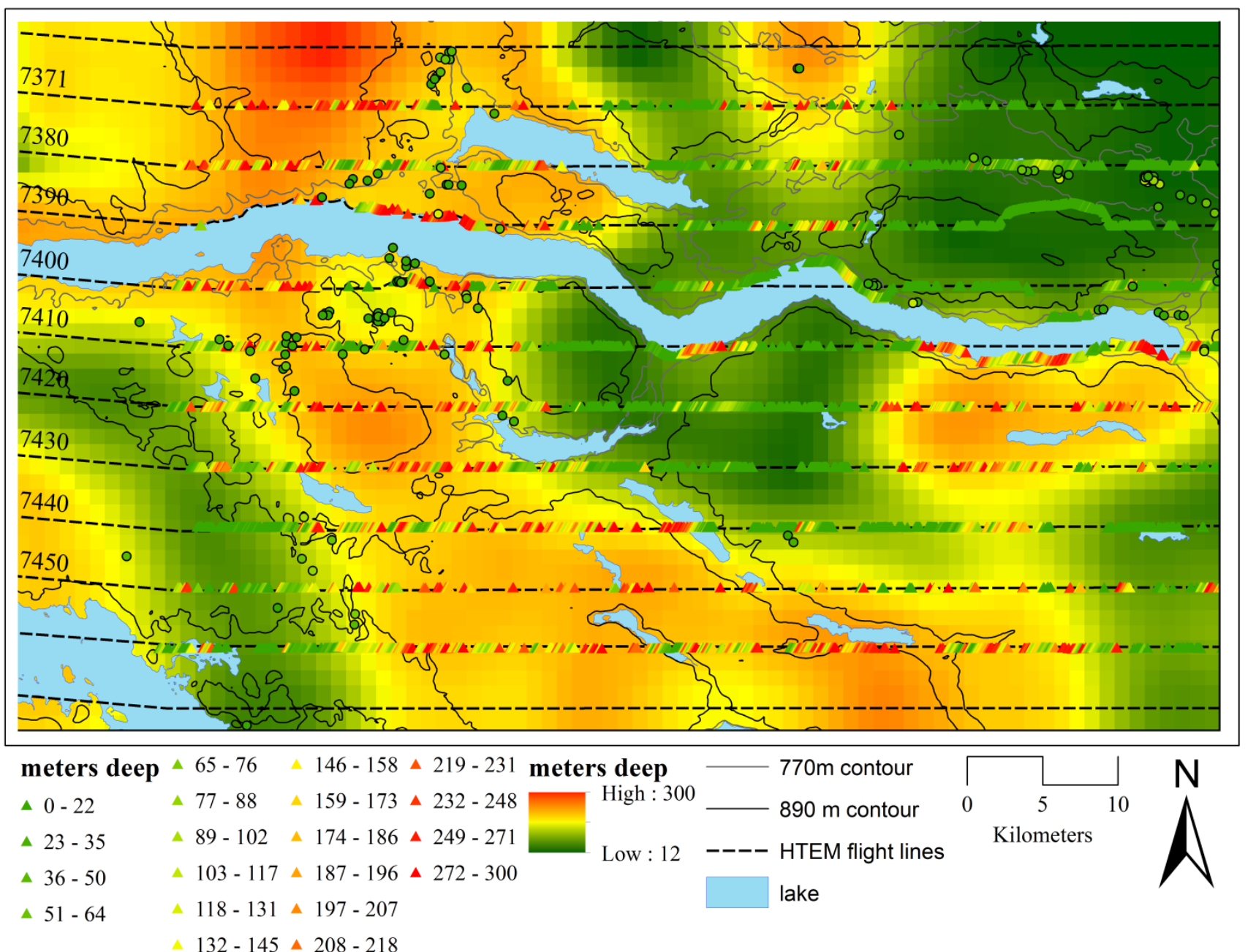

Figure 5.3.1: HTEM overburden thickness map from inversions including resistivity reversals

Thicker overburden is shown by red, orange, yellow. Figure is based on inversion models shown in Figure 4.4.1 B, see Section 4.5. Triangles indicate HTEM stations that inverted successfully; colour indicates the inverted thickness of the overburden in meters. Missing stations, shown by the gaps between triangles where the black hashed line runs, indicate areas where HTEM stations did not invert successfully. 


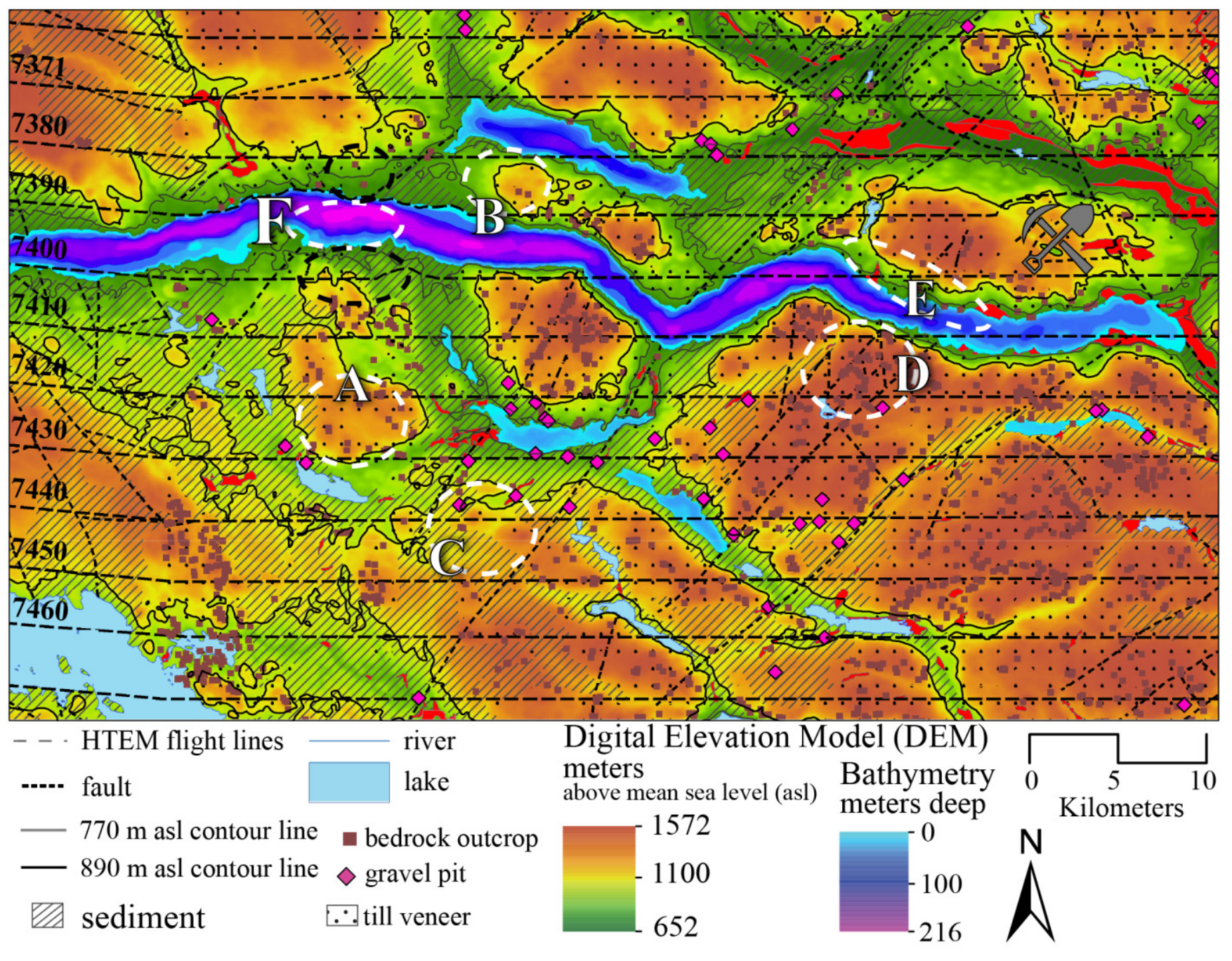

Figure 5.3.2: Surficial geology overlaid on DEM map

Map indicates the location of bedrock outcrops and till veneer. Private and public gravel pits have also been marked with pink triangles, which indicate areas where sand-, gravel-, and pebblesized sediment have been sorted and deposited (Matheson et al. 1996). The sediment layer map is a $1: 250,000$ scale map made of polygons that indicate the locations of unconsolidated Quaternary sediments within the study site (Massey et al. 2005). The highlighted red areas mark where glaciofluvial and glaciolacustrine sediments were observed and mapped by geologists (Plouffe and Mate 2001, Plouffe and Levson 2001, Mate and Levson 2001). White letters indicate features of interest for Bouguer correction analysis. Contour lines indicate estimated highest elevation and extent of fluvial and lacustrine glacial sediment based on published surveys. See Figure 2.1 for source data. 


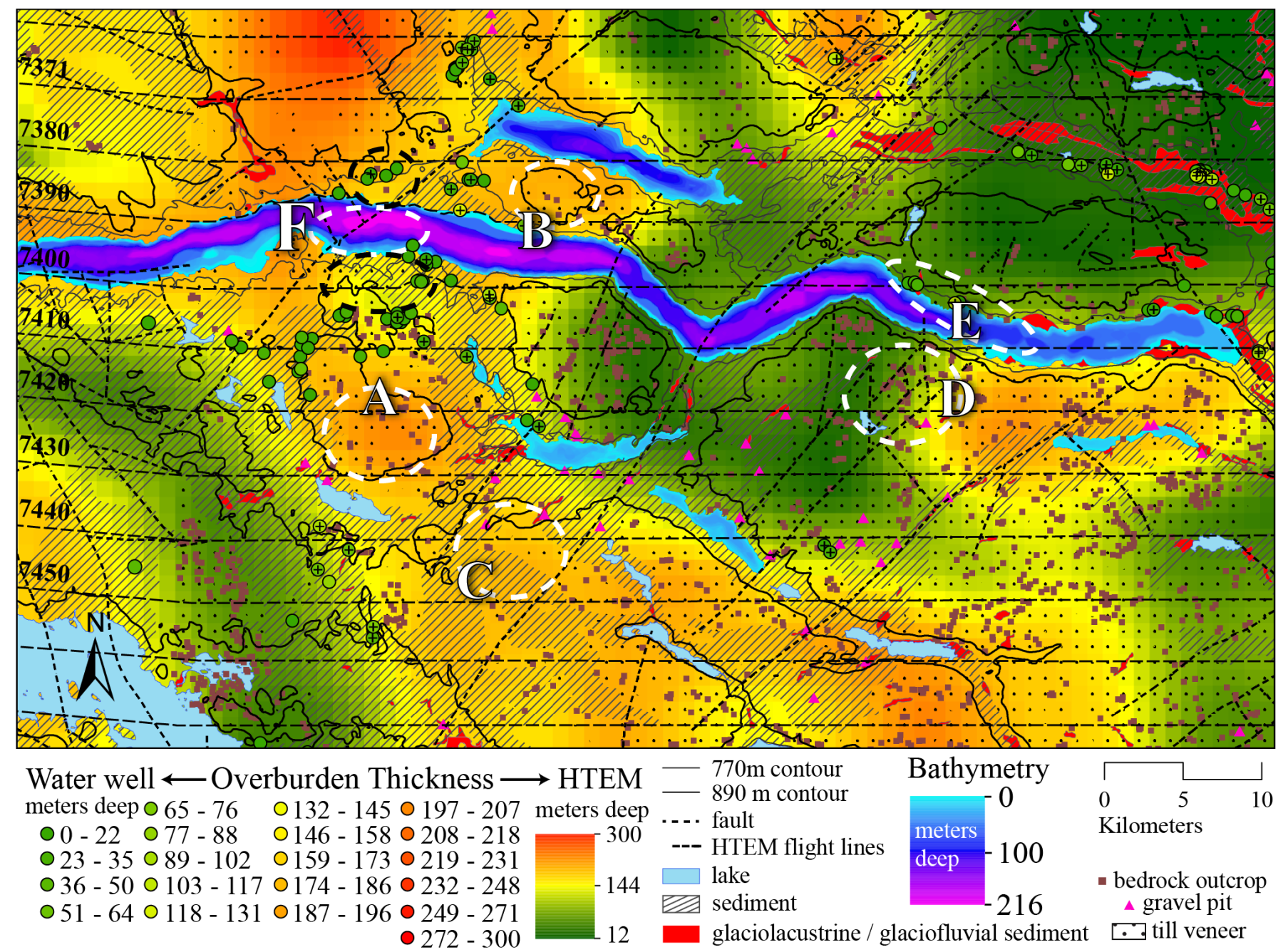

Figure 5.3.3: Surficial geology overlaid on overburden thickness map

HTEM overburden thickness map, generated from results of inversions including resistivity reversals, compared to DEM overburden thickness indicators and water well records. Wells marked with a cross did not contact bedrock. Contour lines indicate estimated highest elevation and extent of fluvial and lacustrine glacial sediment based on published surveys. See Figure 2.1 for source data. 


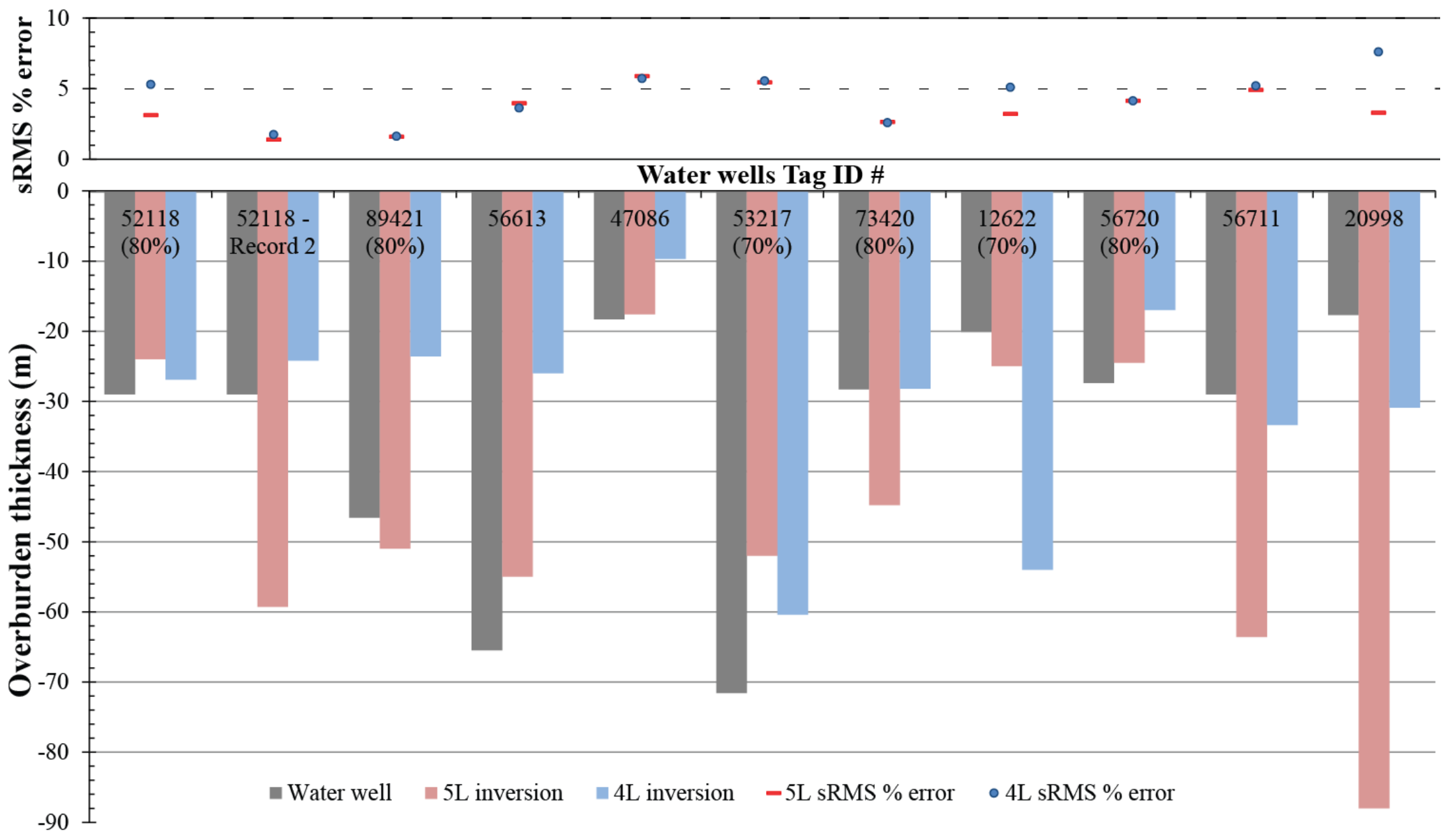

Figure 4.5.1: Figure shows inversion results obtained near water wells. Inversions were conducted using starting models shown in Figure 4.2.1, only 4- and 5-layer results are shown. sRMS \% error for each inversion, is indicated in the graph at the top, a lower value is better. Water well stations where the inversion result from the starting model with the lowest sRMS is chosen and where the result is within $70 \%$ or $80 \%$ of the known overburden thickness is indicated. 


\begin{tabular}{|l|l|}
\hline Location information UTM NAD83 N9 & Geology information \\
Flight line station & Bedrock: Andesite to dacite volcanic with \\
X: 638416.95 Y: 6044179 Z: $628 \mathrm{~m}$ & welded tuff \\
Distance from well: 62 m & Surficial: unknown \\
& \\
$\begin{array}{l}\text { Wells water station Tag ID \# 53217 } \\
\text { X: } 638386 \quad \text { Y: } 6044125 \text { Z: } 620 \mathrm{~m}\end{array}$ & Well water record: \\
$\begin{array}{l}\text { Depth to bedrock: } \mathbf{7 1 . 6} \mathbf{~ m} \\
\text { Overburden: glacial clay and till } \\
\text { well to HTEM elevation difference: } \mathbf{8 ~ m}\end{array}$ & Bedrock: no comment \\
\hline
\end{tabular}
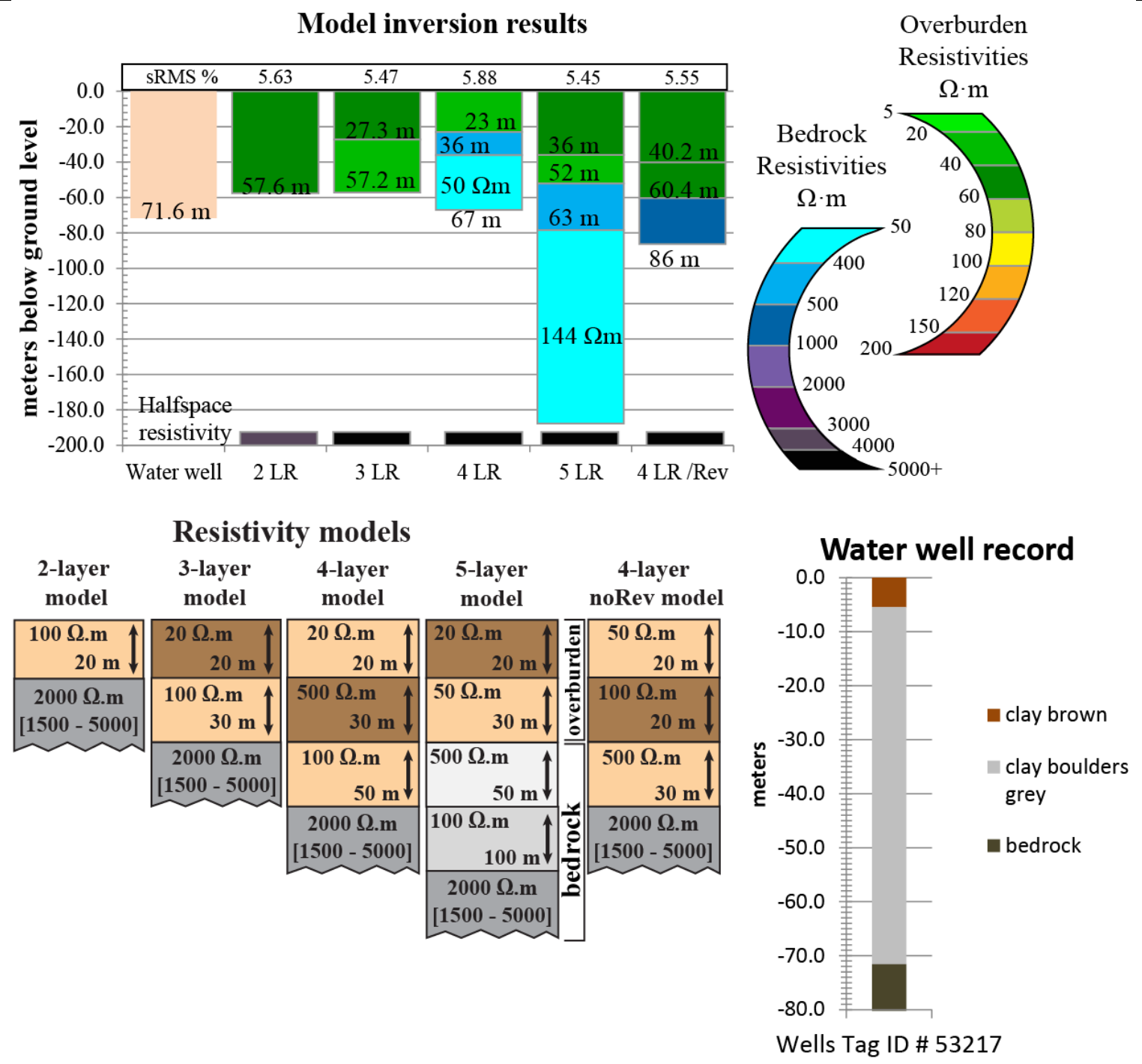

Figure 5.4.2: BC Wells and HTEM inversion record, Block C2, line 6261, BC Wells Tag ID \# 53217 


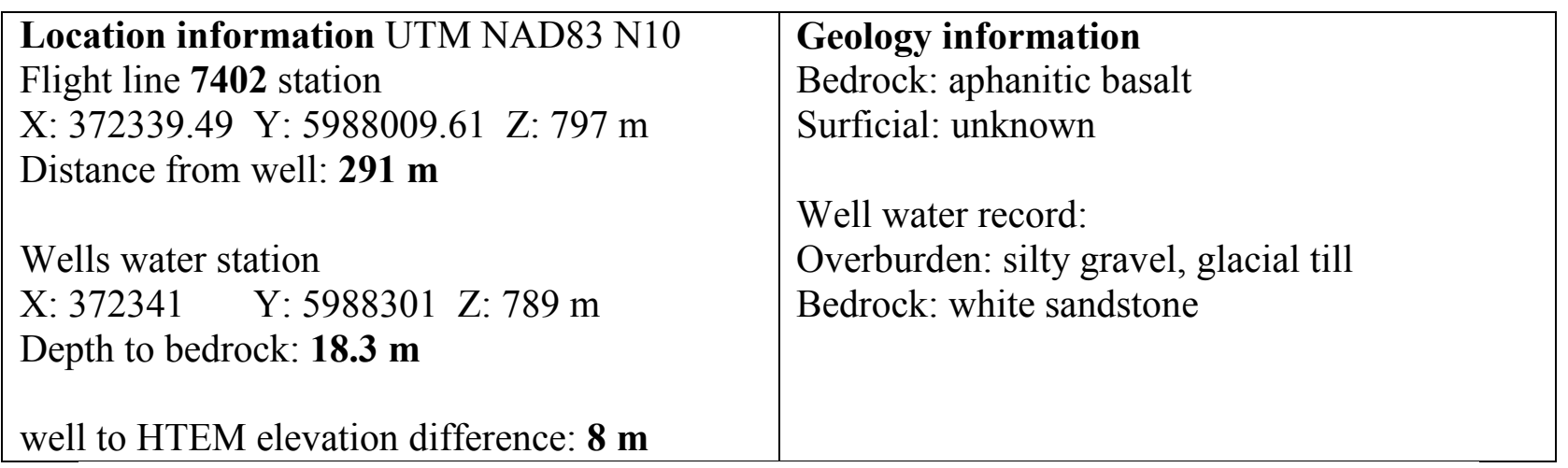

Model inversion results

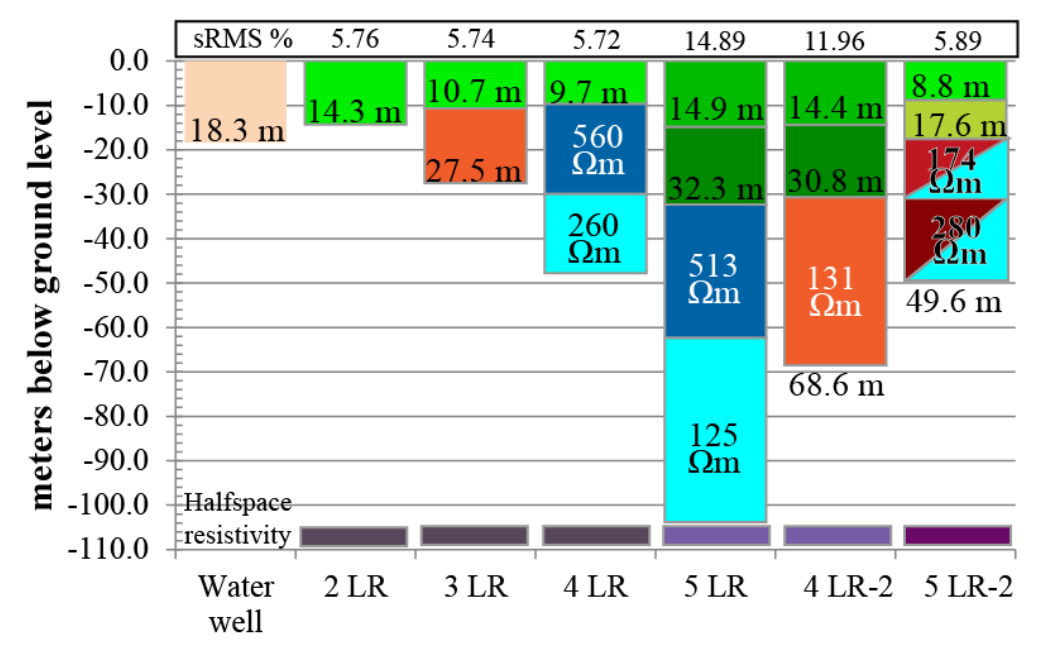

Resistivity models

\begin{tabular}{|c|c|c|c|c|c|c|}
\hline $\begin{array}{r}\text { 2-layer } \\
\text { model }\end{array}$ & $\begin{array}{c}\text { 3-layer } \\
\text { model }\end{array}$ & $\begin{array}{c}\text { 4-layer } \\
\text { model }\end{array}$ & $\begin{array}{c}\text { 5-layer } \\
\text { model }\end{array}$ & & $\begin{array}{c}4 \text { LR-2 } \\
\text { model }\end{array}$ & $\begin{array}{c}5 \text { LR-2 } \\
\text { model }\end{array}$ \\
\hline $\begin{array}{r}100 \Omega . \mathrm{m} \\
20 \mathrm{~m}\end{array}$ & $\begin{array}{r}20 \Omega . \mathrm{m} \\
20 \mathrm{~m}\end{array}$ & $\begin{array}{r}20 \Omega . m \\
20 \mathrm{~m}\end{array}$ & $\begin{array}{r}20 \Omega . \mathrm{m} \uparrow \\
20 \mathrm{~m} \downarrow\end{array}$ & \multirow{2}{*}{ 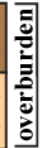 } & $\begin{array}{r}20 \Omega . \mathrm{m} \\
20 \mathrm{~m}\end{array}$ & $\begin{array}{r}20 \Omega . m \uparrow \\
20 \mathrm{~m}\end{array}$ \\
\hline \multirow[t]{4}{*}{$\begin{array}{c}2000 \text { S.m } \\
{[1500-5000]}\end{array}$} & $\begin{array}{r}100 \Omega . m \\
30 \mathrm{~m}\end{array}$ & $\begin{array}{r}500 \Omega . m \\
30 \mathrm{~m}\end{array}$ & $\begin{array}{r}50 \Omega . m \\
30 \mathrm{~m} \downarrow\end{array}$ & & $\begin{array}{r}50 \Omega . \mathrm{m} \\
20 \mathrm{~m}\end{array}$ & $\begin{array}{r}50 \Omega . \mathrm{m} \\
20 \mathrm{~m}\end{array}$ \\
\hline & $\begin{array}{c}2000 \Omega . m \\
{[1500-5000]}\end{array}$ & $\begin{array}{r}100 \Omega . \mathrm{m} \\
50 \mathrm{~m} \downarrow\end{array}$ & $\begin{array}{r}500 \Omega . \mathrm{m} \uparrow \\
50 \mathrm{~m} \downarrow\end{array}$ & \multirow{3}{*}{ 을 } & $\begin{array}{r}100 \Omega . \mathrm{m} \uparrow \\
50 \mathrm{~m} \downarrow\end{array}$ & $\begin{array}{r}100 \Omega . \mathrm{m} \\
50 \mathrm{~m}\end{array}$ \\
\hline & & $\begin{array}{c}2000 \Omega . m \\
{[1500-5000]}\end{array}$ & $\begin{array}{r}100 \Omega . \mathrm{m} \\
100 \mathrm{~m}\end{array}$ & & \multirow{2}{*}{$1000 \Omega . m$} & $\begin{array}{r}100 \Omega . \mathrm{m} \\
100 \mathrm{~m}\end{array}$ \\
\hline & & & 1000 S.m & & & $1000 \Omega . m$ \\
\hline
\end{tabular}

Figure 5.4.3: BC Wells and HTEM inversion record

Record is from Block D Flight Line: 7402 BC Wells Tag ID \#
Overburden

Resistivities
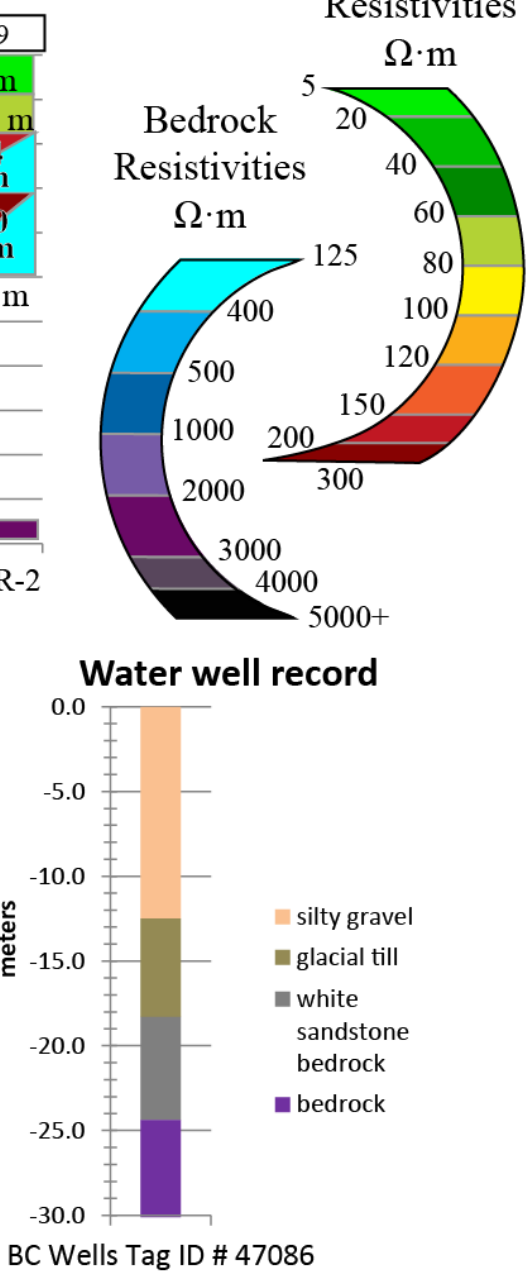


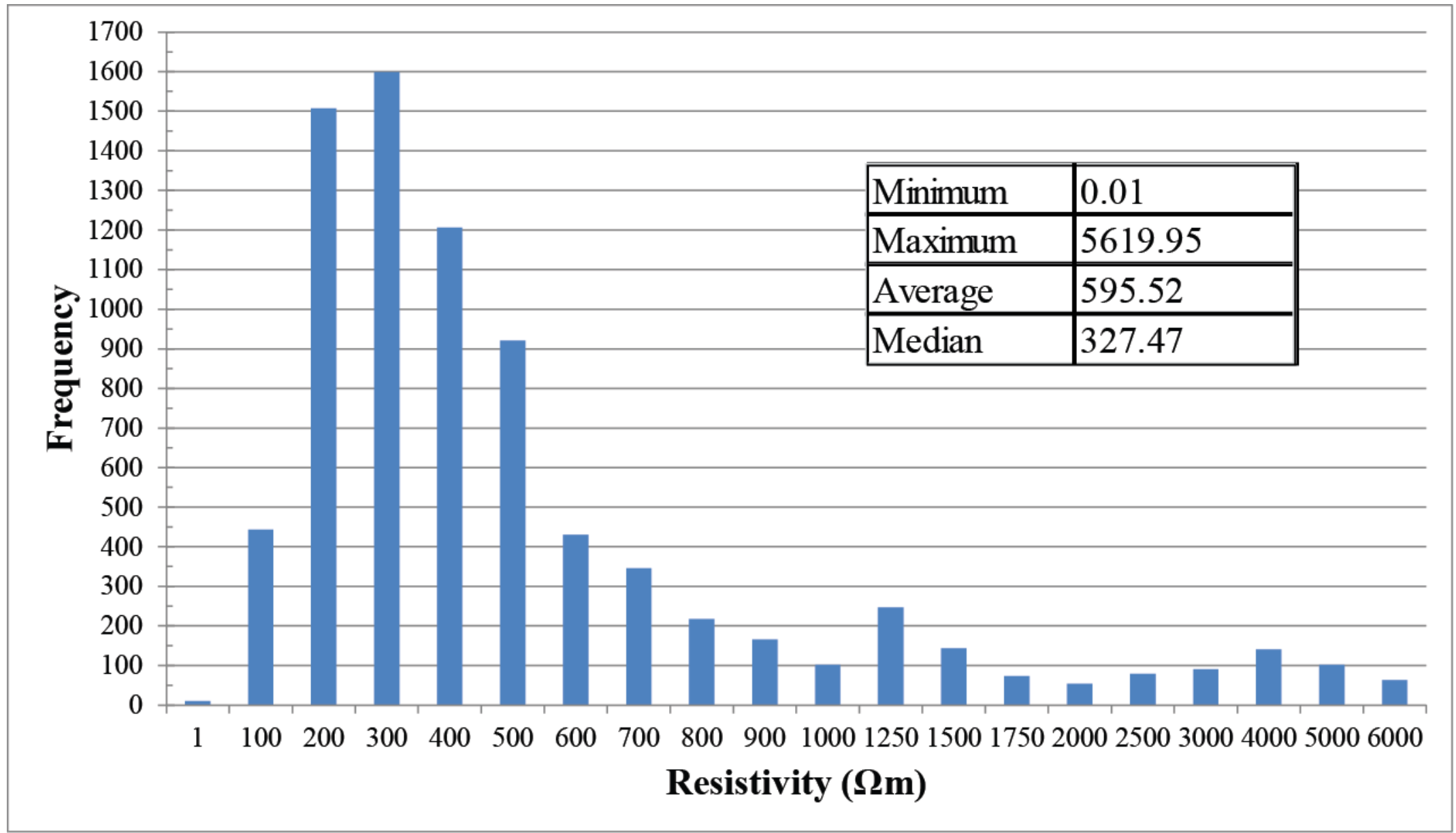

Figure 5.4.4 Bedrock resistivity histogram

Histogram depicts the occurrences of bedrock resistivity layers measured in-situ from 3 geotechnical boreholes within the Nechako Plateau, British Columbia. Bedrock resistivities were measured to have an average of $595.5 \Omega \bullet \mathrm{m}$. Data compiled from the GSC geotechnical boreholes, see Appendix II. 
Table 5.4.5: Water well calibration inversion results by starting model

Table shows comparison of inversion success and accuracy between starting models used for Water well calibration. The resistivity structure inversion methodology applied the lowest sRMS solution among all models tested. Best accuracy for all models shows the accuracy for the best case scenario which chooses the most accurate inversion result regardless of sRMS \% error for that inversion. See Section 5.4 for details. Data is based on inversion results presented in Appendix I. A lower sRMS \% error shows higher accuracy and more consistent results.

\begin{tabular}{|c|cc|}
\hline Starting Model & $\begin{array}{c}\text { Inversion } \\
\text { Success }\end{array}$ & $\begin{array}{c}\text { Accuracy } \\
\text { (sRMS \% error) }\end{array}$ \\
\hline 2-layer & 6 of 13 & 104 \\
3-layer & 5 of 13 & 94 \\
4-layer & 11 of 13 & 55 \\
5-layer & 11 of 13 & 54 \\
Lowest sRMS solution & 11 of 13 & 61 \\
Best accuracy of all models & 11 of 13 & 29 \\
\hline
\end{tabular}




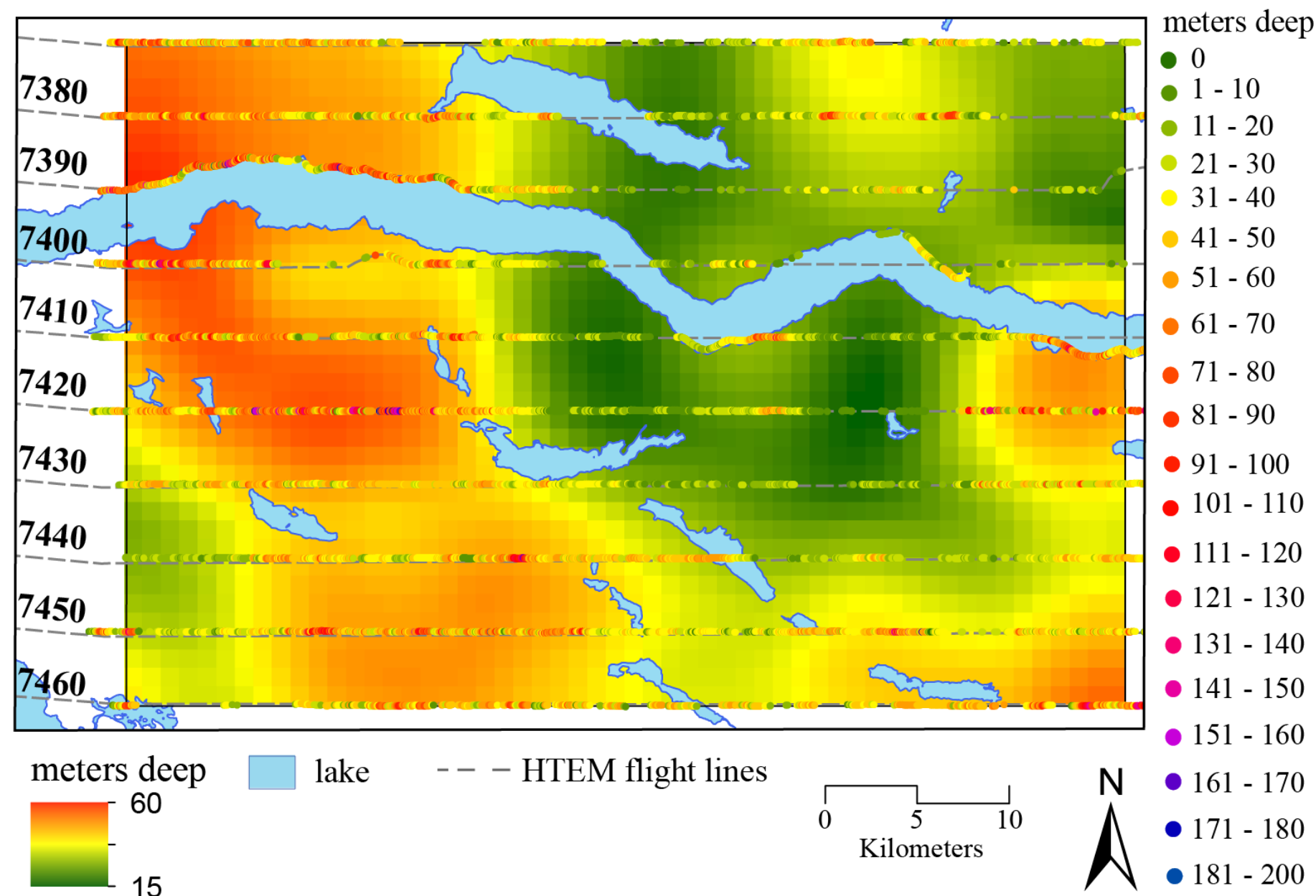

Figure 5.5.1: HTEM Overburden thickness map from Resistivity structure inversions

HTEM overburden thickness map, generated from Resistivity structure inversions, compared to individual inversions of overburden thickness from HTEM stations. Map extents are adjusted to smaller survey size. Note that the graduated colours for the map and the inversions are different but similar as the map values have been averaged over the $1 \mathrm{~km}$ cell size of the map. 


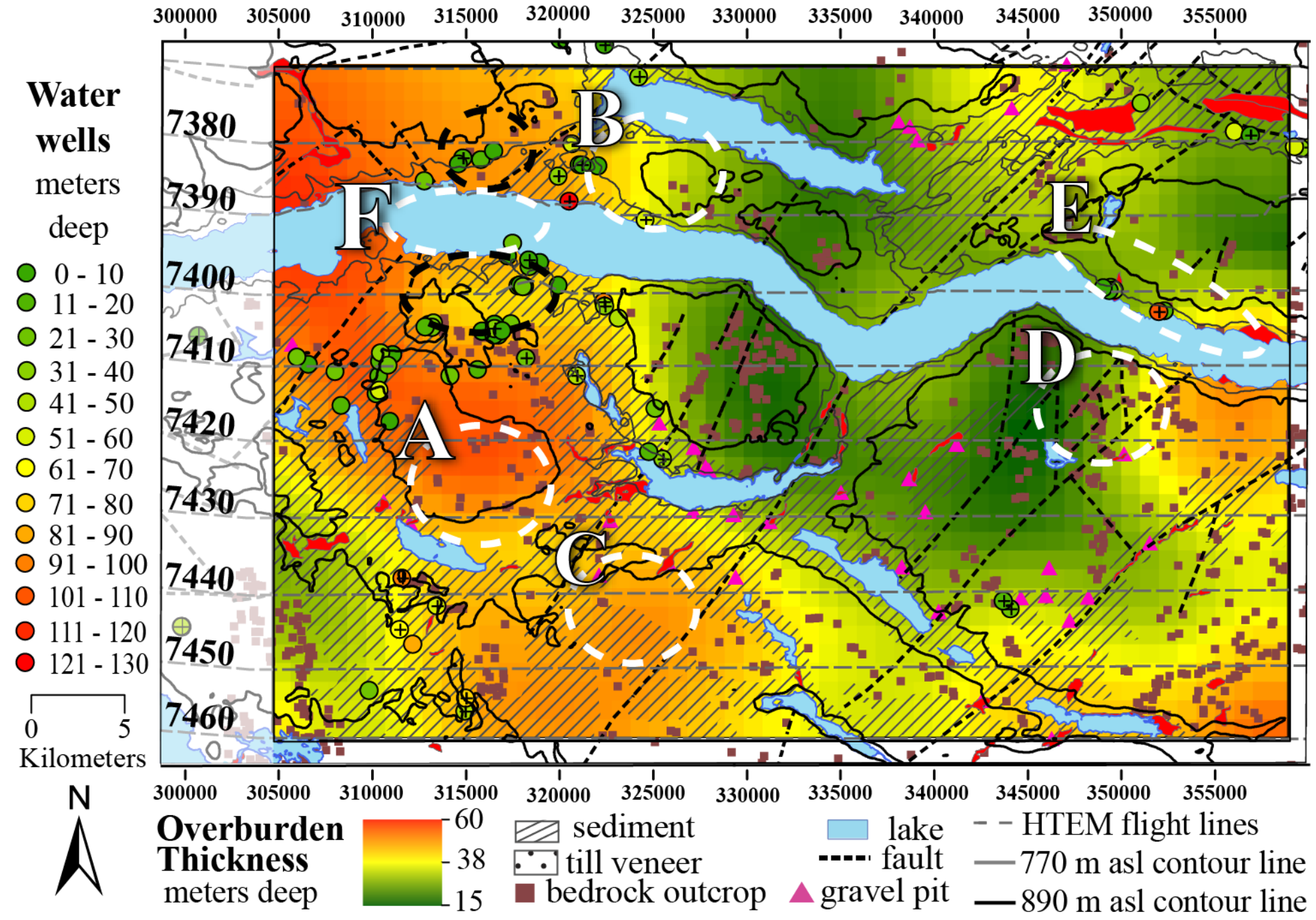

Figure 5.5.2: Surficial geology overlaid on overburden thickness map

HTEM overburden thickness map, generated from Resistivity structure inversions, compared to DEM overburden thickness indicators and water well records. Wells marked with a cross did not contact bedrock. Contour lines indicate estimated highest elevation and extent of fluvial and lacustrine glacial sediment based on published surveys. See Figure 2.1 for source data. 


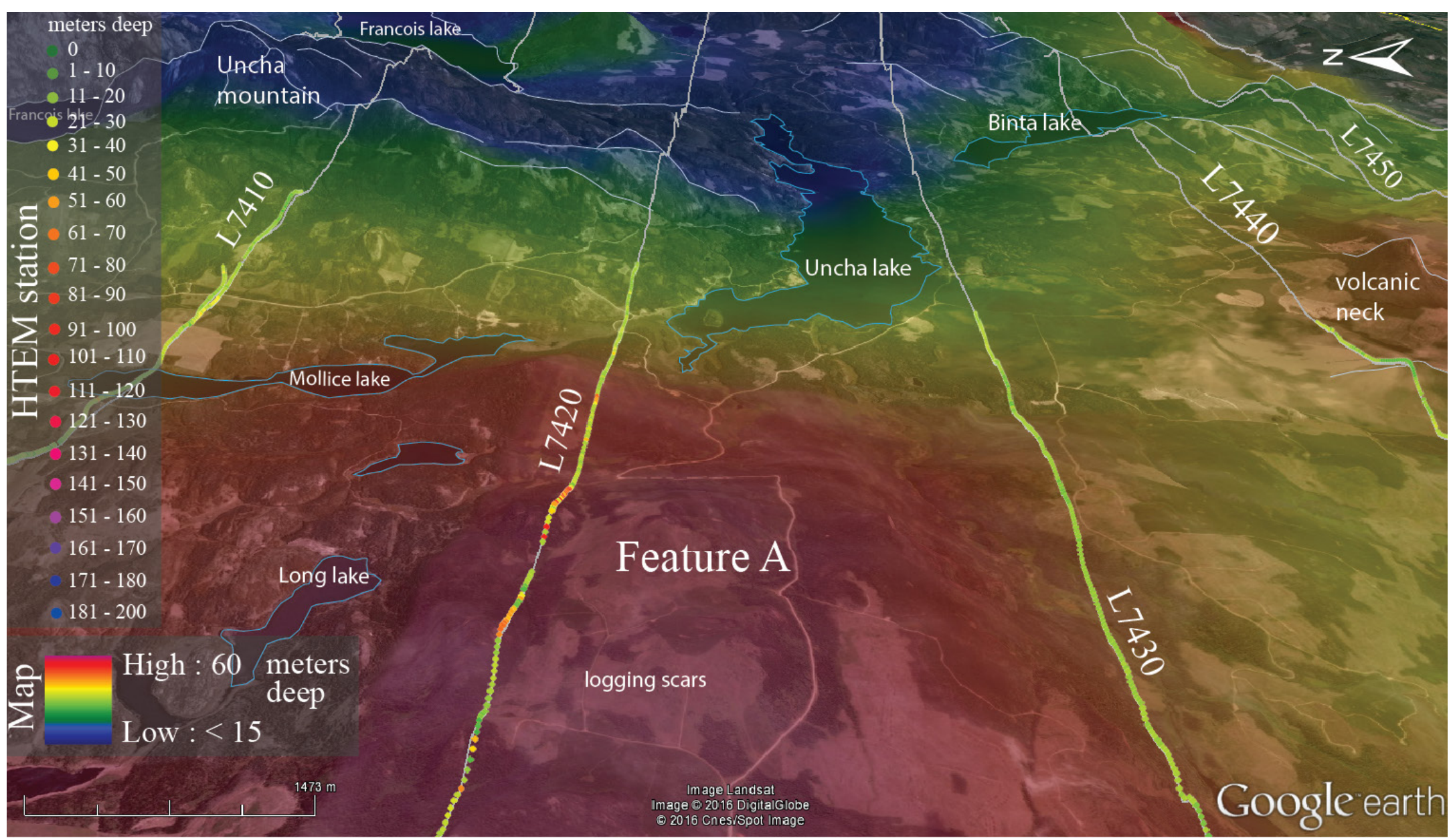

Figure 5.5.3: HTEM overburden thickness map overlaid on a Google Earth satellite image with an east-facing perspective

Perspective shows the center of the study site. Flight line separation is $4 \mathrm{~km}$. Thin (blue) overburden corresponds to angular features (Uncha Mountain) with high relief while thicker overburden (yellow and red) corresponds to smooth features such as a plain or basin. HTEM stations are shown along flight line as coloured dots. Satellite image from Google (Google 2016).

Vertical exaggeration is 3. 


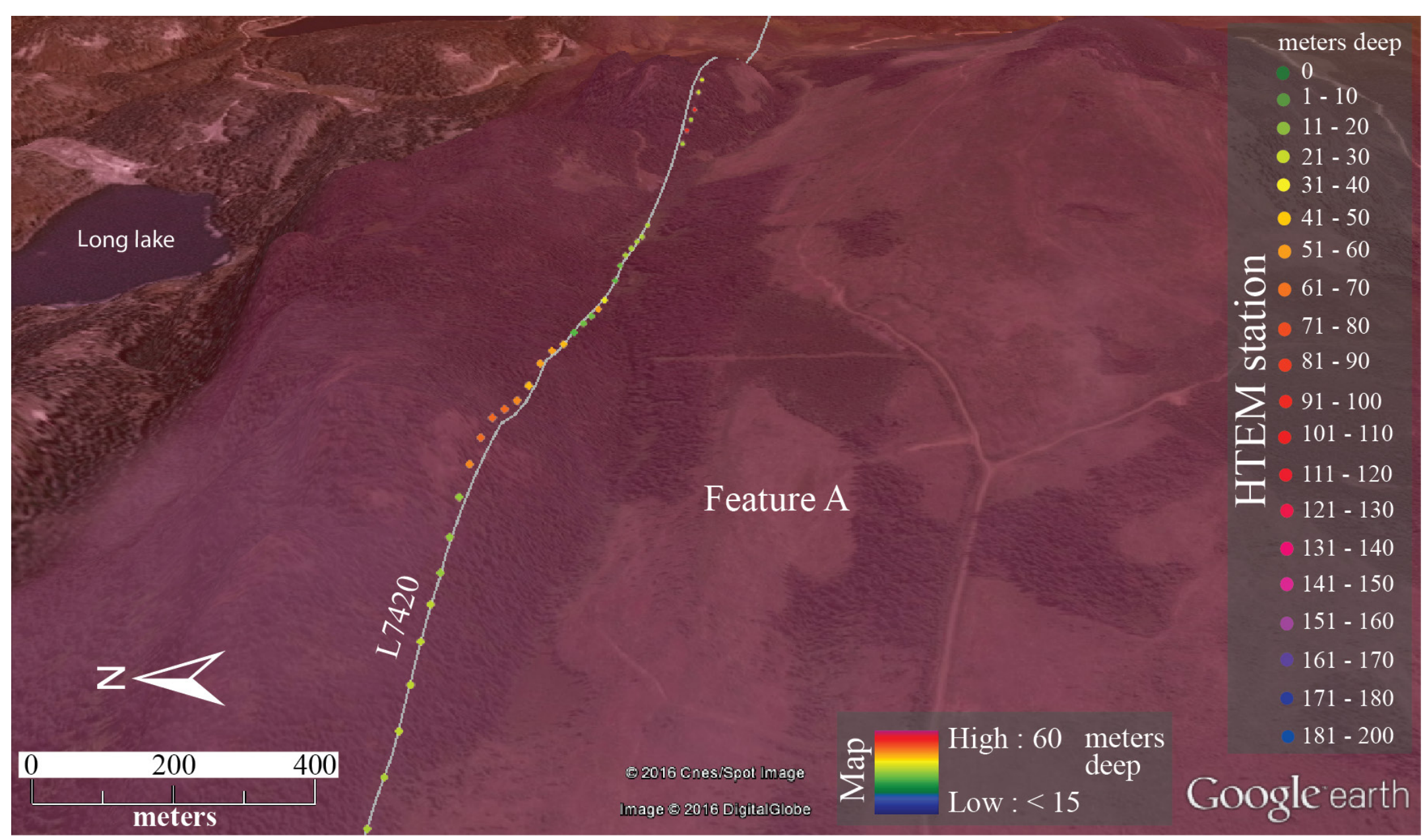

Figure 5.5.4: Line L7420 on satellite image with overburden thickness map

East facing perspective showing HTEM line 7420 and the inversion results of the stations along line. Stations can be seen to be situated on a south facing slope of an east-west striking ridge. (Google 2016) 


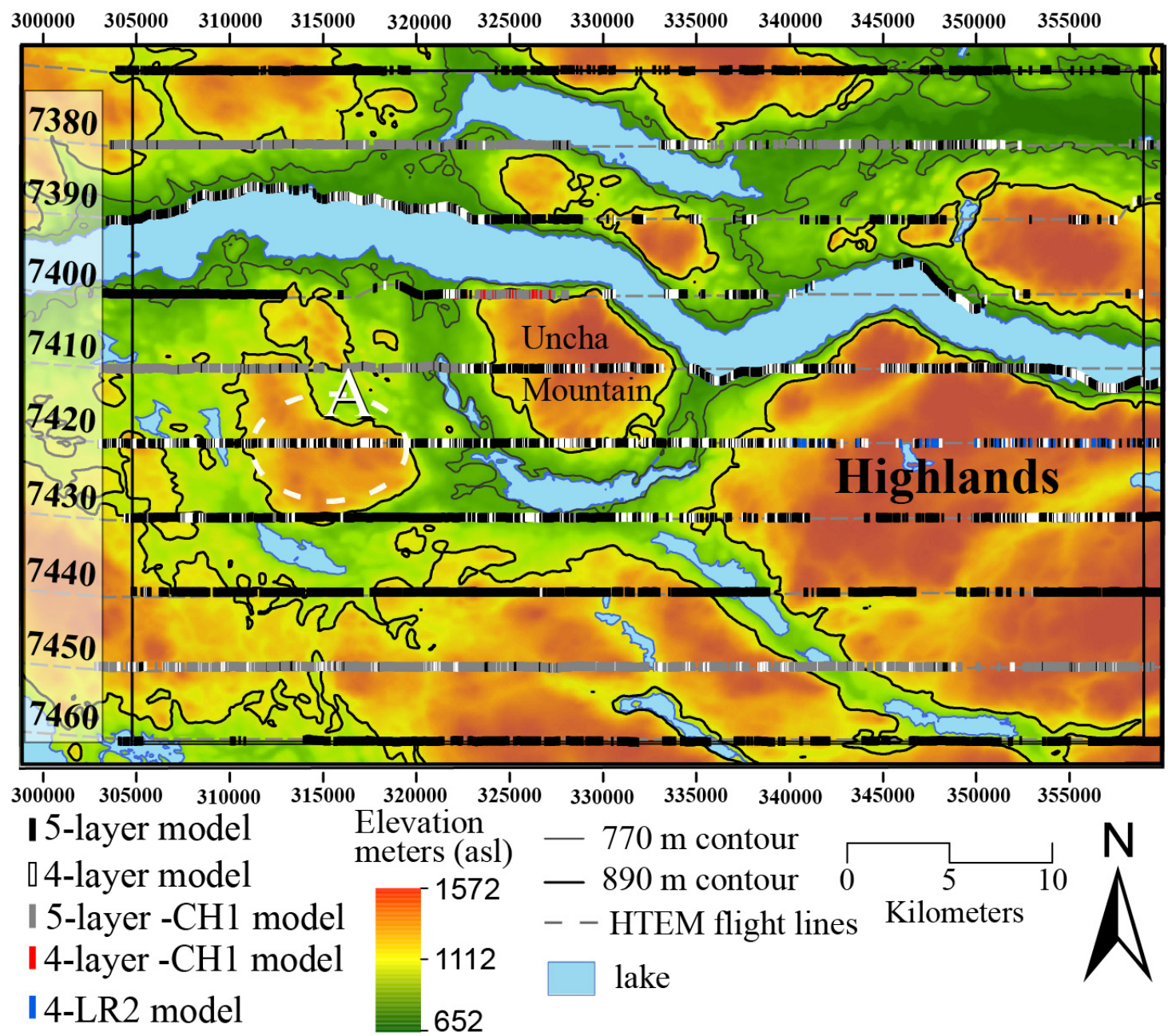

Figure 5.5.5: Location of HTEM inversion starting models by type

Figure shows that the survey area is inverted primarily using the 5-layer and 4-layer starting models, and that these models show a random distribution that is unrelated to topography. The 4LR2 model was only found to be useful on the eastern portion of L7420. Gaps represent areas that did not result in a successful inversion using any of the starting models. 


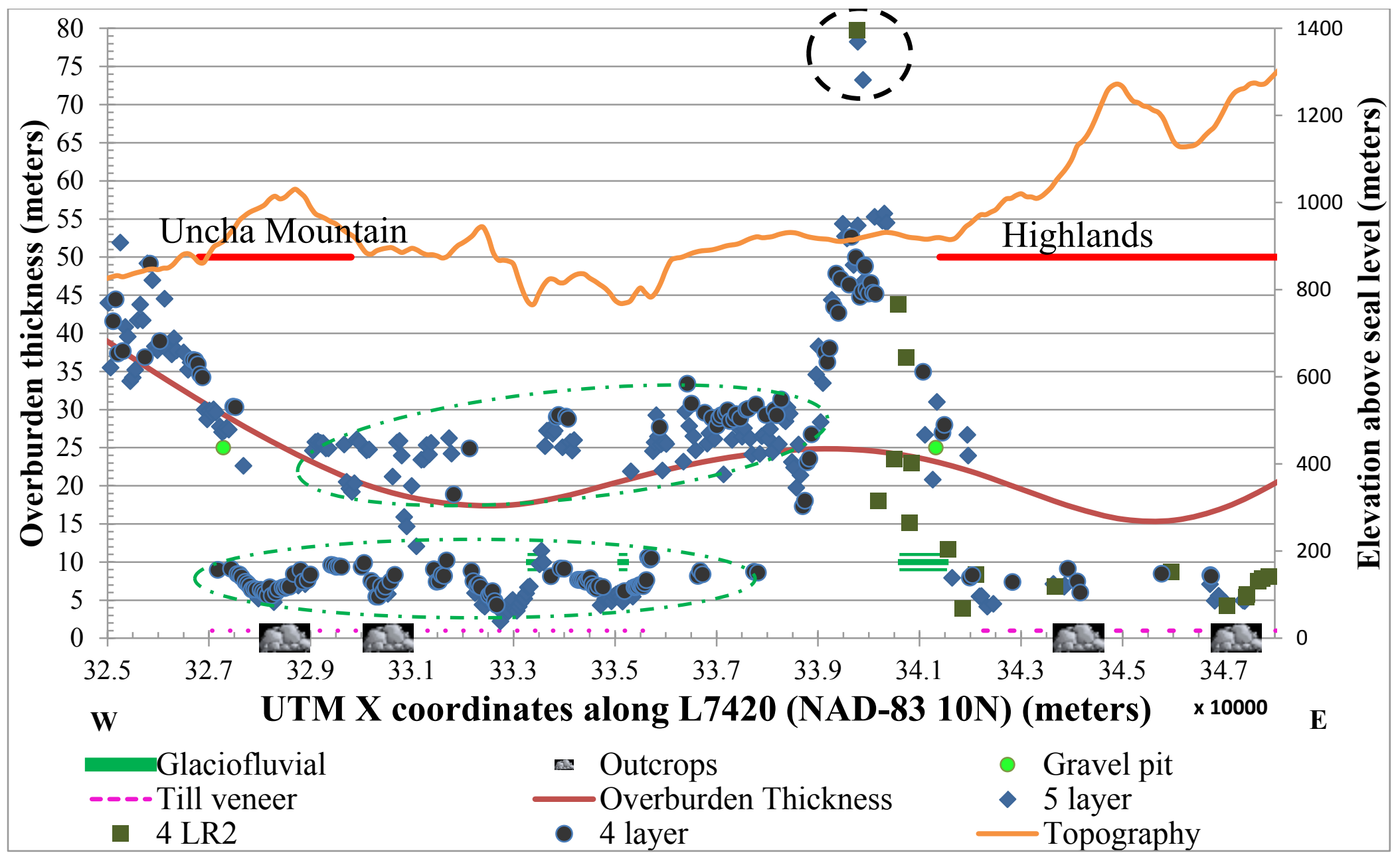

Figure 5.5.6: Inversion results by starting model for a portion of HTEM line $\mathbf{7 4 2 0}$

Figure shows the agreement between adjacent HTEM stations for same, and for different starting models. HTEM stations are $50 \mathrm{~m}$ apart. Overburden thickness indicators are plotted on the graph to illustrate accuracy. Red line represents the grid averaging that occurs when the data is averaged over a $1 \mathrm{~km}$ cell size. Outliers are indicated by dashed circle. Starting models for the 5 layer, 4 layer, and 4 LR can be found in Figure 4.6.1. Topography is plotted on the right-axis. 


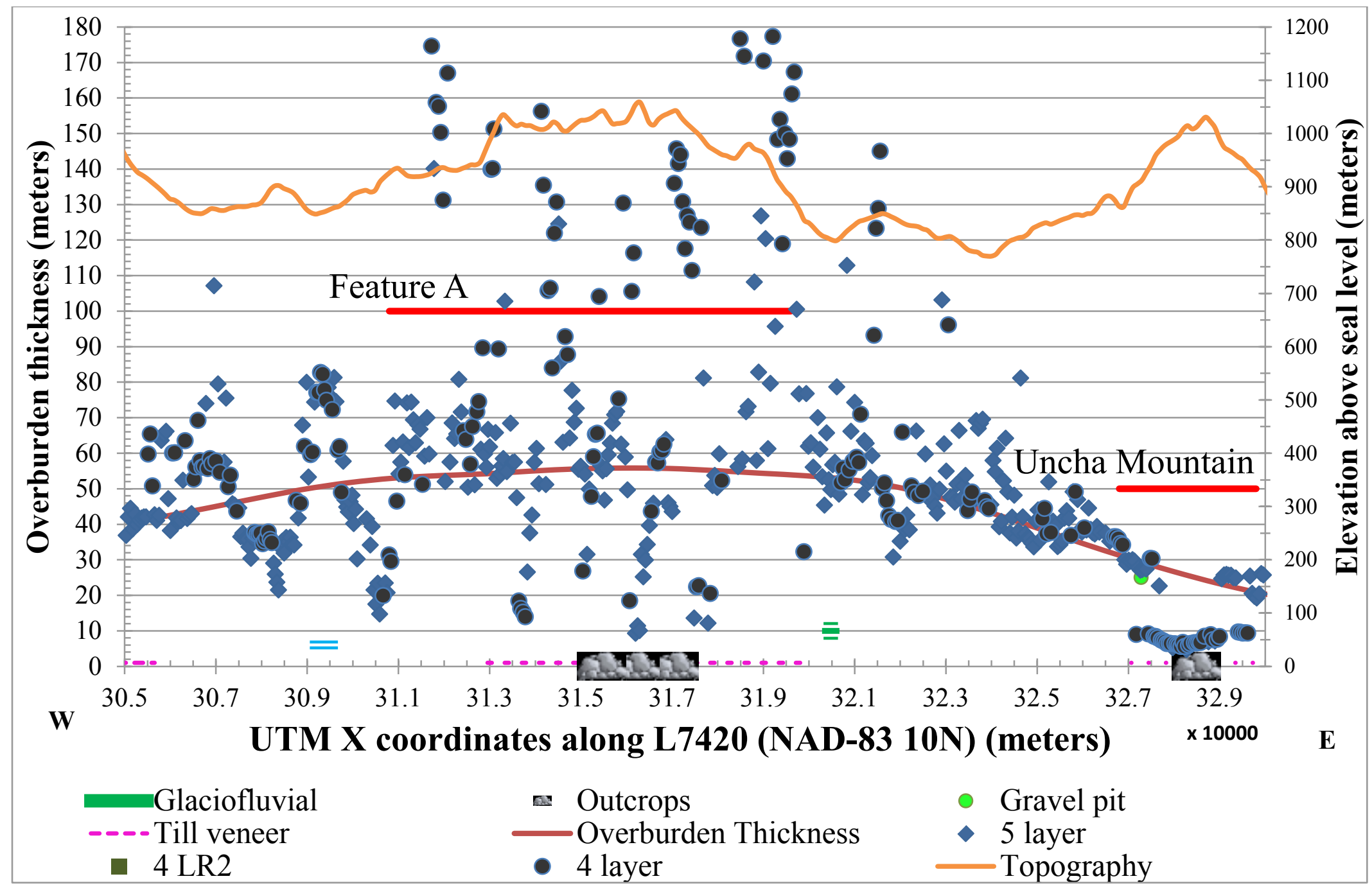

Figure 5.5.7: Inversion results by starting model for HTEM line 7420

Figure shows the scattering that occurred over Feature A. Scattering is reduced over flatter terrain between Feature A and Uncha Mountain and over Uncha Mountain. Red line represents the grid averaging that occurs when the data is averaged over a $1 \mathrm{~km}$ cell size. HTEM stations are 50m apart. Topography is plotted on the right-axis. 


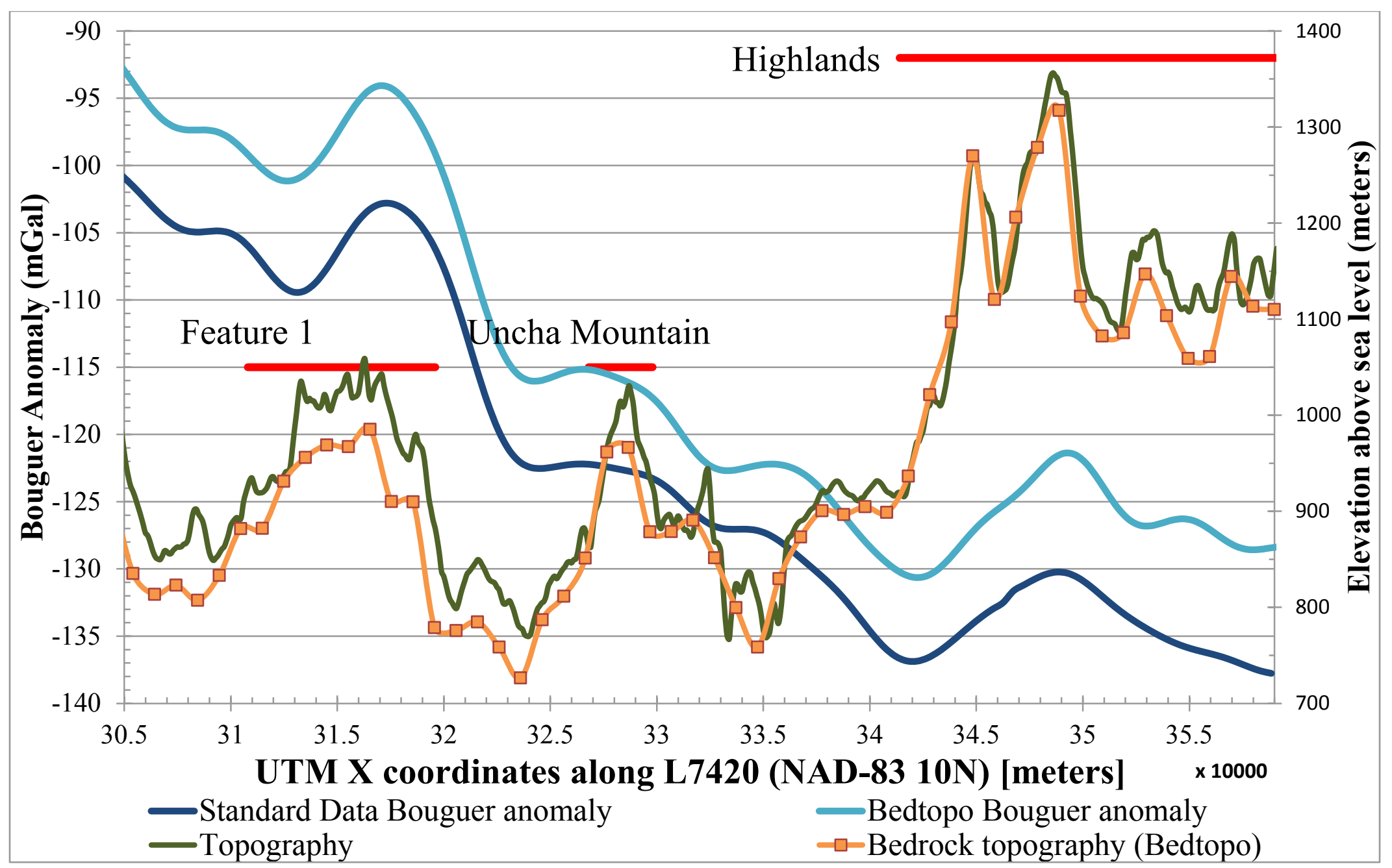

Figure 5.6.1: Comparison of Bouguer anomaly (BA) profiles for HTEM line 7420

Figure shows the along line variations in Bouguer anomaly (BA) intensities for the Standard Data and BedTopo corrections. Figure also shows the difference in elevation between topography (determined from SRTM data) and bedrock topography (determined from BedTopo map). The difference between these two lines is the HTEM inverted overburden thickness. All data is averaged to a $1 \mathrm{~km}$ grid cell size. Bathymetry is corrected. 


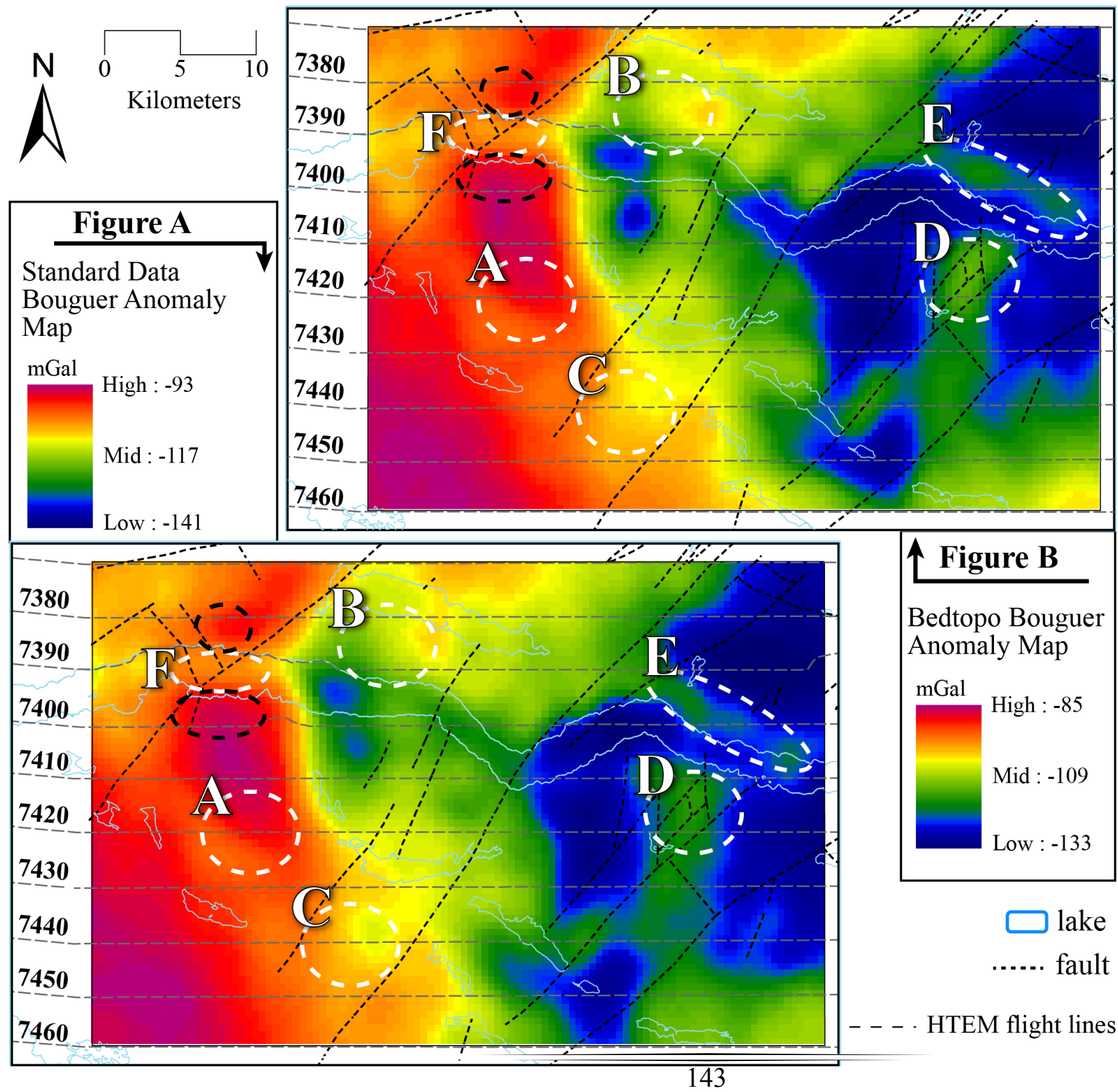

Figure 5.6.2: Bouguer gravity anomaly map comparison

Maps show a comparison of anomalies created from a Bouguer correction done without, Figure A, and with, Figure B, an overburden correction. Bathymetry was not corrected. Maps were interpolated using minimum curvature with a cell size of $500 \mathrm{~m}$. 


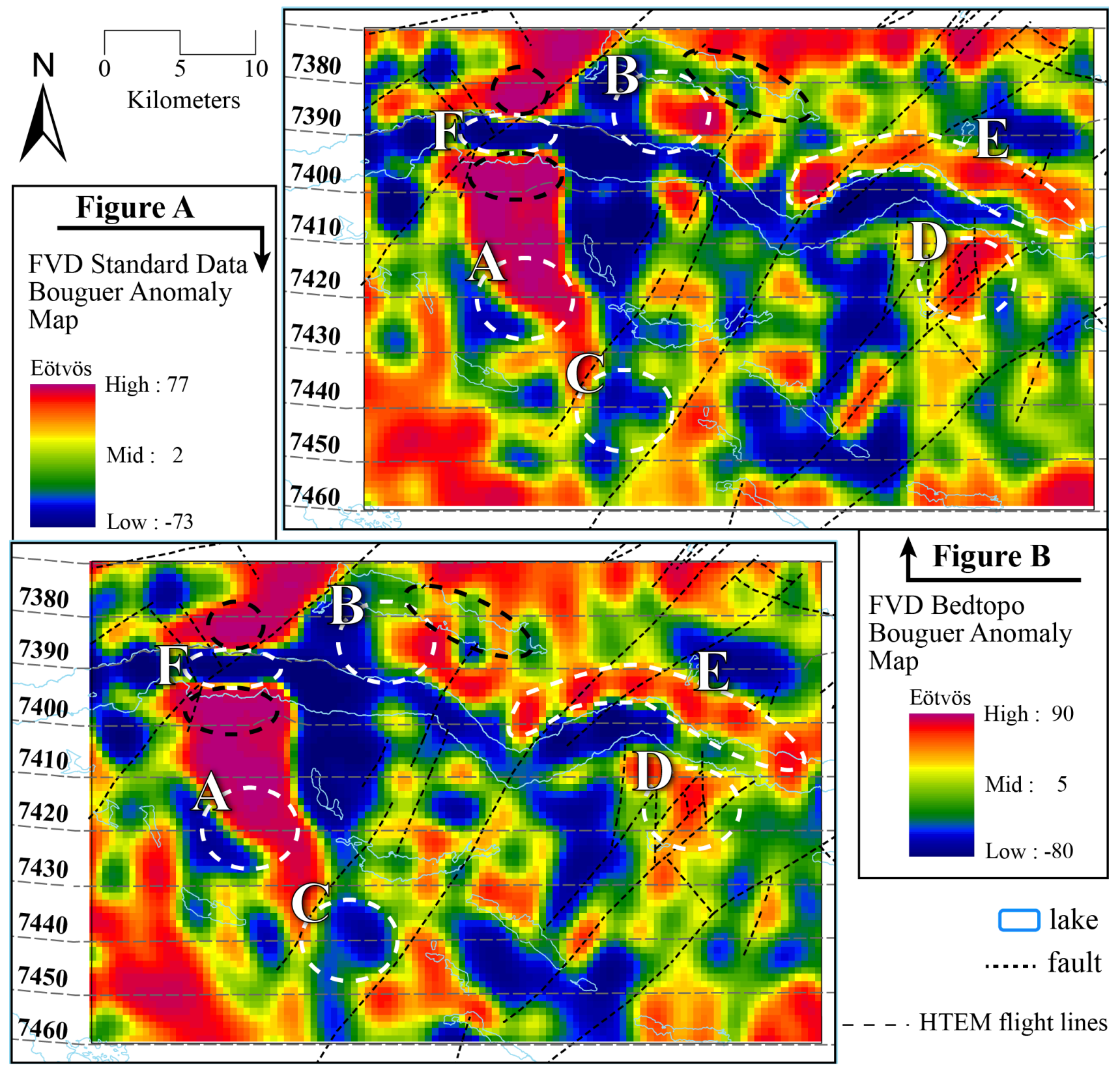

Figure 5.6.3: Bullard FVD Bouguer anomaly map of the study site.

FVD maps show a comparison of anomalies created from a Bouguer correction done without, Figure A, and with, Figure B, an overburden correction. Bathymetry was not corrected. Maps were interpolated using minimum curvature with a cell size of $500 \mathrm{~m}$. 


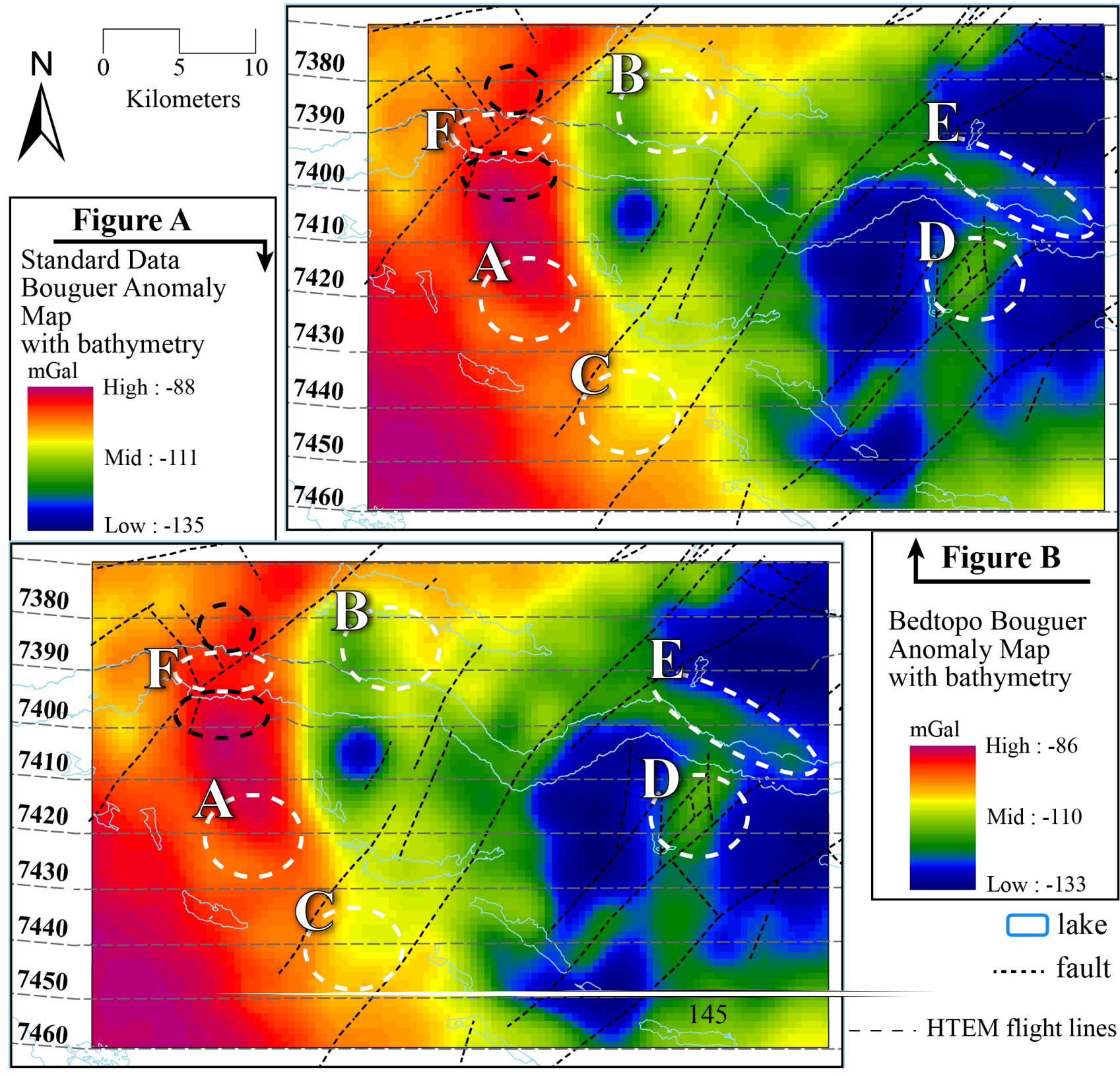

Figure 5.6.4: Bouguer gravity anomaly map comparison with bathymetry corrected Maps show a comparison of anomalies created from a Bouguer correction done without, Figure A, and with, Figure B, an overburden correction. Bathymetry was corrected. Maps were interpolated using minimum curvature with a cell size of $500 \mathrm{~m}$. 


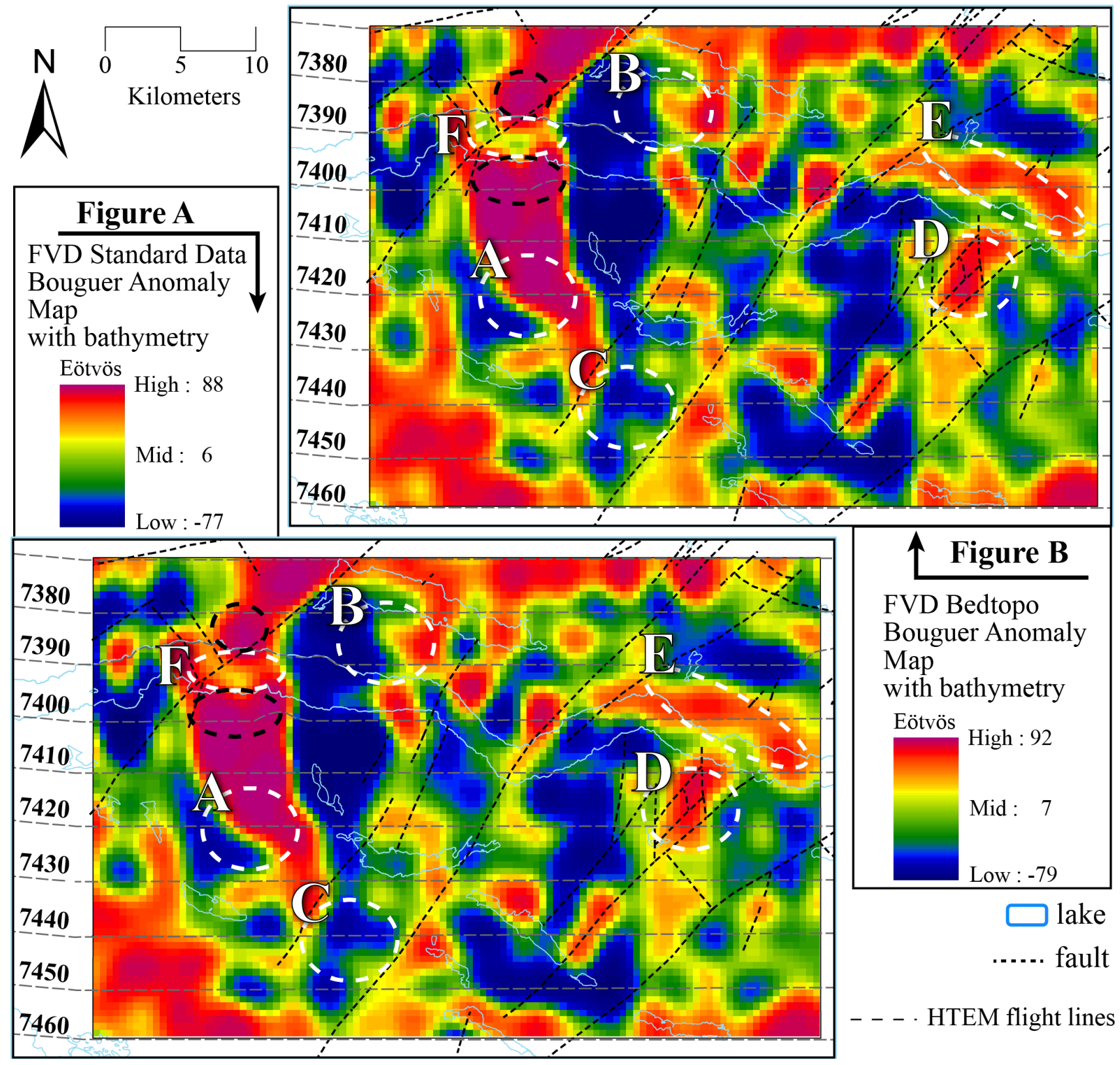

Figure 5.6.5: Bullard FVD Bouguer anomaly map of the study site with bathymetry corrected.

FVD maps show a comparison of anomalies created from a Bouguer correction done without, Figure A, and with, Figure B, an overburden correction. Bathymetry was corrected. Maps were interpolated using minimum curvature with a cell size of $500 \mathrm{~m}$. 


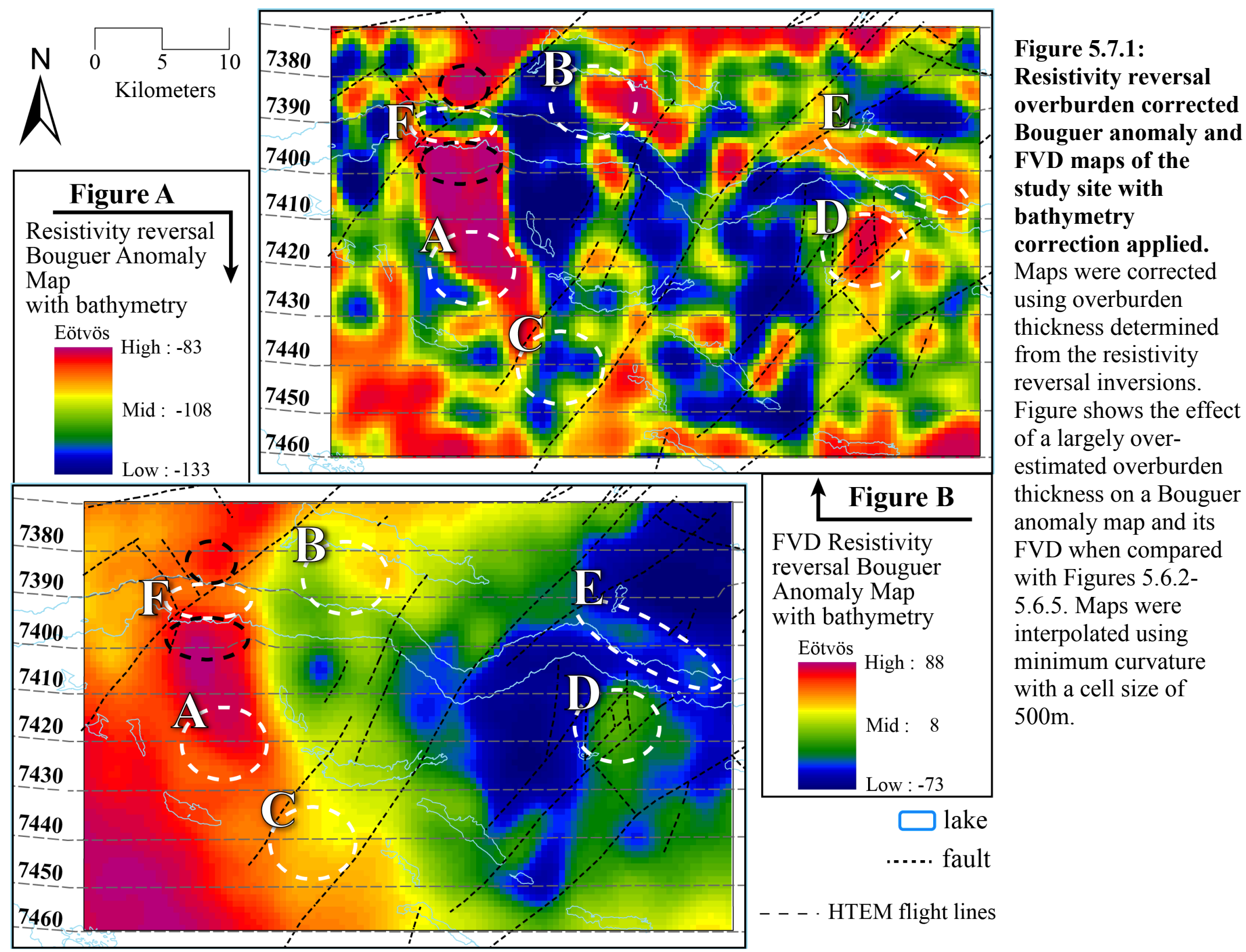




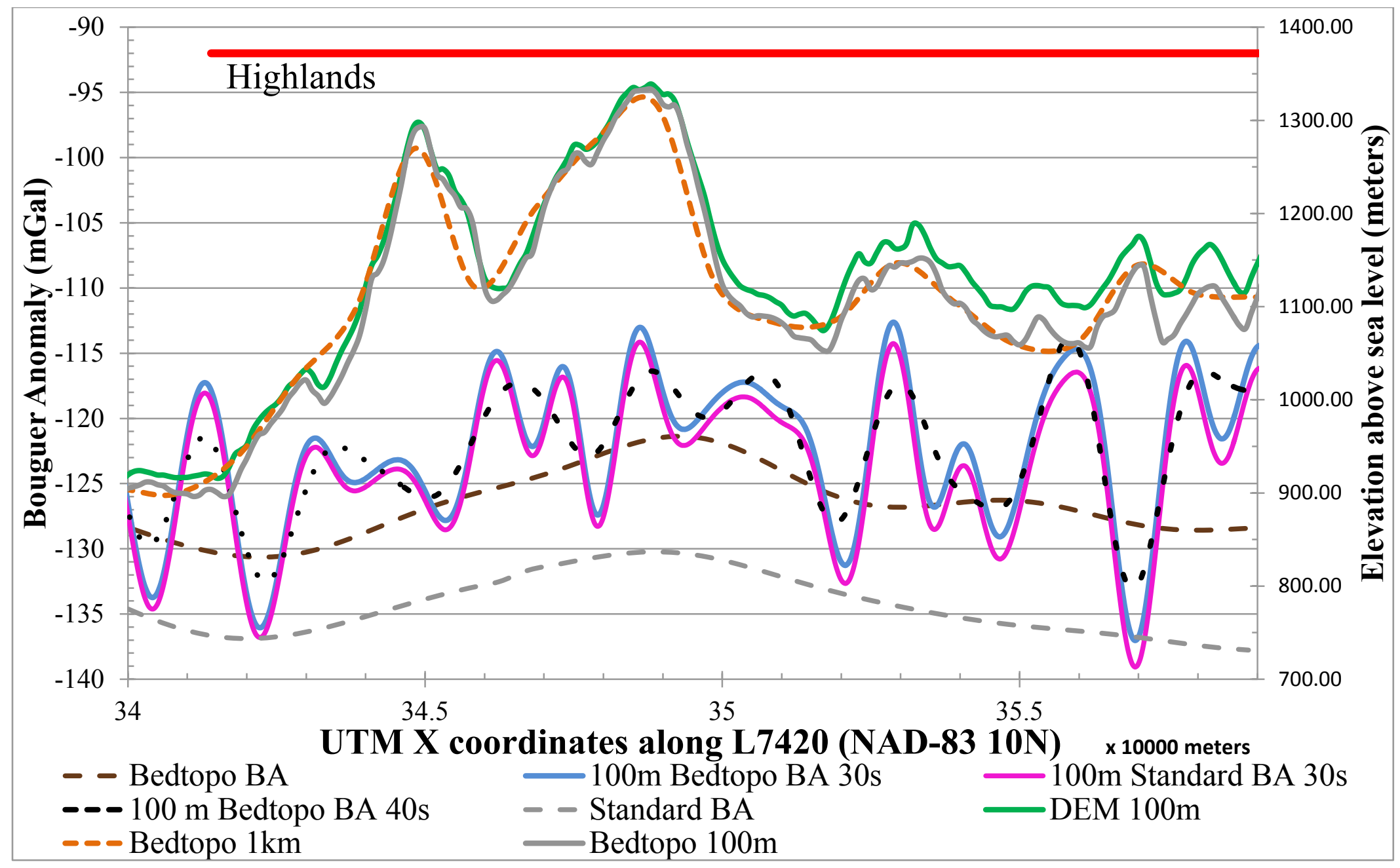

Figure 5.8.1: Comparison of Bouguer anomaly (BA) profiles for HTEM L7420 created using 100m DEM maps.

Figure shows the effect of higher resolution maps on BedTopo corrections. Overburden thickness changes shown by the difference between the BedTopo $100 \mathrm{~m}$ (grey line) and the DEM $100 \mathrm{~m}$ (green line) can be seen to affect gravity data, shown by the difference between the $100 \mathrm{~m}$ BedTopo BA (blue line), and the $100 \mathrm{~m}$ Standard BA (fuchsia line). The $56 \mathrm{~s}$ filer is was applied unless otherwise stated. Filters applied during gravity processing act to filter out overburden-hosted anomalies, shown by the $100 \mathrm{~m}$ BedTopo BA 40s (black dashed line). 


\subsection{Conclusion}

A novel methodology for correcting gravity data due to variations in overburden thickness is presented. The terrain correction is applied as a map layer where DEM, bathymetry, and overburden thickness measurements are used to create three maps that are able to correct for the contribution of gravity from bedrock, a water body, and overburden layer down to the GEOID or the datum.

Also presented is a working methodology for inverting HTEM data to resolve the overburden-bedrock contact using discrete layered-earth models in a highland terrain with volcanogenic bedrock overlain by a glacial-derived overburden, using Nechako Plateau, British Columbia, as a case study.

\subsection{HTEM inversion summary}

Forward modelling results for a purpose-built HTEM system are presented which show that the system should be designed with a square waveform, with a maximum duty time of at least $0.5 \mathrm{~s}$. It also shows that such a system can resolve the overburden using a transmitter current of $100 \mathrm{~A}$, giving a magnetic moment of $15,400 \mathrm{Am}^{2}$, with an as short of a turn-off time as possible, see Section 3.3.

Inversion results conducted using an HTEM system designed for mineral exploration are presented, showing that these systems can also resolve overburden thickness. Layered-earth inversion results were mixed. While the resistivity reversal methodology was the most successful inversion method applied it suffered from 3D 
topography effects and a conductive bedrock unit that led to an overestimation of overburden thickness for a large portion of the south-west area of the study site, see Section 5.5 and 5.6. This over-estimation error was propagated large distances due to line filtering and interpolation over the $4 \mathrm{~km}$ between HTEM lines.

An analysis of Resistivity structure inversion results by station shows that the overburden varied in thickness from $0-265 \mathrm{~m}$ with an average of $38 \mathrm{~m}$. The first layer of overburden has a range in resistivity of 3-680 $\Omega \bullet \mathrm{m}$, with an average of $46 \Omega \bullet \mathrm{m}$, and the bedrock has resistivities with a range of $0.5 \Omega \bullet \mathrm{m}$ to $>10,000 \Omega \bullet \mathrm{m}$.

\subsubsection{Water well calibration summary}

Water well calibration inversions, presented in Appendix I, showed that 2- and 3layer earth models may over-estimate the thickness of the overburden, while maintaining an sRMS error below 5\%. Also shown is that 4- and 5-layer models are often more accurate at determining overburden thickness provided that the Resistivity structure of the model approximates that of the subsurface stratigraphy and therefore the response. This is most likely due to the additional layer modelled as overburden, as water well inversions show a clear difference in resistivity between layers interpreted as overburden and between layers interpreted as bedrock. Starting models that share a similar conductance and geological structure with an overburden and bedrock, but have a slightly different resistivity-depth profile, will vary in degree of success and accuracy when used at different locations. Inversion success and accuracy may be increased if a series of starting models were used for inversion, as opposed to a single model, where each model 
is tailored to different topographical features, such as a slope, while exploring different conductivity-depth profiles. However due to the non-unique nature of the inversion solutions, this method may only reduce the number of inaccurate inversions and will not prevent their occurrence. This is supported by the water well calibrations which showed that the result with the lowest sRMS \% error did not always have the most accurate inversion result. The result with the lowest sRMS error was found to be within $80 \%$ of the total overburden thickness indicated by the water wells in only 4 out of 11 successful inversions, but returned a result within $70 \%$ of the total overburden thickness in 7 out of 11 inversions. This corresponds to a $61 \%$ sRMS error when the HTEM station with the lowest sRMS is chosen.

\subsection{BedTopo Bouguer correction summary}

While the BedTopo Bouguer anomaly and the Standard Bouguer anomaly maps with bathymetry corrected are near identical except for a static shift in gravity intensity, see Figure 5.6.4, the FVD maps show some differences in anomalies at Features F and B. An analysis of the Standard Bouguer and BedTopo Bouguer anomalies along line showed that when local changes in overburden thickness are corrected, the effect acts as a static shift in the amplitude of the gravity signal, due to the use of low frequency-pass cosine filters applied during gravity processing in order to remove GPS noise from the gravity signal.

Comparison of the applied BedTopo corrections across all maps showed that there is a limit on the resolution of airborne gravimeters at detecting changes in overburden 
thickness which is determined primarily by GPS noise. Within the study site, overburden thickness changes smaller than $30 \mathrm{~m}$, with $1 \mathrm{mGal}$ amplitude, may be indistinguishable from GPS noise, and are removed by low-pass filters along with the noise. Overburden thickness changes that are $100 \mathrm{~m}$ in size and larger, producing a gravity anomaly with an amplitude greater than $3 \mathrm{mGal}$, are visible and could lead to interpretation problems on a Bouguer anomaly map if the survey target was associated with a small amplitude anomaly. Such an anomaly can be created from a $200 \mathrm{~m}$ x $350 \mathrm{~m}$ sulphide mineral body that is located at a depth of $50 \mathrm{~m}$ beneath bedrock, see Figure $1.1 \mathrm{~B}$. Should $50 \mathrm{~m}$ of overburden be situated over the mineral body, the gravity signal it generates would decrease by $1 \mathrm{mGal}$. If the anomaly is buried deeper, its signature could become obscured by changes in overburden thickness.

\subsection{BedTopo correction application}

For exploration, a BedTopo gravity correction may only be a concern for high resolution airborne gravity surveys that have a line spacing of $200 \mathrm{~m}$ or less, and for survey areas known to be dotted with basins that are $>100 \mathrm{~m}$ deep. There are also applications for gravity gradiometry and ground gravity survey corrections, as these applications are higher resolution and have a strategy to reduce GPS noise, or are not affected by GPS noise.

Errors in the determination of overburden thickness will only generate misleading anomalies on a Bouguer anomaly map in the event that the overburden is greatly overestimated. Such errors are a product of the long wavelength filters applied to gravity data 
in order to remove GPS noise. High frequency errors in overburden thickness are filtered out of the gravity data along with the GPS noise. Under-estimated changes in overburden thickness are thought to be less of a problem as the change in overburden needs to be at least $30 \mathrm{~m}$ in size to be visible on a Bouguer anomaly map. Local changes in overburden thickness occurring at greater depths below the surface also need to be a larger increase than $30 \mathrm{~m}$ in order to be detectable. Therefore any under-estimated changes in overburden thickness will result in a marginal improvement of the BedTopo Bouguer anomaly map over the Standard Bouguer anomaly map.

HTEM inversion to determine overburden thickness has several practical applications that go beyond gravity data correction. The creation of a bedrock topography map may aid in civil and regional planning for infrastructure and resource development.

\subsection{Future work}

This project raises some suggestions for future research, other than the HTEM inversion strategy outlined in Section 6.1.1. During bathymetry modelling, the lake bottom was modelled to reside in bedrock or overburden depending on the interpolation of overburden thickness. This led to errors that are visible in the FVD BedTopo Bouguer anomaly map, see Feature F in Figure 5.6.5 B. There may be a more suitable method for modelling lake bottom sediment that does not contribute to correction errors.

Infrared remote sensing has been applied successfully to map vegetation cover and shallow sediment thickness (Kustas and Anderson 2009). A method to integrate 
remote sensing data with SRTM and surficial geology data to provide a more accurate estimate of vegetation cover and shallow sediment thickness would also be of benefit.

HTEM inversion provides an indication of maximum overburden thickness, water wells provide an indication of maximum and minimum overburden thickness, and outcrops and till veneer provide an indication of minimum overburden thicknesses, however they are also more easily observed. This higher number of minimum thickness measurements versus actual measurements of overburden thickness could introduce bias in an interpolated map of overburden thickness (Liang et al. 2014). While there is a new interpolation method that can account for, model, and interpolate outcrops in a data set to create a more realistic overburden thickness map (Liang et al. 2014), there is as of yet no method to incorporate this information with topography and drainage patterns which is known to control the location, assortment, and yield of sediment erosion and related deposits (Mitasova et al. 1996, Jain and Das 2010).

Above all this study determined that GPS noise is a major limiting factor in applying a BedTopo correction to gravity data. Research into both improving the accuracy of airborne GPS and correcting for position to reduce GPS noise during gravity surveying will only increase the need for a BedTopo correction of this higher resolution gravity data. 


\section{References}

Abraham, Jared D., Minsley, Burke J., Bedrosian, Paul A, Smith, Bruce D., and Cannia, James C. 2012. Airborne electromagnetic surveys for groundwater characterization. ASEG Extended Abstract, 22nd International Geophysical Conference and Exhibition.

Aeroquest Limited, 2008, Report on a Helicopter-borne AeroTEM system electromagnetic, radiometric \& magnetic survey Aeroquest job \#08087. Amazing Grace Block, British Columbia, Medallion. Aeroquest Surveys. 46p

Aeroquest Limited, 2009, Report on a Helicopter-borne AeroTEM system electromagnetic \& magnetic survey Aeroquest job \#08130. Quest West Project, British Columbia-2009 Geoscience British Columbia Society. Aeroquest Surveys. $28 \mathrm{p}$

Andrews, Graham D.M., Plouffe, Alain, Ferbey, Travis, Russell, James K., Brown, Sarah R., and Anderson, Robert G. 2011. The thickness of Neogene and Quaternary cover across the central Interior Plateau, British Columbia: analysis of water-well drill records and iplications for mineral exploration potential. Canadian Journal of Earth Sciences. Vol. 48, pp. 973-986. doi:10.1139/E10-080.

Arnold, T., and Ferbey, T.. 2016. British Columbia Surficial Geology Map Index, BCGS Open File 2016-03, British Columbia. British Columbia Ministry of Energy and Mines.

Auken, Esben. 1995. 1D Time Domain Electromagnetic Interpretations Over 2D / 3D Structures. Symposium on the Application of Geophysics to Engineering and Environmental Problems 1995: pp. 329-337. doi: 10.4133/1.2922152

Auken, Esben, Christiansen, Anders V., Jacobsen, Lars H., and Sorensen, Kurt L. 2008. A resolution study of buried valleys using laterally constrained inversion of TEM data. Journal of Applied Geophysics. Vol. 65, p. 10-20.

Balco, G. Stone, John O.H., and Jennings, Carrie. 2005. Dating plio-pleistocene glacial sediments using the cosmic-ray-produced radionuclides ${ }^{10} \mathrm{Be}$ and ${ }^{26} \mathrm{Al}$. American Journal of Science. Vol. 305. Pp. 1-41.

Becker, A. DeCarle, R., and Lazenby, P.G. Simplified prediction of transient electromagnetic response. Geophysics. Vol. 49. Pp. 913-917. 
Best, M.E., Levson, V.M., and Diakow, L.J. 1997. Electromagnetic mapping in drift covered regions of the Nechako plateau, British Columbia in Interior Plateau Geoscience Project: Summary of Geological, Geochemical and Geophysical Studies (NTS 092N; 092O; 093B; 093C; 093F; 093G; 093K); Paper 1997-2, Geological Survey of Canada Open File 3448. Geological Survey of Canada. Pp. $225-256$

Briggs, Ian C.. 1974. Machine Contouring Using Minimum Curvature. Geophysics. Vol. 39. No. 1, p. 39-48.

British Columbia. 2014. Bathymetry maps. Ministry of Environment. http://catalogue.data.gov.bc.ca/dataset/bathymetric-maps

British Columbia. 2015. WELLS database. Ministry of the Environment. http://a100.gov.bc.ca/pub/wells/public/

Bullard, E.C. 1936. Gravity measurements in East Africa. Philosophical Transactions of the Royal Society, London 235: 445-534.

Caron, R., Samson, C., Chouteau, M., Bates, M. 2013. Designing a HTEM system for mapping glaciolacustrine overburden thickness: 83rd Annual Meeting of the Society of Exploration Geophysicists, Houston, TX, 22-27 September: SEG Expanded Abstracts 32, 690-694.

Caron, R., Samson, C., Bates, M., and Chouteau, M. 2015. Correcting for overburden thickness in airborne gravity data using electromagnetic data: $85^{\text {th }}$ Annual Meeting of the Society of Exploration Geophysicists, New Orleans, LU, 18-23 October: SEG Expanded Abstracts 34, 2022-2026.

Chen, J. and Macnae, J.C. 1997. Terrain corrections are critical for airborne gravity gradiometer data. Exploration Geophysics, Vol. 28, p. 21-25.

Chen, J. and Raiche, A. 1998. Inverting AEM data using a damped eigenparameter method. Exploration Geophysics 29: 128-132.

Christiansen, Anders Vest, and Auken, Espen. 2010. A global measure for depth of investigation in EM and DC modeling. ASEG Extended Abstracts. Pp: 1-4.

Cui, Y., Miller, D., Nixon, G., and Nelson, J., 2015. British Columbia digital geology. British Columbia Geological Survey Open File 2015-2

Elieff, S., Ferguson, S., 2008. Establishing the 'air truth' from 10 years of airborne gravimeter data: First Break, v.26, no.11, 73-77 
Electromagnetic Imaging Technology (EMIT). 2010. Maxwell Manual. Electromagnetic Imaging Technology. pg. 436.

Enkin, R.J., Vidal, B.S., Baker, J., and Struyk, N.M. 2008. Physical properties and paleomagnetic database for South-Central British Columbia. Geological Fieldwork 2007, Paper 2008-1. Pp: 5-7.

Enkin, R.J. 2014. The rock physical property database of British Columbia, and the distinct petrophysical signature of the Chilcotin basalts. Canadian Journal of Earth Sciences, Vol. 51. Pp: 327-338.

Ferbey, T. 2014. Surficial geology of the Colleymount map area (NTS 093L/01), British Columbia. British Columbia Ministry of Energy and Mines, British Columbia Geological Survey Geoscience Map 2014-02, Geoscience BC Map 2014-09-02, scale 1:50 000 .

Fitterman, D.V. and Anderson, Walter L. 1987. Effect of transmitter turn-off time on transient soundings. Geoexploration, Vol. 24, p. 131-146.

Fitterman, D.V. and Stewart, M.T. 1986. Transient electromagnetic sounding for groundwater. Geophysics, Vol. 51, p. 995-1005.

FreeFlight Systems. 2009. TRA-3000 and TRA-3500 RADAR altimeters, brochure. FreeFlight Systems. http://eongeosciences.com/wp content/uploads/2015/01/RA_3000_3500.pdf

GeoScience BC. 2008. Quest-West Brochure. GeoScience BC. http://www.geosciencebc.com/s/QuestWest.asp

Geotech Limited, 2007, Report on a Helicopter-borne versatile time domain electromagnetic (VTEM) geophysical survey. Quest Project, British Columbia2007 Geoscience British Columbia Society. Geotech Limited. 35p.

Google, earth. 2016. Nechako Plateau, British Columbia, Canada. 5359'51.13"N, $125^{\circ} 32 ' 21.70 " \mathrm{~W}$, DigitalGlobe2015.

Grainger, N.C., and Anderson, R.G. 1999. Geology of the Eocene Ootsa Lake group in northern Nechako River and southern Fort Fraser map areas, central British Columbia. in Current Research 1999-A, Geological Survey of Canada, pp. 139148. 
Hinze, William, Aiken, C., Brozena, J., Coakley, B., Dater, D., Flanagan, G., Forsberg, R., Hildenbrand, T., Randy-Keller, G., Kellogg, J., Kucks, R., Li, X., Mainville, A., Morin, R., Pilkington, M., Plouff, M., Ravat, D., Roman, D., UrrutiaFucugauchi, J., Véronneau, M., Webring, M., Winester, D.2005. New standards for reducing gravity data: the North American gravity database. Geophysics, Vol. 70, pp. 125-132.

Hodges, Greg. 2003. Practical inversions for helicopter electromagnetic data. Symposium on the Application of Geophysics to Engineering and Environmental Problems 2003: pp. 45-58. doi: 10.4133/1.2923189

Howes, D.E. and Kenk, E. 1997. Terrain classification system for British Columbia (version 2) 1997: A system for the classification of surficial materials, landforms and geological processes of British Columbia, MOE manual 10. Recreational Fisheries branch, Ministry of Environment, Surveys and resource mapping branch, Ministry of crown lands, British Columbia, Victoria. Pg. 114.

Huscroft, C. and Plouffe, A. 1999. Field investigations of glacial lake Knewstubb of the Fraser Glaciation, central British Columbia in Current Research 1999-A. Geological Survey of Canada, pp. 174-184.

Jain, Manoj Kumar and Das, Debjyoti. 2010. Estimation of sediment yield and areas of soil erosion and deposition for watershed prioritization using GIS and remote sensing. Water Resources Managerment. Vol. 24, Pp. 2091-2112. DOI 10.1007/s11269-009-9540-0.

Jarvis, A., Rubiano, Jorge, Nelson, Andy, Farrow, Andrew, and Mulligan, Mark. 2004. Practical use of SRTM data in the tropics-Comparison with digital elevation models generated from cartographic data. Centro Internacional de Agricultura Tropical (CIAT), Cali, Columbia.

Jarvis, A., Reuter, H.I., Nelson, A., and Guevara, E. 2008. Hole-filled SRTM for the globe Version 4. available from the CGIAR-CSI SRTM 90m Database: http://srtm.csi.cgiar.org.

Killeen, P.G., Mwenifumbo, C.J., and Elliot, B.E. 1995. Borehole geophysical logs and physical property table for massive sulphide deposits in the Cordillera, British Columbia, including logs from the Buttle Lake, Chu chua, Equity Silver, Goldstream, Highland Valley, Lara and Sullivan deposits. Geological Survey of Canada, Open File 2610, Pp 77. doi:10.4095/204900

Kushnir, A., Andrews, G., Russel, J.K., Enkin, R.J., Kennedy, L.A., Heap, M.J., and Quane, S. 2012. Rock Physical-Property Measurements for the Nechako Basin Oil and Gas Region, Central British Columbia (Parts of NTS 093B, C, E, F, G, K, L) in Geoscience BC Summary of Activities 2011, Geoscience BC, Report 2012-1, pp. 125-150. 
Kustas, William and Anderson, Martha. 2009. Advances in thermal infrared remote sensing for land surface modeling. Agricultural and Forest Meteorology. Environmental Biophysics-Tribute to John Norman. Vol. 149. Pp 2071-2081.

Levson, Victor M. and Giles, Timothy R. 1997. Quaternary geology and till geochemistry studies in the Nechako and Fraser plateaus, central British Columbia (NTS 93 $\mathrm{C} / 1,8,9,10 ; \mathrm{F} / 2,3,7 ; \mathrm{L} / 16 ; \mathrm{M} / 1)$ in Interior plateau geoscience project: summary of geological, geochemical and geophysical studies. Geological Survey of Canada, Open File 3448, 1997, Pp 256 pages, doi:10.4095/208972.

Liang, Min, Marcotte, Denis, and Nicolas, Benoit. 2014. A comparison of approaches to include outcrop information in overburden thickness estimation. Stochastic Environmental Research and Risk Assessment. Vol. 28, Pp. 1733-1741.

Liu, Guimin. 1998. Effect of transmitter current waveform on airborne TEM response. Exploration Geophysics. Vol. 29. Pp. 35-41.

Macintyre, D.G. and Struik, L.C. 1999. Nechako NATMAPProject, Central British Columbia-1999 Overview: Geological Fieldwork 1999, Paper 2000-1. British Columbia Geological Survey, Geological Fieldwork 1999. Pp. 7-13.

Massey, N.W.D., MacIntyre, D.G., Desjardins, P.J. and Cooney, R.T., 2005. Digital Geology Map of British Columbia: Whole Province, B.C. Ministry of Energy and Mines, Geofile 2005-1, scale 1:250,000.

Mate, D.J. and Levson, V.M. 2001. Quaternary stratigraphy of history of the Ootsa LakeCheslatta River area, Nechako Plateau central British Columbia. Canadian Journal of Earth Sciences, v. 38, pp. 751-765.

Matheson, A., Massey, N.W.D., Bobrowsky, P.T., Kilby, C.E. and Manson, G. 1996. Aggregate Inventory of British Columbia-Private Pits: Open File 1996-5: updated in 2004. B.C. Ministry of Energy, Mines and Petroleum Resources, British Columbia.

Meyer, Sol and Bates, Martin, 2008, Project Report airborne gravity survey Quest West, British Columbia-2008 Geoscience British Columbia Society: Sander Geophysics Limited. pg. 129

Mihalynuk, M.G. 2007: Evaluation of mineral inventories and mineral exploration deficit of the Interior Plateau Beetle Infested Zone (BIZ), south-central British Columbia; in Geological Field work 2006, BC Ministry of Energy, Mines and Petroleum Resources, Paper 2007-1 and Geoscience BC, Report 2007-1, pages $137-141$. 
Mira Geoscience. 2008. Geoscience BC report 2008-9a-Development and Application of a Rock Property Database for British Columbia. Mira Geoscience. Geoscience BC. Pp. 21. http://rpds.mirageoscience.com/

Mitasova, Helena, Hofierka, Jaroslav, Zlocha, Maros, and Iverson, Louis R. 1996. Modelling topographic potential for erosion and deposition using GIS. International Journal of Geographical Information Systems. Vol. 10, Pp. 629-641, DOI: $10.1080 / 02693799608902101$

Nabighian, M.N. 1979. Quasi-static transient response of a conducting half-space-an approximate representation. Geophysics, Vol. 44, Pp 1700-1705.

Nabighian, M.N., Ander, M.E., Grauch, V.J.S., Hansen, R.O., LaFehr, T.R., Li, Y., Pearson, W.C., Peirce, J.W., Philips, J.D., and Ruder, M.E. 2005. Historical development of the gravity method in exploration. Geophysics, Vol. 70, Pp 63-89.

Newman, Gregory A., Anderson, Walter, L., and Hohmann, Gerald W. 1987. Interpretation of transient electromagnetic soundings over three-dimensional structures for the central-loop configuration. Geophysics Journal International. Vol. 89, Pp. 889-914.

Nowell, D.A.G. 1999. Gravity terrain corrections-an overview. Journal of Applied Geophysics. Vol. 42, pp. 117-134.

Oldenburg, Douglas W., and Li, Yaoguo. 1999. Estimating depth of investigation in DC resistivity and IP surveys. Geophysics. Vol. 64. Pp. 403-416.

Palacky, G.J. and Stephens L.E. 1990. Mapping of Quaternary sediments in northeastern Ontario using ground electromagnetic methods. Geophysics, Vol. 55, p. 15961604.

Palacky, G.J. 1991. Application of the multifrequency horizontal-loop EM method in overburden investigations. Geophysical Prospecting, Vol. 39, pp. 1061-1082.

Palacky, G.J. and West G.F. 1991 Airborne electromagnetic methods in Electromagnetic methods in applied geophysics, Volume 2. Society of Exploration Geophysics, p.811-879.

Palacky, G.J. 1992. Inversion of horizontal-loop electromagnetic field data: Case histories from Ontario and Northwest Territories, Canada. SEG Expanded abstracts 11: 457-460.

Plouffe, A. 1997. Ice flow and late glacial lakes of the Fraser Glaciation, central British Columbia in Current Research 1997-A Cordillera and Pacific margin. Geological Survey of Canada. 
Plouffe, A. 1998a. Surficial geology, Tahultzu Lake, British Columbia (93 F/NE), Geological Survey of Canada, Open File 3620, scale 1:100 000.

Plouffe, A. 1998b. Surficial geology, Binta Lake, British Columbia (93 F/11, 13, and 14), Geological Survey of Canada, Open file 3640, scale 1:100 000.

Plouffe, A. and Levson, V.M., 2001, Late Quaternary glacial and interglacial environments of the Nechako River-Cheslatta Lake area, central British Columbia: Canadian Journal of Earth Sciences, V. 38, pp. 719-731.

Plouffe, A. and Mate, D.J. 2001. Surficial geology, Binta Lake, British Columbia; Geological Survey of Canada, Open File 3686-3686D, scale 1:100 000.

Raiche, Art. 2007. AirBeo v.4.7.0 manual: Amira project P233F. CSIRO Electromagnetic modelling group,Australia. AMIRA International.

Raiche, Art, Sugeng, Fred, and others. 2008. Report: P223 EM Modelling Projects, Developing the Modelling \& Inversion Environment. CSIRO Electromagnetic modelling group,Australia. AMIRA International.

Reeves, Colin. 2005. Aeromagnetic Surveys: Principles, Practice \& Interpretation. Epublished by GeoSoft Incorporated, 2005.

Reynolds, J. M. 2011. An introduction to applied and environmental geophysics, second edition. Wiley-Blackwell.

Rosen, P., Hensley, S., Gurrola, E., Rogez, F., Chan, S., and Martin, J.. 2001. SRTM Cband topographic data: Quality assessments and calibration activities, IEEE Geoscience and Remote Sensing Symposium, Vol. 2, Pp 739-741.

Sander, Stephen, Lavoie, V., Peirce, J., and Charters R.A. 2003. Advantages of close line spacing in airborne gravimetric surveys, The Leading Edge. Vol. 22(2). Pp 136137.

Sander, Stephen, Elief, Stefan H.P., and Sander, Luise. 2015. Accuracy of SGL's AIRGrav airborne gravity system from the Kauring test site and results from a regional hydrocarbon exploration survey. International Workshop and Gravity, Electrical \& Magnetic Methods and their Applications, Chenghu, China, 19-22 April 2015: pp. 29-32. doi: 10.1190/GEM2015-008.

Sorensen, Kurt I. and Auken, Espen. 2005. SkyTEM-a new high-resolution helicopter transient electromagnetic system. Exploration Geophysics. Vol. 35. Pp. 191-199.

Spies, Brian R. and Frischknecht, Frank C., 1991. Electromagnetic sounding in Electromagnetic methods in applied geophysics-Applications. Soceity of Exploration Geophysicists. Pp. 285-425. 
Steno, Nicolaus. 1667. The prodromus of Nicolaus Seno's dissertation concerning a solid body enclosed by process of nature within a solid; An English version with an introduction and explanatory notes by John Garrett Winter, 1916. The Macmillan \& Company Limited, New York, p. 160.

Stumpf, A.J., Broster, B.E., Levson, V.M. 2000. Multiphase flow of the late Wisconsinan Cordilleran ice sheet in western Canada. Geological Soceity of America Bulletin. Vol. 112, pp. 1850-1863.

Sun, G., Ranson, K.J., Kharuk, V.I. and Kovacs, K.. 2003. Validation of surface height from Shuttle Radar Topography Mission using shuttle laser altimeter. Remote Sensing Environment. Vol. 88. Pp 401-411.

Telford, W.M., Geldart, L.P., Sheriff, R.E., and Keys, D.A.. 1990. Applied Geophysics, 2nd edition. Cambridge University Press. p. 62

Tighe, Lorraine M. and Chamberlain, Drew. 2009. Accuracy comparison of the SRTM, ASTER, NED, NEXTMAP ${ }^{\circ}$ USA digital terrain model over several USA study sites. ASPRS/MAPPS 2009 Fall Conference November 16-19, San Antonio, Texas. Pp 12 pages.

Ward, S. H., and Hohmann, G. W. 1988. Electromagnetic theory for geophysical applications in Electromagnetic methods in applied geophysics: Nabighian, M. N., Ed., Society of Exploration Geophysicists (SEG), Tulsa. Pp: 131-311.

Westenhofer, L., Roberts, AM., and Sharpe, I. 2000. Francois Lake management plan. Province of British Columbia, Smithers, BC. Pp. 132. 


\section{Appendix I}

Appendix I contains water well calibrated inversions conducted at various BC

Water wells that are within $400 \mathrm{~m}$ of an HTEM line, see Section 4.2.1. Each record

contains water well location and HTEM station location information as well as the water well record and inversions conducted on the HTEM data nearest to that specific well.

Some records show inversions conducted with stations removed. Specific notes about each well are also indicated in red. For an explanation of sRMS use for the inversion results, see Section 4.2.7. Results and discussion from these inversions are discussed in Section 5.4. 


\begin{tabular}{|l|l|}
\hline Location information UTM NAD83 N10 & Geology information \\
Flight line station & Bedrock: rhyolite \\
X: 413946.66 Y: 5983977.19 Z: $767 \mathrm{~m}$ & Surficial: unknown \\
Distance from well: $206 \mathbf{~ m}$ & \\
& Well water record: \\
Wells water station & Overburden: clay, till, sand \\
X: $413929 \quad$ Y: $5983771 \quad$ Z: $773 \mathrm{~m}$ & Bedrock: unknown \\
Depth to bedrock: $\mathbf{2 9} \mathbf{~ m}$ & Note: \\
& - Tx max current missreported \\
& \\
\hline
\end{tabular}

Model inversion results

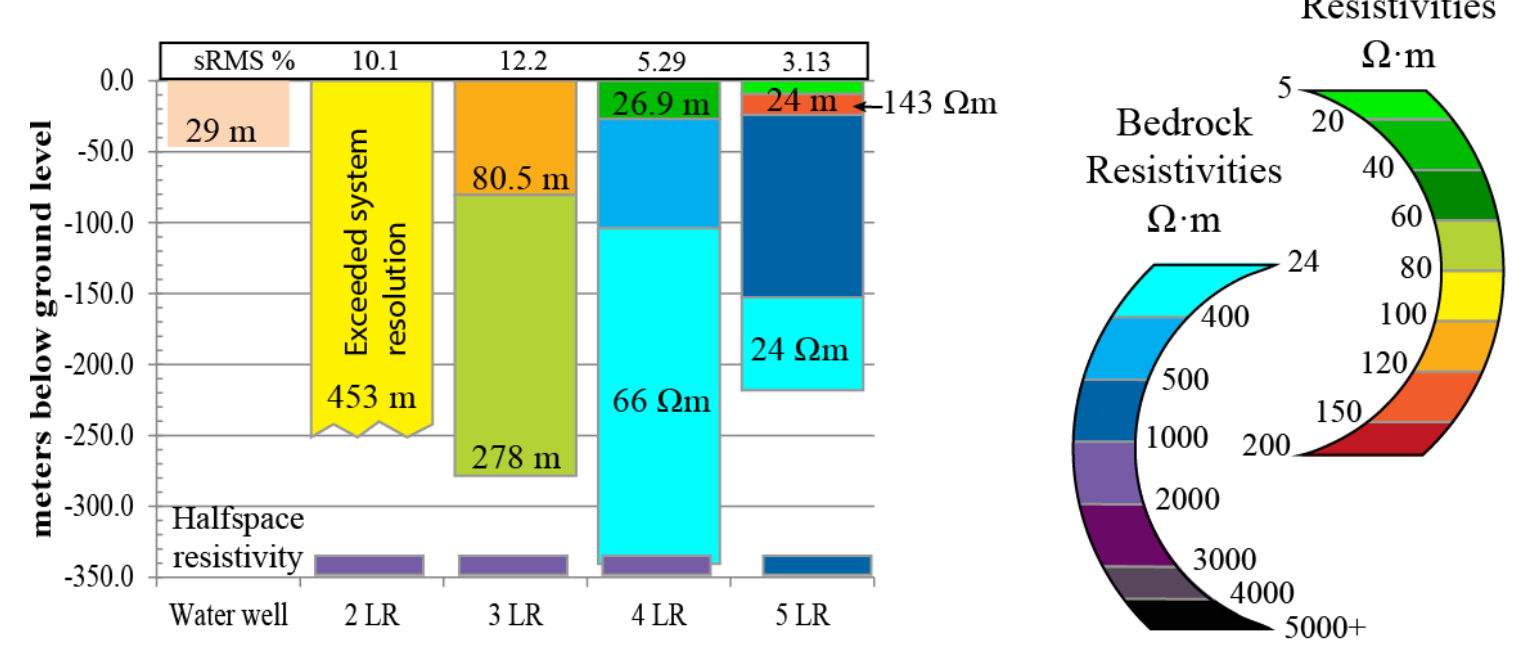

Overburden

Resistivities

\section{Resistivity models}

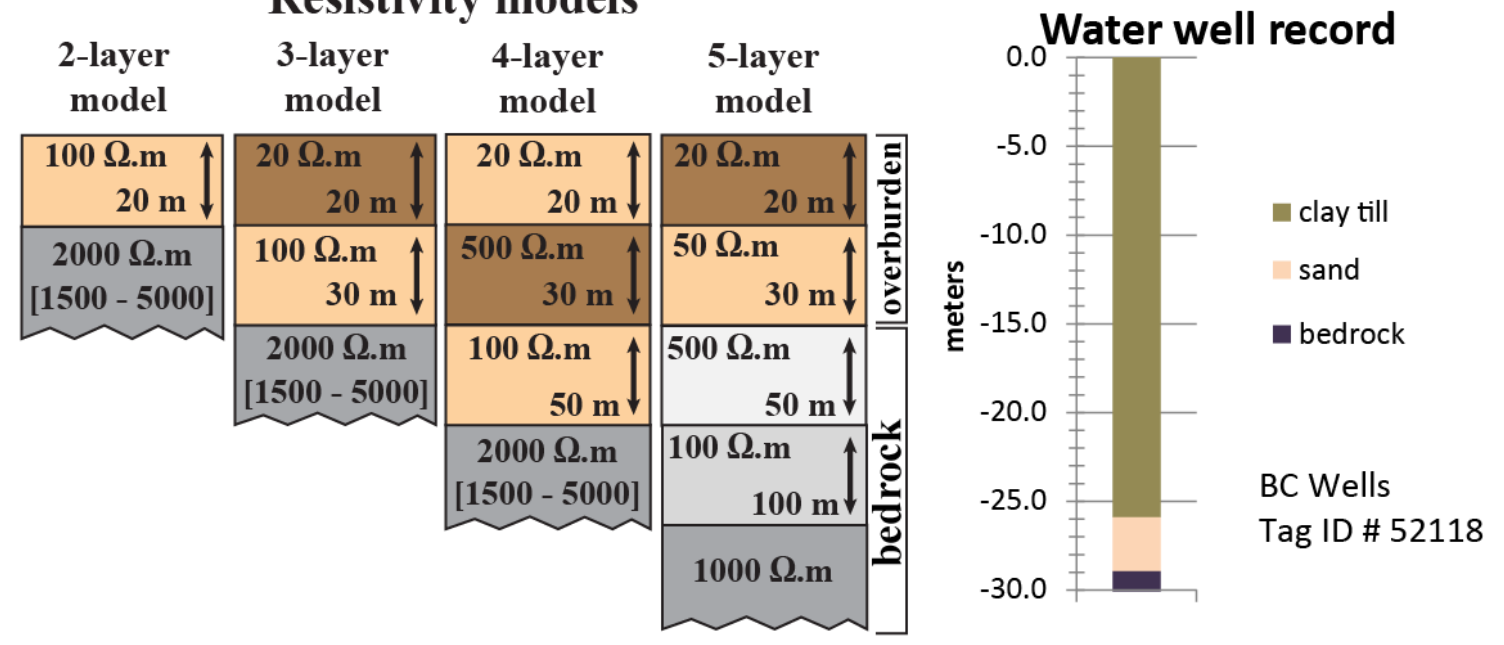

Figure A1-1: BC Wells \#52118 and HTEM inversion record

Record is from Block E Flight Line: 8410 BC Wells Tag ID \# 52118 


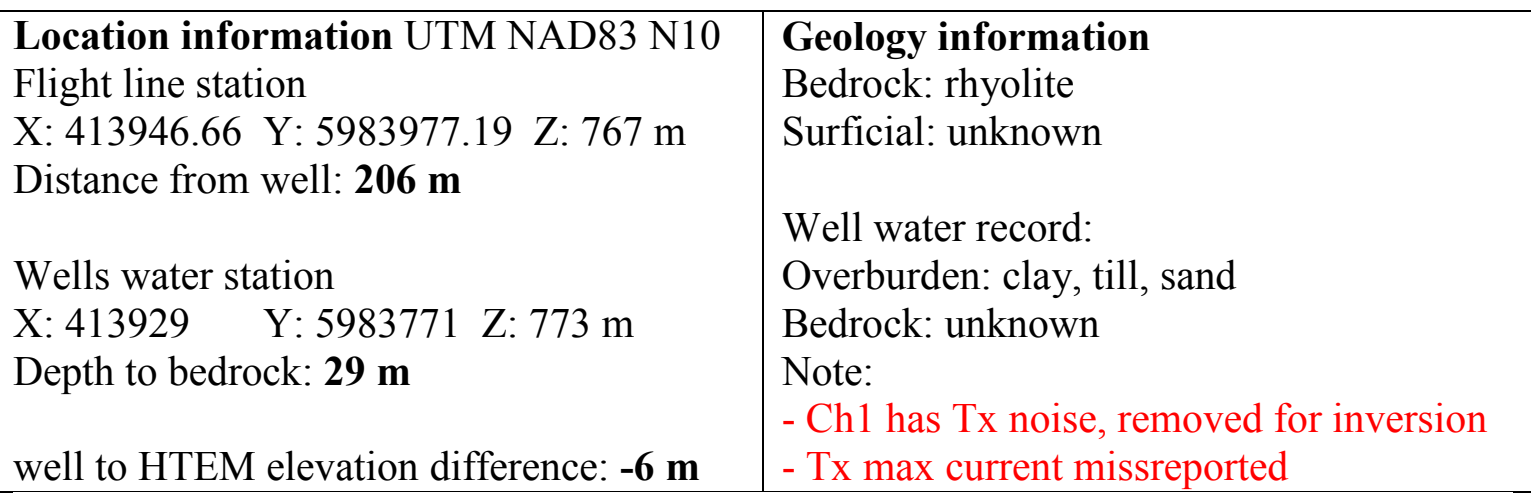

Overburden

Model inversion results

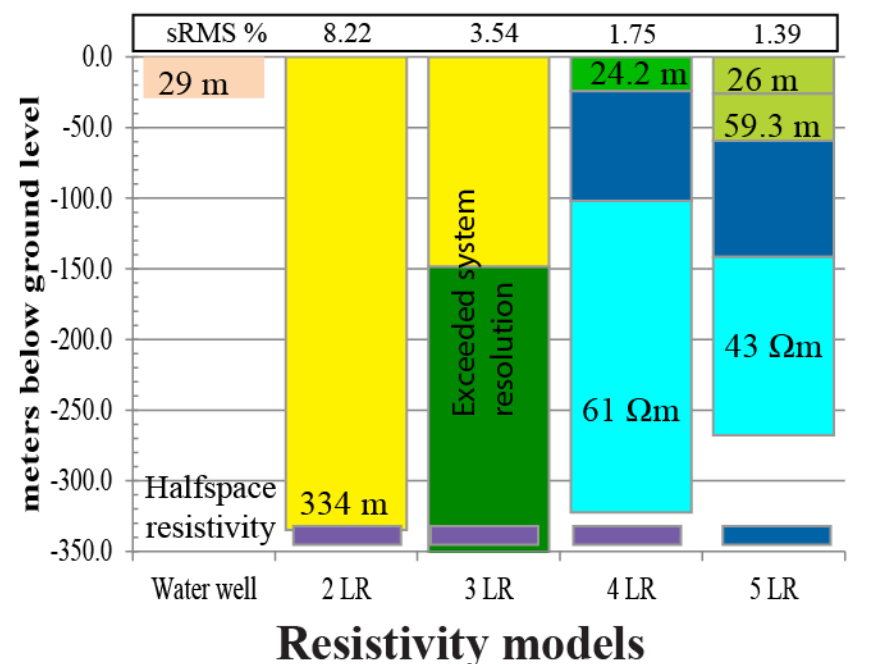

Resistivities

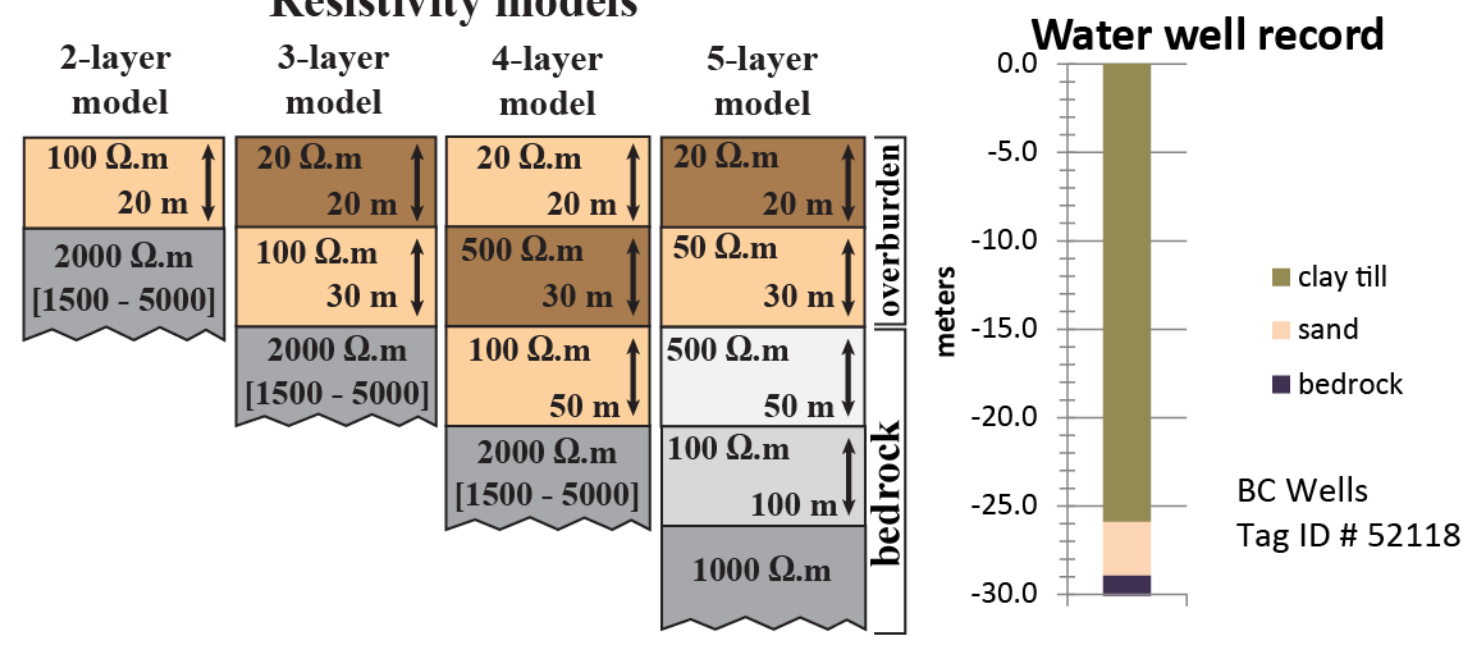

Figure A1-2: BC Wells \#52118 Record 2 and HTEM inversion record

Record is from Block E Flight Line: 8410, record 2 BC Wells Tag ID \# 52118. First offtime recording channel, channel 1 , was removed due to Tx noise for inversion. Record is from the same well as previous record, see Figure A1-1, which has no channels removed. 


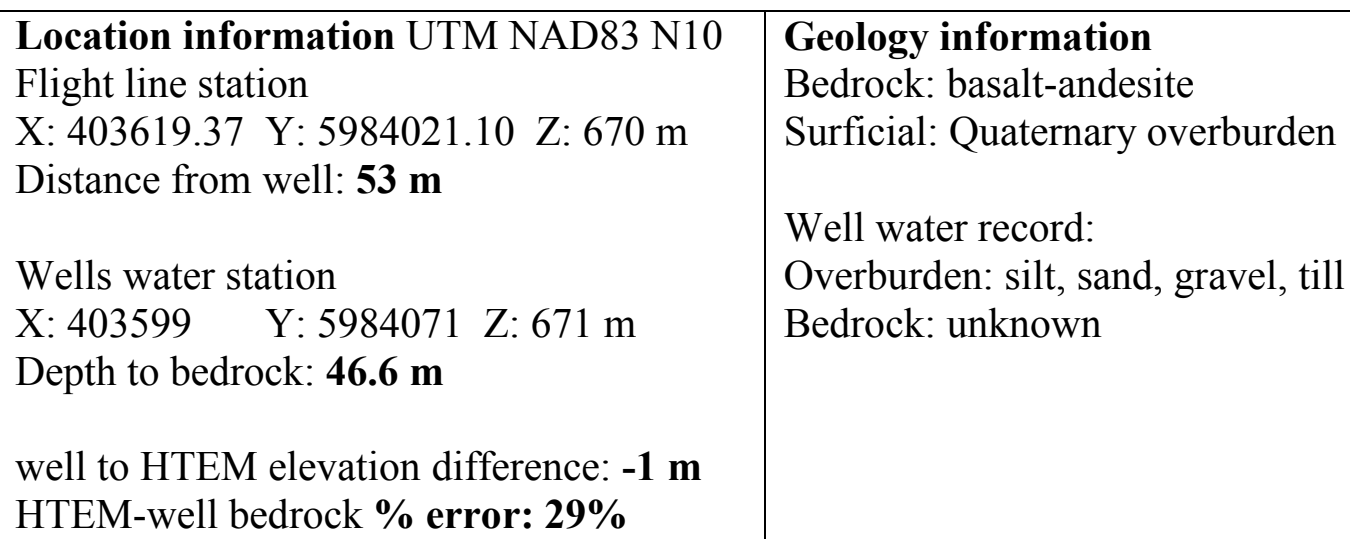
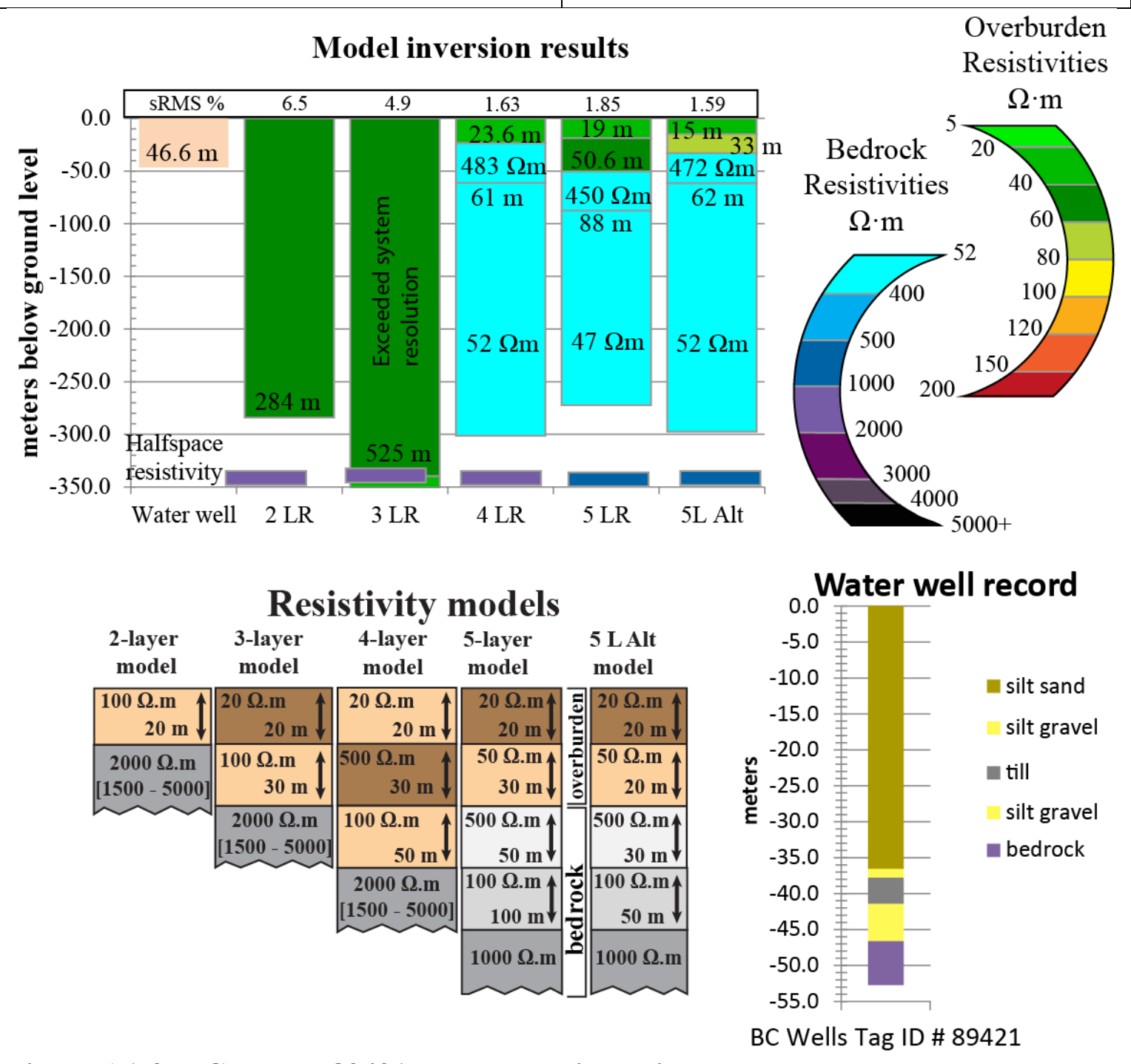

Figure A1-3: BC Wells \#89421 and HTEM inversion record

Record is from Block E Flight Line: 8410 BC Wells Tag ID \# 89421 


\begin{tabular}{|l|l|}
\hline Location information UTM NAD83 N9 & Geology information \\
Flight line station & Bedrock: aphanitic basalt \\
X: 681188.30 Y: $6040005.32 \quad$ Z: $759 \mathrm{~m}$ & Surficial: unknown \\
Distance from well: $\mathbf{7 6} \mathbf{~ m}$ & Well water record: \\
& Overburden: glacial clay and gravel \\
Wells water station & Bedrock: limestone \\
X: $681188 \quad$ Y: $6040081 \quad$ Z: $756 \mathrm{~m}$ & \\
Depth to bedrock: $\mathbf{6 5 . 5} \mathbf{~ m}$ & \\
& \\
well to HTEM elevation difference: $\mathbf{3} \mathbf{~ m}$ & \\
HTEM-well bedrock \% error: $\mathbf{1 5}$ & \\
\hline
\end{tabular}
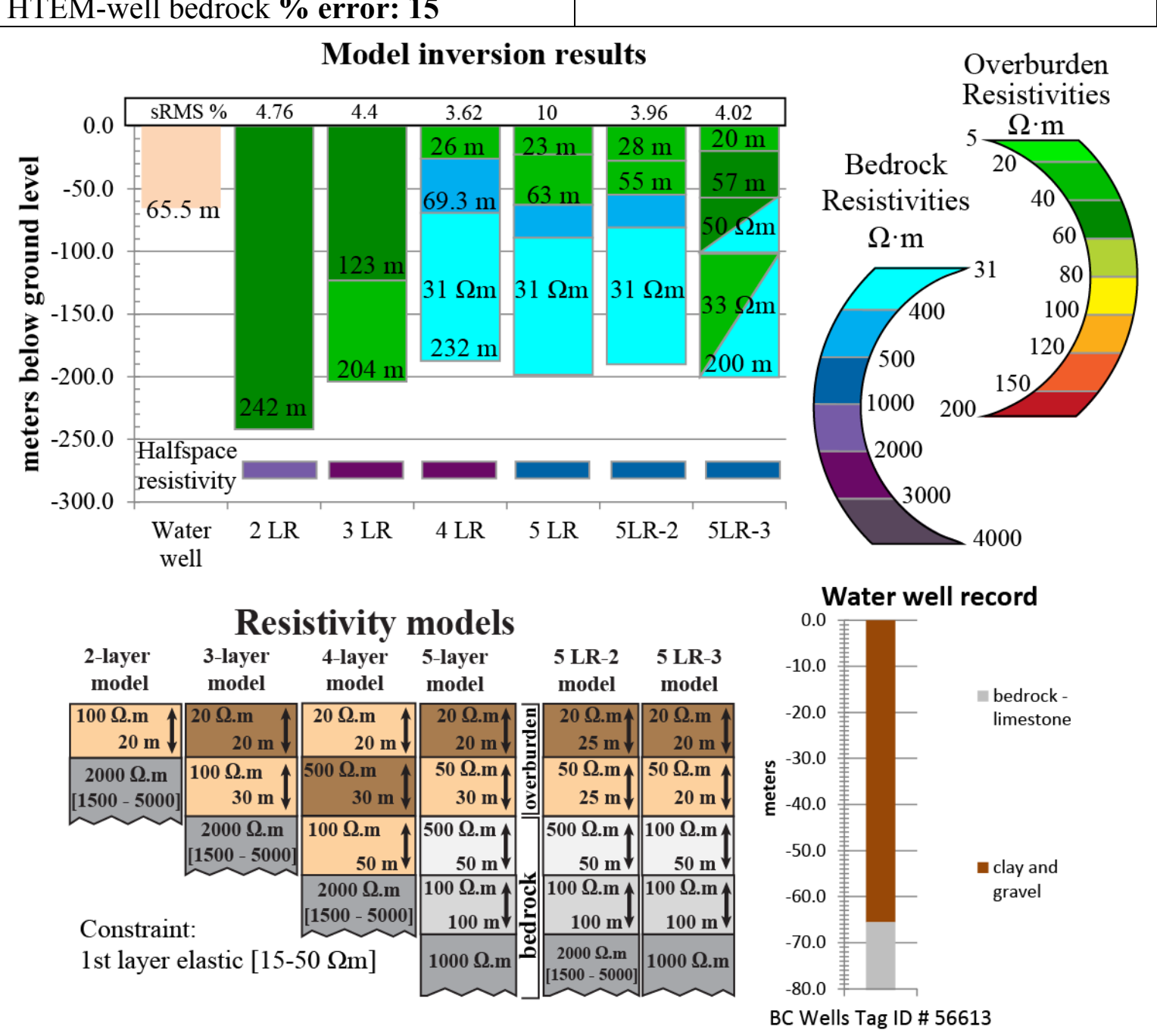

Figure A1-4 BC Wells \#56613 and HTEM inversion record

Record is from Block C2 Flight Line: 6270 BC Wells Tag ID \# 56613 


\begin{tabular}{|l|l|}
\hline Location information UTM NAD83 N10 & Geology information \\
Flight line 7402 station & Bedrock: aphanitic basalt \\
X: 372339.49 Y: $5988009.61 \quad$ Z: $797 \mathrm{~m}$ & Surficial: unknown \\
Distance from well: $291 \mathbf{~ m}$ & \\
& Well water record: \\
Wells water station & Overburden: silty gravel, glacial till \\
X: $372341 \quad$ Y: $5988301 \quad$ Z: $789 \mathrm{~m}$ & Bedrock: white sandstone \\
Depth to bedrock: $\mathbf{1 8 . 3} \mathbf{~ m}$ & \\
& \\
well to HTEM elevation difference: $8 \mathbf{~ m}$ & \\
\hline
\end{tabular}
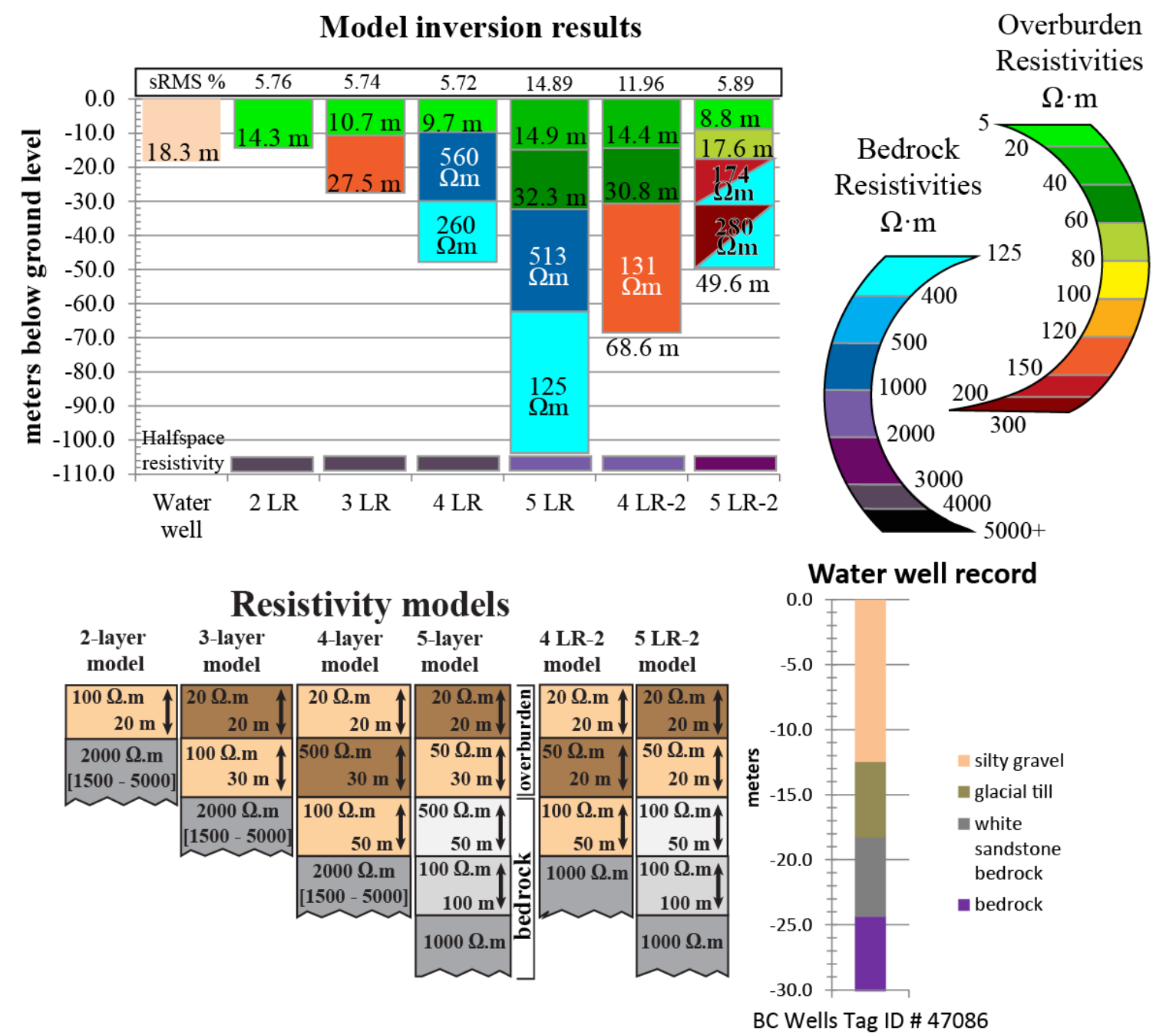

Figure A1-5 BC Wells \#47086 and HTEM inversion record

Record is from Block D Flight Line: 7402 BC Wells Tag ID \# 47086 


\section{Location information UTM NAD83 N9}

Flight line station

X: 638416.95 Y: 6044179 Z: $628 \mathrm{~m}$

Distance from well: 62 m

Wells water station

X: $638386 \quad$ Y: 6044125 Z: $620 \mathrm{~m}$

Depth to bedrock: $\mathbf{7 1 . 6} \mathrm{m}$

\section{Geology information}

Bedrock: Andesite to dacite volcanic with welded tuff

Surficial: unknown

Well water record:

Overburden: glacial clay and till Bedrock: no comment

well to HTEM elevation difference: $8 \mathbf{~ m}$

\section{Model inversion results}

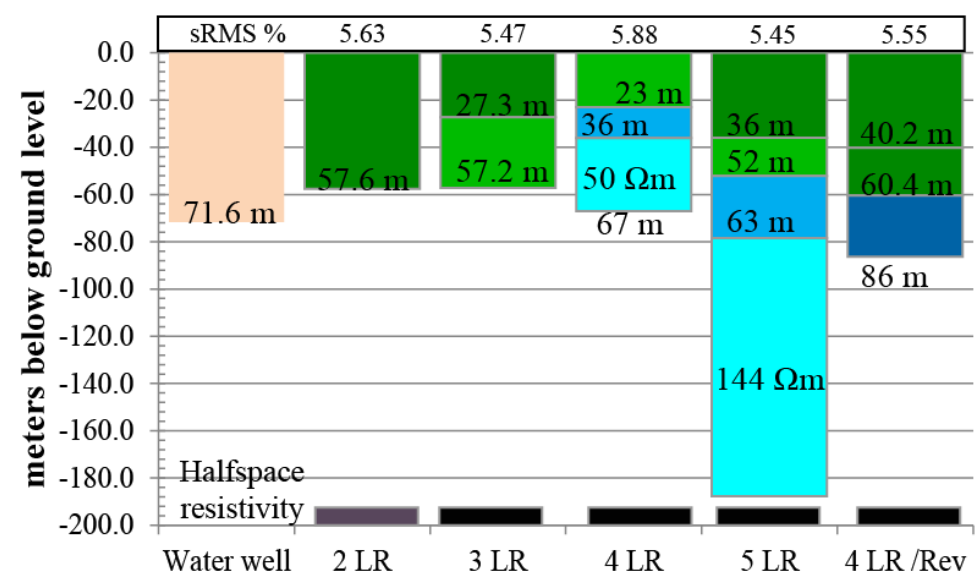

Resistivity models

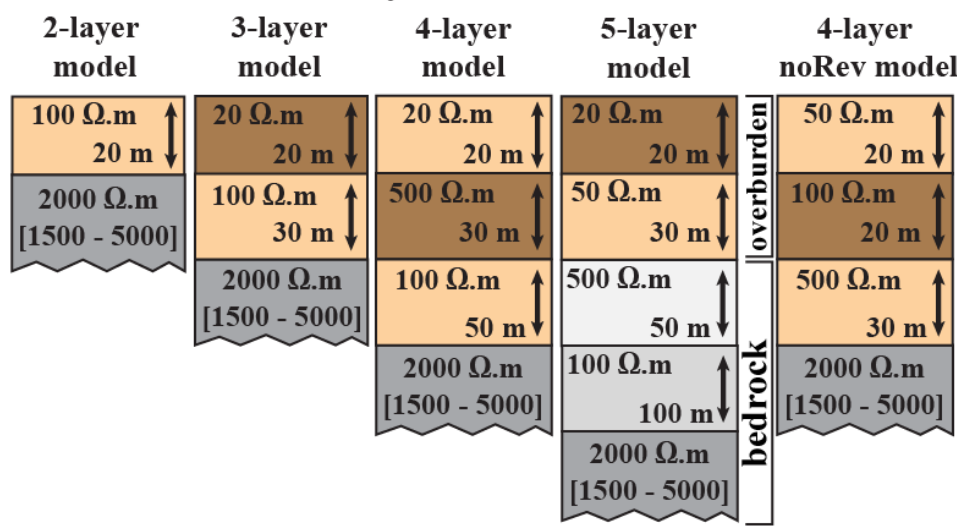

Overburden

Resistivities
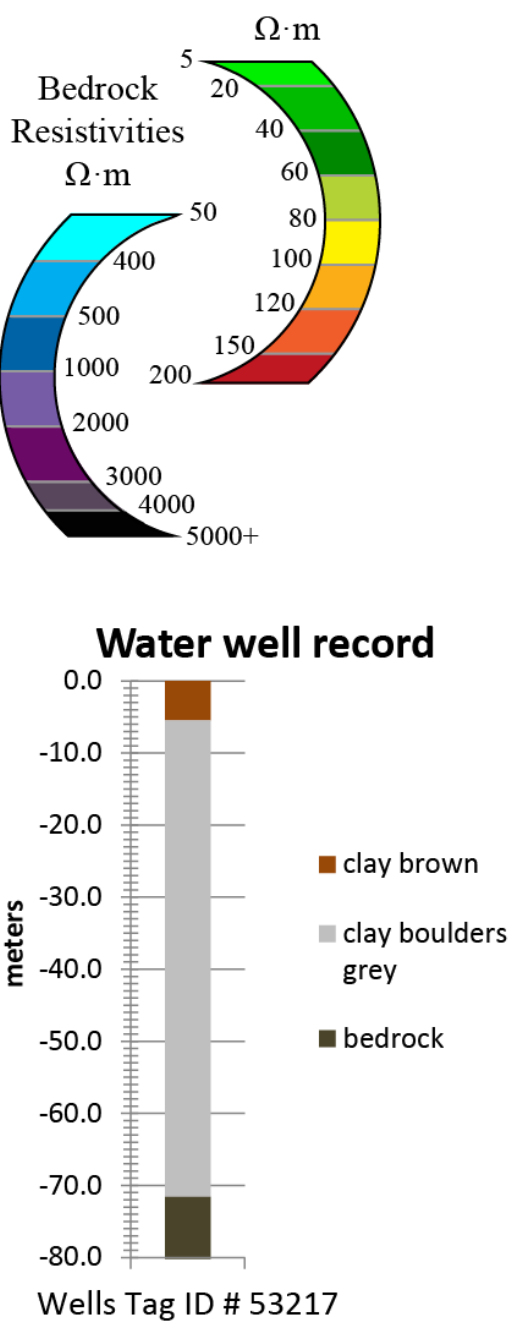

Figure A1-6 BC Wells \#53217 and HTEM inversion record

Record is from Block C2 Flight Line: 6261 BC Wells Tag ID \# 53217 


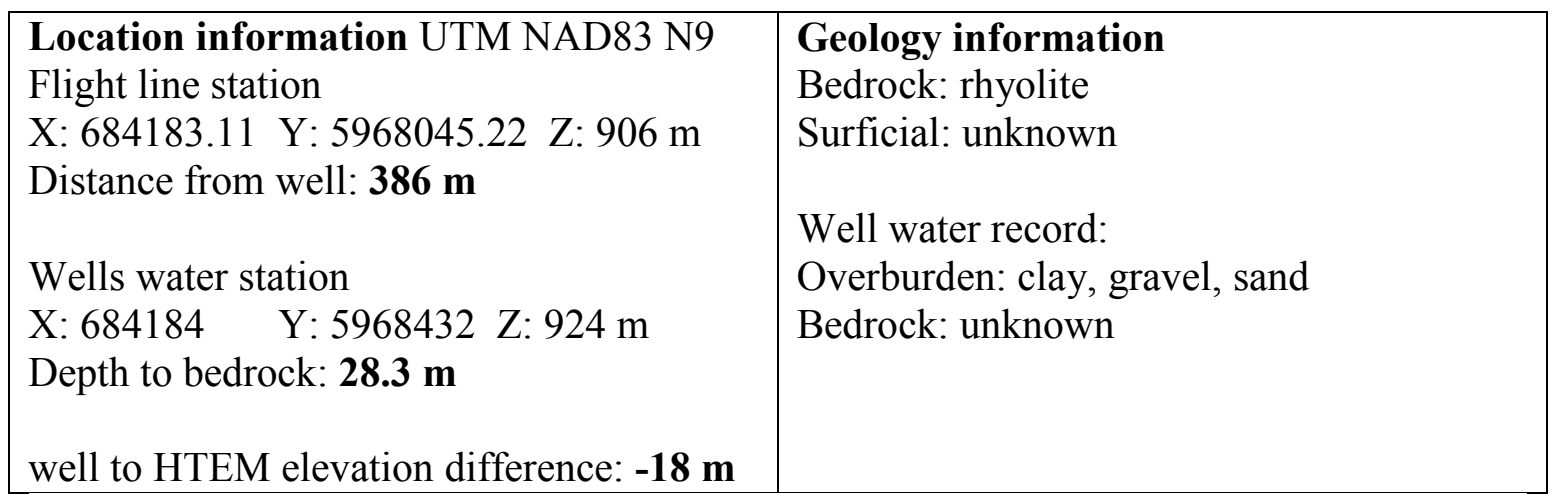
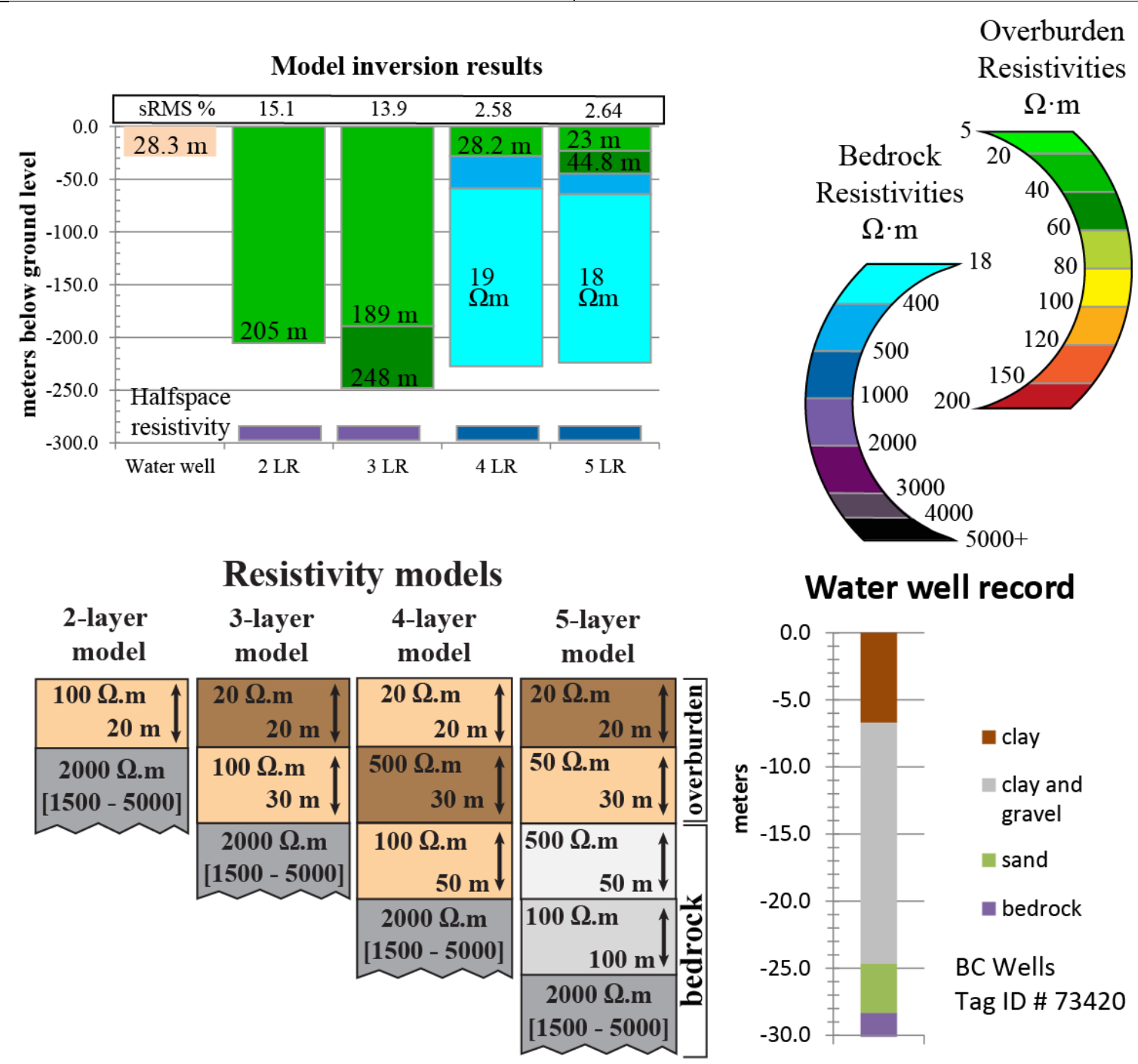

Figure A1-7 BC Wells \#73420 and HTEM inversion record

Record is from Block C2 Flight Line: 6450 BC Wells Tag ID \# 73420 


\section{Location information UTM NAD83 N9}

Flight line station

X: 310952.26 Y: 5983963.56 Z: $926 \mathrm{~m}$

Distance from well: $44 \mathbf{~ m}$

Wells water station

X: 310952 Y: 5984008 Z: $925 \mathrm{~m}$

Depth to bedrock: $\mathbf{2 0 . 1} \mathbf{~ m}$

\section{Geology information}

Bedrock: basalt-andesite

Surficial: Quaternary overburden

Well water record:

Overburden: clay

Bedrock: shale

well to HTEM elevation difference: 1 m

Model inversion results

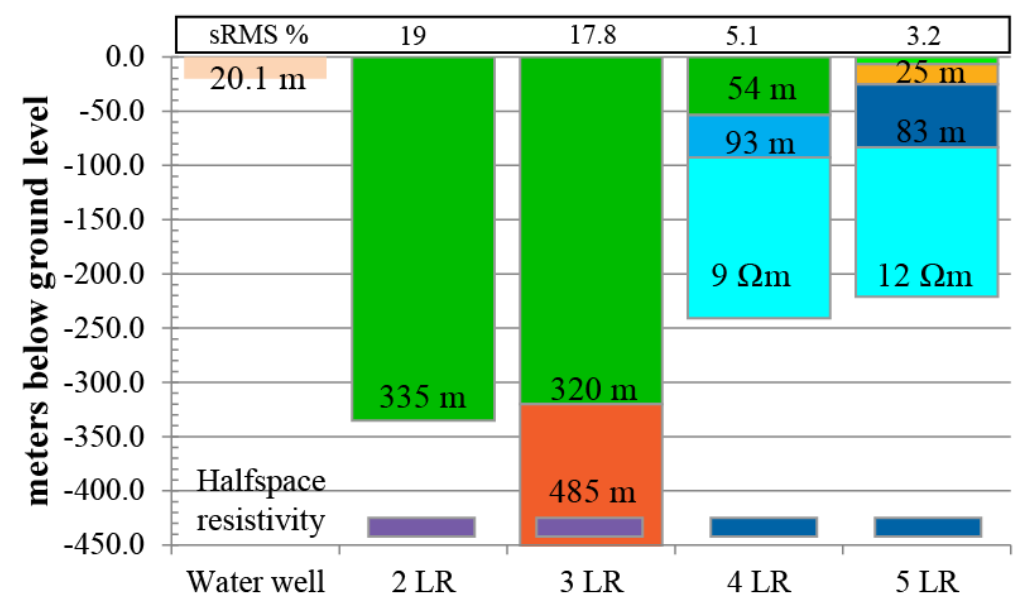

Resistivity models

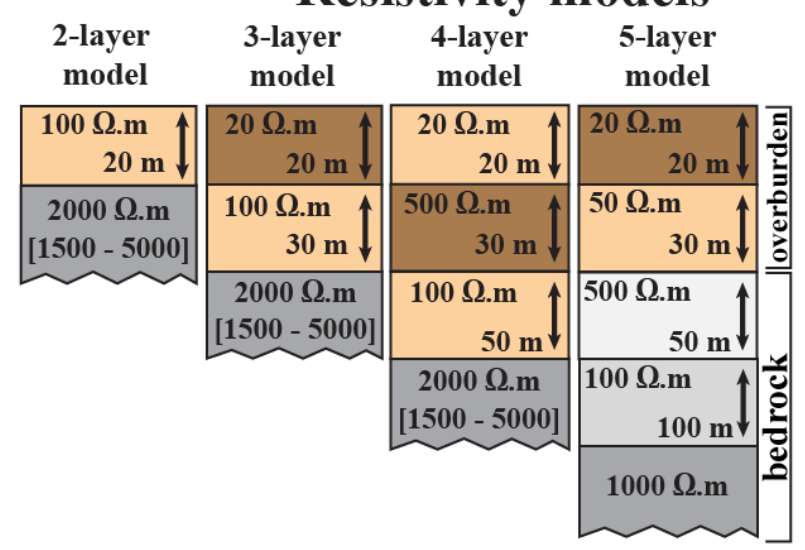

Overburden

Resistivities
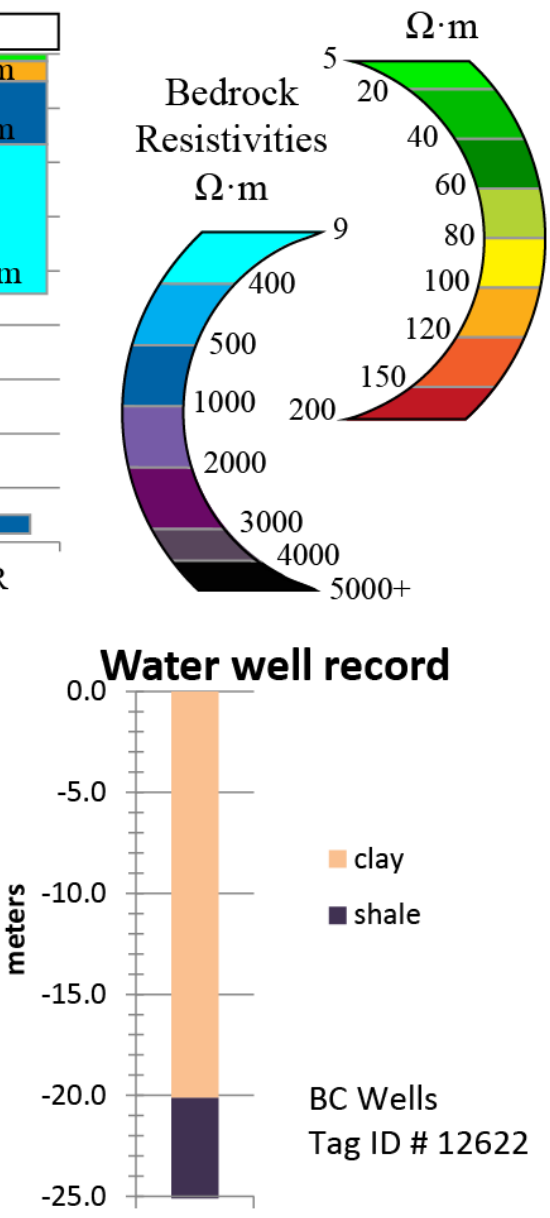

Figure A1-8 BC Wells \#12622 and HTEM inversion record

Record is from Block D Flight Line: 7410 BC Wells Tag ID \# 12622 


\begin{tabular}{|l|l|}
\hline Location information UTM NAD83 N10 & $\begin{array}{l}\text { Geology information } \\
\text { Flight line station }\end{array}$ \\
$\begin{array}{l}\text { X: } 317867.00 \text { Y: } 5988354.00 ~ Z: 818 ~ m \\
\text { Distance from well: } 111 ~ m\end{array}$ & Surficial: unknown \\
& Well water record: \\
Wells water station & Overburden: clay, till, silt, sand \\
X: $317897 \quad$ Y: 5988249 Z: $825 \mathrm{~m}$ & Bedrock: unknown \\
Depth to bedrock: $\mathbf{2 7 . 4} \mathbf{~ m}$ & \\
& Note: \\
well to HTEM elevation difference: $\mathbf{- 7} \mathbf{~ m}$ & - Ch1 has Tx noise, removed for inversion \\
\hline
\end{tabular}

\section{Model inversion results}

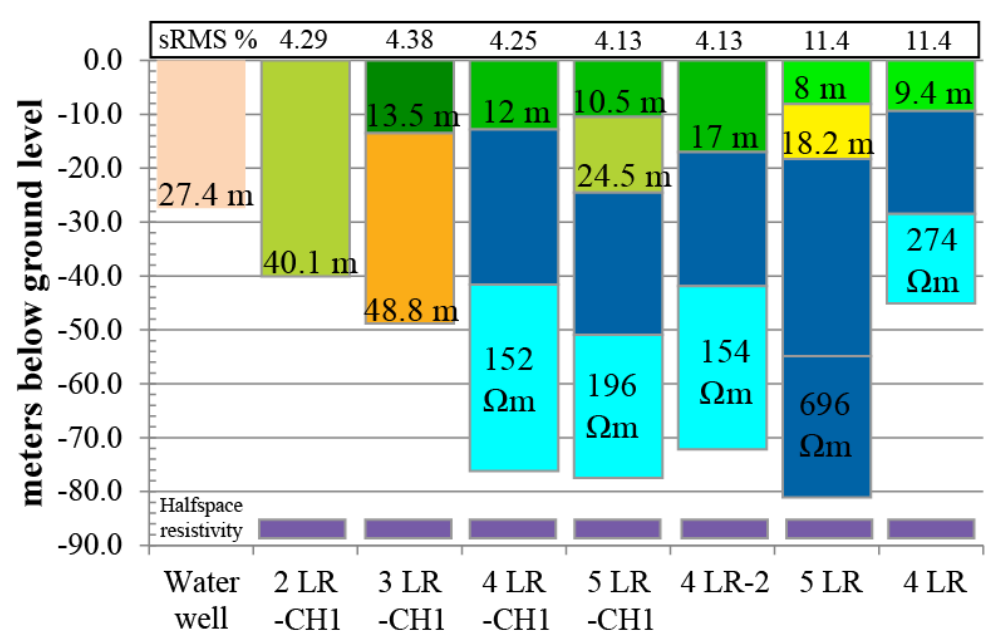

Resistivity models

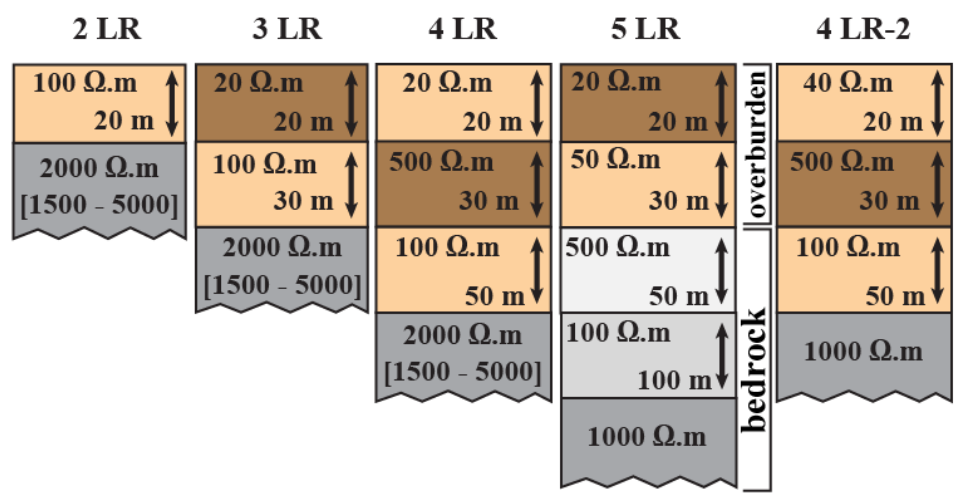

Figure A1-9 BC Wells \#56720 and HTEM inversion record

Record is from Block D Flight Line: 7400 BC Wells Tag ID \# 56720 


\section{Location information UTM NAD83 N10}

Flight line station

X: 312866.51 Y: 5993724.07 Z: $718 \mathrm{~m}$

Distance from well: 145 m

Wells water station

X: $312909 \quad$ Y: 5993856 Z: $718 \mathrm{~m}$

Depth to bedrock: 29 m

well to HTEM elevation difference: $\mathbf{0}$ m
Geology information

Bedrock: sandstone

Surficial: unknown

Well water record:

Overburden: clay,

Bedrock: unknown

Note:

- Ch1 has Tx noise, removed for inversion

- HTEM stations over water (Francois Lake)

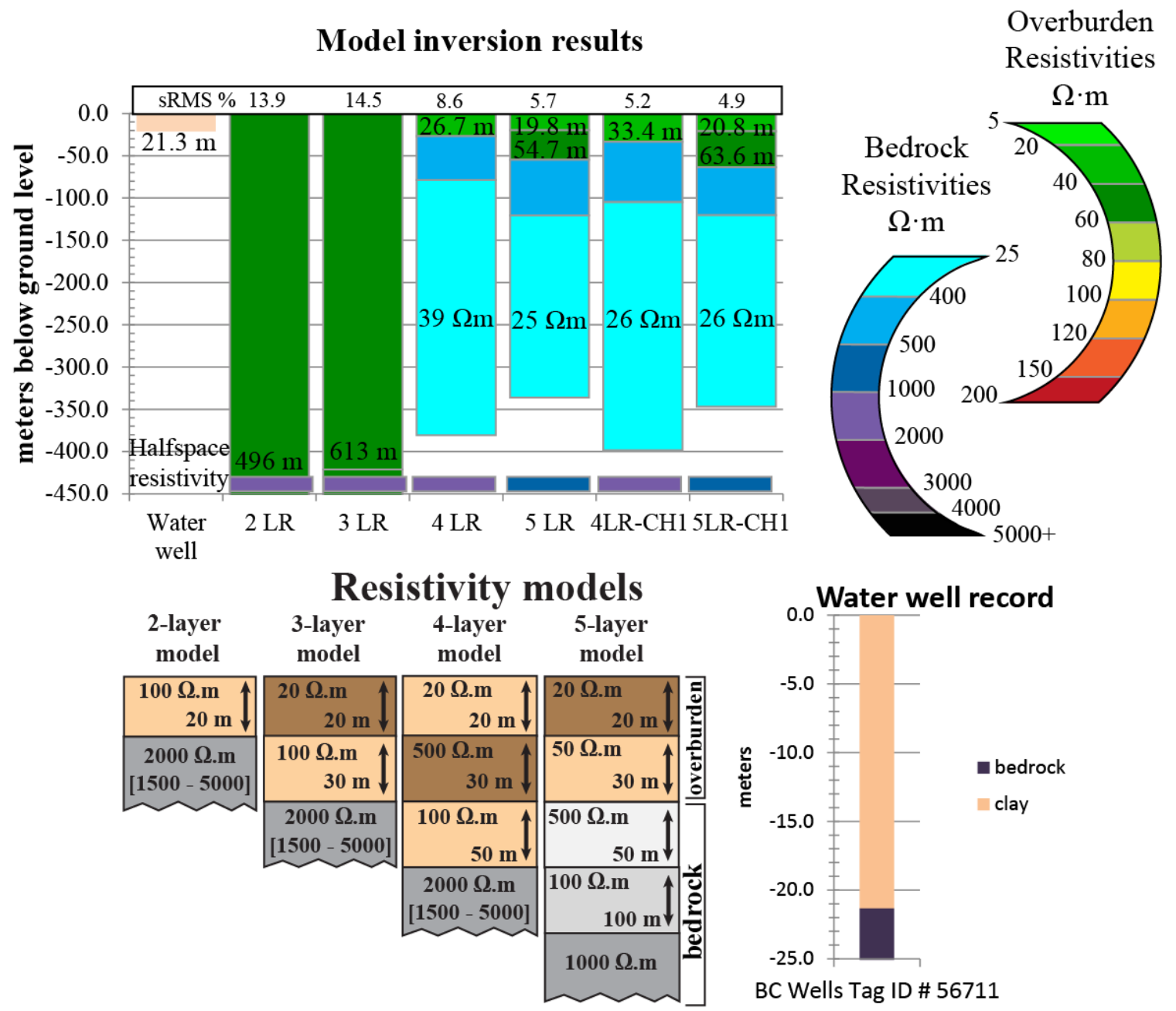

Figure A1-10 BC Wells \#56711 and HTEM inversion record

Record is from Block D Flight Line: 7390, BC Wells Tag ID \# 56711 


\section{Location information UTM NAD83 N10}

Flight line station

X: 318084.38 Y: 6015989.18 Z: $723 \mathrm{~m}$

Distance from well: 135 m

Wells water station

X: $318084 \quad$ Y: 6015998 Z: $721 \mathrm{~m}$

Depth to bedrock: $17.7 \mathrm{~m}$

\section{Geology information}

Bedrock: andesite

Surficial: unknown

Well water record:

Overburden: clay, gravel

Bedrock: shale

Note:

well to HTEM elevation difference: $\mathbf{2}$ m
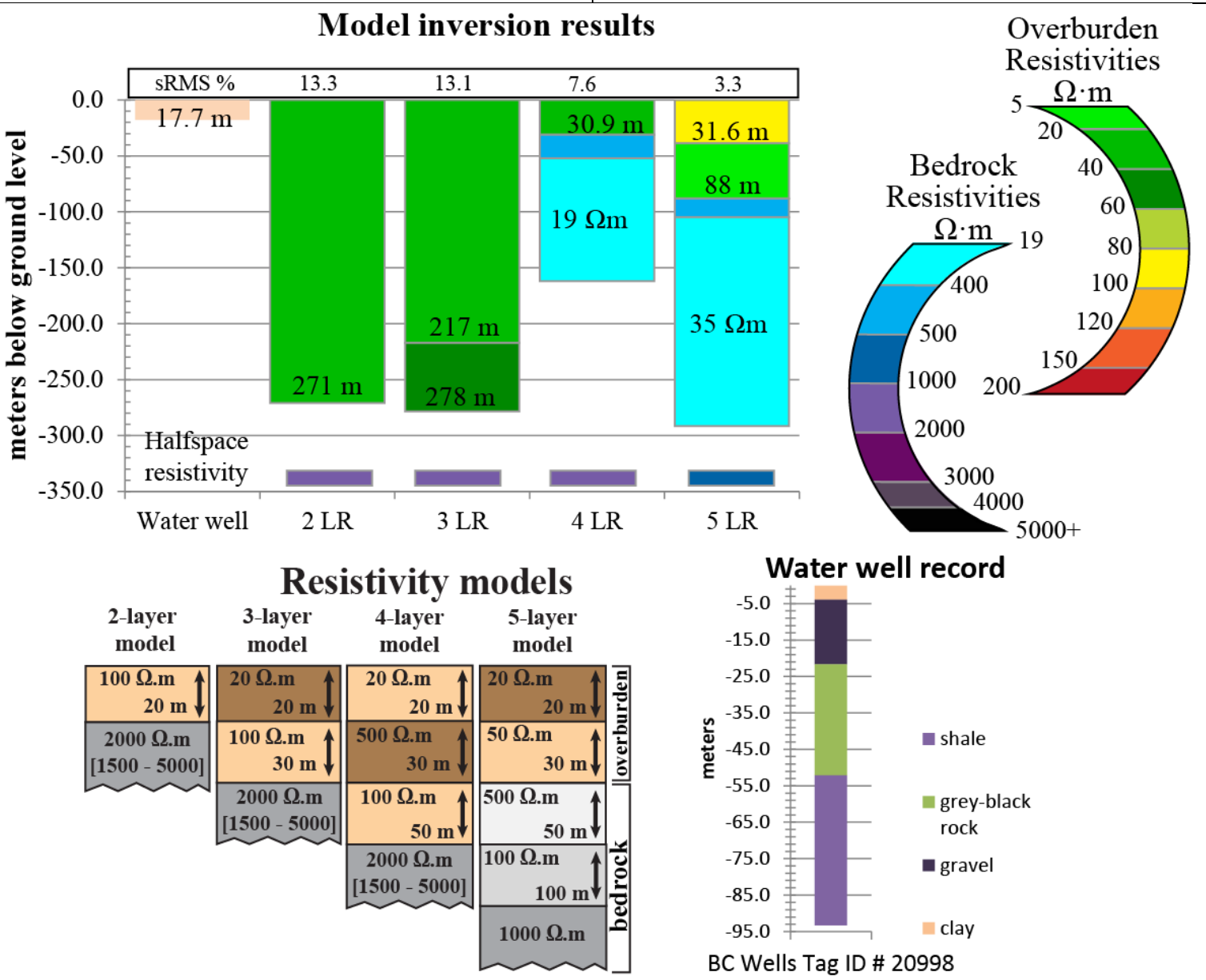

Figure A1-11 BC Wells \#20998 and HTEM inversion record

Record is from Block D Flight Line: 7333, BC Wells Tag ID \# 20998 
Location information UTM NAD83 N9

Flight line station

X: $641620 \quad$ Y: 6047339 Z: $630 \mathrm{~m}$

Distance from well: $\mathbf{1 3 5} \mathbf{~ m}$

Wells water station

X: 641620 Y: 6015998 Z: $631 \mathrm{~m}$

Depth to bedrock: $89.9 \mathrm{~m}$

well to HTEM elevation difference: $\mathbf{1} \mathbf{~ m}$
Geology information

Bedrock: basalt with minor andesite

Surficial: unknown

Well water record:

Overburden: till

Bedrock: unknown (grey)

Note:

Unsuccessful inversion
Model inversion results

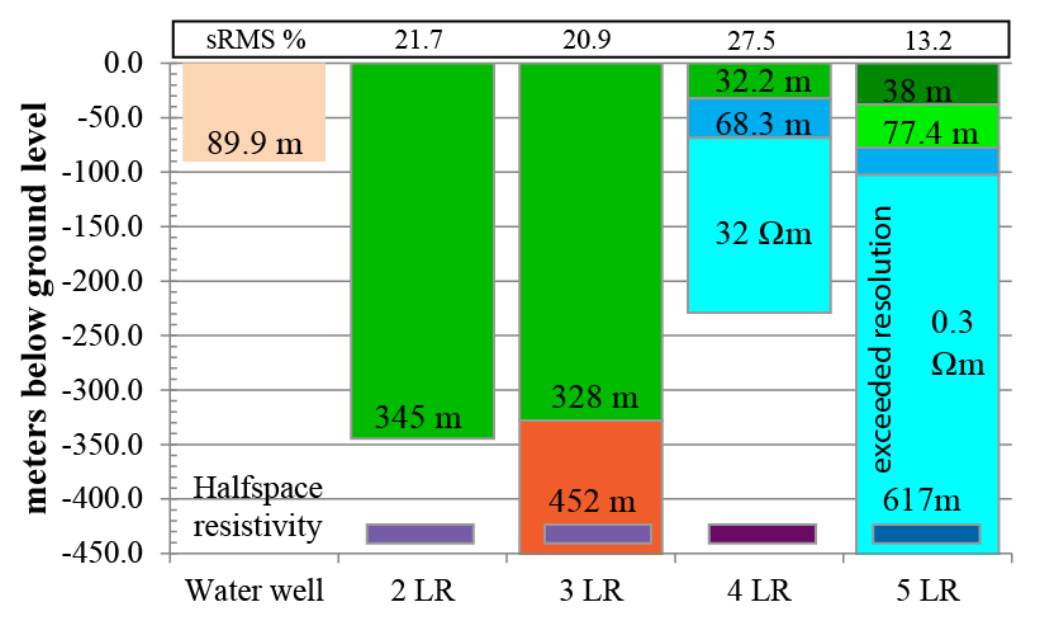

Resistivity models

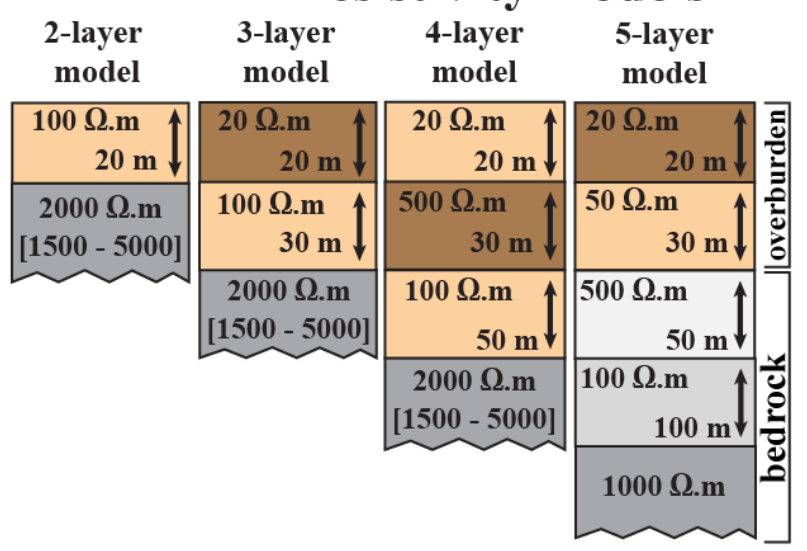

Overburden

Resistivities

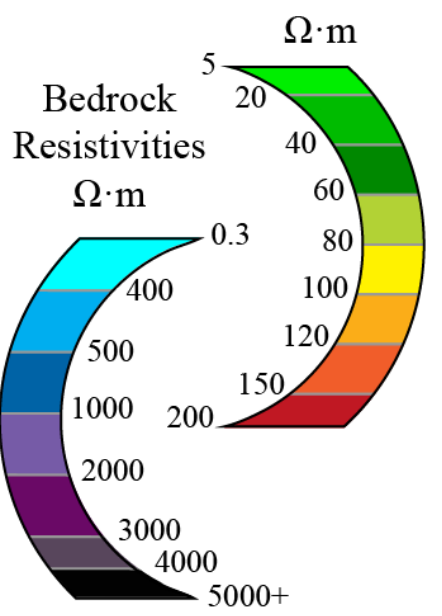

Water well record

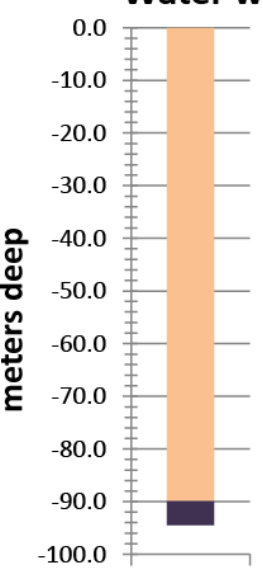

bedrock

till

BC Wells

Tag ID \# 43637

Figure A1-12 BC Wells \#43637 and HTEM inversion record

Record is from Block C2 Flight Line: 6250, BC Wells Tag ID \# 43637 
Location information UTM NAD83 N9

Flight line station

X: $320777 \quad$ Y: 5995896 Z: $764 \mathrm{~m}$

Distance from well: $84 \mathbf{~ m}$

Wells water station

X: $320780 \quad$ Y: 5995812 Z: $755 \mathrm{~m}$

Depth to bedrock: $\mathbf{5 1 . 8} \mathbf{~ m}$

well to HTEM elevation difference: -9 $\mathbf{m}$

\section{Geology information}

Bedrock: rhyolite

Surficial: unknown

Well water record:

Overburden: clay, sand

Bedrock: unknown

Note:

Unsuccessful inversion
Model inversion results

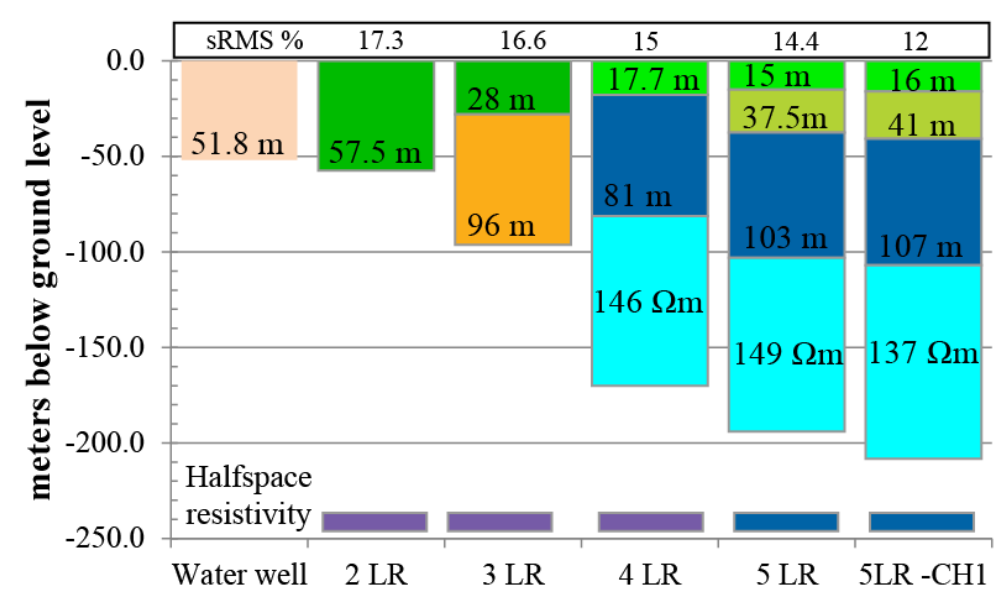

Resistivity models

\begin{tabular}{|c|c|c|c|c|}
\hline $\begin{array}{r}\text { 2-layer } \\
\text { model }\end{array}$ & $\begin{array}{l}\text { 3-layer } \\
\text { model }\end{array}$ & $\begin{array}{l}\text { 4-layer } \\
\text { model }\end{array}$ & $\begin{array}{l}\text { 5-LR } \\
\text { model }\end{array}$ & \\
\hline $\begin{array}{r}100 \Omega . \mathrm{m} \\
20 \mathrm{~m}\end{array}$ & $\begin{array}{r}20 \Omega . \mathrm{m} \\
20 \mathrm{~m}\end{array}$ & $\begin{array}{r}20 \Omega . m \\
20 \mathrm{~m}\end{array}$ & $\begin{array}{r}20 \Omega . m \\
20 \mathrm{~m}\end{array}$ & : \\
\hline \multirow[t]{4}{*}{$\begin{array}{c}2000 \Omega . m \\
{[1500-5000]}\end{array}$} & $\begin{array}{r}100 \Omega . m \\
30 \mathrm{~m}\end{array}$ & $\begin{array}{r}500 \Omega . \mathrm{m} \\
30 \mathrm{~m}\end{array}$ & $\begin{array}{r}50 \text { S.m } \\
30 \mathrm{~m}\end{array}$ & ō \\
\hline & \multirow[t]{3}{*}{$\begin{array}{c}2000 \Omega . m \\
{[1500-5000]}\end{array}$} & $\begin{array}{r}100 \Omega . m \\
50 \mathrm{~m}\end{array}$ & \begin{tabular}{|r|}
$500 \Omega . m$ \\
$50 \mathrm{~m}$
\end{tabular} & \\
\hline & & $\begin{array}{c}2000 \Omega . m \\
{[1500-5000]}\end{array}$ & $\begin{array}{r}100 \Omega . \mathrm{m} \\
100 \mathrm{~m}\end{array}$ & है: \\
\hline & & & 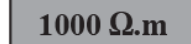 & \\
\hline
\end{tabular}

Overburden

Resistivities
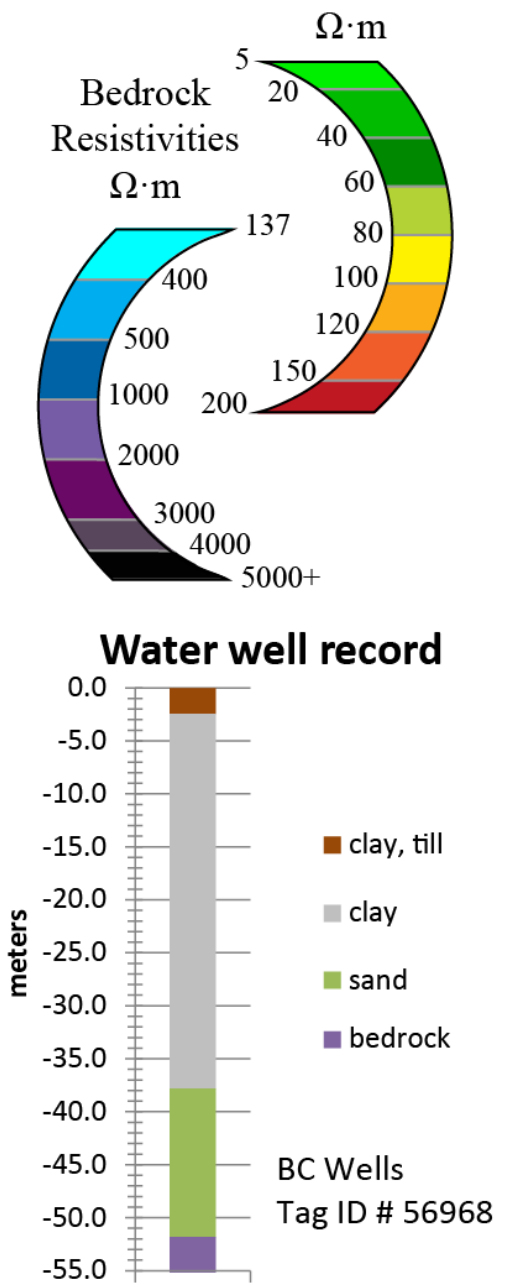

Figure A1-13 BC Wells \#56968 and HTEM inversion record

Record is from Block D Flight Line: 7380, BC Wells Tag ID \# 56968. 


\section{Appendix II}

Appendix II contains GSC borehole records from three Equity Silver geotechnical boreholes, see Section 2.4.2. Figures of the resistivity logs for each well are presented below. Spreadsheet data from these wells were used to create the bedrock resistivity histogram shown in Figure 5.4.4. This data can be obtained from Natural Resources Canada under Open File 2610 (Killeen et al.1995), and from the Rock Property Database System (RPDS) which is a collaboration between Geoscience BC, Mira Geoscience, the Geological Survey of Canada, and CAMIRO (Mira 2008). 


\section{EQUITY SILVER, BRITISH COLUMBIA}

Latitude $\left(54^{\circ}, 12^{\prime}, 0^{\prime \prime}\right)$, Longitude $\left(124^{\circ}, 30^{\prime}, 0^{\prime \prime}\right)$

Borehole 86264

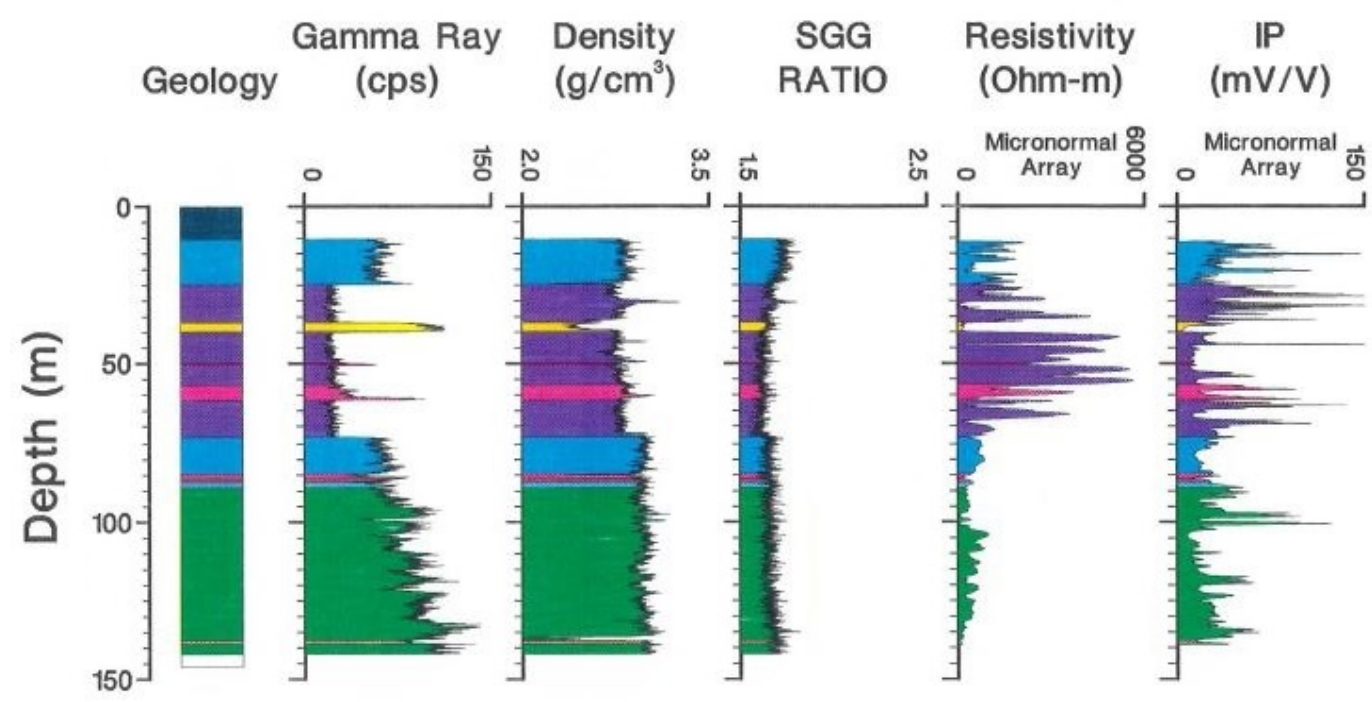

LEGEND

\begin{tabular}{|l|l}
\hline & Trachyandesite Dyke \\
Andesite Dyke \\
Quartz Latite Dyke \\
Pyroclastic Dust Tuff \\
Sedimentary-Volcanic Dust and Ash Tuff \\
Sedimentary-Volcanic Quartz Sandstone \\
Sedimentary-Volcanic Sandstone \\
Sedimentary-Volcanic Chert Pebble Conglomerate \\
Sedimentary-Volcanic Dust Tuff \\
Overburden
\end{tabular}

Figure A2-1 GSC Equity Silver Borehole 86264 


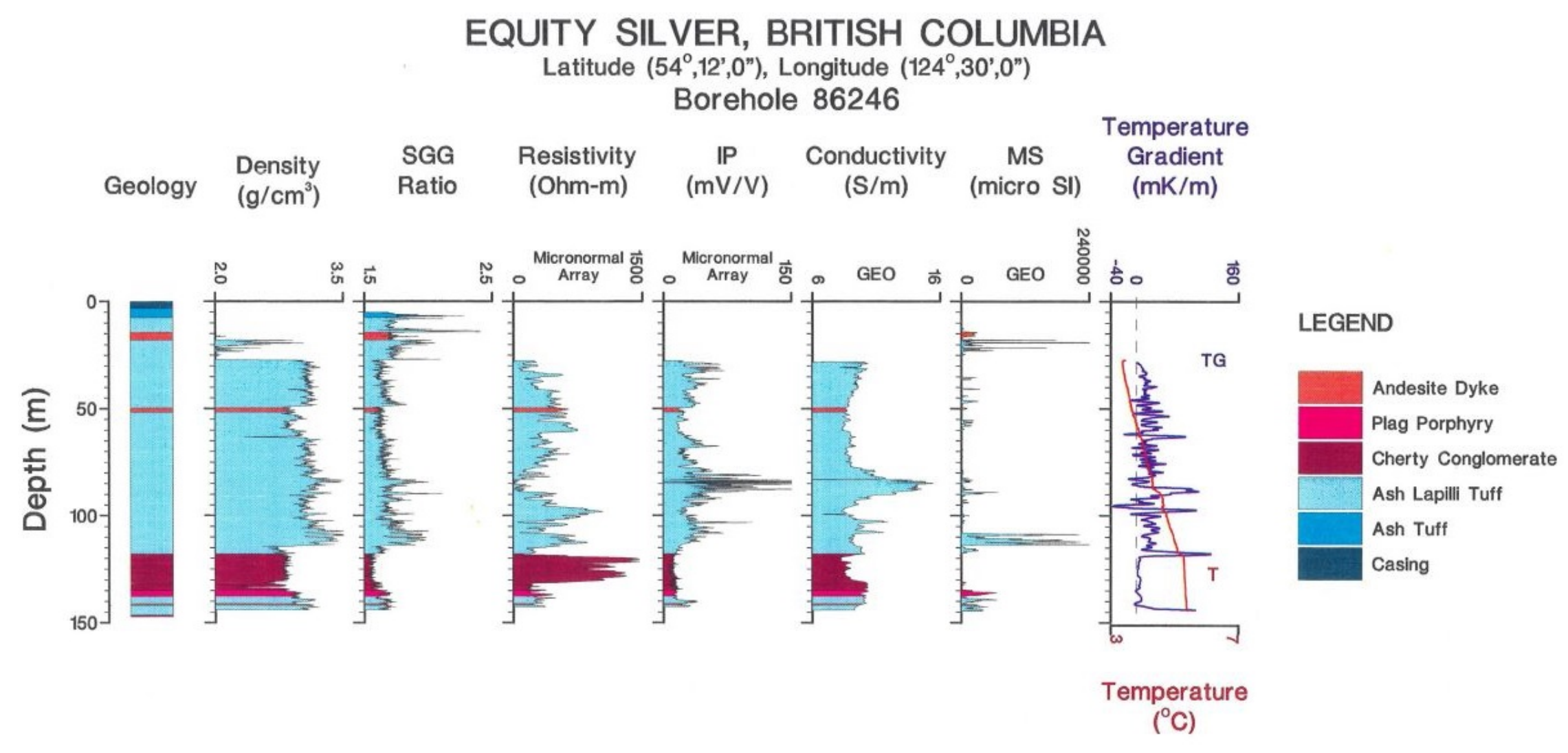

Figure A2-2 GSC Equity Silver Borehole 86246 


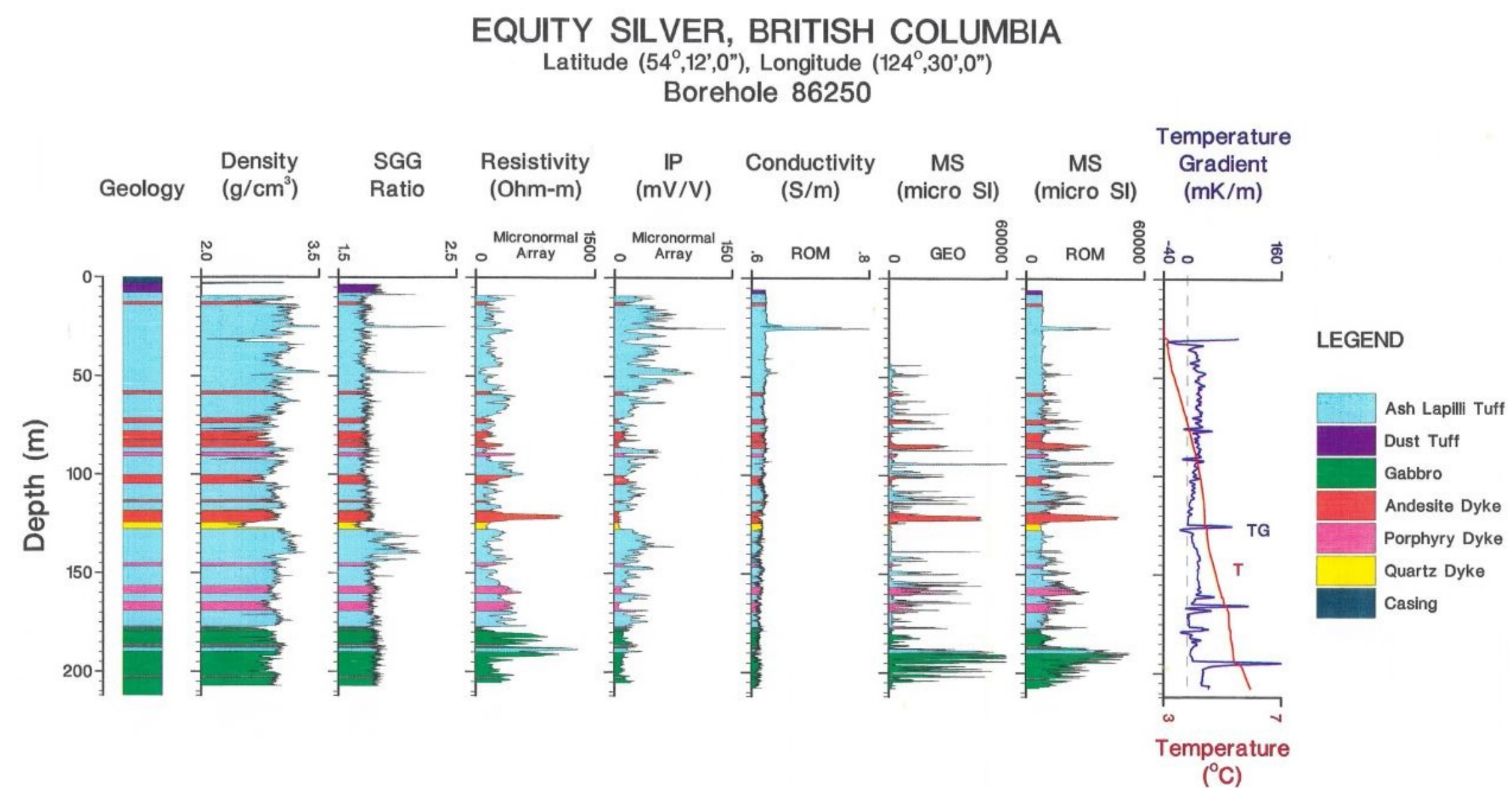

Figure A2-3 GSC Equity Silver Borehole 86250 
